\title{
Auguste Blanqui
}

(1971)

\section{Textes choisis}

PRÉFACE ET NOTES DE V. P. VOLGUINE

MEMBRE DE L'ACADÉMIE DES SCIENCES DE L'U.R.S.S.

\section{Un document produit en version numérique conjointement par Jean-Marie Tremblay et Marcelle Bergeron, bénévoles}

Courriels : jean-marie_tremblay@uqac.ca et mabergeron@videotron.ca

Dans le cadre de la collection : "Les classiques des sciences sociales" dirigée et fondée par Jean-Marie Tremblay, professeur de sociologie au Cégep de Chicoutimi Site web: http://classiques.uqac.ca/

Une collection développée en collaboration avec la Bibliothèque Paul-Émile-Boulet de l'Université du Québec à Chicoutimi Site web: http://classiques.uqac.ca 


\section{Politique d'utilisation de la bibliothèque des Classiques}

Toute reproduction et rediffusion de nos fichiers est interdite, même avec la mention de leur provenance, sans l'autorisation formelle, écrite, du fondateur des Classiques des sciences sociales, JeanMarie Tremblay, sociologue.

Les fichiers des Classiques des sciences sociales ne peuvent sans autorisation formelle:

- être hébergés (en fichier ou page web, en totalité ou en partie) sur un serveur autre que celui des Classiques.

- servir de base de travail à un autre fichier modifié ensuite par tout autre moyen (couleur, police, mise en page, extraits, support, etc...),

Les fichiers (.html, .doc, .pdf., .rtf, .jpg, .gif) disponibles sur le site Les Classiques des sciences sociales sont la propriété des Classiques des sciences sociales, un organisme à but non lucratif composé exclusivement de bénévoles.

Ils sont disponibles pour une utilisation intellectuelle et personnelle et, en aucun cas, commerciale. Toute utilisation à des fins commerciales des fichiers sur ce site est strictement interdite et toute rediffusion est également strictement interdite.

\section{L'accès à notre travail est libre et gratuit à tous les utilisateurs. C'est notre mission.}

Jean-Marie Tremblay, sociologue

Fondateur et Président-directeur général, LES CLASSIQUES DES SCIENCES SOCIALES. 
Cette édition électronique a été réalisée conjointement par Jean-Marie Tremblay, et Marcelle Bergeron, bénévoles, respectivement professeur de sociologie au Cégep de Chicoutimi, d'une part, et professeure retraitée de l'enseignement à la Polyvalente Dominique-Racine de Chicoutimi, à partir du livre de :

Courriels : jean-marie_tremblay@uqac.ca et mabergeron@videotron.ca

\section{Auguste BLANQUI}

Textes choisis. Préface et notes de V. P. Volguine, membre de l'Académie des sciences de l'U.R.S.S. Paris: Les ÉDITIONS SOCIALES, 1971, 223 pages. Collection : Les Classiques du peuple.

Numérisation, reconnaissance de caractères et correction : Jean-Marie Tremblay; Mise en page : Marcelle Bergeron.

Polices de caractères utilisés :

Pour le texte : Times, 12 points.

Pour les citations : Times 10 points.

Pour les notes de bas de page : Times, 10 points.

Édition électronique réalisée avec le traitement de textes Microsoft Word 2003 pour Macintosh.

Mise en page sur papier format

LETTRE (US letter), 8.5’’ x 11’’)

Édition complétée le 18 mai, 2008 à Chicoutimi, Québec. 


\section{Auguste Blanqui}

(1971)

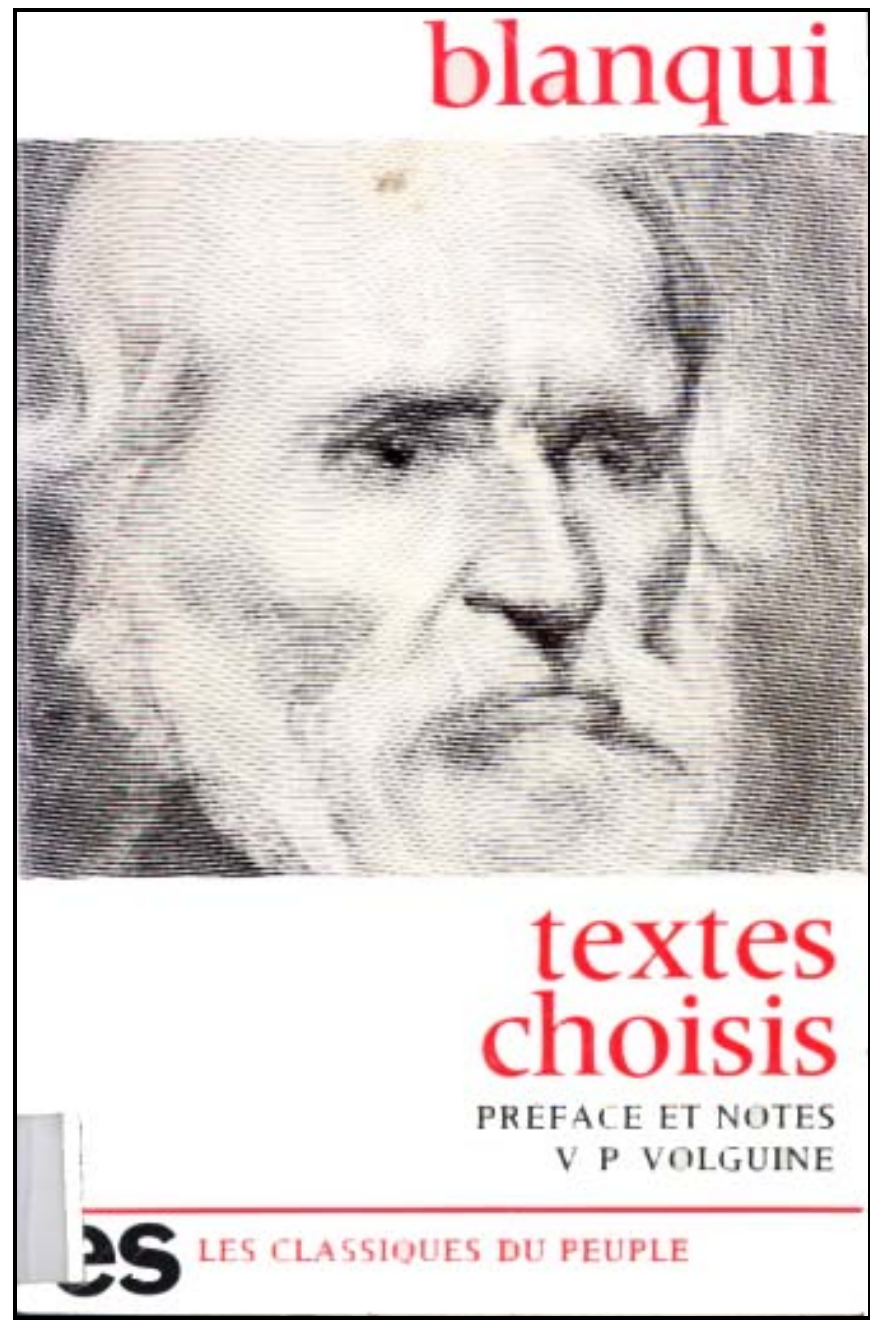


MM. Albert Soboul, Pierre Angrand et Jean Dautry, agrégés de l'Université, ont collaboré à la mise au point de cet ouvrage.

L'introduction de Volguine et la note biographique ont été traduites par Hélène Miakotine et Louise Biraud.

Paris : Éditions Sociales, 1971. 


\section{Table des matières}

Les idées politiques et sociales de Blanqui, par V. P. Volguine

Note biographique

Ouvrages d'Auguste Blanqui

Bibliographie

\section{TEXTES CHOISIS}

I. - BLANQUI AVANT LA RÉVOLUTION DE 1848

1. Le Procès des Quinze. Défense du citoyen Louis-Auguste Blanqui devant la Cour d'Assises (1832)

2. $\quad$ Rapport sur la situation intérieure et extérieure de la France depuis la Révolution de juillet (2 février 1832)

3. Qui fait la soupe doit la manger (1834)

\section{Appendice:}

1. $\quad$ Appel de Blanqui aux étudiants (11 décembre 1830)

2. Formulaire de réception à la Société des Saisons (1830)

3. Appel du Comité de la Société des Saisons (12 mai 1839)

\section{II. - BLANQUI SOUS LA DEUXIÈME RÉPUBLIQUE (1848-1852)}

1. $\quad$ Discours du 25 février 1848

2. $\quad$ Pour le drapeau rouge (26 février 1848)

3. $\quad$ Adresse de la Société Républicaine Centrale au Gouvernement (2 mars 1848)

4. $\quad$ Première pétition pour l'ajournement des élections (6 mars 1848)

5. Deuxième pétition pour l'ajournement des élections (14 mars 1848)

6. $\quad$ Adresse au Gouvernement (17 mars 1848)

7. Aux Clubs démocratiques de Paris (Manifeste du 22 mars 1848)

8. Profession de foi (30 mars 1848)

9. Adresse au Gouvernement provisoire (20 avril 1848)

10. Les massacres de Rouen. La Société Républicaine Centrale au Gouvernement provisoire (2 mai 1848)

11. Avis au peuple. (Toast du 25 février 1851)

12. À propos des clameurs contre l'Avis au peuple (avril 1851)

13. Lettre à Maillard (6 juin 1852) 


\section{III. - LA CRITIQUE SOCIALE}

1. L'usure (1869-1870)

2. Le communisme, avenir de la société (1869-1870)

3. Saint-Étienne. Lutte entre les fabricants et les ouvriers (décembre 1849)

4. L'origine des fortunes (1850)

5. Les partageux (1850)

6. La presse capitaliste (1869)

7. Saint-Simoniens. Crédit intellectuel (mars 1863)

8. La guerre du capital à la révolution (avril 1866)

9. L'infanticide. Ses causes : Dieu et le capital (1867)

10. $\quad$ Projet de discours (août 1867)

11. Grève et coopération (octobre 1867)

12. Le communisme primitif (avril 1869)

13. Coopération et réaction (1870)

14. L'économie politique sans morale (mars 1870)

15. Les conquêtes de l'industrie (juin 1870)

\section{IV. - LA PATRIE EN DANGER}

1. $\quad$ L'affaire de La Villette (16 septembre 1870)

2. La réaction (19 septembre 1870)

3. $\quad$ 1792-1870 (30 octobre 1870)

4. Armistice et capitulation (5 novembre 1870)

5. $\quad$ Alliance ouverte de la réaction avec Bismarck (25 novembre 1870)

6. Les envahisseurs (5 décembre 1870 )

V. - INSTRUCTION POUR UNE PRISE D'ARMES (1868) 


\section{LES IDÉES POLITIQUES ET SOCIALES DE BLANQUI}

$\underline{\text { Retour à la table des matières }}$

Blanqui eut une longue vie : il a donné plus d'un demi-siècle à la cause de la révolution. Ses dernières activités politiques se situent en 1880, mais sa conception du monde, les idées politiques qui orientèrent son action révolutionnaire se sont formées sous le règne de Louis-Philippe et ont pris leur forme définitive au cours de la révolution de 1848. Ni le développement ultérieur de la lutte de classe du prolétariat, ni l'apparition du communisme scientifique n'ont apporté de modifications essentielles à ses idées révolutionnaires.

«Blanqui, écrit Engels en 1874, est un révolutionnaire de la génération passée ${ }^{1}$. » Il s'est arrêté dans son développement idéologique au niveau qu'il avait atteint en 1848. Il n'a su ni comprendre, ni assimiler la théorie du communisme scientifique, bien qu'il ait connu l'activité de Marx et quelques-uns de ses travaux. Toutefois, en tant que représentant du communisme utopique prémarxiste, il mérite que les historiens de la pensée sociale lui accordent une grande attention.

La période 1830-1848 est marquée en France par le développement de la grande industrie capitaliste et par l'essor du mouvement ouvrier ; ce mouvement s'est manifesté par les soulèvements des canuts lyonnais de 1831, de 1834, et par de nombreuses grèves. (En 1832-1833, il y eut des moments où la grève englobait presque toutes les industries parisiennes; en 1840, les grèves s'étendirent à l'ensemble du pays.) En même temps que croissaient l'industrie capitaliste et le mouvement ouvrier, la conscience de classe du prolétariat se développait aussi. Dans la classe ouvrière s'éveillaient la conscience de ses propres tâches politiques et l'idée que, pour l'accomplissement de celles-ci, elle devait parvenir à constituer sa propre organisation. Mais le prolétariat a cherché en tâtonnant les voies qui lui permettraient de forger cette organisation ; ses erreurs lui servirent de leçons.

À mesure que s'affirmait concrètement la lutte de classe du prolétariat, les systèmes utopiques du socialisme perdaient leur sens progressif. Les « écoles » du socialisme utopique dégénéraient en "sectes "; chacune d'elles proposait ses procédés pour éliminer le mal social et pour concilier les contradictions de classes.

MARX-ENGELS : Euvres, t. XV, p. 225 (en russe). 
Les idées du socialisme utopique devenaient de plus en plus le bien de la petite bourgeoisie.

Les traits bourgeois et petits-bourgeois, propres à chaque système utopique, à des degrés divers, se sont ainsi pleinement révélés à cette époque. Ceux qui se considéraient comme les héritiers des grands utopistes inclinaient à chercher de l'aide du côté des classes instruites. La classe ouvrière, au contraire, inclinait de plus en plus vers le communisme.

Le socialisme, a dit Engels en caractérisant les rapports de cette époque, signifiait en 1847 un mouvement bourgeois ; le communisme, un mouvement ouvrier $^{1}$.

Mais la classe ouvrière n'était pas en mesure de se libérer d'un seul coup, et complètement, des influences étrangères à ses intérêts de classe. Les ouvriers français étaient encore très étroitement liés aux milieux petits-bourgeois d'où ils étaient issus pour la plupart et qui, malgré l'essor de la grande industrie, constituaient encore la majorité écrasante de la population laborieuse en France. Il existait encore beaucoup de survivances petites-bourgeoises dans la psychologie des ouvriers. Dans ces conditions, les théoriciens qui cherchaient à poser les bases du communisme ont été impuissants à créer une théorie scientifique du communisme. Dans le meilleur des cas, c'était le matérialisme mécaniste du $\mathrm{XVIII}^{\mathrm{e}}$ siècle qui demeurait la base philosophique de leur système. Aussi ne pouvaient-ils pas dépasser la théorie rationaliste de la société caractéristique du XVIII ${ }^{\mathrm{e}}$ siècle (la théorie de l'« ordre naturel et raisonnable » des rapports sociaux), ni fonder historiquement le communisme. Dans toutes leurs tentatives pour tracer une voie de réalisation au communisme, ils ne dépassaient pas la tradition babouviste. Leur communisme restait un communisme utopique, malgré leur élan révolutionnaire et leur désir de lier le communisme à la lutte ouvrière. Parmi tous ces communistes utopistes, Blanqui, par sa fidélité illimitée à la cause de la transformation révolutionnaire de la société, occupait indiscutablement la première place aux yeux de ses contemporains.

Le prolétariat, a écrit Marx dans "Les luttes des classes en France », se groupe de plus en plus autour du socialisme révolutionnaire, autour du communisme pour lequel la bourgeoisie elle-même a inventé le nom de Blanqui ${ }^{2}$.

Friedrich ENGELS : Préface $\left(1^{\mathrm{er}}\right.$ mai 1890) au Manifeste du Parti communiste, p. 24, Éditions sociales, 1954.

2 Karl MARX : Les Luttes de classes en France. Le 18 Brumaire de Louis Bonaparte, p. 114, Éditions sociales, 1948. 
L'ardente activité révolutionnaire qui a rempli toute la vie consciente de Blanqui a commencé sous la Restauration.

En 1824, le jeune Blanqui participa à l'organisation conspiratrice des Carbonari. En 1827, il fut blessé dans des combats de rues contre la police et la troupe et pour la première fois arrêté. En juillet 1830, il prit une part active à la lutte révolutionnaire et fut profondément déçu par son résultat : l'établissement de la monarchie bourgeoise de Louis-Philippe.

Entré dans l'association républicaine Les Amis du Peuple, Blanqui se plaça à l'aile gauche de celle-ci. Pour les premières années de la monarchie de juillet, deux documents témoignent de ses idées. Le premier est sa déclaration au procès des "Amis du Peuple », en janvier 1832 (Procès des Quinze). Le second est un discours prononcé à une réunion organisée par cette Société, le 2 février de la même année. Le premier de ces documents a été imprimé, à l'époque même, par l'association des "Amis du Peuple»; le second nous est parvenu à l'état de manuscrit.

Devant le tribunal, Blanqui posait nettement le problème de la division de la société en classes; il liait la lutte que mènent les "Amis du peuple" pour les droits politiques aux besoins matériels, aux intérêts et aux souffrances des es populaires. Mais ses idées concernant les classes sociales de son temps n'avaient pas un suffisant degré de précision et son programme social était encore très indéterminé.

Au président du tribunal qui lui demandait sa profession, Blanqui répondit: Prolétaire. Mais la suite de ses explications indique que, pour lui, le mot " prolétaire » désignait le travailleur en général :

C'est la profession de trente millions de Français qui vivent de leur travail et qui sont privés de leurs droits politiques.

Il est clair que Blanqui donnait à la notion de prolétaire Le même sens que les démocrates donnaient à la notion de "peuple». C'est l'opposition entre «l'aristocratie de la richesse et le peuple " ou bien entre "la bourgeoisie et le peuple », qui caractérise la pensée sociale de cette période. L'imprécision dans les termes de cette opposition reflétait le niveau insuffisant du développement capitaliste en France, le non-achèvement de l'évolution industrielle. Comme nous le verrons plus loin, Blanqui confond « prolétaire » et « pauvres ». 
Je suis accusé, poursuit Blanqui dans la même déclaration, d'avoir dit aux 30 millions de Français, prolétaires comme moi, qu'ils avaient le droit de vivre...

En formulant une telle accusation,

le ministère public ne s'est point adressé à votre équité et à votre raison, mais à vos passions et à vos intérêts, dit Blanqui aux juges. Le ministère public vous a dit: vous voyez, c'est la guerre des pauvres contre les riches: tous ceux qui possèdent sont intéressés à repousser l'invasion. Nous vous amenons vos ennemis; frappez-les avant qu'ils ne deviennent plus redoutables. Oui, Messieurs, ceci est la guerre entre les riches et les pauvres ; les riches... sont les agresseurs, seulement ils trouvent mauvais que les pauvres fassent résistance... On ne cesse de dénoncer les pauvres comme des voleurs prêts à se jeter sur les propriétés. [Les riches, ce sont] de légitimes possesseurs menacés du pillage par une avide populace...

Qui donc sont ces « légitimes possesseurs »? Qui sont les « voleurs »? Les « légitimes possesseurs », ce sont les

privilégiés qui vivent grassement de la sueur du prolétaire ... ; ce sont deux ou trois cent mille oisifs qui dévorent paisiblement les milliards payés par les voleurs. [Et les «voleurs » ?] Trente millions de Français qui paient au fisc un milliard et demi, et une somme à peu près égale aux privilégiés.

En effet, poursuivait Blanqui, le gouvernement actuel n'a point d'autre base que cette inique répartition des charges et des bénéfices,

d'autre but que l'exploitation du pauvre par le riche. L'État est une

pompe aspirante et foulante qui foule la matière appelée peuple pour en aspirer des milliards incessamment versés dans les coffres de quelques oisifs...

Tous les moyens légaux qui protègent les intérêts, qui permettent d'agir sur l'opinion publique, sont entre les mains des privilégiés. Le peuple n'en a aucun.

Les lois sont faites par cent mille électeurs, appliquées par cent mille jurés, exécutées par cent mille gardes nationaux... Or, ces électeurs, ces jurés, ces gardes nationaux, ce sont les mêmes individus, lesquels cumulent les fonctions les plus opposées et se trouvent tout à la fois législateurs, juges et soldats.

Trente millions de prolétaires restent en dehors de ce système que font-ils ?

Ils paient... [Mais comment] des hommes de cœur et d'intelligence... pourraient-ils demeurer indifférents... aux souffrances des prolétaires... ? Leur devoir est d'appeler les masses à briser un joug de misère... 
à prendre les affaires politiques entre leurs mains. Le peuple veut faire et il fera les lois qui doivent le régir ; alors ces lois ne seront plus faites contre lui ; elles seront faites pour lui, parce qu'elles le seront par lui.

La conclusion à laquelle Blanqui conduit ses auditeurs est claire: pour supprimer les maux de la société, il est indispensable de créer une démocratie politique. Au cours de sa déclaration, il ne fait pas de proposition de caractère socialiste ; mais la tendance socialiste est indiscutable. Il considère comme but de la lutte l'établissement de l'égalité sociale ; mais, comme mesure concrète pour améliorer le sort des opprimés, il n'indique que la réforme des impôts. Ceci est assurément dû au fait que Blanqui considère naïvement le système fiscal comme le mécanisme essentiel qui permet aux riches de piller les pauvres. Ces impôts "pillards» doivent être supprimés et remplacés par un impôt qui « devra s'emparer du superflu des oisifs », pour le répartir par « un système de banques nationales » (idée probablement inspirée par la propagande saint-simonienne) " entre cette masse de gens indigents que le manque d'argent condamne à l'inaction ${ }^{1} »$.

Dans son discours du 2 février 1832, Blanqui a caractérisé de manière plus concrète les forces de classes en lutte dans la France de son époque.

Il ne faut pas se dissimuler qu'il y a guerre à mort entre les classes qui composent la nation... le parti vraiment national, celui auquel les patriotes doivent se rallier, c'est le parti des masses.

Dans la France de son temps, Blanqui constate l'existence de trois intérêts :

Celui de la classe dite très élevée, celui de la classe moyenne ou bourgeoise, enfin celui du peuple... En 1814 et 1815, la classe bourgeoise fatiguée de Napoléon, surtout parce que la guerre... nuisait à sa tranquillité et empêchait le commerce d'aller, reçut les soldats étrangers en libérateurs et les Bourbons comme les envoyés de Dieu.

Aussi les Bourbons récompensèrent-ils la bourgeoisie " par la Charte ». Par le moyen de la Charte, la haute société et les grands propriétaires, d'une part, la classe moyenne, d'autre part, se partageaient entre elles le pouvoir. « Le peuple fut mis de côté. » " Privé de chefs », démoralisé par la défaite, il se taisait. La bourgeoisie a prêté son appui aux Bourbons jusqu'en 1825. Mais, par la suite, Charles X,

se croyant assez fort sans les bourgeois voulut procéder à leur exclusion, comme on avait fait pour le peuple en 1815

La bourgeoisie devint furieuse.

Procès des Quinze, publié par la Société des Amis du Peuple, Paris 1832 p. 77-86. (Voir plus loin : Textes choisis, p. 73 et suiv.) 
Alors commença cette guerre de journaux et d'élections [menée par elle contre Charles X]. Mais les bourgeois combattaient au nom de la Charte, rien que pour la Charte... [Le peuple] restait spectateur silencieux de la querelle; et chacun sait bien que ses intérêts ne comptaient pas dans les débats survenus entre ses oppresseurs... en voyant ses maîtres se disputer, il épiait en silence le moment de s'élancer sur le champ de bataille et de mettre les parties d'accord.

Lorsque, dans cette lutte entre la bourgeoisie et le gouvernement, la victoire commença à pencher vers la première, Charles $\mathrm{X}$ résolut de faire un coup d'État. Il décréta la dissolution de la Chambre des députés et menaça de se servir de la force armée. Les royalistes se montraient sûrs d'eux, et la bourgeoisie était prise de panique. Ni l'une, ni l'autre partie ne s'attendait à l'intervention du peuple.

Lorsque le peuple se dressa, réveillé d'un sommeil qui avait duré quinze ans, une frayeur plus grande encore saisit les bourgeois.

Au travers des débris, des flammes et de la fumée, sur le cadavre de la royauté, le peuple leur apparaît debout, debout comme un géant, le drapeau tricolore à la main ; ils demeurent frappés de stupeur...

D'abord, ils avaient redouté la victoire de Charles $\mathrm{X}$ et ils avaient tremblé devant ses conséquences. Ensuite, quand le peuple triompha, contre toute attente, les bourgeois furent stupéfaits.

Pendant ces jours où le peuple fut si grand, les bourgeois ont été ballottés entre deux peurs, celle de Charles X d'abord et celle des ouvriers ensuite.

Mais comment se fait-il qu'une révélation si soudaine et si redoutable de la force des masses soit demeurée stérile ?...

[Cette révolution] devait marquer la fin du régime exclusif de la bourgeoisie, ainsi que l'avènement des intérêts de la puissance populaire.

Comment « n'a-t-elle eu d'autre résultat que d'établir le despotisme de la classe moyenne » ? C'est que « le peuple n'a pas su profiter de sa victoire ».

Le combat fut si court que ses chefs naturels, ceux qui auraient donné cours à sa victoire, n'eurent pas le temps de sortir de la foule ! [Le peuple accordait sa confiance à ceux] qui avaient figuré en tête de la bourgeoisie dans la lutte parlementaire contre les Bourbons.

La victoire une fois remportée, le peuple rentra «dans ses ateliers »; la bourgeoisie entra dans l'arène. N'osant, par crainte du peuple, rétablir Charles X, elle proclama roi un autre Bourbon. 
La classe moyenne qui s'est cachée pendant le combat et qui l'a désapprouvé... a escamoté le fruit de la victoire remportée malgré elle. Le peuple, qui a tout fait, reste zéro comme devant. [Mais il est entré malgré tout sur la scène] il n'en a pas moins fait acte de maître... C'est désormais entre la classe moyenne et lui que va se livrer une guerre acharnée. Ce n'est plus entre les hautes classes et les bourgeois ; ceux-ci auront même besoin d'appeler à leur aide leurs anciens ennemis pour mieux lui résister, pour résister à l'offensive menaçante des prolétaires.

La peur du peuple, le désir de trouver un soutien dans l'aristocratie déterminent toute la politique du gouvernement de Louis-Philippe ; réactionnaire en toutes ses manifestations, ce gouvernement « copie la Restauration ».

« Deux principes divisent la France, le principe de la légitimité et celui de la souveraineté du peuple », déclare Blanqui, en conclusion de son aperçu historique. « Il n'y a pas de troisième drapeau, de terme moyen. » Tous ceux qui dénoncent « l'anarchie » et qui soutiennent « la vieille organisation du passé » se groupent autour du drapeau de la légitimité.

Le principe de la souveraineté du peuple rallie tous les hommes d'avenir, les masses qui, fatiguées d'être exploitées, cherchent à briser ces cadres clans lesquels elles se sentent étouffer ${ }^{1}$.

Comme nous le voyons, dans ce discours aussi, les groupes sociaux sont assez mal définis ; et on n'y rencontre pas non plus un exposé des mesures concrètes qui permettraient aux masses de se libérer de l'exploitation. À défaut, l'attention de Blanqui se concentre sur le but politique de la lutte: l'établissement de la souveraineté du peuple. Mais les tendances égalitaires, communes à presque tous les démocrates de cette époque, étaient aussi celles de Blanqui ; il est très probable que, dès 1832, il avait une certaine sympathie pour le socialisme. Il n'est pas douteux qu'il ait connu, avant même la Révolution de 1830, les œuvres des saintsimoniens et le livre de Buonarroti : La Conspiration pour l'Égalité. En tout cas, au début de 1834, ses convictions socialistes avaient déjà pris forme. Dans un article écrit cette même année, et qu'il avait destiné au journal Le Libérateur, Blanqui se prononce non seulement contre l'inégalité, mais aussi contre les grossières recettes de l'égalitarisme pour lutter contre le mal social ; il leur oppose le principe de l'association.

Il existe deux sources de la richesse :

l'intelligence et le travail, l'âme et la vie de l'humanité, écrit-il. Mais ces deux forces ne peuvent agir qu'à l'aide d'un élément passif, le sol, qu'elles mettent en

Discours du 2 février 1832, manuscrits de Blanqui, Bibliothèque nationale, acquisitions nouvelles, cote 9591-I, feuillets 314 et suivants. (Voir R. GARAUDY ; Les sources françaises du socialisme scientifique, p. 222-232, Paris, Hier et aujourd'hui, 1948). 
œuvre par leurs efforts combinés... Cet instrument indispensable devrait appartenir à tous les hommes. Il n'en est rien.

La terre est devenue propriété particulière.

Des individus se sont emparés par ruse ou par violence de la terre commune, et, s'en déclarant les possesseurs, ils ont établi par des lois qu'elle serait à jamais leur propriété... Ce droit de propriété s'est étendu... du sol à d'autres instruments, produits accumulés du travail désignés par le nom générique de capitaux.

L'établissement de la propriété a engendré un conflit entre « les droits humains même celui de vivre » et « le privilège du petit nombre ... »

Comme les capitaux stériles d'eux-mêmes ne fructifient que par la maind'œuvre et que, d'un autre côté, ils sont nécessairement la matière première œuvrée par les forces sociales, la majorité, exclue de leur possession, se trouve condamnée aux travaux forcés, au profit de la minorité possédante... La conséquence logique d'une telle organisation, c'est l'esclavage.

Cependant, le principe d'égalité, gravé au fond des cœurs et qui conspire, avec les siècles, à détruire sous toutes ses formes l'exploitation de l'homme par l'homme, porta le premier coup au droit sacrilège de propriété, en brisant l'esclavage domestique.

Les esclaves, propriété "à titre de meuble ", ont été transformés en serfs, "propriété immeuble annexe et inséparable de l'immeuble territorial ». Mais l'esclavage existe encore de nos jours.

La servitude, en effet, ne consiste pas seulement à être la chose de l'homme, ou le serf de la glèbe. Celui-là n'est pas libre qui, privé des instruments de travail, demeure à la merci des privilégiés qui en sont détenteurs... «La transmission héréditaire du sol et des capitaux place les citoyens sous le joug des propriétaires. »

La condition de l'ouvrier est pire que celle des nègres esclaves dans les plantations.

Car l'ouvrier n'est pas un capital à ménager comme l'esclave ; sa mort n'est pas une perte, il y a toujours concurrence pour le remplacer.

Le pauvre, poursuit Blanqui, ne connaît pas la source de ses maux. L'ignorance, fille de l'asservissement, fait de lui un instrument docile des privilégiés... Si à Lyon il [le prolétariat] s'est levé comme un seul homme, c'est que l'antagonisme flagrant des intérêts ne permettait plus l'illusion à l'aveuglement même le plus obstiné.

La situation est grosse de révoltes. Le sentant bien, les défenseurs de l'ordre s'évertuent à prêcher 
la communauté des intérêts et, par suite, la solidarité entre le capitaliste et le travailleur... Ces homélies trouvent encore des dupes, mais peu. Chaque jour fait plus vive la lumière sur cette prétendue association du parasite et de sa victime. Les faits ont leur éloquence ; ils prouvent le duel, le duel à mort entre le revenu et le salaire.

Blanqui est convaincu que, au bout de cette lutte, la victoire restera non aux oisifs, mais aux travailleurs.

Oui, ajoute-t-il, le droit de propriété décline... Il disparaîtra un jour avec les derniers privilèges qui lui servent de refuge et de réduit... L'humanité n'est jamais stationnaire. Elle avance ou recule.

La marche rétrograde remonterait jusqu'à l'esclavage personnel, dernier mot du droit de propriété. La marche progressive la conduit à l'égalité.

Disons tout de suite, explique Blanqui en conclusion de cet article, que l'égalité n'est pas le partage agraire. Le morcellement infini du sol ne changerait rien, dans le fond, au droit de propriété... La richesse provenant de la possession des instruments de travail plutôt que du travail lui-même, le génie de l'exploitation resté debout saurait bientôt, par la reconstruction des grandes fortunes, restaurer l'inégalité sociale. L'association, substituée à la propriété individuelle, fondera seule le règne de la justice par l'égalité ${ }^{1}$.

On distingue, dans cet article, une certaine influence de la théorie saintsimonienne sur Blanqui. Principalement, l'idée que le progrès consiste dans la substitution des formes d'exploitation. Il est possible que la notion de la société future présentée sous l'aspect de l'association relève aussi de cette influence, bien que la propagande de Fourier et de ses disciples ait joué un rôle important dans la diffusion de l'idée d'association. Tout en notant les influences des écoles utopiques du début du $\mathrm{XIX}^{\mathrm{e}}$ siècle qui ont pu s'exercer sur Blanqui, il est indispensable d'indiquer immédiatement qu'il est toujours resté étranger à l'utopisme pacifique, à la teinte religieuse de ces théories. En assimilant telle ou telle idée de Saint-Simon ou de Fourier, il les reliait aux traditions révolutionnaires du babouvisme.

Dans ce même article de 1834, il est encore un trait qui mérite d'être souligné : c'est la façon de présenter le travailleur salarié dans le régime capitaliste. La caractéristique est évidemment très abstraite. Nous pouvons en trouver de semblables, dès le XVIII ${ }^{\mathrm{e}}$ siècle (par exemple, chez Linguet). Toutefois, Blanqui fait un certain pas en avant. Il en vient à préciser la notion de " prolétaire »; il tend à comprendre le rôle de la véritable force sociale qui porte en elle la société future.

Comme nous l'avons remarqué, Blanqui n'est jamais parvenu à la pleine clarté sur cette question. Nul doute que ce pas en avant dans le développement de ses

BLANQUI : Critique sociale, t. II, p. 118-127. 
opinions sociales, il l'effectua sous la pression de la réalité environnante, sous l'impulsion qu'il reçut du développement de la lutte de classe du prolétariat français, de la lutte des ouvriers lyonnais dont il parle dans son article.

L'année 1834 peut être considérée comme l'année tournante de la France révolutionnaire sous la monarchie de Juillet. En 1834, après l'écrasement des insurrections lyonnaise et parisienne, sous l'oppression accrue de l'État, les représentants de la bourgeoisie et des intellectuels bourgeois, qui avaient joué un rôle important dans les sociétés secrètes de la période précédente, s'écartèrent des organisations révolutionnaires.

Les sociétés secrètes qui se reforment alors recrutent leurs membres, presque exclusivement, dans les milieux ouvriers et de la petite bourgeoisie, les plus proches du prolétariat. Dans ces nouvelles sociétés secrètes, les Familles, les Saisons, Blanqui est porté aux postes dirigeants. Nous ne pouvons connaître les opinions professées par Blanqui que par les formulaires d'initiation de ces sociétés. Sans doute, il n'était pas le seul à participer à leur rédaction, mais il en acceptait assurément les idées fondamentales.

Ces documents exposent d'abord que le gouvernement cristant « fonctionne dans l'intérêt d'un petit nombre de privilégiés ». Avant 1830, c'était l'aristocratie de naissance ; lorsque celle-ci fut renversée en 1830, ce fut l'aristocratie des riches qui prit sa place :

Hommes d'argent, banquiers, fournisseurs, monopoleurs... en un mot les exploiteurs qui s'engraissaient aux dépens du peuple.

... Le peuple, c'est-à-dire l'ensemble de ceux qui travaillent,

comment est-il traité par les lois ? Il est traité en esclave... Le sort du prolétaire est semblable à celui du serf et du nègre ; sa vie n'est qu'un long tissu de misères, de fatigues et de souffrances.

Renverser le gouvernement en place doit être le but final de l'organisation.

Faut-il faire une révolution politique ou une révolution sociale ? Il faut faire une révolution sociale. Faut-il se contenter de renverser la royauté ? Il faut détruire les aristocraties quelconques, les privilèges quelconques; autrement ce ne serait rien faire. Que devons-nous mettre à sa place ? Le gouvernement du peuple par lui-même, c'est-à-dire la république.

Mais le peuple ne peut prendre le pouvoir en main 
immédiatement après la révolution. L'état social étant gangrené, pour passer à un état sain, il faut des remèdes héroïques ; le peuple aura besoin, pendant quelque temps, d'un pouvoir révolutionnaire ${ }^{1}$.

Les documents que nous venons de présenter, tout comme la déclaration de Blanqui en 1832, ne nous apportent pas de réponse claire concernant les buts sociaux de la révolution, bien qu'elle soit définie comme une révolution sociale. Sous ce rapport, on se limite seulement à des formules générales : l'égalité doit être la base de la société ; l'existence de chaque membre de la société doit être assurée, à condition qu'il soit un travailleur ; tous les membres de la société ont des droits égaux, et les mêmes devoirs. La contradiction entre l'aristocratie de la richesse et «le peuple», considéré comme l'ensemble des travailleurs, apparaît comme l'opposition fondamentale de la société. L'exigence d'une dictature révolutionnaire que Blanqui a reçue du babouvisme, et qui est au cœur de sa conception du processus révolutionnaire, est la particularité importante du document. On doit cependant remarquer que cette dictature, dans son idée, est la dictature d'une organisation révolutionnaire et non pas la dictature de laclasse révolutionnaire.

Le 12 mai 1839, la Société des Saisons, dont Blanqui était l'un des chefs, essaya de provoquer un soulèvement à Paris. Cette tentative avait un caractère de conjuration. Le manifeste des insurgés appelait à fonder le règne de l'égalité et à abolir l'exploitation.

Périsse enfin l'exploitation et que l'égalité s'asseye triomphante sur les débris confondus de la royauté et de l'aristocratie.

Or la classe ouvrière, seule, pouvait se soulever au nom de tels principes. Mais la classe ouvrière française, en 1839, n'était pas encore en état de faire triompher une révolution sociale.

La tactique de conjuration qu'avait adoptée la Société des Saisons étant erronée, la tentative révolutionnaire de 1839 n'eut pas le succès qu'elle aurait pu espérer dans les conditions du début de la monarchie de Juillet.

Élevés à l'école de la conjuration, liés par la stricte discipline qui lui est propre, ils partaient de cette idée qu'un nombre relativement petit d'hommes résolus et bien organisés était capable, le moment venu, non seulement de s'emparer du pouvoir, mais aussi, en déployant une grande énergie et de l'audace, de s'y maintenir assez longtemps pour réussir à entraîner la masse du peuple dans la Révolution ${ }^{2}$,

Procès des accusés du 12 et 13 mai 1839. Rapport de Mérilhou, p. 9-10 et 220-221. - DE LA HODDE : Histoire des sociétés secrètes, p. 173-174 et 192-194.

2 Friedrich ENGELS : Introduction à l'édition allemande de 1891 de La guerre civile en France. (Voir Karl MARX : La guerre civile en France, Annexes. p. 299, Éditions sociales, 1953.) 
a dit Engels en parlant des blanquistes.

Les caractères de conjuration, indiqués par Engels, correspondaient à l'immaturité de la conscience de classe du prolétariat ; ils se manifestèrent avec une grande évidence dans le mouvement de 1839. Tout en appréciant justement la valeur de la discipline et de l'organisation, les révolutionnaires de 1839 (et Blanqui avec eux) ne comprenaient pas que ces magnifiques qualités ne sauraient assurer le succès que lorsque l'organisme qui les possède est étroitement lié aux masses de la classe ouvrière et lorsqu'il se présente comme le représentant et le chef naturel des masses ouvrières. La Société des Saisons n'avait pas cette liaison ; elle ne l'avait pas même avec les ouvriers parisiens, pour ne pas parler de l'ensemble du prolétariat français. Les masses ne sortirent pas dans la rue le 12 mai 1839 et le coup de force des groupes isolés de conjurés fut facilement réprimé.

L'arrestation de Blanqui s'ensuivit (14 octobre 1839), après six mois de vaines recherches policières ; elle arracha Blanqui des rangs des révolutionnaires jusqu'à la révolution de 1848. Ces années d'emprisonnement ne furent pas, pour lui, des années infécondes. Il rentra dans l'action en lutteur incomparablement plus mûr sur le terrain politique, capable de saisir souvent les solutions pratiques qui correspondaient le mieux aux intérêts des travailleurs. Mais il demeurait comme auparavant impropre à créer une théorie socialiste éclairant scientifiquement la voie vers le triomphe du communisme.

Dès les premiers jours de la révolution en apparence victorieuse, Blanqui montra le danger qui menaçait la jeune République. Il constatait l'existence de deux tendances dans le processus de la lutte, l'une « pour la république égalitaire », l'autre «pour le constitutionnalisme bourgeois ». Toute son activité, toutes ses déclarations étaient dirigées vers un seul but : lutter contre la réaction bourgeoise qui menaçait de détruire les résultats de la victoire populaire de Février. Blanqui formula nettement le but final de la lutte, dans le discours qu'il prononça le 31 mars à la Société Républicaine Centrale, qu'il avait organisée :

La République pour nous, déclare Blanqui en précisant le contenu de cette «République égalitaire », c'est l'émancipation complète des travailleurs. C'est l'avènement d'un ordre nouveau qui fera disparaître la dernière forme de l'esclavage, le Prolétariat. La tyrannie du Capital est plus impitoyable que celle du sabre et de l'encensoir. La révolution de Février a eu pour but de la briser. Ce but est aussi celui de la Société Républicaine Centrale et chacun de ses membres s'engage à le poursuivre jusqu'à ce qu'il soit atteint ${ }^{1}$.

Blanqui considérait en premier lieu les ouvriers parisiens comme la force principale capable de mener la lutte pour la « République égalitaire ».

\footnotetext{
Manuscrits de Blanqui. Cf. MOLINIER : Blanqui, p. 42, Paris, 1848.
} 
La première intervention contre le gouvernement provisoire concerne la question du drapeau de la République. Au fond, il s'agissait pour lui d'un choix à faire entre la voie « égalitaire »et la voie « bourgeoise » de la révolution.

Le drapeau tricolore n'est pas le drapeau de la République ; il est celui de Louis-Philippe et de la monarchie... Il s'est baigné vingt fois dans le sang des ouvriers. Le peuple a arboré les couleurs rouges sur les barricades de 48, comme

il les avait arborées sur celles de juin 1832, d'avril 1834, de mai 1839. Elles ont reçu la double consécration de la défaite et de la victoire. Ce sont désormais les siennes... Leur chute est un outrage au peuple, une profanation de ses morts... Déjà, conclut Blanqui, la réaction se déchaîne... Ouvriers ! c'est votre drapeau qui tombe. Écoutez-le bien ! La République ne tardera pas à le suivre ${ }^{1}$.

Quelques jours après, le 2 mars, à son club, Blanqui fit présenter une adresse au gouvernement provisoire. L'adresse énumérait les mesures que celui-ci devait prendre pour assurer la liberté de la presse, le droit d'association et de réunion. Il s'y trouve aussi deux paragraphes touchant directement les intérêts des ouvriers et leur place dans la révolution.

Le paragraphe 8 réclame

l'organisation immédiate en garde nationale de tous les ouvriers... sans exception, avec indemnité de deux francs par jour pour chaque jour de service actif.

Le paragraphe 9 demande

l'abrogation des articles 415 et 416 du Code pénal, ces articles interdisant les coalitions ouvrières ${ }^{2}$.

La campagne que mena Blanqui pour l'ajournement des élections à l'Assemblée Constituante présente un grand intérêt.

La contre-révolution, écrit-il dans sa pétition du 17 mars, a seule la parole depuis cinquante ans... Le peuple ne sait pas, il faut qu'il sache...

Pour connaître la vérité, un jour, un mois sont insuffisants.

Il faut que la lumière se fasse presque dans les moindres hameaux... Et ne dites pas que nos craintes sont chimériques. Les élections, si elles s'accomplissent, seront réactionnaires... Le parti royaliste, le seul organisé grâce à sa longue domination, va les maîtriser par l'intrigue, la corruption, les influences sociales ; il sortira triomphant de l'urne ! [Mais] ce triomphe, ce serait

\footnotetext{
Manuscrits de Blanqui. Cf. MOLINIER : op. cit., p. 36.
}

Ibidem, p. 37. 
la guerre civile, car Paris, le cœur et le cerveau de la France, Paris ne reculera pas devant le retour offensif du passé.

Réfléchissez, poursuit Blanqui,

aux sinistres conséquences d'un conflit entre la population parisienne et une assemblée qui croirait représenter la nation et qui ne la représenterait pas ; car le vote de demain sera une surprise et un mensonge.

Ainsi Blanqui exigeait l'ajournement des élections, comme condition indispensable à la rééducation politique des masses paysannes. En partant de la même compréhension du rapport des forces sociales, il a montré avec une grande perspicacité l'importance politique de l'impôt des quarante-cinq centimes décrété par le gouvernement provisoire ; cette mesure qui éloignait les masses paysannes de la révolution, il la considère comme « la sentence de mort de la République ».

Blanqui comprenait que la bourgeoisie, effrayée par la Révolution, était la principale force réactionnaire. Mais il dénonçait avec une violence particulière ceux qui, se donnant pour des démocrates, trahissaient les intérêts du peuple et servaient la cause de la réaction bourgeoise. En intervenant avec une fermeté de plus en plus marquée contre le gouvernement provisoire, Blanqui condamnait sévèrement son aile gauche, la Montagne de 1848. Ces "Montagnards ", il les distinguait des Montagnards de 1793 par le fait qu'ils étaient absolument détachés des masses parisiennes. Il devinait aussi le sens de la création de la Commission du Luxembourg : c'était une manœuvre de diversion destinée à détourner les ouvriers de l'action révolutionnaire. En 1851, faisant le bilan de l'expérience révolutionnaire, Blanqui écrivait :

Quel écueil menace la révolution de demain ? L'écueil où s'est brisée celle d'hier : la déplorable popularité de bourgeois déguisés en tribuns. Ledru-Rollin, Louis Blanc, Crémieux, Lamartine, Garnier-Pagès, Dupont de l'Eure, Flocon, Albert, Arago, Marrast.... Liste funèbre ! Noms sinistres, écrits en caractères sanglants sur tous les pavés de l'Europe démocratique. C'est le gouvernement provisoire qui a tué la Révolution. C'est sur sa tête que doit retomber la responsabilité de tous les désastres, le sang de tant de milliers de victimes. La réaction n'a fait que son métier en égorgeant la démocratie. Le crime est aux traîtres que le peuple confiant avait acceptés pour guides et qui l'ont livré à la réaction.

La haine que ressentaient pour Blanqui non seulement les réactionnaires déclarés, mais aussi les hommes qui couvraient de phrases libérales, démocratiques et même socialistes, leur servilité envers la réaction est donc parfaitement naturelle. «Toute la contre-révolution devient pâle au seul nom de Blanqui », écrivait Proudhon. Dans sa lutte contre l'ennemi le plus dangereux pour elle, contre l'homme le plus capable de grouper autour de lui les masses parisiennes, la réaction ne recula devant aucune ignominie. Le 31 mars, à Paris, fut 
publié un document qui prétendait apporter la preuve que Blanqui aurait fait devant le juge d'instruction de Louis-Philippe un témoignage compromettant sur ses camarades de l'insurrection de 1839. Barbès, l'ancien camarade de Blanqui à la Société des Saisons, apporta son adhésion, à cette campagne de mensonges. Blanqui démentit cette calomnie, mais elle jeta un certain trouble dans les rangs de ses partisans. Le 26 mai, Blanqui fut arrêté pour avoir participé à la manifestation du 15 mai ; pendant les journées de juin, les ouvriers parisiens furent privés de leur guide le plus fidèle, et du chef qui avait le plus d'autorité. Blanqui fut, à nouveau et pour de nombreuses années, écarté de la lutte directe pour la cause de la Révolution.

Son action révolutionnaire de 1848 a été hautement appréciée par Marx et Engels. Ils appelaient Blanqui un "révolutionnaire prolétarien » ${ }^{1}$. Dans Le 18 Brumaire de Louis Bonaparte, Marx a écrit au sujet de la manifestation du 15 mai :

Le 15 mai n'eut d'autre résultat que d'éloigner de la scène publique Blanqui et ses partisans, les communistes révolutionnaires, c'est-à-dire les véritables chefs du parti prolétarien ${ }^{2}$.

Dans la seconde adresse du Comité central de la Ligue des Communistes, il était indiqué :

Parmi les révolutionnaires français, le parti véritablement prolétarien dont Blanqui est le chef s'est réuni à nous ${ }^{3}$.

Dans l'une de ses lettres, Marx écrivait qu'il considérait Blanqui « comme la tête et le cœur du parti prolétaire en France ${ }^{4}$ ». En mars-avril 1850, Marx et Engels eurent des entrevues avec deux envoyés de Blanqui à Londres; ils conclurent avec eux un accord sur la base duquel étaient reconnues, comme but commun, l'exclusion des classes privilégiées du pouvoir politique et la soumission de ces classes à la dictature du prolétariat jusqu'à la réalisation du communisme.

Après l'échec de la révolution de 1848, dans sa prison, jusqu'à l'amnistie de 1859, Blanqui continuait, malgré tout, à œuvrer pour la Révolution, en cherchant à maintenir la liaison avec les amis laissés en liberté, en leur adressant des lettres pour diriger leurs activités, et des notes de caractère politique. Le 14 août 1870, Blanqui prit part à la tentative malheureuse qui visait à renverser le gouvernement de Napoléon III, compromis par les défaites subies dans la guerre francoprussienne. Après la chute de Napoléon, Blanqui publia le journal La Patrie en

MARX-ENGELS E Euvres, t. VIII, p. 305, Édition russe.

2 MARX-ENGELS Euvres, t. VIII. p. 329, Édition russe, ou en français, MARX : Le 18 brumaire de Louis Bonaparte, p.179, Éditions sociales, 1948.

MARX-ENGELS : Euvres, t. VIII, p. 495, Édition russe.

4 MARX : Lettre au $\mathrm{D}^{\mathrm{r}}$ Watteau, 10 novembre 1861. 
danger, où il fit une ardente propagande en faveur de la défense de la France, foyer de la révolution opposé au prussianisme réactionnaire.

Dans les premiers jours de la République, Blanqui commit une grave erreur politique, en appelant les masses à soutenir sans condition le gouvernement provisoire bourgeois, au nom de la «défense de la Patrie ${ }^{1}$ ». Il ne sut pas comprendre que ce gouvernement, contre-révolutionnaire dans son essence même, redoutait plus les ouvriers français armés qu'il ne craignait l'occupation prussienne ; et que, pour cette raison, il était tout à fait incapable d'organiser la défense, et qu'il était, comme le disait Marx, non « un gouvernement de défense nationale, mais un gouvernement de défection nationale ${ }^{2}{ }$. La suite des événements obligea Blanqui à abandonner cette position erronée et à se prononcer énergiquement contre les politiciens bourgeois qui, par peur du mouvement révolutionnaire des masses, étaient prêts à trahir leur pays, en faisant alliance avec Guillaume et Bismarck. Le 17 mars 1871, à la veille de la proclamation de la Commune, Blanqui fut arrêté pour avoir participé à une tentative de soulèvement contre le gouvernement provisoire, le 31 octobre 1870. Élu membre de la Commune, il ne put prendre part à son activité. Après sa libération en 1879, Blanqui, malgré ses soixante-quatorze ans, reprit la lutte politique, à laquelle seule sa mort mit un terme, le 1er janvier 1881.

\section{II}

Blanqui n'a pas laissé d'exposé systématique de ses idées politiques, sociales et philosophiques. Son héritage littéraire consiste en articles de journaux sur diverses questions de philosophie et de politique, en un très grand nombre de manuscrits disparates et qui restent encore, pour la plupart, inédits. Toutefois, l'étude comparative de ces articles, notes et écrits permet de rétablir assez sûrement les positions théoriques qui inspiraient son activité révolutionnaire.

Les deux tendances principales du socialisme utopique français au début du $\mathrm{XIX}^{\mathrm{e}}$ siècle, le fouriérisme et le saint-simonisme par leurs principes

Nous croyons utile de rapporter la critique exprimée sur ce point dans un article publié dans la revue soviétique Questions d'histoire, ${ }^{\circ}$ 6, 1955 : «À notre avis, on ne peut être entièrement d'accord avec Volguine quand il affirme catégoriquement que Blanqui aurait apporté son soutien absolu au gouvernement provisoire bourgeois dans les premiers jours de la Troisième République. Face à l'ennemi extérieur, Blanqui a effectivement appelé dans son journal, le 7 septembre 1870, les Français à une union nationale complète. Mais il ne serait pas juste de croire qu'il n'avait pas conscience de la nature contre-révolutionnaire du gouvernement TrochuFavre ; le 18 septembre, Blanqui a écrit dans le même journal : « Le doute envahit notre âme, au soupçon d'un immense mensonge »... Il pressentait une lutte inévitable « entre deux courants, celui du dévouement et celui de l'égoïsme... » Il mettait le peuple en garde également contre la possibilité de la conclusion d'une paix honteuse derrière son dos et conseillait aux ouvriers de «ne compter que sur eux-mêmes ». (N. T.)

2 Karl MARX : La Guerre civile en France, p. 23, Éditions sociales, 1953. 
philosophiques généraux, touchaient à l'idéalisme. Les aspirations religieuses étaient le propre de l'une et de l'autre école, bien que ces aspirations différassent du christianisme officiel. Certains communistes utopistes, à cette même époque, ne s'étaient pas libérés, non plus, de ces tendances religieuses. Buonarroti, le propagandiste du communisme révolutionnaire, à tradition babouviste, continuait Rousseau et Robespierre, défendait l'idée d'une religion civique et considérait que la croyance en l'Être suprême et en l'immortalité de l'âme étaient indispensables pour le progrès et l'affermissement de la société humaine.

L'idéalisme est étranger à la conception du monde de Blanqui ; il reste un adepte logique des matérialistes français du XVIII ${ }^{\mathrm{e}}$ siècle, avec tous leurs côtés faibles et forts. Pour lui le spiritualisme n'est pas seulement « une erreur philosophique; il est un crime politique et social ». En effet, le spiritualisme est « le père de toutes les religions » et les religions sont « la source de l'ignorance, de l'exploitation, de la misère... ». «Le spiritualisme est la pierre angulaire « de l'oppression, l'instrument par excellence de la tyrannie ». Or la religion est l'alliée naturelle du conservatisme, car son essence est " l'immobilisme », l'immutabilité. La religion interdit à ses adeptes l'aspiration vers le progrès. " Dieu » est un mot qui sert à masquer notre impuissance et notre ignorance. Ce mot «prétend tout expliquer, mais il n'explique rien et interdit toute explication ». La religion condamne l'esprit et la volonté à la stagnation. Sitôt que l'esprit humain cesse de comprendre, il dit : dieu. » Ce mot a toujours " tenu l'esprit humain à la chaîne et s'efforce encore de l'y retenir toujours ». Seule, la science, en renversant les obstacles qu'élève la foi, peut conduire l'humanité par les voies de la connaissance et de l'action qui assureront sa grandeur et sa liberté. La foi dit à l'homme : « À genoux ! impie, on ne passe pas. La science lui dit froidement : Lève-toi et passons et l'homme passe ${ }^{1}$ ». La connaissance signifie mouvement et vie.

Les peuples n'ont pas de plus cruel ennemi que la religion. Le christianisme et l'opium sont deux poisons identiques par leurs effets,

écrit Blanqui. En détournant la pensée et l'action humaines de problèmes sociaux, terrestres, en les dirigeant vers le ciel, la religion rend l'homme indifférent à tout, sauf à la vie future ; elle affaiblit sa lutte pour la justice. La lutte contre la religion occupe chez Blanqui une place aussi considérable que chez les philosophes des «lumières » au XVIII ${ }^{\mathrm{e}}$ siècle. Il considère que la première tâche de la révolution doit être de réduire à néant le monothéisme.

Si Blanqui dénonce le rôle social des religions historiques, il n'en est pas moins sévère à l'égard des faux messies du XIX ${ }^{\mathrm{e}}$ siècle.

Leurs tentatives, dit-il, sont rétrogrades par nature, bien qu'elles se dissimulent sous une fausse apparence de progrès.

\footnotetext{
Manuscrits de Blanqui, B. N. Nouv. acq. 9583-9587. Cf. GARAUDY : op. cit., p. 263-264.
} 
Les masses n'ont pas besoin de ces caricatures du passé. Le trait commun de ces nouvelles religions, saint-simonisme, fouriérisme, positivisme, est leur attitude négative vis-à-vis de la révolution. Toutes, elles la " traitent en ennemie »; elles prétendent la remplacer. Mais, en se séparant de la révolution, elles quittent inéluctablement «la route de l'avenir»; elles en viennent «à s'allier aux gouvernements du passé »; elles cherchent à obtenir leur soutien, et elles « achètent ce triste secours par leurs outrages à la révolution et à ses défenseurs ».

Saint-Simoniens, fouriéristes, positivistes se sont montrés identiquement craintifs, flagorneurs, diplomates, mendiants vis-à-vis des pouvoirs contrerévolutionnaires... On peut en retrouver les débris au Sénat, dans les conseils ou dans les auxiliaires du gouvernement impérial (celui de Napoléon III).

À toutes les fantaisies religieuses et idéalistes, Blanqui oppose le matérialisme et l'athéisme.

L'affirmation qui va prendre possession du monde est l'athéisme, l'univers incréé, éternel, vivant par lui-même, de sa propre force. Cette affirmation a pour base la science, et la science moderne est venue apporter et apporte chaque jour de nouveaux arguments à l'appui de cette conclusion...[Les religions, sont] maîtresses encore aujourd'hui en apparence... [Mais déjà] les dogmes sont morts pour toujours. Le monde est en marche, la science à sa tête. L'écroulement des religions est inéluctable.

Tout comme ses maîtres en philosophie, Helvétius et d'Holbach, Blanqui n'était pas en mesure de s'élever à la compréhension matérialiste dialectique du développement de la société. Les lois des phénomènes de la vie sociale lui paraissaient sans liaison avec les progrès de la société humaine, avec le perfectionnement des rapports sociaux, comme résultats de l'activité consciente des hommes. Le mot « loi », écrivait-il, n'a de sens que par rapport à la nature ; ce qu'on nomme « loi », règle immuable, est incompatible avec la raison et la volonté. Là où l'homme agit, il n'y a point place pour la loi.

Dans ce domaine Blanqui est en retard sur Saint-Simon et Fourier.

Blanqui considérait le processus historique comme un mouvement progressif. Mais ce sont la raison et la volonté, la pensée et l'expérience de l'homme qui lui confèrent ce caractère progressif.

Rien ne s'est improvisé dans l'histoire des hommes... L'humanité n'a franchi que par des transitions insensibles les étapes sans nombre qui séparent son berceau de son âge viril... Les révolutions elles-mêmes, avec leurs apparences si brusques, ne sont que la délivrance d'une chrysalide. Elles avaient grandi lentement sous l'enveloppe rompue. 
Elles sont «bien différentes de la conquête, invasion brutale d'une force extérieure »... L'évolution intérieure d'une race, d'une peuplade n'offre rien de pareil ;

elle s'accomplit par degrés, sans trouble sensible comme le développement d'une plante... Chaque siècle a son organisme et son existence propres, faisant partie de la vie générale de l'humanité ${ }^{1}$.

Blanqui ne laisse pas de comprendre l'importance des rapports économiques dans le développement de la société. Il souligne fréquemment que les luttes qui se produisent dans la société sont déterminées par des intérêts matériels, que les idées et principes expriment ces intérêts. Mais dans la complexité des forces qui agissent dans l'histoire des hommes, il attribue au développement des connaissances, à l'instruction, au perfectionnement de la raison humaine le rôle de moteur principal dans le progrès de l'humanité. La philosophie, déclare-t-il, dirige le monde : c'est son axiome.

Le contenu fondamental de l'histoire des sociétés est pour Blanqui la marche vers le communisme :

L'humanité a commencé par l'individualisme absolu, et, à travers une longue série de perfectionnements, elle doit aboutir à la communauté.

Il rejette de façon décisive l'idée du communisme primitif, du communisme « des premiers âges de l'humanité ».

Il est faux que le communisme ait jamais été l'enfance d'une société quelconque. Ces assertions sont diamétralement le contraire de la vérité.

« Le non-partage des terres » n'est pas le communisme.

À quoi bon partager ce qu'on ne cultive pas ? C'est comme si on disait les peuples actuels communistes parce qu'ils ne divisent pas la mer en lots particuliers.

Ce n'est pas le communisme, mais l'individualisme qui est « la première force de la société. Son règne est celui de l'ignorance, de la sauvagerie ». Les sauvages sont extrêmement individualistes. Le communisme est incompatible avec l'ignorance; il est le dernier mot de la science sociale, "le terme final de l'association. Chaque pas dans cette voie est la conséquence d'un progrès dans l'instruction », du travail de la raison humaine. Les arrêts dans cette voie sont provoqués par les retards dans le développement de la raison. Ainsi le progrès a été retardé, interrompu par le christianisme. Le communisme se réalisera

Critique sociale, t. I, p. 41-45. 
par le triomphe absolu des lumières. Il en sera la suite inéluctable, l'expression sociale et politique ${ }^{1}$.

Nous avons parlé d'une influence possible du saint-simonisme sur la pensée de Blanqui relativement à l'histoire. Manifestement, cette influence ne fut pas très profonde. En tout cas, la périodisation historique de Blanqui diffère grandement de celle des saints simoniens. Chez Blanqui, l'apparition de la division du travail sépare nettement deux périodes différentes de l'histoire des sociétés humaines ${ }^{2}$. Avant la division du travail, l'individualisme conserve ses traits fondamentaux isolement économique de chaque famille; les hommes ne connaissent pas l'échange ; chaque famille produit elle-même tout ce qui est nécessaire. Mais, au cours de cette époque d'économie par groupes isolés, l'humanité traverse trois phases de développement : Première phase - l'âge de la pierre. L'homme, isolé de ses semblables, ne connaît pas d'autre lien social que la famille. Deuxième phase : suite de l'âge de la pierre et commencement de l'âge du bronze ; rapprochement des hommes par tribus. Ils vivent de l'élevage et de la chasse; la terre reste commune. Point de culture encore, ni d'appropriation du sol. Ébauche de gouvernement, une hiérarchie, un ou plusieurs chefs. La troisième phase : âge du bronze, âge $d u$ fer. Les hommes passent au travail de la terre qui suit l'appropriation du sol. Du point de vue historique, selon Blanqui,

ce pas apparent vers l'individualisme est au contraire un progrès sensible de l'association parmi les hommes et un acheminement vers la communauté.

Dans cette période apparaissent le pouvoir politique et social de la monarchie et de l'aristocratie, les castes, les rapports de vassalité. Mais il n'y a « ni échange, ni monnaie, ni par conséquent exploitation capitaliste », conclut-il. ${ }^{3}$

La division du travail introduit une importante nouveauté dans la vie de l'humanité ; elle élève le rendement, améliore la qualité de la production. Elle détruit l'isolement des individus et établit un nouveau principe : " chacun travaillera pour tous, tous pour chacun ${ }^{4}$ ». Mais ce progrès indiscutable est payé du « sacrifice de l'indépendance individuelle », de "l'esclavage réciproque sous l'apparence de solidarité ». L'abandon de l'indépendance personnelle n'est ni spontané, ni conscient. "Personne ne l'aurait consenti. » Pas un homme n'aurait accepté d'échanger le sentiment de la liberté personnelle... contre le collier doré de la civilisation ${ }^{5}$.

Le régime de la division du travail n'a dû remplacer l'isolement individuel que par une série de transformations réparties sur une période immense. Chaque

Critique sociale, t. II, 67-75 ; t. I, p. 73 et suivantes.

Ibidem, t. II, p. 79 ; t. I p. 3 et suivantes.

Critique sociale, t. II, p. 77-79.

Ibidem, t. I, p. 9.

Ibidem, t. I, p. 39-42. 
pas dans cette voie était applaudi comme une victoire attendue, désirée, et le changement s'est ainsi opéré peu à peu, à travers une longue suite de générations sans froissement de mœurs, d'habitudes, ni même de préjugés.

Avec la consolidation du principe de la division du travail,

La société repose sur l'échange... Or, si le troc en nature suffisait aux temps primitifs, alors que la consommation portait sur un très petit nombre d'objets, tous de nécessité absolue, il devenait radicalement impossible entre les milliers de produits d'une industrie perfectionnée. Un intermédiaire était donc indispensable. Les qualités spéciales des métaux précieux ont dû les désigner de bonne heure à l'attention publique. Car l'origine de la monnaie remonte à des époques inconnues. Ce qui nous touche c'est l'expérience acquise que les services rendus par le numéraire ont été payés bien cher.

[Car] la condition fondamentale de l'échange, c'est l'équivalence des objets échangés ; [c'est la loi même de l'échange]. Si cette loi avait été observée, l'usage de la monnaie eût été fécond en bienfaits.

[Au contraire, cet usage] a enfanté un cruel abus... Il a créé l'usure, l'exploitation capitaliste et ses fines sinistres, l'inégalité, la misère ${ }^{1}$.

Quand naquit la monnaie, déclare Blanqui, deux procédés s'offraient aux hommes pour l'emploi de ce moyen d'échange: la fraternité, l'égoïsme. La droiture eût conduit rapidement à l'association intégrale... Bientôt les exigences d'une industrie plus avancée auraient déterminé la coopération des activités particulières.

Mais les égoïstes, les hommes de rapine ont rapidement compris la puissance de l'argent ; ils ont saisi l'importance que pouvait avoir la possession « de cette lampe merveilleuse ». Le « vampirisme » de ces hommes a conduit la société sur la voie de l'égoïsme.

L'accumulation du capital s'est opérée non par l'association, mais par l'accaparement individuel, aux dépens de la masse, au profit du petit nombre.

Quelques-uns se trouvèrent possesseurs des instruments de travail et le plus grand nombre fut obligé de travailler pour eux. Pouvait-il en être autrement, « dans les âges de ténèbres et de sauvagerie »? alors que les hommes «ne connaissaient d'autre droit que la force, d'autre morale que le succès ». C'est ainsi que s'est établi, comme le dit Blanqui, le pouvoir de l'Empereur Écu et que « l'usure est devenue la plaie universelle ${ }^{2}$.

Critique sociale, t. I, p. 3-5, 42-43.

Ibidem, t. I, p. 43-45. 
Nous ne rencontrons pas, chez Blanqui, une analyse fouillée du capitalisme. Dans sa conception du capital et de l'exploitation capitaliste, il reste au niveau des utopistes petits-bourgeois de la première moitié du $\mathrm{XIX}^{\mathrm{e}}$ siècle. Pour lui, le capital est synonyme d'usure; il voit la source du profit capitaliste dans la nonéquivalence de l'échange. Sa critique du capitalisme repose principalement sur un jugement de caractère moral et rationnel. L'ordre existant ne répond pas aux exigences de la justice, de la logique, du bon sens. Or « la justice, déclare-t-il, est le seul critérium vrai applicable aux choses humaines ». Son application conduit inévitablement au socialisme. L'économie politique bourgeoise est indifférente à la morale, et "son indifférence morale lui ôte toute puissance de critique, son scepticisme la frappe d'impuissance ${ }^{1}$. Blanqui accuse l'économie politique bourgeoise de violer le principe de

l'équivalence des objets échangés, axiome qu'elle-même a posé, reconnu et proclamé, en justifiant le prêt à intérêt.

Il est naturel que Blanqui se plaçant sur des positions petites-bourgeoises, au sujet de la nature de l'exploitation capitaliste, ne soit pas en mesure de comprendre la structure de classe de la société capitaliste. Il n'est pas douteux que sa conception petite-bourgeoise de l'exploitation capitaliste est liée à ce fait qu'il assimile le prolétariat à tout l'ensemble des groupes sociaux vivant de leur travail sans exploiter le travail d'autrui.

Cette même théorie, profondément erronée, concernant l'exploitation capitaliste le conduit à déformer la perspective historique et à mêler, dans son esprit, les formes diverses de l'exploitation. Pour lui, le pouvoir despotique de l'Empereur Écu a commencé dès les temps les plus reculés :

avant même que le rideau de l'histoire se lève, sa majesté l'Empereur Écu gouverne en despote l'Europe, l'Asie et l'Afrique. [Le capital règne] sur l'Égypte, la Phénicie, la Grèce, Carthage. Il trône dans Rome républicaine. Les patriciens ... sont des usuriers, maîtres à la fois par le glaive et par le sesterce.... Tous les grands hommes classiques [de la République romaine] Scipion, Pompée, Lucullus, Caton, Brutus, Cassius, etc., [étaient] prêteurs sur gages, pressureurs impitoyables... Cinq cents années durant, Patriciat et Prolétariat sont aux prises sur la question politique et sociale.

Et, déclare Blanqui : «L'histoire romaine n'est qu'un long récit de la lutte entre le Capital et le Travail. » Bien que dans cette lutte la défaite ait réduit les créanciers insolvables à la condition d'esclaves, la situation du prolétariat à Rome est au fond analogue, suppose Blanqui, «à la situation du travailleur européen » ; mais, dans la République romaine, les trois instruments de tyrannie, le sacerdoce, la monnaie et le sabre, sont réunis dans les mêmes mains...

\footnotetext{
Critique sociale, t. I, p. II et t. II, p. 58.
} 
Des trois jougs que le plébéien subit, le plus lourd est celui du capital. Les deux autres lui servent de gendarmes.

Le triomphe de César sur la République a été rendu possible par le fait que les masses se sont mises du côté de César. Le césarisme dut son succès à la haine générale contre la tyrannie des usuriers. Mais les masses n'ont rien gagné à cette révolution.

«Le sabre n'était plus aux mains des usuriers », mais l'usure dirigeait Rome, comme auparavant. "À ces deux fléaux, s'en était joint un troisième, le Christianisme ... ! » « Tous ensemble, ils engloutirent le vieux monde. »

Le christianisme engendré par la civilisation antique l'a détruite. Entre Rome et le monde contemporain se place le règne véritable du christianisme ; le moyen âge, époque de barbarie ${ }^{1}$.

Dans la société féodale, qui s'est élevée sur les ruines de Rome,

la noblesse et le clergé se partagent la puissance. L'homme d'argent est la proie de l'homme de guerre... [Mais le monde] a remonté peu à peu les pentes de la civilisation. Aujourd'hui, le revirement est complet.

Le capitalisme domine la société, obsédé par la cupidité, la chasse au profit.

Il a saisi la portée de l'association et ce magnifique instrument de progrès est devenu entre ses mains... [une arme) pour exterminer la petite et moyenne industrie, le moyen et le petit commerce.

... Sur les ruines du bourgeois modeste s'élève, plus savante et plus terrible que le vieux patriciat, cette triple féodalité financière, industrielle et commerciale qui tient sous ses pieds, la société entière ${ }^{2}$.

La société marche à l'abîme, comme saisie d'une

furie aveugle... En vain le cri presque universel réclame l'égalité. Chaque jour, la tranchée se creuse plus profonde entre deux castes uniques, l'opulence et la misère. Les situations intermédiaires disparaissent. Toutes les conquêtes de la science deviennent une arme terrible entre les mains du Capital contre le Travail et la Pensée ${ }^{3}$.

Résumant ses considérations sur l'histoire, Blanqui en arrive à la généralisation suivante :

Voir manuscrits de Blanqui ; cité par E. MASON : «Blanqui and Communism» Political Science Quarterly, 1929, XLIV, p. 505.

Critique sociale, t. I, p. 176 et suivantes.

Critique sociale, t. I, p. 74. 
Les procédés de la tyrannie sont immuables. On les retrouve partout et toujours, debout sur les mêmes assises, l'ignorance et la crédulité... Ainsi se passent les choses depuis les temps historiques.

Mais il est convaincu que ce régime basé sur l'exploitation ne peut être le destin du genre humain. «Le genre humain est-il voué à l'exploitation perpétuelle ? » Nous savons que, pour Blanqui, la lutte contre le « Capital » est le trait essentiel de l'histoire de la société et cela dès l'histoire de la République romaine. Tout comme ses maîtres, les babouvistes, il est enclin à penser que « la lutte des pauvres contre les riches » est le propre de toute société où règne l'inégalité. Mais, d'autre part, il explique non sans quelque contradiction avec cette conception, que « l'Empereur Écu... aujourd'hui pour la première fois, se heurte à la révolte de ses victimes ${ }^{1}$. »

Une lutte acharnée existe dans la société entre deux classes la bourgeoisie et le prolétariat. ${ }^{2}$ Les prolétaires

ne peuvent se passer vingt-quatre heures des instruments de travail qui sont au pouvoir des privilégiés; mais conclure qu'il y a entre ces deux classes communauté d'intérêt, c'est un étrange raisonnement... Ce n'est pas là une communauté, mais une opposition d'intérêts ; il n'existe d'autre rapport que celui de la lutte.

La domination des oppresseurs chancelle. Leur classe « est avec César son dernier espoir », tandis que « le peuple est avec la République ». Les oppresseurs cherchent un soutien dans l'Église catholique :

Les industriels d'Elbeuf se rangent sous la bannière de Loyola ; ils vont à la messe tous les dimanches, afin de prier pour la conservation de leurs privilèges sociaux et de leurs écus.

« D'un côté, la violence, l'iniquité, les ténèbres ; de l'autre la justice, la fraternité, les lumières ». L'issue de la lutte, selon Blanqui, ne fait aucun doute ${ }^{3}$.

Bien qu'il y ait des gens appartenant par leur naissance à la bourgeoisie qui se soient placés dans les rangs du prolétariat, bien qu'il y ait des prolétaires qui combattent dans les rangs de la bourgeoisie, la lutte se déroule entre le Profit et le Salaire, entre le Capital et le Travail. Il est naturel, dit Blanqui, que les chefs du mouvement révolutionnaire sortent de la bourgeoisie. Dans les rangs de la bourgeoisie se trouve une certaine minorité d'élite, cœur et cerveau de la

Ibidem, t. I, p. 46.

Dans l'appréciation de cette position de Blanqui, on ne saurait évidemment oublier l'acception qu'il donne au terme de prolétariat : il compte en France 32 millions de prolétaires, à savoir tous les gens n'ayant pas de « propriété » importante et vivant du travail de leurs mains.

3 Critique sociale, t. I, p. 51. 
Révolution. Les bourgeois déclassés activent la fermentation des masses, les conduisent au combat contre la bourgeoisie dans l'intérêt du prolétariat. Mais Blanqui raille de façon acerbe les gens qui se proclament «démocrates » et déclarent qu'ils n'appartiennent ni au camp de la bourgeoisie ni à celui du prolétariat. Seuls, ceux qui cherchent à tromper le peuple peuvent se cacher sous des phrases aussi creuses; ceux à qui sont véritablement chers les intérêts du peuple doivent, sans réserve et sans hésitation, rejoindre son camp et porter ouvertement sa cocarde. Blanqui évoque les hommes d'action de la Montagne de 1793 ; il les idéalise pour les donner en exemple aux démocrates de son temps.

Depuis le 10 août, chute de la Monarchie, jusqu'au 1er prairial, dernière convulsion des faubourgs, le Peuple et la Montagne marchent comme un seul homme, déclare-t-il, inséparables dans la victoire et dans la défaite ${ }^{1}$.

Blanqui ne croit pas à la possibilité de changer les conditions de vie des masses opprimées par les moyens que proposent les différentes écoles du socialisme utopique. Il reconnaît qu'en posant la question de la transformation sociale elles ont été d'une certaine utilité, car elles ont montré les défauts de l'ordre existant et ont inspiré aux masses l'espoir dans un avenir meilleur, dans le socialisme. Mais aucune de ces écoles socialistes ne peut prétendre avoir donné une recette qui sauverait l'humanité de tous les maux sociaux. Il appelle les raisonnements des utopistes sur l'avenir de la société, «une scolastique révolutionnaire ». Les discussions de ces doctrines n'aboutiraient qu'à un lamentable avortement si le peuple se laissait entraîner par les utopistes, s'il «négligeait le seul élément pratique de succès : la force ».

La société future ne saurait être la création de l'esprit de tel ou tel penseur.

Le communisme [de l'avenir] n'est pas une utopie. Il est le développement normal de tout un processus historique et n'a aucune parenté avec les trois ou quatre systèmes sortis tout équipés de cervelles fantaisistes... Le communisme est une résultante générale, et non point un œuf pondu et couvé dans un coin de l'espèce humaine par un oiseau à deux pieds, sans plumes ni ailes ${ }^{2}$.

Les rêveries utopiques sur l'édification d'une société nouvelle, sans renverser l'ancien régime, paraissent à Blanqui absolument irréalisables. Dès que les gouvernements remarquent le danger, ils brisent sans difficulté toutes les tentatives faites pour la réalisation de ces plans utopiques. Blanqui considère aussi que tous les essais pour améliorer la condition des travailleurs par la « coopération » n'ont aucune valeur sérieuse.

1 Discours au banquet des «Travailleurs socialistes » (3 décembre 1848). Cf. La Révolution de 1848, n LXI, sept. 1925, p. 546.

2 Critique sociale, t. I, p. 199. 
Le mouvement coopératif, c'est, dit-il, un «piège pour les prolétaires », un moyen de les attirer insensiblement dans le camp de l'ennemi ${ }^{1}$.

Les organisations coopératives, accessibles seulement à la couche supérieure du prolétariat, introduisent une stratification dans la classe ouvrière. Elles détournent des masses les hommes qui seraient les plus aptes à devenir leurs chefs; elles font de ceux-ci une caste semi-bourgeoise conservatrice. Au mouvement coopératif, Blanqui oppose le mouvement gréviste, instrument naturel et par surcroît instrument de masse dans la lutte du Travail contre le Capital ${ }^{2}$.

La grève, malgré les inconvénients, est le moyen naturel à la portée de tous, auquel tous participent... La seule arme vraiment populaire dans la lutte contre le Capital.

Mais elle n'est qu'un moyen temporaire de défense contre l'oppression.

Appuyés provisoirement sur la grève comme moyen défensif contre l'oppression du Capital, les masses populaires doivent concentrer tous leurs efforts vers les changements politiques, reconnus seuls capables d'opérer une transformation sociale ${ }^{3}$...

L'État, dit Blanqui, est le gendarme des riches contre les pauvres. Il faut donc fabriquer un autre État qui soit la gendarmerie des pauvres contre les riches. Ne vous y trompez pas : le socialisme, c'est la Révolution ${ }^{4}$...

La révolution que prévoit Blanqui, et vers laquelle il s'oriente, aura pour tâche immédiate le renversement du pouvoir du Capital et, pour but final, l'instauration du régime communiste, l'élimination complète de toute exploitation. Mais les conceptions de Blanqui sur les forces motrices de la révolution et sur les voies d'édification du communisme demeurent entièrement utopiques. Son imprécise compréhension de la structure de classe de la société ne peut pas ne pas se refléter négativement sur cette partie de ses opinions. En considérant le prolétariat comme dissous dans la masse générale du peuple, dans l'ensemble des " pauvres », il n'a pu déterminer correctement la place historique de la lutte de classe du prolétariat dans le processus qui prépare la révolution sociale, et dans le mouvement même de la révolution.

Ibidem, t. II, p. 129-130.

L'article déjà cité page 26 et publié dans la revue Questions d'histoire apporte sur ce point la précision suivante : «Volguine souligne avec juste raison que Blanqui ne niait pas l'importance de la lutte gréviste comme arme des ouvriers contre le capital. Mais il n'attire pas l'attention sur le fait que Blanqui et les blanquistes ont toujours considéré les grèves comme une affaire secondaire et n'ont pas du tout lutté pour les besoins quotidiens de la classe ouvrière. » (N. T.) Critique sociale, t. II, p. 166-167.

Lettre à Maillard, 1852. 
Le blanquisme, a écrit Lénine, attend la libération de l'humanité de l'esclavage salarié non pas par la lutte de classe du prolétariat, mais par la conjuration d'une petite minorité d'intellectuels ${ }^{1}$.

Nous savons déjà que Blanqui se représentait la révolution comme une insurrection armée, réalisée par des conspirateurs bien organisés. Organisation, ordre, discipline, voilà le principal, voilà ce qui est nécessaire, d'après lui, pour le succès de l'insurrection. Il accordait une grande attention à la préparation technique de l'insurrection, et il a rédigé à ce sujet une instruction particulièrement minutieuse. Il supposait que la révolution à venir serait une insurrection déclenchée dans l'intérêt du prolétariat, et qu'elle parachèverait la lutte séculaire des pauvres et des riches, du « Travail et du Capital ». Il comptait sur les ouvriers parisiens pour entreprendre l'insurrection. Pendant la révolution de 1848, l'organisation qu'il dirigeait défendit énergiquement la cause du prolétariat et, en ce sens, elle fut « un parti prolétaire ».

Mais l'activité révolutionnaire de Blanqui, qui atteignit son apogée en 1848, n'était pas éclairée par une théorie révolutionnaire. Il n'a pas su apprécier l'importance de ce facteur révolutionnaire : la conscience de classe grandissante du prolétariat, la croissance de sa capacité d'organisation. Il n'a pas su comprendre que, pour réaliser la révolution sociale, il faut « un parti ouvrier s'appuyant sur le mouvement ouvrier, un parti de classe ${ }^{2}{ }^{2}$.

C'est pourquoi il se représentait mal la liaison entre le groupe discipliné des révolutionnaires et les masses. Il ne comprenait pas la nécessité d'un lien direct et vivant entre l'organisation révolutionnaire et la lutte concrète de classe menée par le prolétariat. Il n'accordait pas une attention à la lutte pour les besoins matériels des masses.

Blanqui prend une attitude critique à l'égard de l'idée traditionnelle et fortement enracinée : après la victoire de la révolution, élection d'une assemblée constituante. Il accable de sarcasmes le parlementarisme bourgeois ; il démasque la cupidité, la vénalité, l'indifférence pour les intérêts du peuple qui caractérisent les soi-disant « représentants du peuple », dans les parlements bourgeois. Il n'accorde pas non plus une grande importance au suffrage universel comme sauvegarde des intérêts du peuple. En effet, le degré de conscience du peuple étant insuffisant, le peuple lui-même souffrant d'un manque d'organisation, la présence et la puissance des moyens d'action spirituels et matériels placés entre les mains de la classe dirigeante font que les résultats du suffrage universel ne sauraient être que très douteux. Pendant des dizaines d'années, le peuple n'a entendu qu'un son de cloche ; pour juger sainement, il faut qu'il ait le temps d'entendre l'autre.

LÉNINE : Euvres, t. X, p. 360, Édition russe.

Idem, t. XVII, p. 129. 
C'est un tribunal aveugle qui a écouté soixante-dix ans une seule des deux parties. Il se doit à lui-même d'écouter soixante-dix ans la partie adverse ${ }^{1}$.

Pour assurer le triomphe de la révolution, pour accomplir les transformations indispensables, ce ne sont ni des élections, ni une assemblée constituante qui paraissent nécessaires; mais c'est, pense Blanqui, une dictature révolutionnaire. Comme nous l'avons dit, la dictature, dans son idée, n'est pas une dictature de classe. Pour la définir, il parle de « dictature parisienne ».

Le gouvernement de Paris, affirme-t-il, est le gouvernement du pays par le pays... c'est une véritable représentation nationale ${ }^{2}$.

Paris est le cerveau de la France ; le caractère révolutionnaire de la capitale indique sa capacité de diriger la France. Cependant, il est évident que Blanqui, lorsqu'il parle de "dictature parisienne », a en vue la dictature de l'organisation révolutionnaire appuyée sur une partie déterminée de la population parisienne. La première tâche du gouvernement révolutionnaire, et dont l'accomplissement s'impose pour assurer les résultats de la révolution, pour garantir les intérêts du peuple, c'est

le désarmement des gardes bourgeoises, et l'armement et l'organisation des milices nationales de tous les ouvriers (Blanqui dit parfois : les ouvriers et les populations républicaines)...

Ainsi la garde nationale bourgeoise doit être licenciée et, à sa place, doit être créée une milice nationale formée d'ouvriers. En premier lieu, Blanqui pense aux ouvriers parisiens, comme à la partie la plus éduquée des travailleurs. Mais, plus tard, il rêvera de la "parisiennisation » de toute la France, qui assurera définitivement le triomphe de la révolution.

L'armement, l'organisation, déclare-t-il, voilà les instruments décisifs de progrès, le moyen sérieux d'en finir avec l'oppression et la misère. Qui a du fer a du pain. La France hérissée de travailleurs en armes, c'est l'avènement du socialisme. Devant les prolétaires appuyés sur leurs fusils, obstacles, résistance, impossibilité, tout s'évanouit ${ }^{3}$.

Le pouvoir révolutionnaire doit porter des coups décisifs au système actuel du gouvernement et de la justice, au système qui sert à renforcer et à défendre le pouvoir des riches sur les pauvres. L'armée existante doit être dissoute et, à sa place, on procédera à la "formation d'une armée nationale sédentaire ». Le pouvoir judiciaire actuel doit être supprimé ; les magistrats seront révoqués. Les fonctions judiciaires seront assumées par des « arbitres au civil, par des jurés au criminel ». Des mesures doivent être également prises contre l'Église, qui sanctifie

Critique sociale, t. I p. 206.

Ibidem, t. I, p. 206-208.

Avis au peuple (novembre 1850), La Révolution de 1848, loc. cit. 
l'ordre existant par le dogme et l'autorité spirituelle. Toute « l'armée noire » (mâle et femelle) sera " expulsée ». Seront également chassés les aristocrates ; « les vrais ennemis de la République » doivent être déférés aux tribunaux. Enfin, d'une manière générale, aucune liberté ne sera laissée aux ennemis de la République ${ }^{1}$.

Cet exposé sur les moyens de réaliser les principes communistes est la partie la plus utopique des conceptions de Blanqui sur la révolution sociale. Il n'envisage pas que le communisme puisse s'établir rapidement. «La disposition présente des esprits » ne l'engage pas à l'optimisme mais à la prudence.

Il importe au salut de la révolution qu'elle sache unir la prudence à l'énergie. L'attaque contre le principe de la propriété serait aussi inutile que dangereuse ${ }^{2}$.

Nous savons que le principal soutien du système social injuste réside, selon la conception idéaliste de Blanqui, dans l'ignorance. Au-contraire, le communisme est incompatible avec l'ignorance.

Ignorance et communauté sont incompatibles. Généralité de l'instruction sans communisme, et communisme sans généralité de l'instruction, constituent deux impossibilités égales... Entre ces deux choses, instruction et communisme, le lien est si étroit que l'une ne saurait faire sans l'autre, ni un pas en avant, ni un pas en arrière. Elles ont constamment marché de conserve et de front dans l'humanité et ne se distanceront jamais d'une ligne jusqu'à la fin de leur commun voyage ${ }^{3}$.

Ainsi le communisme ne peut entrer dans la vie sans sa compagne indispensable, la culture la plus largement répandue.

Il y a de nombreux obstacles sur la route qui mène au communisme.

L'armée, la magistrature, le christianisme, l'organisation politique, simples haies. L'ignorance, bastion formidable. Un jour pour la haie ; pour le bastion, vingt ans ${ }^{4}$.

... La communauté ne peut être établie que sur l'emplacement du bastion détruit; [pour cette raison], il n'y faut pas compter pour le lendemain. La communauté s'avancera pas à pas, parallèlement à l'instruction, sa compagne et son guide. Elle sera complète le jour où, grâce à l'universalité des lumières, pas un seul homme ne pourra être la dupe d'un autre. Le communisme naîtra fatalement de l'instruction généralisée et ne peut naître que de là ${ }^{5}$.

1 Critique sociale, t. I, p. 205-206, 211. Blanqui a maintes fois insisté sur ce point particulier : la liberté bourgeoise est un mensonge.

Ibidem, t. I, p. 208, 211.

Critique sociale, t. I, p. 177-178.

Ibidem, t. I, p. 183.

Ibidem, t. I, p. 183, 185, 187-188. 
Blanqui esquisse un programme de mesures économiques à prendre immédiatement par le gouvernement révolutionnaire, au lendemain de la victoire. L'État confisquera les biens de l'Église et des aristocrates chassés.

Réunion au domaine de l'État de tous les biens meubles et immeubles des églises, communautés et congrégations des deux sexes, ainsi que de leurs prêtenoms.

L'État établira son contrôle sur les grandes entreprises commerciales et industrielles. Des accords seront passés avec les chefs des entreprises industrielles et commerciales, accords qui obligeront ceux-ci à maintenir provisoirement le statu quo: en conservant leur personnel et sans changer les salaires. Les chefs d'industrie qui repousseraient ces accords seraient « expulsés » du territoire et on substituerait une « régie à tout patron expulsé pour cause de refus ».

Il s'agit évidemment là, en premier lieu, d'une mesure de défense contre les réactions possibles de la bourgeoisie (« le coup de Jarnac du Capital » dans le domaine économique). Toutefois cette mesure peut contribuer à faire passer ultérieurement les grandes entreprises privées dans le domaine de l'État.

Pour toutes les autres questions économiques, y compris les questions des associations ouvrières et du crédit, Blanqui se borne à indiquer la nécessité de « convoquer des assemblées compétentes qui en discuteront ${ }^{1}$ ». Mais, pour que les principes de l'association puissent véritablement entrer dans la vie, il est indispensable que les bienfaits de l'association soient compréhensibles aux larges masses. Par leur politique, les gouvernements, jusqu'à notre époque, ont fait obstacle à cela ; car ils cherchent à maintenir le peuple dans l'ignorance.

Néanmoins, les bienfaits manifestes de l'association ne tarderont pas à éclater aux yeux de tout le prolétariat de l'industrie, dès que le pouvoir travaillera à la diffusion des lumières ; et le ralliement peut s'accomplir avec une extrême rapidité ${ }^{2}$.

Notons que Blanqui fait ici des ouvriers de l'industrie une catégorie spéciale, plus réceptive aux idées d'association. Il considère qu'il sera plus difficile d'attirer à l'association la paysannerie qui est beaucoup plus ignorante et qui est fortement attachée à son lopin de terre. Il recommande de considérer avec circonspection, avec une grande prudence, les intérêts et les dispositions de la paysannerie, que les mots de "partage » et de "communauté » effrayent encore. Il comprend l'importance de la paysannerie pour le succès de la cause de la révolution. Il faut expliquer aux paysans que la révolution ne portera pas atteinte à la propriété petite et moyenne, que les arrêts du pouvoir révolutionnaire

Critique sociale, t. I, p. 204.

Ibidem, t. I, p. 209. 
respecteront les petits et moyens propriétaires, et il faut déclarer nettement que nul ne pourra être forcé de s'adjoindre avec son champ à une association quelconque, et que, s'il y entre, ce sera toujours de sa pleine et libre volonté ${ }^{1}$.

Dans l'ensemble, les conceptions de Blanqui sur la période transitoire conduisant du régime actuel au communisme ou à «l'association intégrale » restent très naïves et très vagues. On découvre chez lui des positions qui témoignent de sa capacité d'apprécier sainement les rapports réels de forces, pendant la période de lutte directe pour l'édification du communisme (sabotage possible des chefs d'entreprise, dispositions d'esprit de la paysannerie). Mais ces positions se noient dans des considérations sur l'instruction, considérée comme la condition préalable essentielle à la transformation sociale, tenue pour la force qui conduit automatiquement au triomphe du communisme. Engels a très justement indiqué que, chez Blanqui, il n'y avait pas au fond «de propositions pratiques déterminées de réorganisation sociale ${ }^{2}$ ».

Il considère que toutes les tentatives pour représenter l'avenir du régime communiste sont incertaines et inutiles. Il se moque des adversaires du communisme qui exigent aussitôt qu'on leur dise qui, en régime communiste, « videra le pot de chambre »?

Il expose ainsi ses vues :

Occupons-nous d'aujourd'hui. Demain ne nous appartient pas, ne nous regarde pas. Notre seul devoir est de lui préparer de bons matériaux pour son travail d'organisation. Le reste n'est plus de notre compétence ${ }^{3}$.

Il essaie de fonder en théorie son refus de discuter les problèmes de la société future. Il affirme que l'ordre existant est comme une barrière qui nous cache l'avenir, que son influence couvre l'avenir d'une brume impénétrable. Tant que le moment de la mort et de la renaissance de la société n'est pas venu, les vues que l'on peut avoir sur l'avenir ne sont que des obscurités.

À peine des pressentiments, des échappées de vue, un coup d'œil fugitif et vague sont-ils possibles au plus clairvoyant. La Révolution seule, en déblayant le terrain, éclaircira l'horizon, lèvera peu à peu les voiles, ouvrira les routes ou plutôt les sentiers multiples qui conduisent vers l'ordre nouveau ${ }^{4}$.

Seule la mort du vieux monde libérera les éléments dont la combinaison devra organiser l'ordre nouveau. Aucun effort de pensée ne pourrait anticiper sur cette

Critique sociale, t. I, p. 209-211.

MARX-ENGELS : Euvres, t. XV, p. 225. Édition russe.

Critique sociale, t. I, p. 196.

Critique sociale, t. II, p. 115-116. 
libération qui ne peut se réaliser qu'à un moment déterminé. Pour cette raison, selon Blanqui, la question sociale ne pourra faire l'objet d'un examen sérieux, qu'à partir du moment où la question politique aura été pleinement résolue.

Blanqui garde une attitude ironique à l'égard des discussions entre les diverses écoles socialistes sur l'avenir de la société. Elles

se disputent avec acharnement au bord d'un fleuve pour décider si l'autre rive est un champ de mais ou un champ de blé. Elles s'entêtent à résoudre la question avant de franchir l'obstacle. Eh ! passons d'abord ! Nous verrons là-bas ! ${ }^{1}$

Blanqui est l'un des représentants les plus intéressants du communisme utopique prémarxiste français et du mouvement révolutionnaire français. Toute sa vie a été consacrée à la lutte révolutionnaire au nom du communisme. Il a passé de nombreuses années de sa vie en prison, sous la monarchie de Juillet, sous le second Empire, sous la troisième République. Mais il n'a pas su donner un fondement matérialiste et scientifique à l'inéluctabilité du communisme. Il n'a pas su se libérer des vieilles idées de conjuration en ce qui concerne le processus de la révolution. Il n'a su ni comprendre ni apprécier l'importance historique de la lutte de classe menée par le prolétariat. Dans ses conceptions sur le développement de la société, il ne s'est pas dégagé des traditions idéalistes qu'il avait reçues de l'époque des «lumières ", du XVIII ${ }^{\mathrm{e}}$ siècle. Dans ses opinions sur la nature de l'exploitation capitaliste, il se rattache à la conception petite-bourgeoise qui fait dériver le profit capitaliste de l'échange non-équivalent.

Staline a écrit :

L'histoire connaît des chefs prolétariens, chefs des temps d'orage, chefs du travail pratique, pleins d'abnégation et d'audace, mais faibles en théorie ${ }^{2}$.

Au nombre de ces chefs pleins d'abnégation, mais faibles en théorie, Staline compte Blanqui. Ne possédant pas la théorie scientifique du socialisme, Blanqui, au cours de sa longue vie politique, a commis certaines erreurs théoriques et pratiques. Ses défauts et ses erreurs ont été conditionnés, en premier lieu, par les rapports sociaux de l'époque où se sont formées ses opinions: le niveau relativement bas de l'industrie, le degré relativement faible de la conscience de classe du prolétariat français au cours de la monarchie de Juillet. Il convient évidemment de ne pas l'oublier. Mais, d'autre part, on ne doit pas oublier que la fidélité de Blanqui à la cause du communisme et son ardent tempérament

Ibidem, p. 314.

J. STALINE «Lénine organisateur et chef du Parti communiste de Russie, 23 avril 1920 », Euvres, t. IV, p. 278. Éditions Sociales, 1955, Lénine : Éditions sociales, 1946, p. 14. 
révolutionnaire lui ont permis, sous beaucoup de rapports, de s'élever bien plus haut que ne l'ont fait les autres théoriciens et hommes d'action de son époque. C'est précisément autour de son drapeau que se réunissaient les éléments d'avant-garde de la classe ouvrière française, au nom de la lutte pour le communisme. Marx, en 1848, a appelé son parti «le parti du prolétariat révolutionnaire ». Et, de nombreuses années après, Engels l'a considéré comme «le seul homme capable d'être à la tête du mouvement révolutionnaire en France ${ }^{1}$ ».

\footnotetext{
MARX-ENGELS : E Euvres, t. VIII, p. 329, 495 ; Ibidem, t. XXIV, p. 384, Édition russe.
} 


\section{NOTE BIOGRAPHIQUE}

Le devoir d'un révolutionnaire, c'est la lutte toujours, la lutte quand même, la lutte jusqu'à extinction.

A. BLANQUI.

$\underline{\text { Retour à la table des matières }}$

Louis-Auguste Blanqui naquit le $1^{\mathrm{er}}$ février 1805 dans la petite ville de PugetThéniers (Alpes-Maritimes), à une cinquantaine de kilomètres de Nice. Son père, Dominique Blanqui, avait été membre de la Convention et Girondin. Il approuva le coup d'État de Bonaparte et en 1800 fut nommé sous-préfet à Puget-Théniers. La mère de Louis-Auguste, Sophie Brionville, originaire de Picardie, se distinguait par sa grande beauté et par ses hautes qualités morales. Blanqui tint d'elle son caractère résolu et intransigeant. Jusqu'à sa mort, la mère de Blanqui témoigna d'un grand amour pour son fils. À soixante ans, elle contribua activement à préparer l'évasion de Blanqui et de ses camarades de la prison du mont Saint-Michel ; à soixante-quinze ans encore, elle l'aidait une nouvelle fois à organiser sa fuite et celle de son ami Cazavan du pénitencier de Belle-Île. Le frère aîné d'Auguste, l'économiste bien connu, Adolphe Blanqui, fut très lié avec lui pendant sa jeunesse ; il partageait alors ses idées politiques. Mais il ne tarda pas à se détacher de lui.

Blanqui resta au contraire en excellents termes avec ses sœurs, Mmes Antoine et Barrellier, qui jouèrent un rôle important dans sa vie. Toutes les deux voyaient avec sympathie son activité révolutionnaire, se montraient pleines d'attention pour lui au long de ses tribulations, prenaient soin de lui quand il était en prison, l'aidaient moralement et matériellement, le cachaient, lorsqu'il vivait à Paris.

À l'âge de treize ans, Blanqui partit pour Paris où il devait rejoindre son frère aîné Adolphe qui était à cette époque professeur à l'institution Massin ${ }^{1}$. Pendant six ans - de 1818 à 1824 - le jeune Blanqui fit ses études, d'abord à l'institution Massin, puis au lycée Charlemagne. Il s'adonnait au travail avec passion et avec

L'institution Massin envoyait ses plus grands élèves suivre les cours du lycée Charlemagne, conformément au statut de l'enseignement secondaire établi par Napoléon ${ }^{\text {er }}$. 
une assiduité extraordinaire et surprenait son entourage par ses aptitudes. Son frère Adolphe écrit dans une lettre à son père : « Cet enfant étonnera le monde ! ».

Blanqui termina brillamment ses études au lycée à dix-neuf ans. Il devint alors répétiteur, d'abord dans la famille du général Compans, puis au bout de deux ans à l'institution Massin. En 1824, il entra dans la société secrète des Carbonari. En 1827, il prit part à toutes les manifestations d'étudiants et fut blessé trois fois, deux fois par des coups de sabre, puis le 19 novembre par une balle sur la barricade de la rue aux Ours.

Il passa l'année 1828 et une partie de l'année 1829 à voyager dans le Midi. Il visita l'Italie, l'Espagne, et en août 1829, regagna Paris. Il y travailla quelques mois comme sténographe au journal Le Globe. Au cours de cette période, il se familiarisa avec les doctrines de Saint-Simon et de Fourier.

En juillet 1830, quand s'élevèrent les premières protestations contre les ordonnances de Charles X, Blanqui quitta la rédaction du Globe et se hâta, selon ses propres termes, de "prendre le fusil et d'arborer la cocarde tricolore ». Au cours des journées révolutionnaires, il se rangea aux côtés du peuple parisien contre les troupes de Charles X. Enivré par la lutte, il était persuadé que le peuple serait victorieux et que c'en était fini à tout jamais de la monarchie et du joug qu'elle faisait peser. Il fut déçu par l'issue de la révolution : la monarchie ressuscita sous une nouvelle forme Charles $\mathrm{X}$ fut remplacé sur le trône par le «roibourgeois » Louis-Philippe.

Aussitôt après la Révolution, Blanqui donna son adhésion à la Société des Amis du peuple, dirigée par Godefroy Cavaignac. Cette société propageait activement les idées républicaines. Blanqui prit souvent la parole à ses réunions. Par hasard, Henri Heine entendit son discours du 2 février 1832 qu'il qualifie de " discours plein de sève, de droiture et de colère » à l'égard de la bourgeoisie. Ce discours fut prononcé en présence de mille cinq cents personnes, dans une atmosphère qui rappelait celle de 1793.

Au début de 1831, Blanqui, qui prenait une part active aux manifestations d'étudiants, fut arrêté par la police et enfermé à la Force, d'où il sortit au bout de trois semaines. La Force fut la première des nombreuses prisons dans lesquelles Blanqui passa la moitié de sa vie.

En 1832, Casimir Périer, ministre de l'Intérieur du gouvernement de LouisPhilippe, qui voulait dissoudre la Société des Amis du peuple et arrêter ses dirigeants, obtint la mise en jugement de la société sous l'inculpation de violation des lois sur la presse et de complot contre la sûreté de l'État. En janvier 1832, Blanqui, Raspail, Thouret, Huber et d'autres furent arrêtés. Ce fut le fameux Procès des Quinze qui eut lieu du 10 au 12 janvier devant la Cour d'assises de la Seine. La cour d'assises acquitta les accusés, mais la défense que prononça Blanqui lui valut 
d'être inculpé par le procureur d'atteinte à la tranquillité publique. Blanqui fut condamné à un an de prison et 200 francs d'amende. Il subit sa peine d'abord à la prison de Versailles, puis à celle de Sainte-Pélagie à Paris.

Cependant les épreuves subies ne firent que fortifier Blanqui. À sa sortie de prison, il se mit avec une énergie accrue à répandre les idées révolutionnaires. Parallèlement, il élargissait et approfondissait ses connaissances en matière sociale et politique. Au cours de cette période, Blanqui subit l'influence de Buonarroti, l'ami de Babeuf, qui transmettait et diffusait la tradition glorieuse des «Égaux ». Blanqui fut également influencé dans une certaine mesure par Raspail, savant et révolutionnaire. Les premières années de la monarchie de Juillet étaient pleines de mouvements importants. Les troubles parisiens en septembre 1831, le soulèvement des ouvriers lyonnais en novembre 1831, l'insurrection républicaine de Paris en juin 1832, la deuxième insurrection des ouvriers lyonnais en avril 1834 et ses répercussions sur les autres villes françaises (les journées du 13 et du 14 avril à Paris et leur fin tragique, les massacres de la rue Transnonain), cette suite d'événements historiques ne put que renforcer Blanqui dans ses convictions révolutionnaires.

En 1832, Blanqui s'était marié avec Suzanne-Amélie Serre. Mais une vie familiale heureuse ne le détourna pas de l'activité sociale. En 1835 fut fondée avec son concours la clandestine Société des Familles, dont le programme définissait non seulement des objectifs politiques, mais aussi des objectifs sociaux.

Les membres de la Société se préparaient à l'insurrection et faisaient fabriquer de la poudre au no 113 de la rue de Lourcine. En mars 1836, à la suite d'une dénonciation, la police découvrit l'existence de la Société des Familles et arrêta 24 de ses membres, dont Blanqui. Pour sa part de conspiration dans ce qu'on appelle l'affaire des poudres, il fut condamné à deux ans de réclusion et à 2000 francs d'amende. Il fut conduit à la prison de Fontevrault (Maine-et-Loire).

Le 8 mai 1837, une amnistie fut décrétée à l'occasion du mariage du duc d'Orléans. Blanqui fut libéré, mais sa réclusion fit place à la résidence surveillée dans la région de Pontoise. Avec sa famille, il s'établit dans le village de Jancy, sur les rives pittoresques de l'Oise. La période de Jancy fut la plus calme de la vie personnelle de Blanqui. Cependant il réfléchissait sans cesse aux événements contemporains et aux moyens d'instaurer le pouvoir populaire. Il était persuadé que le facteur essentiel du succès était l'organisation d'un noyau de conspirateurs solidement unis et disciplinés. Pour remplacer la Société des Familles, il fonda en 1837 une nouvelle organisation, la Société des Saisons, dont les dirigeants étaient Blanqui, Barbès et Martin-Bernard.

En 1839, Blanqui jugea la conjoncture favorable à l'insurrection. La crise économique parvenait à sa phase aiguë ; elle provoquait la misère croissante des classes populaires et le chômage. Elle se doublait d'une crise politique: la 
Chambre des députés était dissoute ; le président du Conseil des ministres, Molé, avait donné sa démission. Louis-Philippe ne réussissait pas à former un nouveau cabinet. Le peuple de Paris s'agitait.

Au début de l'année, Blanqui regagna Paris. Les conspirateurs estimaient que l'heure de l'insurrection armée, de la chute de la monarchie et de la constitution d'un gouvernement révolutionnaire était arrivée. Les armes manquaient, mais on pensait se les procurer dans les arsenaux pendant l'insurrection. Le jour fixé, le 12 mai, les courses hippiques devaient retenir l'attention de la police urbaine et d'une partie de la bourgeoisie, et l'Hôtel de Ville serait mal défendu. À l'heure dite, plus de 500 révolutionnaires en armes, concentrés dans les rues Saint-Denis et SaintMartin, à un signal de Blanqui, marchèrent sur l'Hôtel de Ville et l'occupèrent. Mais ils furent cernés par les troupes royales. Une lutte inégale, livrée pendant plus de deux jours, se solda par l'écrasement de l'insurrection. Barbès, blessé, fut pris ; Blanqui réussit à s'échapper. Mais le 14 octobre, comme il s'apprêtait à prendre la diligence qui devait le mener en Suisse, il fut arrêté. Au procès qui se déroula au mois de janvier 1840, Blanqui se refusa à toute déclaration. Il fut condamné à la peine de mort, commuée, comme celle de Barbès, en réclusion à vie. Il fut envoyé au mont Saint-Michel, une des plus sombres prisons de France, immense construction de pierre qui fait corps avec le roc sur lequel elle s'élève, Cet ancien monastère servait alors de prison depuis la fin du $\mathrm{XVII}^{\mathrm{e}}$ siècle.

Sept mois plus tôt, Barbès, Martin-Bernard, Delsade et autres avaient été conduits au mont Saint-Michel. Le régime pénitentiaire du mont Saint-Michel était affreux : chaînes, coups, supplices, railleries des gardiens, saleté, vermine ; toutes ces causes de souffrance accumulées conduisaient les uns au suicide, d'autres à la folie. Blanqui ne tarda pas à songer à l'évasion.

Dès avant son départ pour le mont Saint-Michel, il était entendu que sa femme viendrait s'établir non loin de la prison, mais une longue maladie avait empêché celle-ci de réaliser ce projet. Pendant toute une année, Blanqui attendit sa guérison. Mais, le 31 janvier 1841, Suzanne-Amélie mourait à l'âge de vingt-six ans. Blanqui supporta très mal le choc. Selon ses propres aveux, l'image de sa femme le hanta pendant des années. Le fils de Blanqui reçut une éducation religieuse dans sa famille maternelle, qui le dressait contre son père.

Après une longue préparation à laquelle prit part la mère de Blanqui, celui-ci et Barbès, Martin-Bernard et Huber tentèrent de s'évader. Cette tentative échoua et le régime de la prison se durcit encore.

Les détestables conditions de la vie de prison menacèrent la santé de Blanqui qui n'était pas solide. En 1844, au bout de quatre années de réclusion au mont Saint-Michel, Blanqui fut transporté à la prison de Tours, puis placé sous surveillance à l'hôpital, tandis que ses complices de l'insurrection étaient transférés dans d'autres prisons. Quand une maladie incurable fut diagnostiquée, Louis- 
Philippe le gracia par arrêt du 6 décembre 1844. Mais Blanqui refusa catégoriquement d'accepter sa grâce des mains du roi. Il le déclara ouvertement le 26 décembre, dans une lettre violente adressée au maire de Tours. Il resta à l'hôpital et dut garder le lit pendant vingt mois. Il ne put se lever et reprendre peu à peu son activité qu'en octobre 1845. À l'hôpital de Tours, il recevait des visites d'ouvriers et d'hommes politiques. Il reprit des contacts avec les milieux révolutionnaires. Lorsque, en 1846, éclatèrent à Tours des troubles provoqués par la crise économique, on accusa la société communiste locale de les avoir fomentés à l'instigation de Blanqui. Il, fut reconduit en prison. Au procès, qui eut lieu du 26 au 29 avril à Blois, Blanqui fut acquitté, faute de preuves, et regagna l'hôpital de Tours.

La révolution de février 1848 le libéra.

Le 25 février il arrivait à Paris. Des membres des sociétés secrètes, des partisans, anciens et nouveaux, les jeunes révolutionnaires, pour qui le nom de Blanqui était le symbole de la lutte révolutionnaire, se pressèrent en nombre autour de lui.

Le jour même, Blanqui apprenait que le gouvernement provisoire avait refusé de planter le drapeau rouge à l'Hôtel de Ville, malgré les réclamations des masses populaires. À cette nouvelle, les membres des sociétés secrètes, indignés, se réunirent à la salle Prado pour décider des moyens de faire pression sur le gouvernement. Ils étaient là, quelques milliers d'hommes armés, prêts à marcher sur le gouvernement provisoire. Mais Blanqui, par un discours plein de rigueur et de sang-froid, persuada les assistants de n'en rien faire. Il préférait attendre les actes ultérieurs du gouvernement provisoire et éviter le risque d'une contrerévolution.

Le même soir fut fondé un club qui prit le nom de Société républicaine centrale. La Société avait pour dirigeants Blanqui et Dézamy. C'est en son sein que, dès lors, Blanqui exerça son activité. Chaque jour il prenait la parole dans la salle du Conservatoire, rue Bergère, où elle se réunissait. Il expliquait aux membres de la société l'évolution de la situation politique, montrait les nouvelles perspectives, appelait à l'action.

Pendant les premiers jours de la révolution, l'activité de Blanqui ne se relâcha pas. Partout, dans les faubourgs ouvriers et au sein du club, il recrutait des partisans, il rassemblait des hommes fidèles à la révolution. Il ne tarda pas à être déçu par la politique du gouvernement provisoire : dès le 2 mars, il réclamait de lui des actes décisifs.

Blanqui voyait que le peuple n'était pas suffisamment préparé politiquement pour élire une Assemblée constituante et que, si les élections avaient lieu, le pouvoir passerait inévitablement aux mains des réactionnaires. Les 7 et 14 mars, il 
prenait la parole à la Société républicaine centrale pour demander l'ajournement des élections fixées au 9 avril; le 17 mars, il organisait une manifestation pacifique, mais impressionnante, dans le même sens.

La lutte des classes en France s'aggravait de jour en jour. Blanqui était l'un des ennemis les plus dangereux de la bourgeoisie, qui s'en rendait parfaitement compte. La contre-révolution ne recula devant rien pour détacher les masses ouvrières de lui. Elle déclencha une campagne, dont la manifestation la plus odieuse fut le document Taschereau, pamphlet diffamatoire fabriqué par la police. Voici en bref ce dont il s'agissait. Taschereau, journaliste dénué de principes, qui avait servi les régimes les plus divers avec un dévouement égal, publia, sous l'inspiration du gouvernement, dans le numéro du 31 mars 1848 de La Revue rétrospective, un document intitulé « Déclarations faites par xxx devant le ministre de l'Intérieur sur l'affaire du 12 mai 1839 ». D'après ce document, ces dépositions avaient été faites les 22, 23 et 24 octobre 1839 au moment où Blanqui avait été arrêté à la suite de l'affaire du 12 mai. Le contenu et l'aspect de ces dépositions laissaient supposer que Blanqui avait trahi le secret de la Société des Familles et de la Société des Saisons, et qu'il en avait livré les principaux chefs. Enfin, il était fait mention des événements qui avaient précédé la manifestation du 12 mai. Le document n'était pas signé et portait toutes les marques du faux fabriqué d'après les dépositions de policiers qui avaient pénétré dans les sociétés secrètes. La publication de ce document avait pour but manifeste de ruiner, à coups de calomnies, l'autorité et l'influence de Blanqui. Le 14 avril, Blanqui fit paraître la «Réponse du citoyen Auguste Blanqui » contresignée par 50 de ses amis. Dans cette réponse, Blanqui flétrissait la turpitude des auteurs du document et démontrait que ces calomnies étaient absurdes.

Et c'est moi, triste débris, qui traîne par les rues un corps meurtri sous des habits râpés, c'est moi qu'on foudroie du nom de vendu ! tandis que les valets de Louis-Philippe, métamorphosés en brillants papillons républicains, voltigent sur les tapis de l'Hôtel de Ville... Réacteurs de l'Hôtel de Ville, vous êtes des lâches !

Plus de 400 anciens prisonniers politiques signèrent une protestation contre l'accusation dont Blanqui était victime. Cette protestation fut publiée dans La Gazette des tribunaux du 14 avril et dans Le National du 15 avril. Parmi ceux qui avaient pris position pour Blanqui, il y avait Dézamy. Mais un de ses anciens camarades de combat, Armand Barbès, s'était rangé aux côtés des calomniateurs.

Le coup fut douloureux, et cependant Blanqui ne suspendit pas un seul jour son activité révolutionnaire.

Le 16 avril, il se rendit au Champ-de-Mars où des ouvriers s'étaient rassemblés pour élire les officiers d'état-major de la Garde nationale. De là, ils se dirigèrent vers l'Hôtel de Ville pour remettre au gouvernement une pétition demandant l'« organisation du travail et l'abolition de l'exploitation de l'homme par l'homme ». 
Mais ils se heurtèrent à la résistance des gardes nationaux, mobilisés sous le prétexte de faire échec à la « conspiration communiste ».

Les résultats des élections à l'Assemblée constituante firent honneur à la perspicacité et à la clairvoyance de Blanqui qui avait réclamé leur ajournement. Dans plusieurs villes, des barricades s'élevèrent le jour des élections. Le choc entre la bourgeoisie et les ouvriers fut particulièrement rude à Rouen, les 27 et 28 avril, où les ouvriers furent véritablement massacrés; ce fut une nouvelle «SaintBarthélemy ». Dans une proclamation consacrée à cet événement, Blanqui dénonçait la responsabilité du gouvernement : "Est-ce trahison ou lâcheté ? " demandait-il. "Le sang du peuple répandu ne doit, ne peut rester sans vengeance. »

L'Assemblée constituante se réunit pour la première fois le 4 mai. Elle légitima la république bourgeoise en France. Il n'y eut pas de place au sein du nouveau gouvernement pour les représentants ouvriers. Les masses populaires parisiennes étaient profondément déçues. Leur mécontentement à l'égard des premières mesures gouvernementales se manifesta par la démonstration du 15 mai. Les ouvriers, voulant faire pression sur le gouvernement provisoire, envahirent la salle où se trouvait l'Assemblée constituante. Ils demandaient que l'on porte secours immédiatement aux Polonais insurgés. Blanqui prit la parole à l'Assemblée ; mais il n'avait pas été l'instigateur de la manifestation ; bien au contraire, pensant qu'elle échouerait, il avait essayé d'en détourner les membres de son club. À l'Assemblée, Blanqui réclame une assistance prompte aux Polonais, une enquête sur les événements de Rouen et le jugement des coupables, du travail pour tous les chômeurs et l'amélioration de la condition des classes populaires.

L'Assemblée constituante déclarée dissoute, les manifestants marchèrent sur l'Hôtel de Ville où un nouveau gouvernement fut constitué, composé de Barbès, Raspail, Albert, Ledru-Rollin, Louis Blanc etc. Blanqui n'en fit pas partie. Mais, très vite, l'Hôtel de Ville fut occupé par l'armée. Elle dispersa le peuple, arrêta Barbès et Albert. Blanqui réussit à se cacher pendant onze jours, mais il fut arrêté le 26 mai et enfermé au château de Vincennes.

Les nouvelles des journées de juin, baignées dans le sang du peuple parisien, parvenaient à Blanqui qui souffrait de son impuissance et de son inaction. Ce ne fut que le 7 mars 1849, neuf mois après l'arrestation de Blanqui, que la Haute Cour délibéra sur l'affaire du 15 mai.

Le procès eut lieu à Bourges. À cette époque, Blanqui avait quarante-quatre ans. Pâle, épuisé, les cheveux tout blancs, il avait l'air d'un vieillard. Mais ni les prisons ni les privations n'avaient ébranlé sa force d'esprit. Comme en 1832, au procès des Quinze, Blanqui fut son propre défenseur. Il disait : 
Debout sur la brèche pour défendre la cause du peuple, les coups que j'ai reçus ne m'ont jamais atteint en face... Le temps a trop prouvé que les traits lancés contre moi, de n'importe quelle main, sont tous allés au travers de mon corps frapper la Révolution. C'est ma justification et mon honneur.

À la dernière séance de la Cour eut lieu une scène pénible : la confrontation de Blanqui et de Barbès qui parla de nouveau du document Taschereau. Dans sa réponse, Blanqui dit :

L'antiquité avait attribué à Hercule tous les faits des temps héroïques : la réaction personnifie en moi tous les crimes et toutes les atrocités ${ }^{1}$.

On accusa Blanqui d'avoir voulu dissoudre de force l'Assemblée constituante. Blanqui répondit malicieusement qu'avec son expérience de conspirateur et d'organisateur d'insurrections il aurait agi tout autrement que les manifestants du 15 mai. Et il développa avec feu le plan possible d'une dissolution de l'Assemblée.

Le 2 avril 1849, Blanqui fut condamné à dix ans de prison. Il fut conduit à la prison de Doullens (Somme).

Blanqui resta dix-neuf mois à Doullens. À son habitude, il y lut et écrivit beaucoup. Le 20 octobre 1850, il fut emmené avec d'autres prisonniers politiques à Belle-Île-en-Mer.

Il y avait alors près de 250 prisonniers politiques à Belle-Île. Le régime pénitentiaire n'était pas très rigoureux. Les prisonniers pouvaient se rencontrer à certaines heures de la journée, converser, prendre leur repas ensemble, etc. Les discussions politiques et philosophiques devenaient facilement passionnées. Presque aussitôt deux partis se formèrent, opposant les partisans de Blanqui à ceux de Barbès. Au début, les blanquistes étaient rares. Barbès, par contre, était entouré de gens qui étaient hostiles à Blanqui et le persécutaient. Il y eut même un moment où Blanqui craignit pour sa vie. Il proposa à Barbès un arbitrage, mais en vain. Peu à peu, Blanqui s'attacha une grande partie des prisonniers, surtout les ouvriers. Plusieurs d'entre eux venaient écouter ses cours d'économie politique.

En février 1851, à l'occasion du troisième anniversaire de la révolution de Février, Blanqui écrivit le célèbre toast, adressé aux émigrés de Londres sous le titre d' " Avis au peuple ». Blanqui dénonçait la trahison de Louis Blanc, de LedruRollin et des autres «socialistes " de 48. Marx, qui à cette époque vivait à Londres, envoya la traduction de ce texte aux communistes allemands. Pour lui, l' « Avis au peuple », faisait le bilan de la lutte de classes qui venait de se livrer.

1 Procès des accusés du 15 mai 1848, Haute Cour Nationale de justice séant à Bourges, Imprimerie des ouvriers associés, Bordeaux 1849. 
À Belle-Île, Blanqui lisait beaucoup, approfondissait ses connaissances en philosophie, en économie politique, en sciences naturelles et particulièrement en géographie, pour laquelle il avait une prédilection. Sa mère et ses sœurs lui faisaient parvenir des livres et des atlas. Blanqui écrivait des articles et des comptes rendus de livres nouveaux, correspondait avec ses amis. Il était au courant de ce qui se passait au-delà des murs de la prison. Au mois de novembre 1851, dans une lettre à Rouget, un ancien prisonnier de Belle-Île, il prédisait un prochain coup d'État en France et celui-ci se produisit, en effet, le 2 décembre 1851. Dès 1853 la guerre de Crimée était, selon lui, inévitable.

Blanqui, qui passa la moitié de sa vie en prison, avait une capacité de résistance extraordinaire. On s'étonne que cet homme, chétif et de santé chancelante, ait pu supporter tant d'épreuves. Grâce à une force d'âme extraordinaire, il savait se détacher des détails de la vie quotidienne et se retrancher dans son propre monde intérieur. Il avait mis au point un mode de vie et une hygiène qu'il observait scrupuleusement. Il faisait de la culture physique, suivait un régime spécial qui excluait le vin, comportait peu de viande et beaucoup de laitages, de légumes et de fruits. À Belle-Île, il passait beaucoup de temps à cultiver un jardin potager qui se trouvait sous sa fenêtre et où il faisait pousser des fraises et des légumes.

À la fin de 1852, Blanqui pensa à s'évader. C'est alors que la mère et le fils de Blanqui, qui avait quinze ans, arrivèrent à Belle-Île. La mère se procura tout ce qui était nécessaire à l'évasion. Mais le ministère en eut connaissance par l'interception d'une lettre qui se trouvait dans un panier de pêcheur à fond double. Blanqui fut mis au cachot et sa garde fut renforcée.

Et cependant en 1853 Blanqui et Cazavant, son voisin de cellule, recommencèrent à préparer leur évasion. Ils avaient l'intention de fuir en Angleterre. Ils imaginèrent un plan audacieux dont l'exécution demandait beaucoup de temps. Blanqui et Cazavant laisseraient dans leur cellule des poupées, habillées de leurs vêtements de prison et assises comme ils avaient coutume de le faire. Mais pour que la fuite ne soit pas découverte immédiatement, pendant un certain temps, Blanqui et Cazavant ne répondirent plus aux questions que leur posaient les gardiens ni à l'appel de leur nom. Et les surveillants cessèrent bientôt d'y prêter attention. Le 5 avril, Blanqui et Cazavant s'évadèrent sous une pluie torrentielle. Parvenus à un puits, ils descendirent avec des cordes jusqu'au niveau de l'eau, ne bougèrent pas jusqu'à la fin de la ronde, après quoi ils sortirent et franchirent la clôture ; ils errèrent toute la nuit à travers l'île et enfin, épuisés, atteignirent la case d'un pêcheur, point désigné à l'avance où ils se dissimulèrent au grenier jusqu'au matin. Mais le pêcheur, qui avait reçu de Blanqui et de Cazavant une forte somme pour les transporter sur le continent, les trahit : il dénonça leur fuite aux autorités de la prison. Blanqui fut jeté au cachot du château Fouquet à Belle-Île, d'où il fut bientôt transféré de nouveau au département des prisonniers politiques, mais sous une surveillance plus sévère. 
En automne 1854, Barbès fut libéré et les rapports entre les partis rivaux à l'intérieur de la prison s'améliorèrent. En 1857, Blanqui, avec 31 camarades, fut transféré en Corse, à Corte, où la population rassemblée les accueillit chaleureusement.

Blanqui resta dans sa prison corse, humide et mal aérée, jusqu'au 2 avril 1859. Ensuite, en raison de la loi dite de sécurité publique de 1858, il fut transféré en Afrique, à Mascara. Le 16 août 1859, après l'amnistie générale, Blanqui reçut le droit de rentrer à Paris. Mais à Toulon, sur le chemin du retour, il fut de nouveau arrêté ; on menaçait de l'exiler à Cayenne. Enfin Mme Antoine, la sœur de Blanqui, réussit à obtenir pour lui la permission de gagner Paris. Il y rencontra son fils, qui avait alors vingt-quatre ans. Au cours de ses séjours en prison, Blanqui n'avait pu voir son fils que cinq ou six fois. C'était un homme borné et superficiel, n'ayant rien de commun avec son père. Il le connaissait si peu et si mal qu'il lui proposa de renoncer à la vie politique et de partager sa vie bourgeoise. À Paris, Blanqui eut une autre déconvenue ; il apprit que ses manuscrits, fruits d'un long travail, avaient été brûlés en exécution des dernières volontés de sa mère, morte en 1858. Cette nouvelle plongea Blanqui dans le désespoir.

Peu après son retour à Paris, Blanqui se rendit à Londres. De nombreux émigrés politiques y vivaient, parmi lesquels ses amis : Lacambre et Barthélemy. À son retour à Paris, Blanqui s'adonna de nouveau à l'activité révolutionnaire. Il se cachait habilement de la police, mais celle-ci était constamment à ses trousses et réussit à la longue à l'arrêter. Au mois de juin 1861, il fut accusé d'avoir pris part à l'organisation d'une société secrète et condamné à quatre ans de prison. Cette condamnation suscita l'indignation des milieux révolutionnaires. Marx et Engels, qui avaient beaucoup d'estime pour Blanqui en qui ils voyaient le représentant du « parti révolutionnaire de la France ", aidèrent son ami Denonville à publier un pamphlet contre l'ignoble procès de Blanqui.

De nouveau, Blanqui fut conduit à la prison de Sainte-Pélagie qu'il avait déjà connue en 1832 après son discours au procès des Quinze et en 1835 après le procès de la Société des Familles. La prison de Sainte-Pélagie avait enfermé entre ses murs de nombreuses personnalités politiques françaises. En 1793 : M-O Rolland et certains Girondins; et par la suite Béranger, Paul-Louis Courier, Marrast, Godefroy Cavaignac, Daumier, Lamennais, Félix Pyat, les révolutionnaires de 1848.

Silencieux et peu sociable, méfiant à l'égard des inconnus, Blanqui était cependant un pôle d'attraction pour les détenus dont certains devinrent ses amis ou ses disciples fidèles. Ses connaissances, sa forte personnalité, son sort d' « enfermé »perpétuel, son dévouement exceptionnel à la cause de la révolution, son attitude évidemment critique à l'égard du parti républicain parlementaire lui conféraient une autorité grandissante. 
Blanqui se lia surtout avec Gustave Tridon et les étudiants en médecine Villeneuve, Clemenceau, etc. Il connut intimement Arthur Ranc qui lui dédia son Complot romantique. Ranc devint pour quelque temps un blanquiste acharné. C'est à la prison de Sainte-Pélagie que prit naissance le parti blanquiste.

En 1864, Blanqui tomba malade. On le transporta à l'hôpital Necker où on le mit dans une salle particulière, sous la surveillance d'un policier. Des amis venaient le voir. C'est là qu'il fit la connaissance de Charles Longuet.

Au début de 1865, Blanqui participa à la publication du journal Candide, dont le rédacteur en chef était Gustave Tridon, élève préféré de Blanqui. Sous le pseudonyme de Suzamel (Suzanne-Amélie, le prénom de sa femme), Blanqui publia dans ce journal quelques articles sur des sujets philosophiques et scientifiques. Mais, après la parution du no 8 , le journal fut suspendu et ses rédacteurs arrêtés.

Blanqui chercha à s'évader de l'hôpital. De nouveau, il habitua les surveillants à son absence au repas du soir et à l'appel. En compagnie de ses amis, Cazavant, Lamblin et les frères Levraud tous étudiants, Blanqui, coiffé d'une perruque claire et d'un chapeau à larges bords, passa devant le policier de garde et prit le train pour Bruxelles.

Le lendemain de son départ Blanqui envoya aux journaux parisiens une lettre ouverte; il y disait que, condamné à quatre ans de prison, il avait été détenu pendant quatre ans et six mois et que le devoir l'obligeait à refuser le cadeau de cent jours supplémentaires de son existence. Il s'était évadé de crainte d'être transporté à Cayenne au terme de sa réclusion.

À Bruxelles, il vécut chez son ami le Dr Watteau. Il y fit de nouvelles connaissances, revit son ami Charles Longuet qui éditait à Bruxelles le journal La Rive gauche. Au congrès de Liège ${ }^{1}$, en 1865, Blanqui rencontra Tridon, Paul Lafargue et Granger qui devint par la suite son meilleur ami. Au cours de ces années, Blanqui écrivit beaucoup. Quelques essais de cette époque, consacrés aux questions d'économie politique, de philosophie et de socialisme, furent publiés après sa mort en deux volumes, sous le titre : La Critique sociale.

En même temps, Blanqui continuait à correspondre avec ses amis parisiens. C'est alors que se constitua en France le groupe de combat blanquiste dont les membres étaient recrutés après une sélection sévère. En 1870, ils atteignirent l'effectif de 2500 . Blanqui venait souvent à Paris, en secret et pour un temps très

Congrès international d'étudiants (29 octobre-Ier novembre 1865) tenu à Liège. Les délégués parisiens, à leur retour, sont traduits devant le Conseil académique, frappés de diverses sanctions disciplinaires. Il en résulte une grande agitation dans les milieux universitaires en fin décembre 1865. Les cours sont provisoirement suspendus dans les facultés. 
court. Puis, quand l'activité de l'organisation prit de larges proportions, Blanqui resta à Paris plusieurs mois d'affilée.

En 1867-1868, Blanqui écrivit une « Instruction pour une prise d'armes » où il exposait en détail les mesures à prendre après la révolution pour établir une dictature parisienne. Il développait son plan de combat, indiquait les rues où l'on devait élever des barricades, donnait des modèles d'appels au peuple, à l'armée, etc. Les amis de Blanqui le pressaient de passer à la lutte ouverte contre l'Empire ; ils pensaient que le climat général du pays et le mécontentement à l'égard du régime étaient favorables à l'insurrection. Mais la crainte de nouveaux échecs rendait Blanqui prudent. Il y eut tout de même une tentative d'insurrection, le jour des funérailles de Victor Noir, jeune journaliste tué par un membre de la famille Bonaparte. Mais cette tentative ne réussit pas ; il n'y eut pas de collision entre la foule et les troupes, malgré une très large agitation à la Chambre et parmi le peuple.

Pendant la guerre de 1870, l'armée française connut, dès le début, une série de défaites. Les masses populaires furent indignées. Le peuple, qui se rassemblait sur la place de la Concorde, proclamait hautement sa colère et son indignation. Les blanquistes jugèrent que le moment était venu de renverser sans difficulté l'Empire et lancèrent un appel pressant à Blanqui qui se trouvait à Bruxelles. Il arriva à Paris le 12 août. L'insurrection devait avoir lieu le 14, au centre des quartiers ouvriers, boulevard de La Villette. On pensait occuper la caserne des pompiers du boulevard de La Villette pour s'approvisionner en armes, puis proclamer la république. Mais une fois encore la tentative échoua. La plupart de ses auteurs furent arrêtés, quelques-uns condamnés à mort, mais le verdict ne fut pas mis à exécution. Après la capitulation de Napoléon, survenue le 2 septembre à Sedan, l'Empire touchait à sa fin. Le 4 septembre, la République française fut proclamée, et le gouvernement de la défense nationale, dont faisaient partie Arago, Crémieux, Favre, Gambetta, Garnier-Pagès, Rochefort, Jules Simon et le général Trochu, fut constitué à Paris.

Aussitôt après la révolution du 4 septembre, Blanqui fonda le club et le journal La Patrie en danger. Dans son premier numéro daté du 7 septembre, Blanqui appelait les masses à accorder leur appui au gouvernement ; toutes les divisions devaient disparaître devant l'ennemi commun. Il ne comprenait pas qu'un gouvernement bourgeois, contre-révolutionnaire dans son essence, ne pouvait assurer la défense du pays, car il était guidé non pas par des intérêts nationaux, mais par des intérêts de classe.

Les collaborateurs du journal les plus proches de Blanqui : Tridon, les frères Levraud, Regnard, Granger et Verlet, faisaient également appel à l'union pour la défense de la patrie. Du 7 septembre au 9 décembre parurent 89 numéros, et dans chaque numéro Blanqui publiait des articles, des appels, des proclamations, dans lesquels il indiquait comment il fallait mener la défense de Paris, quelles mesures 
il fallait prendre pour le préserver. Dans ces conseils, il faisait preuve d'une profonde intelligence, de perspicacité et d'une grande connaissance de la tactique militaire.

Le soir, dans les clubs, Blanqui exposait les fautes et les crimes du gouvernement et indiquait les mesures à prendre pour constituer une armée nationale.

Au mois de septembre, à une réunion de gardes nationaux, Blanqui, après avoir prononcé un discours, fut élu commandant du 169e bataillon. Poste qu'il n'occupa pas longtemps, car, le 19 octobre, le général Trochu fit dissoudre le bataillon. Dans un des numéros de La Patrie en danger, Blanqui écrivait : "Le premier acte de la défense doit être la révocation de ceux qui rendent la défense impossible. » Le gouvernement de la défense nationale et le général Trochu, qui était à la tête des forces armées parisiennes, montrèrent au peuple français leur vrai visage, le visage de la trahison nationale. À la nouvelle de la capitulation de Metz, connue à Paris le 31 octobre, les masses populaires manifestèrent leur émotion. La capitulation menaçait Paris ; il fallait à tout prix sauver la capitale. Le 31 octobre, les masses populaires et les bataillons de la garde nationale, après avoir occupé l'Hôtel de Ville et mis en état d'arrestation les membres du gouvernement, créèrent un comité provisoire, chargé d'assurer la sécurité générale et de fixer les élections municipales. Blanqui et ses partisans prirent la tête du mouvement du 31 octobre et la candidature de Blanqui fut posée au nouveau gouvernement. Mais le mouvement du 31 octobre échoua comme les précédents; le gouvernement de la défense nationale conserva le pouvoir, en promettant de ne pas poursuivre ceux qui avaient participé à l'insurrection. Blanqui resta à Paris. Dans le journal qu'il continuait d'éditer, il lançait des appels en faveur de l'armement de tous les citoyens pour défendre la capitale et s'indignait de l'inaction du gouvernement :

Les pouvoirs légitimes sont aux mains de qui résiste. Le bulletin de vote, aujourd'hui, c'est la cartouche.

Blanqui et son groupe jouèrent un rôle actif dans la manifestation du 22 janvier 1871, qui avait pour but de renverser le gouvernement de la défense nationale. Mais cette manifestation populaire, aussi peu préparée que les autres, échoua.

Même après la capitulation de Paris et l'amnistie du 28 janvier, Blanqui espérait encore que la France serait sauvée. Le 8 février 1871 devaient avoir lieu les élections à l'Assemblée nationale. Le nom de Blanqui ne se trouvait pas sur la liste des 43 candidats présentés par les clubs, les comités et les rédactions des journaux. Après les élections, où il recueillit néanmoins 52839 voix, Blanqui se décida à partir pour Bordeaux. En quittant Paris le 12 février, il fit apposer une affiche, intitulée Un dernier mot, dans laquelle il résumait tout ce qu'il avait écrit dans La Patrie en danger. Il y était question de la conduite du gouvernement pendant le siège de Paris, des mesures qu'on aurait dû prendre pour sa défense, de 
la nécessité d'évacuer en province un million de femmes et d'enfants et de les remplacer par autant de jeunes provinciaux en état de porter les armes, du ravitaillement de Paris, de son armement à prélever sur les arsenaux de province, etc. Un dernier mot se terminait par une mise en accusation du gouvernement traître.

De Bordeaux, Blanqui se rendit à Loulié (Lot), chez sa nièce, pour se reposer des événements parisiens. Mais ce repos fut de courte durée, car il tomba malade. C'est alors que, le 9 mars, il fut mis en jugement pour sa participation à la journée du 31 octobre. Le gouvernement violait son engagement de ne pas poursuivre les auteurs de ce soulèvement. Par décision du ministère de la justice, Blanqui fut arrêté à Loulié le 17 mars et conduit, tout malade qu'il était, à l'hôpital de Figeac le 18 mars, le jour même où la classe ouvrière prenait le pouvoir et proclamait la Commune à Paris. Lorsqu'on l'avisa de l'arrestation de Blanqui, Thiers, le bourreau de la Commune, s'écria : « Nous le tenons enfin, ce scélérat ! »

Le 20 mars, Blanqui fut transféré à la prison de Cahors, où il fut incarcéré avec des prisonniers de droit commun, jusqu'à ce qu'on le mette au secret.

Le 26 mars, il fut élu membre de la Commune de Paris ${ }^{1}$ avec d'autres blanquistes : Tridon, Eudes, Flourens, Édouard Vaillant, Rigault, etc., qui avaient joué un rôle actif dans la révolution du 18 mars.

Aux premières séances de la Commune, Blanqui fut élu président d'honneur. Ses amis eurent l'idée de proposer au gouvernement de Thiers de l'échanger contre certains otages de la Commune, parmi lesquels l'archevêque Darboy. Les pourparlers engagés entre un homme de confiance de l'archevêque et Thiers durèrent plus d'un mois, mais ne menèrent à rien. Thiers ne voulait pas libérer Blanqui, même contre 74 otages, et déclarait que « rendre Blanqui à l'insurrection équivalait à lui envoyer un régiment ».

Après cet échec, la Commune vota un crédit de 50000 francs pour préparer l'évasion de Blanqui de la prison de Cahors. Mais Granger, ami intime de Blanqui, à qui on avait confié cette mission, ne parvint pas à l'accomplir.

Le 22 mai, Blanqui fut conduit au fort du Taureau, dans la baie de Morlaix, où il arriva deux jours plus tard. Il avait alors soixante-six ans et sa santé était compromise. Cependant le régime du fort du Taureau était très rigoureux. La cellule de Blanqui, située au sous-sol, était froide, sombre et humide. La surveillance était extrêmement sévère. Le commandant avait reçu l'ordre de tirer à la moindre tentative de fuite; pendant la promenade, Blanqui était toujours accompagné de gardiens armés; on interdisait aux bateaux d'accoster, etc. En outre le bruit incessant de la prison empêchait Blanqui de travailler et de se

Dans le XVIII ${ }^{\mathrm{e}}$ et dans le $\mathrm{XX}^{\mathrm{e}}$ arrondissements. 
reposer, et la nourriture était très mauvaise. Livré à lui-même, il s'adonnait à la méditation. Pendant la promenade, il étudiait le ciel et la mer, suivait le mouvement des planètes. Les conclusions de ses observations se retrouvent dans L'Éternité par les astres et dans l'exposé sur les causes de la lumière zodiacale qui, plus tard, le 8 janvier 1872, fut lu à l'Académie des Sciences et publié le 27 janvier dans La République française. La même année, L'Éternité par les astres fut éditée en volume à Paris.

Le 12 novembre 1871, Blanqui fut subitement transféré à la prison de Versailles. Pendant deux jours (le 15 et le 16 février 1872), après presque un an de détention préventive, le $\mathrm{IV}^{\mathrm{e}}$ Conseil de guerre de Versailles eut à se prononcer sur sa participation aux événements du 31 octobre et à d'autres manifestations ainsi que sur sa responsabilité «morale » dans l'existence de la Commune. Blanqui, alors âgé de soixante-sept ans, était un vieillard pâle et grêle d'aspect. Mais aucune prison n'avait pu le briser moralement. Il réfuta tous les arguments de l'accusation et termina par cette fière déclaration.

Je ne suis pas ici pour le 31 octobre. C'est le moindre de mes forfaits. Je représente ici la République traînée à la barre de votre tribunal par la monarchie. M. le commissaire du gouvernement a condamné tour à tour la révolution de 1789, celle de 1830, celle de 1848, celle du 4 septembre. C'est au nom des idées monarchiques, c'est au nom du droit ancien en opposition au droit nouveau, comme il dit, que je suis jugé et que, sous la République, je vais être condamné.

Blanqui fut reconnu coupable et condamné à la déportation et à la privation des droits civiques. La cour de cassation annula le jugement. Mais le 29 avril, le $\mathrm{VI}^{\mathrm{e}}$ Conseil de guerre le condamna à nouveau. On se proposait de l'exiler en NouvelleCalédonie, lieu de déportation des membres de la Commune, mais la commission médicale reconnut qu'il n'était pas en état de supporter un aussi long voyage. Le condamné à vie fut conduit à la prison centrale de Clairvaux (Aube).

Clairvaux, vieille abbaye, avait été convertie en prison en 1789. À son arrivée, Blanqui y trouva 140 détenus politiques, condamnés comme anciens Communards. Il fut mis dans une cellule isolée, longue de $2 \mathrm{~m}$ et large de $1 \mathrm{~m} 50$, avec une fente étroite qui tenait lieu de fenêtre ; il était séparé des autres détenus et on ne lui donnait que rarement la permission de recevoir des visites familiales. Dans la prison humide de Clairvaux, la santé de Blanqui fut définitivement compromise ; pendant de longs mois, il ne quitta pas le lit. Plus tard, on lui donna une cellule plus large, mais toujours isolée, où il se sentait "enterré vivant », comme il l'écrivait à sa sœur.

En janvier 1878, le journal socialiste L'Égalité fit campagne pour sa libération. On présenta sa candidature aux élections. En avril 1879, il fut élu député de Bordeaux au second tour de scrutin par 6801 voix contre 5330 au républicain bourgeois Lavertujon, ami de Gambetta. Mais la Chambre invalida l'élection de 
Blanqui. L'active campagne en faveur de la candidature et de la libération de l'« Enfermé » contraignit enfin le gouvernement à gracier Blanqui le 10 juin 1879.

Il était resté à Clairvaux huit ans et trois mois. Ce fut sa dernière prison. Au total, il avait été détenu pendant trente sept ans. Le lendemain du jour où il fut libéré, Blanqui, âgé de soixante-quatorze ans, revint à Paris avec sa sœur. Le 25 juin, il partit pour Bordeaux pour remercier ses électeurs et pour se présenter devant eux à nouveau. Les habitants de Bordeaux accueillirent Blanqui avec enthousiasme. Cependant, au cours de la campagne électorale, ses ennemis exhumèrent le document Taschereau, et, bien qu'il n'y eût aucune preuve de sa culpabilité, il recueillit 158 voix de moins que son adversaire.

Mais ce revers ne diminua pas son énergie, il entreprit un voyage à travers la France et prit la parole dans de nombreuses réunions ouvrières. Les milieux populaires l'accueillaient avec enthousiasme, et à Bordeaux, Marseille, Toulon, Lyon, Nice, etc., on fit des banquets en son honneur.

Dans l'été 1880, la candidature de Blanqui fut posée à Lyon, mais il n'obtint pas la majorité. En juin, les droits civiques lui furent rendus. Au début du mois de novembre suivant, il fit partie des délégués des comités républicains envoyés en Italie pour assister aux fêtes organisées en l'honneur de Garibaldi.

À la fin du mois de novembre, Blanqui et ses amis, Granger, Eudes, Vaillant et d'autres fondèrent le quotidien $\mathrm{Ni}$ Dieu, ni maître, dont Blanqui fut le rédacteur en chef. Le manque de ressources le força à transformer ce journal, à partir du $25^{\mathrm{e}}$ numéro, en hebdomadaire. Dans le même temps, il écrivait une brochure, L'armée esclave et opprimée, et, le 21 novembre, accompagné de Granger, il avait fait une conférence à Lille devant 6000 personnes qui l'avaient acclamé avec enthousiasme.

Jusqu'à sa mort, Blanqui, comme s'il voulait rattraper le temps perdu en prison, multiplia ses discours dans les réunions ouvrières de Paris. Le 27 décembre 1880 il assista à la réunion de la salle Ragache, rue Lecourbe, où il prononça en faveur du drapeau rouge son dernier discours. À son retour à une heure tardive, il fut subitement terrassé par une attaque d'apoplexie. Le $1^{\text {er }}$ janvier 1881 , après avoir lutté cinq jours, il mourait à l'âge de soixante-seize ans.

Ses funérailles eurent lieu le 5 janvier. La nouvelle de sa mort bouleversa tous les révolutionnaires français. Près de 200000 hommes accompagnèrent sa dépouille. Des délégués et des couronnes, envoyés par les organisations d'avantgarde de la France entière, affluèrent à Paris.

Il fut enterré au Père-Lachaise. Le 9 août 1885, les ouvriers parisiens firent édifier un monument sur sa tombe, avec sa statue en bronze, chef-d'œuvre du sculpteur Jules Dalou. 


\section{OUVRAGES \\ D'AUGUSTE BLANQUI}

$\underline{\text { Retour à la table des matières }}$

Défense du citoyen Auguste Blanqui devant la cour d'assises. Paris, 1832.

Réponse du citoyen Auguste Blanqui. Paris, 1848.

« Avis au peuple ». La Patrie, 27 février 1851

« Pages inédites » (1848-1852). La Révolution de 1848, 1925, t. XXIII, no III, pp. 541-558.

« Lettre à Maillard » (1852). Le Cri du peuple, 1, 2, 3 octobre 1878.

" Instruction pour une prise d'armes. » (La première partie a été publiée dans La Pensée, 1948, n 19.)

La Patrie en danger. Paris, 1871.

Un dernier mot. Paris, 1871.

L'Éternité par les astres. Paris, 1872.

« La comédie des programmes ». L'Égalité, 16 juin 1878.

L'Armée esclave et opprimée. Paris, 1880.

Ni Dieu, ni Maître. Paris, 1880.

Critique Sociale, 2 volumes. Paris, 1885. 


\section{BIBLIOGRAPHIE}

$\underline{\text { Retour à la table des matières }}$

BOURGIN (G.) et FERRIER (M.). - Album de 1848, Paris, 1948.

BRUXAT (J.). - Les journées de Février 1848. Paris, 1948.

DA COSTA (Ch.). Les Blanquistes. Paris, 1912.

DAUTRY (J.). - Histoire de la révolution de 1848 en France.

Paris, 1948.

DOMMANGET (M.). - Blanqui, la guerre de 1870 et la Commune. Paris, 1947, - Un drame politique en 1848 (Blanqui et Le document Taschereau). Paris, 1948.

FLOTTE (B.). - Blanqui et les otages en 1871 (Documents historiques). Paris, 1885.

GARAUDY (R.). - Les Sources françaises du socialisme scientifique. Paris, 1948,

GEFFROY (G.). - L'Enfermé. Paris, 1897.

GIRARD (F.). - Histoire du mont Saint-Michel. Paris, 1849.

JAURÈS (J.). - Blanqui. Dans JAURÈS (J.) : Euvres, t. III. Études socialistes, I, 1888-1897, Paris, 1931.

MASON (E.) - «Blanqui and communism ». Political Science Quarterly, 1929, vol XLIV, $n^{\circ} 4$.

MOLINIER (S.). - Blanqui. Paris, 1948 (Centenaire de la Révolution de 1848)

PERREUX (J.) - Au temps des sociétés secrètes. Paris, 1935.

POSTGATE (R. W.). - « The prisoner L. A. Blanqui », dans Out of the Past, Londres, 1922.

- How to make a Revolution. Londres, 1934.

STEWART (N.). - Blanqui. A Biography. Londres, 1939.

TCHERNOFF (I.). - Le Parti républicain sous la monarchie de Juillet. Paris, 1901.

WASSERMANN (S.). - Les Clubs de Barbès et de Blanqui en 1848. Paris, 1913.

ZÉVARES (A.). - Auguste Blanqui, patriote et socialiste français. Paris, 1920.

— Une Révolution manquée : l'insurrection du 22 mai 1839. Paris, 1933. 


\title{
TEXTES CHOISIS
}

I

\author{
BLANQUI AVANT LA \\ RÉVOLUTION DE 1848
}

\section{1. - LE PROCÈS DES QUINZE ${ }^{1}$. \\ DÉFENSE DU CITOYEN LOUIS-AUGUSTE BLANQUI DEVANT LA COUR D'ASSISES}

$\underline{\text { Retour à la table des matières }}$

(12 janvier 1832).

Messieurs les jurés,

Je suis accusé d'avoir dit à trente millions de Français, prolétaires comme moi, qu'ils avaient le droit de vivre. Si cela est un crime, il me semble du moins que je ne devrais en répondre qu'à des hommes qui ne fussent point juges et parties dans la question. Or, Messieurs, remarquez bien que le ministère public ne s'est point adressé à votre équité et à votre raison, mais à vos passions et à vos intérêts ; il n'appelle pas votre rigueur sur un acte contraire à la morale et aux lois ; il ne cherche qu'à déchaîner votre vengeance contre ce qu'il vous représente comme une menace à votre existence et à vos propriétés. Je ne suis donc pas devant des juges, mais en présence d'ennemis ; il serait bien inutile dès lors de me défendre. Aussi je suis résigné à toutes les condamnations qui pourraient me frapper, en protestant néanmoins avec énergie contre cette substitution de la violence à la justice, et en

Le Procès des Quinze, Paris, 1832.

Le prétexte pour la mise en jugement des quinze dirigeants de la Société des Amis du Peuple : Raspail, Gervais, Trélat, Blanqui, Thouret, Hubert, Delaunay, etc., fut la publication dans le recueil Au peuple d'une série d'articles pénétrés d'esprit républicain et pleins d'attaques contre le gouvernement de Louis-Philippe. Voir l'esquisse biographique, p. 51. 
me remettant à l'avenir du soin de rendre la force au droit. Toutefois, s'il est de mon devoir, à moi prolétaire, privé de tous les droits de la cité, de décliner la compétence d'un tribunal où ne siègent que des privilégiés qui ne sont point mes pairs, je suis convaincu que vous avez le cœur assez haut placé pour apprécier dignement le rôle que l'honneur vous impose dans une circonstance où on livre en quelque sorte à votre immolation des adversaires désarmés. Quant au nôtre, il est tracé d'avance ; le rôle d'accusateur est le seul qui convienne aux opprimés.

Car il ne faut pas s'imaginer que des hommes investis par surprise et par fraude d'un pouvoir d'un jour pourront à leur gré traîner les patriotes devant leur justice, et nous contraindre, en montrant le glaive, à demander miséricorde pour notre patriotisme. Ne croyez pas que nous venions ici pour nous justifier des délits qu'on nous impute ! bien loin de là, nous nous honorons de l'imputation, et c'est de ce banc même des criminels, où on doit tenir à honneur de s'asseoir aujourd'hui, que nous lancerons nos accusations contre les malheureux qui ont ruiné et déshonoré la France, en attendant que l'ordre naturel soit rétabli dans les rôles pour lesquels sont faits les bancs opposés de cette enceinte, et qu'accusateurs et accusés soient à leur véritable place.

Ce que je vais dire expliquera pourquoi nous avons écrit les lignes incriminées par les gens du roi, et pourquoi nous en écrirons encore.

Le ministère public a, pour ainsi dire, montré en perspective à vos imaginations une révolte des esclaves, afin d'exciter votre haine par la crainte. « Vous voyez, at-il dit, c'est la guerre des pauvres contre les riches ; tous ceux qui possèdent sont intéressés à repousser l'invasion. Nous vous amenons vos ennemis ; frappez-les avant qu'ils ne deviennent plus redoutables. »

Oui, Messieurs, ceci est la guerre entre les riches et les pauvres: les riches l'ont ainsi voulu, car ils sont les agresseurs. Seulement ils trouvent mauvais que les pauvres fassent résistance ; ils diraient volontiers, en parlant du peuple : «Cet animal est si féroce qu'il se défend quand on l'attaque. »Toute la philippique de $\mathrm{M}$. l'avocat général peut se résumer dans cette phrase.

On ne cesse de dénoncer les prolétaires comme des voleurs prêts à se jeter sur les propriétés : pourquoi ? Parce qu'ils se plaignent d'être écrasés d'impôts au profit des privilégiés. Quant aux privilégiés, qui vivent grassement de la sueur du prolétaire, ce sont de légitimes possesseurs menacés du pillage par une avide populace. Ce n'est pas la première fois que les bourreaux se donnent des airs de victimes. Qui sont donc ces voleurs dignes de tant d'anathèmes et de supplices ? Trente millions de Français qui paient au fisc un milliard et demi et une somme à peu près égale aux privilégiés. Et les possesseurs que la société entière doit couvrir de sa puissance, ce sont deux ou trois cent mille oisifs qui dévorent paisiblement les milliards payés par les voleurs. Il me semble que c'est là, sous une nouvelle 
forme, et entre d'autres adversaires, la guerre des barons féodaux contre les marchands qu'ils détroussaient sur les grands chemins.

En effet, le gouvernement actuel n'a point d'autre base que cette inique répartition des charges et des bénéfices. La restauration l'a instituée en 1814 sous le bon plaisir de l'étranger, dans le but d'enrichir une imperceptible minorité des dépouilles de la nation. Cent mille bourgeois en forment ce qu'on appelle, par une ironie amère, l'élément démocratique. Que sera-t-il, bon Dieu ! des autres éléments ? Paul Courier ${ }^{1}$ a déjà immortalisé la marmite représentative; cette pompe aspirante et foulante qui foule la matière appelée peuple, pour en aspirer des milliards incessamment versés dans les coffres de quelques oisifs, machine impitoyable qui broie un à un vingt-cinq millions de paysans et cinq millions d'ouvriers pour extraire le plus pur de leur sang et le transfuser dans les veines des privilégiés. Les rouages de cette machine, combinés avec un art merveilleux, atteignent le pauvre à tous les instants de la journée, le poursuivent dans les moindres nécessités de son humble vie, se mettent de moitié clans son plus petit gain, dans la plus misérable de ses jouissances. Et ce n'est pas assez de tant d'argent qui voyage des poches du prolétaire à celles du riche, en passant par les abîmes du fisc ; des sommes plus énormes encore sont levées directement sur les masses par les privilégiés, au moyen des lois qui régissent les transactions industrielles et commerciales, lois dont ces privilégiés possèdent la fabrication exclusive.

Pour que le propriétaire retire de ses champs un gros fermage, les blés étrangers sont frappés d'un droit d'entrée qui augmente le prix du pain ; or vous savez que quelques centimes de plus ou moins sur une livre de pain, c'est la vie ou la mort de plusieurs milliers d'ouvriers. Cette législation des céréales écrase surtout les populations maritimes du Midi. Pour enrichir quelques gros fabricants et prolétaires des forêts, on soumet à des droits énormes d'Allemagne et de Suède, en sorte que les paysans sont contraints de payer bien cher de mauvais outils, tandis qu'ils pourraient s'en procurer d'excellents à bon marché ; l'étranger à son tour se venge de nos prohibitions en repoussant les vins français de ses marchés, ce qui, joint aux impôts qui pèsent sur cette denrée à l'intérieur, réduit à la misère les contrées les plus riches de la France, et tue la culture de la vigne, la plus naturelle au pays, la culture véritablement indigène, celle qui favorise le plus la mobilisation du sol et la petite propriété. Je ne parlerai pas de l'impôt sur le sel, de la loterie, du monopole des tabacs, en un mot, de cet inextricable réseau d'impôts, de monopoles, de prohibitions, de droits de douane et d'octroi, qui enveloppe le prolétaire, qui enchaîne et atrophie ses membres? Il suffit de dire que cette masse

Paul-Louis COURIER (1772-1825) : Écrivain et pamphlétaire. Sans appartenir à un parti politique, il combattit avec une plume mordante et impitoyable la réaction nobiliaire et cléricale. Ses pamphlets ont joué un rôle considérable dans la préparation de la révolution de 1830. Ses écrits les plus connus sont : Pétition aux deux Chambres (1816); Simple Discours de Paul-Louis, vigneron de la Chavonnière (1821) ; Pamphlet des pamphlets (1824) 
d'impôts est répartie de manière à épargner toujours le riche, et à peser exclusivement sur le pauvre, ou plutôt que les oisifs exercent un indigne pillage sur les masses laborieuses. Le pillage est indispensable en effet.

Ne faut-il pas une grosse liste civile pour défrayer la royauté, la consoler du sacrifice sublime qu'elle a fait de son repos au bonheur du pays ? Et, puisqu'un des principaux titres des Bourbons cadets à l'hérédité consiste dans leur nombreuse famille, l'État n'ira pas faire mesquinement les choses, et refuser des apanages aux princes, de dots aux princesses. Il y a aussi cette immense armée dessinécuristes, de diplomates, de fonctionnaires que la France, pour son bonheur, doit fournir de gros traitements, afin qu'ils enrichissent de leur luxe la bourgeoisie privilégiée, car tout l'argent des parties prenantes au budget est dépensé dans les villes, et il ne doit pas retourner aux paysans un seul sou du milliard et demi dont ils payent les cinq sixièmes.

Ne faut-il pas aussi que ce nouvel astre financier, ce Gil Blas du XIX ${ }^{\mathrm{e}}$ siècle, courtisan et apologiste de tous les ministères, favori du comte d'Olivarès comme du duc de Lerme, puisse vendre les hauts emplois à beaux deniers comptants ? Il est indispensable de graisser les grands rouages de la machine représentative, de doter richement fils, neveux, cousins, cousines. Et les courtisans, les courtisanes, les intrigants, les croupiers qui cotent à la Bourse l'honneur et l'avenir du pays, les entremetteuses, les maîtresses, les agents fournisseurs, les écrivains de police, qui spéculent sur la chute de la Pologne, toute cette vermine des palais et des salons, ne faut-il pas gorger d'or tout cela ? Ne faut-il pas pousser à la fermentation ce fumier qui féconde si heureusement l'opinion publique?

Voilà le gouvernement que les bouches d'or du ministère nous donnent comme le chef-d'œuvre des systèmes d'organisation sociale, le résumé de tout ce qu'il y a eu de bien et de parfait dans les divers mécanismes administratifs depuis le déluge ; voilà ce qu'ils vantent comme le nec plus ultra de la perfectibilité humaine en matière de gouvernement ! C'est tout bonnement la théorie de la corruption poussée à ses dernières limites. La plus forte preuve que cet ordre de choses n'est institué qu'en vue de l'exploitation du pauvre par le riche, qu'on n'a cherché d'autre base qu'un matérialisme ignoble et brutal, c'est que l'intelligence est frappée d'ilotisme. En effet, elle est une garantie de moralité, et la moralité introduite par mégarde dans un pareil système ne pourrait y entrer que comme élément infaillible de destruction.

Je le demande, Messieurs, comment les hommes de cœur et d'intelligence, rejetés au rang des parias par une plate aristocratie d'argent, ne ressentiraient-ils pas profondément un si cruel outrage? Comment pourraient-ils demeurer indifférents à la honte de leur pays, aux souffrances des prolétaires, leurs frères d'infortune ? Leur devoir est d'appeler les masses à briser un joug de misère et d'ignominie; ce devoir je l'ai rempli malgré les prisons; nous le remplirons jusqu'au bout en bravant nos ennemis. Quand on a derrière soi un grand peuple qui 
marche à la conquête de son bien-être et de sa liberté, on doit savoir se jeter dans les fossés pour servir de fascines et lui faire un chemin.

Les organes ministériels répètent avec complaisance qu'il y a des voies ouvertes aux doléances des prolétaires, que les lois leur présentent des moyens réguliers d'obtenir place pour leurs intérêts. C'est une dérision. Le fisc est là, qui les poursuit de sa gueule béante ; il faut travailler, travailler nuit et jour pour jeter incessamment de la pâture à la faim toujours renaissante de ce gouffre; bien heureux s'il leur reste quelques bribes pour tromper celle de leurs enfants. Le peuple n'écrit pas dans les journaux ; il n'envoie pas de pétition aux chambres : ce serait temps perdu. Bien plus, toutes les voix qui ont un retentissement dans la sphère politique, les voix des salons, celles des boutiques, des cafés, en un mot de tous les lieux où se forme ce qu'on appelle l'opinion publique, ces voix sont celles des, privilégiés ; pas une n'appartient au peuple ; il est muet ; il végète éloigné de ces hautes régions où se règlent ses destinées. Lorsque, par hasard, la tribune ou la presse laissent échapper quelques paroles de pitié sur sa misère, on se hâte de leur imposer silence au nom de la sûreté publique, qui défend de toucher à ces questions brûlantes, ou bien on crie à l'anarchie. Que si quelques hommes persistent, la prison fait justice de ces vociférations qui troublent la digestion ministérielle. Et puis, quand il s'est fait un grand silence, on dit : «Voyez, la France est heureuse, elle est paisible : l'ordre règne ! ... »

Mais qu'en dépit des précautions le cri de faim, poussé par des milliers de malheureux, parvienne jusqu'aux oreilles des privilégiés, ils rugissent, ils s'écrient. « Il faut que force reste à la loi ! Une nation ne doit se passionner que pour la loi ! »Messieurs, suivant vous, toutes les lois sont-elles bonnes ? N'y en a-t-il jamais eu qui vous fissent horreur? N'en connaissez-vous aucune de ridicule, d'odieuse ou d'immorale ? Est-il possible de se retrancher ainsi derrière un mot abstrait, qui s'applique à un chaos de quarante mille lois, qui signifie également ce qu'il y a de meilleur et ce qu'il y a de pire ? On répond : "S'il y a de mauvaises lois, demandez-en la réforme légale ; en attendant, obéissez... » Ceci est une dérision encore plus amère. Les lois sont faites par cent mille électeurs, appliquées par cent mille jurés, exécutées par cent mille gardes nationaux urbains, car on a soigneusement désorganisé les gardes nationales des campagnes, qui ressemblent trop au peuple. Or ces électeurs, ces jurés, ces gardes nationaux, ce sont les mêmes individus, lesquels cumulent les fonctions les plus opposées et se trouvent tout à la fois législateurs, juges et soldats, en sorte que le même homme crée le matin un député, c'est-à-dire la loi, applique cette loi à midi en qualité de juré, et l'exécute le soir dans la rue sous le costume de garde national. Que font les trente millions de prolétaires dans toutes ces évolutions ? Ils paient.

Les apologistes du gouvernement représentatif ont principalement fondé leurs éloges sur ce que ce système consacrait la séparation des trois pouvoirs législatif, judiciaire et exécutif. Ils n'avaient pas assez de formules admiratives pour ce merveilleux équilibre qui avait résolu le problème si longtemps cherché de l'accord 
de l'ordre avec la liberté, du mouvement avec la stabilité. Eh bien ! il se trouve que c'est précisément le système représentatif, tel que les apologistes l'appliquent, qui concentre les trois pouvoirs entre les mains d'un petit nombre de privilégiés unis par les mêmes intérêts. N'est-ce point là une confusion qui constitue la plus monstrueuse des tyrannies, de l'aveu même des apologistes ?

Aussi qu'arrive-t-il ? Le prolétaire est resté en dehors. Les Chambres, élues par les accapareurs de pouvoir, poursuivent imperturbablement leur fabrication de lois fiscales, pénales, administratives, dirigées dans le même but de spoliation. Maintenant que le peuple aille, en criant la faim, demander aux privilégiés d'abdiquer leurs privilèges, aux monopoleurs de renoncer à leur monopole, à tous d'abjurer leur oisiveté, ils lui riront au nez. Qu'eussent fait les nobles en 1789, si on les eût humblement suppliés de déposer leurs droits féodaux ? Ils auraient châtié l'insolence... On s'y est pris autrement.

Les plus habiles de cette aristocratie sans entrailles, sentant tout ce qu'il y a de menaçant pour eux dans le désespoir d'une multitude privée de pain, proposent d'alléger un peu sa misère, non par humanité, à Dieu ne plaise ! mais pour se sauver du péril. Quant aux droits politiques, il n'en faut pas parler, il ne s'agit que de jeter aux prolétaires un os à ronger.

D'autres hommes, avec de meilleures intentions, prétendent que le peuple est las de liberté et ne demande qu'à vivre. Je ne sais quelle velléité de despotisme les pousse à exalter l'exemple de Napoléon, qui sut rallier les masses en leur donnant du pain en échange de la liberté. Il est vrai que ce despote niveleur se soutint quelque temps, et ce fut surtout en flattant la passion de l'égalité, car il faisait fusiller les fournisseurs voleurs, qui en seraient quittes aujourd'hui pour être députés. Il n'en périt pas moins pour avoir tué la liberté. Cette leçon devrait profiter à ceux qui veulent se porter ses héritiers.

Il n'est pas permis d'arguer des cris de détresse d'une population affamée, pour redire le mot insolent de Rome impériale : Panem et circenses! Qu'on sache bien que le peuple ne mendie plus ! Il n'est pas question de laisser tomber d'une table splendide quelques miettes pour l'amuser; le peuple n'a pas besoin d'aumônes ; c'est de lui-même qu'il entend tenir son bien-être. Il veut faire et il fera les lois qui doivent le régir : alors ces lois ne seront plus faites contre lui ; elles seront faites pour lui parce qu'elles le seront par lui. Nous ne reconnaissons à personne le droit d'octroyer je ne sais quelles largesses qu'un caprice contraire pourrait révoquer. Nous demandons que les trente-trois millions de Français choisissent la forme de leur gouvernement, et nomment, par le suffrage universel, les représentants qui auront mission de faire les lois. Cette réforme accomplie, les impôts qui dépouillent le pauvre au profit du riche seront promptement supprimés et remplacés par d'autres établis sur des bases contraires. Au lieu de prendre aux prolétaires laborieux pour donner aux riches, l'impôt devra s'emparer du superflu des oisifs pour le répartir entre cette masse d'hommes indigents que le manque 
d'argent condamne à l'inaction; frapper les consommateurs improductifs pour féconder les sources de la production; faciliter de plus en plus la suppression du crédit public, cette plaie sanieuse du pays ; enfin substituer au funeste tripotage de bourse un système de banques nationales où les hommes actifs trouveront des éléments de fortune. Alors, mais seulement alors, les impôts seront un bienfait.

Voilà, Messieurs, comme nous entendons la république, pas autrement. 93 est un épouvantail bon pour les portiers et les joueurs de domino. Notez, Messieurs, que c'est à dessein que j'ai prononcé ce mot de suffrage universel, pour montrer notre mépris de certains rapprochements. Nous savons bien tout ce qu'un gouvernement aux abois met en œuvre de mensonges, de calomnies, de contes ridicules ou perfides, pour redonner quelque créance à cette vieille histoire qu'il exploite depuis si longtemps, d'une alliance entre les républicains et les carlistes ${ }^{1}$, c'est-à-dire entre ce qu'il y a de plus antipathique au monde. C'est là son ancre de salut, sa grande ressource pour retrouver quelque appui ; et les plus stupides conspirations de mélodrame, les plus odieuses farces de police ne lui paraissent pas un jeu trop dangereux s'il parvient, en effrayant la France du carlisme qu'elle déteste, à la détourner quelques jours encore des voies républicaines où l'instinct de son salut la précipite. Mais à qui persuadera-t-on la possibilité de cette union contre nature ? Les carlistes n'ont-ils pas sur les mains le sang de nos amis morts sur les échafauds de la Restauration? Nous ne sommes pas si oublieux de nos martyrs. N'est-ce pas contre l'esprit révolutionnaire, représenté par le drapeau tricolore, que les Bourbons ont ameuté l'Europe pendant vingt-cinq ans, et qu'ils cherchent encore à l'ameuter ? Ce drapeau n'est pas le vôtre, apôtres de la quasilégitimité ! c'est celui de la République! C'est nous, républicains, qui l'avons relevé en 1830, sans vous et malgré vous, qui le brûliez en 1815 ; et l'Europe sait bien que la France républicaine seule le défendra, quand il sera de nouveau assailli par les rois. S'il y a quelque part alliance naturelle, c'est entre vous et les carlistes ; non pas que le même homme vous convienne pour le moment ; ils tiennent au leur qui n'est pas ici; mais vous feriez probablement bon marché du vôtre, par accommodement et pour mieux arriver à la chose que vous souhaitez en commun avec eux, d'autant que vous ne feriez en cela que retourner à votre ancien râtelier.

En effet, le mot de carlistes est un non-sens ; il n'y a et ne peut y avoir en France que des royalistes et des républicains. La question se tranche chaque jour davantage entre ces deux principes ; les bonnes gens qui avaient cru à un troisième principe, espèce de genre neutre appelé juste milieu, abandonnent petit à petit cette absurdité, et reflueront tous vers l'un ou l'autre drapeau, selon leur passion et leur intérêt. Or, vous, hommes monarchiques, qui faites de la monarchie comme vous parlez, on sait sous quelle bannière vos doctrines vous appellent. Vous n'avez pas

Il s'agit des légitimistes français, les partisans de Charles X. Blanqui les appelle les carlistes par analogie avec les légitimistes espagnols, partisans de Don Carlos. 
attendu dix-huit mois pour la choisir. Le 28 juillet 1830, à dix heures du matin ${ }^{1}$, m'étant avisé de dire dans le bureau d'un journal que j'allais prendre mon fusil et ma cocarde tricolore, l'un des puissants personnages d'aujourd'hui s'écria, plein d'indignation : "Monsieur, les couleurs tricolores peuvent bien être les vôtres, mais elles ne seront jamais les miennes; le drapeau blanc est le drapeau de la France. » Alors comme à présent ces messieurs faisaient tenir la France sur un canapé ${ }^{2}$.

Eh bien ! nous, nous avons conspiré quinze ans contre le drapeau blanc, et c'est en grinçant les dents que nous le voyions flotter sur les Tuileries et sur l'Hôtel de Ville, où l'étranger l'avait planté. Le plus beau jour de notre vie a été celui où nous l'avons traîné dans la boue des ruisseaux, et où nous avons foulé aux pieds la cocarde blanche, cette prostituée des camps ennemis. Il faut une rare dose d'impudence pour nous jeter au nez cette accusation de connivence avec le royalisme ; et d'un autre côté c'est une bien maladroite hypocrisie que de s'apitoyer sur notre prétendue crédulité, sur notre bonhomie niaise, qui nous rend, dit-on, dupes des carlistes. Si je parle ainsi, ce n'est point pour insulter des ennemis à terre ; ils se disent forts, ils ont leur Vendée ; qu'ils recommencent, nous verrons !

Au reste, je le répète, il y aura bientôt nécessité d'opter entre la monarchie monarchique et la république républicaine ; on verra pour qui est la majorité. Déjà même, si l'opposition de la Chambre des députés, toute nationale qu'elle est, ne peut rallier complètement le pays; si elle donne le droit au gouvernement de l'accuser d'incapacité et d'impuissance, c'est que, tout en repoussant nettement la royauté, elle n'a pas osé se déclarer avec la même franchise pour la république ; c'est qu'en disant ce qu'elle ne voulait pas, elle n'a pas articulé ce qu'elle voulait. Elle ne se résout pas à décliner ce mot de république, dont les hommes de la Corruption s'efforcent de faire peur à la nation, sachant bien que la nation vaut la chose presque unanimement. On a défiguré l'histoire, depuis quarante ans, avec un succès incroyable, dans ce but d'effrayer; mais les dix-huit derniers mois ont détrompé de bien des erreurs, dissipé bien des mensonges, et le peuple ne prendra plus longtemps le change. Il veut à la fois la liberté et le bien-être. C'est une calomnie de le représenter comme prêt à donner toutes ses libertés pour un morceau de pain : il faut renvoyer cette imputation aux athées politiques qui l'ont lancée. N'est-ce pas le peuple qui, dans toutes les crises, s'est montré prêt à sacrifier son bien-être et sa vie pour des intérêts moraux ? N'est-ce pas le peuple qui demandait à mourir, en 1814, plutôt que de voir l'étranger dans Paris ? Et cependant, quel besoin matériel le poussait à cet acte de dévouement ? Il avait du pain le 1er avril aussi bien que le 30 mars.

La seconde journée des « Trois Glorieuses », les insurgés s'emparèrent de l'Hôtel de Ville, sur lequel ils hissèrent le drapeau tricolore.

2 Sous la Restauration, le mot canapé désignait ironiquement les doctrinaires (membres d'une fraction du parti royaliste constitutionnel dirigée par Guizot, Royer-Collard, etc.). On disait que ce groupe était si peu nombreux qu'il pouvait tenir sur un canapé. 
Ces privilégiés, au contraire, qu'on aurait supposé si faciles à remuer par les grandes idées de patrie et d'honneur, en raison de l'exquise sensibilité qu'ils doivent, à l'opulence ; qui auraient pu du moins calculer mieux que d'autres les funestes conséquences de l'invasion étrangère ; ne sont-ce pas eux qui ont arboré la cocarde blanche en présence de l'ennemi, et embrassé les bottes du cosaque ? Quoi ! des classes qui ont applaudi au déshonneur du pays, qui professent hautement un dégoûtant matérialisme, qui sacrifieraient mille ans de liberté, de prospérité et de gloire à trois jours d'un repos acheté par l'infamie, ces classes auraient en leurs mains le dépôt exclusif de la dignité nationale ! Parce que la corruption les a abruties, elles ne reconnaîtraient au peuple que des appétits de brute, afin de s'arroger le droit de lui dispenser ce qu'il faut d'aliments pour entretenir sa végétation animale qu'elles exploitent !

Ce n'est pas la faim non plus qui, en juillet, a poussé les prolétaires sur la place publique ; ils obéissaient à des sentiments d'une haute moralité, le désir de se racheter de la servitude par un grand service rendu au pays, la haine des Bourbons surtout ! car le peuple n'a jamais reconnu les Bourbons ; il a couvé sa haine quinze ans, épiant en silence l'occasion de se venger ; et, quand sa main puissante a brisé leur joug, elle a cru déchirer en même temps les traités de 1815. C'est que le peuple est un plus profond politique que les hommes d’État ; son instinct lui disait qu'une nation n'a point d'avenir, quand son passé est grevé d'une honte qui n'a point été lavée. La guerre donc! non point pour recommencer d'absurdes conquêtes, mais pour relever la France d'interdiction, pour lui rendre l'honneur, condition première de prospérité; la guerre! afin de prouver aux nations européennes nos sœurs, que, loin de leur garder rancune de l'erreur fatale pour nous et pour elles, qui les conduisit en armes au sein de la France en 1814, nous savions venger elles et nous en châtiant les rois menteurs, et en portant à nos voisins la paix et la liberté ! Voilà ce que voulaient les 30 millions de Français qui ont salué avec enthousiasme l'ère nouvelle.

Voilà ce qui devait sortir de la révolution de Juillet. Elle est venue pour servir de complément à nos quarante années révolutionnaires. Sous la république, le peuple avait conquis la liberté au prix de la famine ; l'empire lui avait donné une sorte de bien-être en le dépouillant de sa liberté. Les deux régimes surent glorieusement rehausser la dignité extérieure, ce premier besoin d'une grande nation. Tout périt en 1815, et cette victoire de l'étranger dura quinze ans. Qu'étaitce donc que le combat de juillet, sinon une revanche de cette longue défaite, et la chaîne de notre nationalité renouée ? Et toute révolution étant un progrès, celle-ci ne devait-elle pas nous assurer la jouissance complète des biens que nous n'avions obtenus jusque-là que partiellement, nous rendre enfin tout ce que nous avions perdu par la Restauration?

Liberté ! bien-être! dignité extérieure ! telle était la devise inscrite sur le drapeau plébéien de 1830. Les doctrinaires y ont lu: Maintien de tous les privilèges ! Charte de 1814 ! quasi légitimité ! En conséquence, ils ont donné au 
peuple la servitude et la misère au-dedans, au-dehors l'infamie. Les prolétaires ne se sont-ils donc battus que pour un changement d'effigie sur ces monnaies qu'ils voient si rarement ? Sommes-nous à ce point curieux de médailles neuves, que nous renversions des trônes pour nous passer cette fantaisie ? C'est l'opinion d'un publiciste ministériel qui assure qu'en juillet nous avons persisté à vouloir la monarchie constitutionnelle, avec la variante de Louis-Philippe à la place de Charles X. Le peuple, selon lui, n'a pris part à la lutte que comme instrument des classes moyennes ; c'est-à-dire que les prolétaires sont des gladiateurs qui tuent et se font tuer pour l'amusement et le profit des privilégiés, lesquels applaudissent des fenêtres... bien entendu la bataille finie. La brochure qui contient ces belles théories de gouvernement représentatif a paru le 20 novembre ; Lyon a répondu le $21^{1}$. La réplique des Lyonnais a paru si péremptoire, que personne n'a plus dit un mot de l'œuvre du publiciste.

Quel abîme les événements de Lyon viennent de dévoiler aux yeux ! Le pays entier s'est ému de pitié à la vue de cette armée de spectres à demi consumés par la faim, courant sur la mitraille pour mourir au moins d'un seul coup.

Et ce n'est pas seulement à Lyon, c'est partout que les ouvriers meurent écrasés par l'impôt. Ces hommes, si fiers naguère d'une victoire qui liait leur avènement sur la scène politique au triomphe de la liberté ; ces hommes auxquels il fallait toute l'Europe à régénérer, ils se débattent contre la faim, qui ne leur laisse plus assez de force pour s'indigner de tant de déshonneur ajouté au déshonneur de la Restauration. Le cri de la Pologne expirante n'a pu même détourner de la contemplation de leurs propres misères, et ils ont gardé ce qui leur reste de larmes pour pleurer sur eux et sur leurs enfants. Quelles souffrances que celles qui ont pu faire oublier si vite les Polonais exterminés !

Voilà la France de juillet telle que les doctrinaires nous l'ont faite. Qui l'eût dit ! dans ces jours d'enivrement, lorsque nous errions machinalement, le fusil sur l'épaule, au travers des rues dépavées et des barricades, tout étourdis de notre triomphe, la poitrine gonflée de bonheur, rêvant la pâleur des rois et la joie des peuples quand viendrait à leurs oreilles le mugissement lointain de notre Marseillaise ; qui l'eût dit que tant de joie et de gloire se changerait en un tel deuil! Qui eût pensé en voyant ces ouvriers grands de six pieds, dont les bourgeois, sortis tremblants de leurs caves, baisaient à l'envi les haillons, et redisaient le désintéressement et le courage avec des sanglots d'admiration, qui eût pensé qu'ils mourraient de misère sur ce pavé, leur conquête, et que leurs admirateurs les appelleraient la plaie de la société !

Ombres magnanimes! glorieux ouvriers, dont ma main a serré la main mourante en signe d'adieu, sur le champ de bataille, dont j'ai voilé avec des haillons le visage agonisant, vous mouriez heureux au sein d'une victoire qui

Il s'agit de la révolte des canuts du 21 novembre 1831, étouffée le 3 décembre par l'armée. 
devait racheter votre race ; et, six mois plus tard, j'ai retrouvé vos enfants au fond des cachots, et chaque soir je m'endormais sur mon grabat, au bruit de leurs gémissements, aux imprécations de leurs bourreaux, et au sifflement du fouet qui faisait taire leurs cris.

Messieurs, n'y a-t-il pas quelque imprudence dans ces outrages prodigués à des hommes qui ont fait l'essai de leur force, et qui se trouvent dans une condition pire que celle qui les poussa au combat? Est-il sage d'apprendre si amèrement au peuple qu'il a été dupe de sa modération dans le triomphe ? Est-on tellement certain de ne plus avoir besoin de la clémence des prolétaires, qu'on puisse, avec pleine sécurité, s'exposer à les trouver impitoyables ? Il semble qu'on ne prenne d'autres précautions contre les vengeances populaires que d'en exagérer d'avance le tableau, comme si cette exagération, les peintures imaginaires de meurtre et de pillage étaient le seul moyen d'en conjurer la réalité. Il est aisé de mettre la baïonnette sur la poitrine à des hommes qui ont rendu leurs armes après la victoire.

Ce qui sera moins facile, c'est d'effacer le souvenir de cette victoire. Voici bientôt dix-huit mois employés à reconstruire pièce à pièce ce qui fut renversé en quarante-huit heures, et les dix-huit mois de réaction n'ont pas même ébranlé l'ouvrage des trois jours. Nulle force humaine ne saurait repousser dans le néant le fait qui s'est accompli. Demandez à celui qui se plaignait d'un effet sans cause, s'il se flatte qu'il puisse y avoir des causes sans effets. La France a conçu dans les embrassements sanglants de six mille héros; l'enfantement peut être long et douloureux ; mais les flancs sont robustes, et les empoisonneurs doctrinaires ne la feront point avorter.

Vous avez confisqué les fusils de Juillet. Oui ; mais les balles sont parties. Chacune des balles des ouvriers parisiens est en route pour faire le tour du monde ; elles frappent incessamment ; elles frapperont jusqu'à ce qu'il n'y ait plus debout un seul ennemi de la liberté et du bonheur du peuple. 


\title{
2. - RAPPORT SUR LA SITUATION INTÉRIEURE, ET EXTÉRIEURE DE LA FRANCE DEPUIS LA RÉVOLUTION DE JUILLET
}

$\underline{\text { Retour à la table des matières }}$

\author{
(DISCOURS PRONONCÉ À LA SÉANCE DU 2 FÉVRIER \\ 1832 DE LA SOCIÉTÉ DES AMIS DU PEUPLE) ${ }^{1}$
}

Il ne faut pas se dissimuler qu'il y a guerre à mort entre les classes qui composent la nation. Cette vérité étant bien reconnue, le parti vraiment national, celui auquel les patriotes doivent se rallier, c'est le parti des masses.

Il y a eu jusqu'ici trois intérêts en France, celui de la classe dite très élevée, celui de la classe moyenne ou bourgeoise, enfin celui du peuple. Je place le peuple en dernier parce qu'il a toujours été le dernier et que je compte sur une prochaine application de la maxime de l'évangile : les derniers seront les premiers.

En 1814 et 1815, la classe bourgeoise fatiguée de Napoléon, non pas à cause du despotisme (elle se soucie peu de la liberté qui ne vaut pas à ses yeux une livre de bonne cannelle ou un billet bien endossé), mais parce que, le sang du peuple épuisé, la guerre commençait à lui prendre ses enfants, et surtout parce qu'elle nuisait à sa tranquillité et empêchait le commerce d'aller, la classe bourgeoise, donc, reçut les soldats étrangers en libérateurs, et les Bourbons comme les envoyés de Dieu. Ce fut elle qui ouvrit les portes de Paris, qui traita de brigands les soldats de Waterloo, qui encouragea les sanglantes réactions de 1815 !

Louis XVIII l'en récompensa par la Charte ${ }^{2}$. Cette Charte constituait les hautes classes en aristocratie et donnait aux bourgeois la Chambre des députés, dite Chambre démocratique. Par là, les émigrés, les nobles et les grands propriétaires, partisans fanatiques des Bourbons, et la classe moyenne qui les acceptait par intérêt se trouvaient maîtres, par portions égales, du gouvernement. Le peuple fut mis de côté. Privé de chefs, démoralisé par l'invasion étrangère, n'ayant plus foi à la liberté, il se tut et subit le joug, en faisant ses réserves. Vous savez l'appui constant que la classe bourgeoise a prêté à la Restauration jusqu'en 1825. Elle

Manuscrits de Blanqui, Bibl. Nat. NAF 9591-I, feuillet 314 et sq.

Après la chute de Napoléon, Louis XVIII fut obligé d'octroyer une Constitution ou Charte (le 4 juin 1814). La Charte transformait la France en une monarchie constitutionnelle où le pouvoir du roi était limité par la Chambre des pairs et par la Chambre des députés qui, à elles deux, représentaient les intérêts des propriétaires fonciers et de la couche supérieure de la bourgeoisie. Un cens élevé limitait le droit de vote à 100000 personnes, le droit à l'éligibilité à 15 ou 16000. 
prêta les mains aux massacres de 1815 et $1816^{1}$, aux échafauds de Borie et de Berton ${ }^{2}$, à la guerre d'Espagne, à l'avènement de Villèle ${ }^{3}$ et au changement de la loi d'élection ; elle ne cessa d'envoyer des majorités dévouées au pouvoir, jusqu'en 1827.

Dans l'intervalle de 1825 à 1827, Charles X, voyant que tout lui réussissait et se croyant assez fort sans les bourgeois, voulut procéder à leur exclusion, comme on avait fait pour le peuple en 1815 ; il fit un pas hardi vers l'ancien régime et déclara la guerre à la classe moyenne en proclamant la domination exclusive de la noblesse, et du clergé sous la bannière du jésuitisme. La bourgeoisie est essentiellement antispirituelle, elle déteste les églises, ne croit qu'aux registres en partie double. Les prêtres l'irritèrent ; elle avait bien consenti à opprimer le peuple de moitié avec les classes supérieures, mais voyant son tour venu aussi, pleine de ressentiment et de jalousie contre la haute aristocratie, elle se rallia à cette minorité de la classe moyenne qui avait combattu les Bourbons depuis 1815 et qu'elle avait sacrifiée jusque-là. Alors commença cette guerre de journaux et d'élections menée avec tant de constance et d'acharnement. Mais les bourgeois combattaient au nom de la Charte, rien que pour la Charte. La Charte, en effet, assurait leur puissance ; fidèlement exécutée, elle leur donnait la suprématie dans l'État. La légalité fut inventée pour représenter cet intérêt de la bourgeoisie et lui servir de drapeau. L'ordre légal devint comme une divinité devant laquelle les opposants constitutionnels brûlaient leur encens quotidien. Cette lutte se poursuivit de 1825 à 1830, toujours plus favorable aux bourgeois qui gagnaient rapidement du terrain et qui, maîtres de la Chambre des députés, menacèrent bientôt le gouvernement d'une complète défaite.

Que faisait cependant le peuple au milieu de ce conflit? Rien. Il restait spectateur silencieux de la querelle et chacun sait bien que ses intérêts ne comptaient pas dans les débats survenus entre ses oppresseurs. Certes, les bourgeois se souciaient peu de lui et de sa cause, qu'on regardait comme perdue depuis quinze ans. Vous vous souvenez que les feuilles les plus dévouées aux constitutionnels répétaient à l'envi que le peuple avait donné sa démission entre les mains des électeurs, seuls organes de la France. Ce n'était pas seulement le gouvernement qui considérait les masses comme indifférentes au débat ; la classe moyenne les méprisait peut-être plus encore et certainement elle comptait recueillir seule les fruits de la victoire. Cette victoire n'allait pas au-delà de la Charte. Charles X et la Charte avec une bourgeoisie toute puissante, tel était le but des constitutionnels. Oui, mais le peuple entendait autrement la question; le peuple se moquait de la Charte et exécrait les Bourbons et, voyant ses maîtres se

\footnotetext{
Il s'agit de la terreur blanche en France, après les Cent-Jours.

BORIE et BERTON. Le général Berton fit, avec le concours de Carbonari, le 24 février 1822, une tentative de renverser les Bourbons. Le coup de force échoua, Berton et quelques autres Carbonari furent exécutés.

3 VILLÈLE : Ultra-royaliste, chef du cabinet de 1821 à1828.
} 
disputer, il épiait en silence le moment de s'élancer sur le champ de bataille et de mettre les partis d'accord.

Quand les classes en vinrent à ce point que le gouvernement n'avait plus de ressources que dans le coup d'État, et que cette menace d'un coup d'État fut suspendue sur la tête des bourgeois, comme la peur les prit ! Qui ne se rappelle les regrets et les terreurs des $221^{1}$, après l'ordonnance de dissolution qui répondit à leur fameuse adresse ? Charles X parlait de sa ferme résolution d'avoir recours à la force et la bourgeoisie pâlissait. Déjà, la plupart désapprouvaient hautement les pauvres 221 de s'être laissé emporter à des excès révolutionnaires. Les plus hardis mettaient leur espoir dans le refus de l'impôt qui eût été bel et bien payé, et dans l'appui des tribunaux qui auraient presque tous et de grand cœur fait l'office de cours prévôtales ${ }^{2}$. Si les royalistes montraient tant de confiance et de résolution, si leurs adversaires laissaient paraître tant de crainte et d'incertitude, c'est que les uns et les autres regardaient le peuple comme démissionnaire et s'attendaient à le trouver neutre dans la bataille. Ainsi, d'un côté, le gouvernement appuyé sur la noblesse, le clergé et les grands propriétaires, de l'autre la classe moyenne, prêts à en venir aux mains, après avoir préludé cinq ans par une guerre de plume et de boules $^{3}$, le peuple silencieux depuis quinze ans et cru démissionnaire.

C'est dans cette situation que le combat s'engage. Les ordonnances sont lancées, et la police brise les presses des journaux. Je ne vous parlerai pas de notre joie à nous, citoyens, qui frémissions sous le joug et qui assistions enfin à ce réveil du lion populaire qui avait dormi si longtemps. Le 26 juillet fut le plus beau jour de notre vie. Mais les bourgeois ! Jamais crise politique n'offrit le spectacle d'une telle épouvante, d'une si profonde consternation. Pâles, éperdus, ils entendaient les premiers coups de feu comme la première décharge du piquet qui devait les fusiller l'un après l'autre. Vous avez tous présente à la mémoire la conduite des députés les lundi, mardi et mercredi. Ce que la peur leur laissait de présence d'esprit et de facultés, ils l'ont employé à prévenir, à arrêter le combat ; dans la préoccupation de leur propre lâcheté, ils se refusaient à prévoir une victoire populaire, et tremblaient déjà sous le couteau de Charles X. Mais, le jeudi, la scène changea. Le peuple est vainqueur. C'est alors une autre terreur qui les saisit, bien autrement profonde et accablante. Adieu, leurs rêves de charte, de légalité, de royauté constitutionnelle, de domination exclusive de la bourgeoisie ! Ce fantôme impuissant de Charles X s'est évanoui. Au travers des débris, des flammes et de la fumée, sur le cadavre de la Royauté, le peuple leur apparaît debout, debout comme un géant, le drapeau tricolore à la main; ils demeurent frappés de stupeur. Oh! c'est alors qu'ils

1 Les deux cent vingt et un députés de l'opposition à la Chambre. En réponse au discours de Charles X du 2 mars 1830, ces députés avaient rédigé une adresse dans laquelle ils protestaient contre les agissements du gouvernement qui ne prenait pas en considération les « désirs du peuple ».

Cours d'exception, à procédure expéditive, créées en 1815 pour juger les délits politiques.

Il s'agit des boules que les députés déposaient dans l'urne pour voter. 
regrettent que la garde nationale n'ait point existé le 26 juillet, qu'ils accusent l'imprévoyance et la folie de Charles X qui a brisé lui-même l'ancre de son salut. Il était trop tard pour ces regrets. Vous voyez que pendant ces jours, où le peuple fut si grand les bourgeois ont été ballottés entre deux peurs, celle de Charles $\mathrm{X}$ d'abord et celle des ouvriers ensuite. Noble et glorieux rôle pour ces fiers guerriers qui font flotter de si hauts panaches dans les parades du Champ de Mars.

Mais, citoyens, comment se fait-il qu'une révélation si soudaine et si redoutable de la force des masses soit demeurée stérile ? Par quelle fatalité, cette révolution faite par le peuple seul et qui devait marquer la fin du régime exclusif de la bourgeoisie ainsi que l'avènement des intérêts et de la puissance populaire, n'a-telle eu d'autre résultat que d'établir le despotisme de la classe moyenne, d'aggraver la misère des ouvriers et des paysans et de plonger la France un peu plus avant dans la boue ? Hélas ! le peuple, comme cet autre ancien ${ }^{1}$, a su vaincre, mais n'a pas su profiter de la victoire. La faute n'en est pas toute à lui. Le combat fut si court que ses chefs naturels, ceux qui auraient donné cours à sa victoire, n'eurent pas le temps de sortir de la foule. Il se rallia forcément aux chefs qui avaient figuré en tête de la bourgeoisie dans la lutte parlementaire contre les Bourbons. D'ailleurs, il savait gré aux classes moyennes de leur petite guerre de cinq ans contre ses ennemis, et vous avez vu quelle bienveillance, je dirai presque quel sentiment de déférence il montrait envers les hommes à habit qu'il rencontrait dans les rues après la bataille. Le cri de "Vive la Charte » dont on a si perfidement abusé n'était qu'un cri de ralliement pour prouver son alliance avec ces hommes. Sentait-il déjà, comme par instinct, qu'il venait de jouer un tour fort désagréable aux bourgeois, et, dans sa générosité de vainqueur, voulait-il faire les avances et offrir paix et amitié à ses futurs adversaires ? Quoi qu'il en soit, les masses n'avaient exprimé formellement aucune volonté politique positive. Ce qui s'agitait en elles, ce lui les avait jetées sur la place publique, c'était la haine des Bourbons, la résolution ferme de les renverser. Il y avait du bonapartisme et de la République dans les vœux qu'elles formaient pour le gouvernement qui devait sortir des barricades.

Vous savez comment le peuple, dans sa confiance aux chefs qu'il avait acceptés et que leurs anciennes hostilités contre Charles $\mathrm{X}$ lui faisaient considérer comme ennemis aussi implacables que lui-même de toute la famille des Bourbons, se retira de la place publique après la bataille terminée. Alors les bourgeois sortirent de leurs caves et s'élancèrent par milliers dans les rues que la retraite des combattants laissait libres. Il n'est personne qui ne se souvienne avec quelle merveilleuse soudaineté la scène changea dans les rues de Paris, comme sur un coup de théâtre, comment les habits remplacent les vestes en un clin d'œil, comme si la baguette d'une fée avait fait disparaître les uns et surgir les autres. C'est que les balles ne sifflaient plus. Il ne s'agissait plus d'attraper les coups, mais de ramasser le butin.

Il s'agit d'Hannibal. 
Chacun son rôle; les hommes des ateliers s'étaient retirés, les hommes du comptoir parurent.

C'est alors que les malheureux auxquels la victoire avait été remise en dépôt, après avoir essayé de replacer Charles $\mathrm{X}$ sur son trône, sentant qu'il y allait de leur vie, et n'ayant point le courage de braver les dangers d'une telle trahison, s'arrêtèrent à une trahison moins périlleuse ; un Bourbon fut proclamé roi ; dix à quinze mille bourgeois installés à demeure dans les cours du nouveau palais, pendant nombre de jours, saluèrent le maître de leurs cris d'enthousiasme, sous la direction des agents payés par l'or royal. Quant au peuple, comme il n'a pas de rentes et n'a pas les moyens de flâner sous les fenêtres des palais, il était dans ses ateliers. Mais il n'a point été complice de cette indigne conspiration qui ne se fût pas accomplie impunément s'il avait trouvé des hommes capables de guider les coups de sa colère et de sa vengeance. Trahi par ses chefs, abandonné des écoles, il s'est tu en faisant ses réserves comme en 1815. Je vous citerai un exemple. Un cocher de cabriolet qui me conduisait samedi dernier, après m'avoir raconté la part qu'il avait prise au combat des trois jours, ajouta : " Je rencontrai sur le chemin de la Chambre la procession des députés qui se dirigeaient vers l'Hôtel de Ville. Je les suivis pour voir ce qu'ils allaient faire. Alors j'ai vu Lafayette paraître sur le balcon avec Louis-Philippe et dire : "Français, voici votre roi ! " Monsieur, quand j'ai entendu ce mot-là, c'est comme si j'avais reçu un coup de poignard. Je n'y voyais plus, je me suis en allé. » Cet homme, c'est le peuple.

Telle est donc la situation des partis immédiatement après la révolution de juillet. La haute classe est écrasée ; la classe moyenne, qui s'est cachée pendant le combat et qui l'a désapprouvé, montrant autant d'habileté qu'elle avait montré de prudence, escamote le fruit de la victoire remportée malgré elle. Le peuple, qui a tout fait, reste zéro comme devant. Mais un fait terrible s'est accompli. Le peuple est entré brusquement comme un coup de tonnerre sur la scène politique qu'il a enlevée d'assaut, et, bien que chassé presque au même instant, il n'en a pas moins fait acte de maître, il a repris sa démission. C'est désormais entre la classe moyenne et lui que va se livrer une guerre acharnée. Ce n'est plus entre les hautes classes et les bourgeois ; ceux-ci auront même besoin d'appeler à leur aide leurs anciens ennemis pour mieux lui résister. En effet, la bourgeoisie n'a plus longtemps dissimulé sa haine contre le peuple...

Que si nous examinons la conduite du gouvernement, il y a dans sa politique la même marche, la même progression de haine et de violence que dans la bourgeoisie dont il représente les intérêts et les passions...

Dans le principe, lorsque les pavés des barricades jonchaient encore les rues, on ne parlait que du programme de l'Hôtel de Ville, des institutions républicaines ; les poignées de main, les proclamations populaires, les grands mots de liberté, 
d'indépendance, de gloire nationale étaient prodigués. Puis, quand le pouvoir a tenu à sa disposition une force militaire organisée, les prétentions ont monté. Toutes les lois, toutes les ordonnances de la Restauration ont été invoquées et appliquées. Plus tard, les poursuites contre la presse, les persécutions contre les hommes de Juillet, le peuple sabré et traqué à coups de baïonnette, les impôts augmentés et perçus avec une rigueur inouïe sous la Restauration, tout ce déploiement de violences, cet appareil de tyrannie ont révélé les haines et les craintes du gouvernement. Mais il sentait bien aussi que le peuple devait lui rendre cette haine et, ne se jugeant pas assez fort avec l'appui de la seule bourgeoisie, il a cherché à rallier à sa cause les hautes classes, afin qu'établi sur cette double base il fût en état de résister avec plus de succès à l'invasion menaçante des prolétaires. C'est à cette manœuvre pour se concilier l'aristocratie qu'il faut rattacher tout le système qu'il a développé depuis dix-huit mois. C'est la clef de sa politique. Or cette haute classe est presque entièrement composée de royalistes. Pour l'entraîner, il était donc nécessaire de se rapprocher le plus possible de la Restauration, de suivre ses errements, de la continuer. C'est ce qu'on a fait. Rien n'a été changé, sauf le nom du roi. On a nié, foulé aux pieds la souveraineté du peuple, la cour a pris le deuil des princes étrangers, on a copié la légitimité en tout et partout. Les royalistes ont été maintenus dans leurs places et ceux qui avaient dû se retirer dans le premier lot de la révolution ont tous retrouvé des positions plus lucratives ; la magistrature a été conservée, de sorte que l'administration entière y est aux mains des hommes dévoués aux Bourbons aînés.

Dans les provinces où les patriotes et les royalistes se trouvent en nombre presque égal, dans le Midi, par exemple, toutes les fois que les deux Partis se sont trouvés en présence, par suite de la faiblesse et de la trahison du gouvernement, le gouvernement est intervenu contre les patriotes en faveur des carlistes ; aujourd'hui enfin, il ne cherche pas à cacher sa haine pour les uns et sa prédilection pour les autres. Il était difficile à l'aristocratie de résister à de si tendres avances.

Aussi, une partie de cette haute classe, la partie la plus pourrie, celle qui veut avant tout de l'or et des plaisirs, a daigné promettre sa protection à l'ordre public. Mais l'autre partie, celle que j'appellerai la moins gangrenée, afin de ne pas prononcer le mot honorable, celle qui a le respect d'elle-même et foi en ses opinions, qui a voué un culte à son drapeau et à ses vieux souvenirs, ceux-là repoussent avec dégoût les caresses du juste milieu. Ils ont derrière eux la plus grande partie des hommes du Midi et de l'Ouest ; tous ces paysans de la Vendée et de la Bretagne qui, demeurés étrangers au mouvement de la civilisation, conservent une foi ardente dans le catholicisme et qui confondent dans leurs adorations le catholicisme et la légitimité avec grande raison, car ce sont deux choses qui ont vécu et qui doivent mourir ensemble. Croyez-vous que ces hommes simples et croyants soient accessibles aux séductions des banquiers? Non, citoyens! Car le peuple, soit que, dans son ignorance, il soit enflammé du fanatisme de la religion, soit que, plus éclairé, il se laisse emporter par l'enthousiasme de la liberté, le peuple est toujours grand et généreux : il n'obéit 
point à des vils intérêts d'argent, mais aux plus nobles passions de l'âme, aux inspirations d'une moralité élevée. Eh bien ! la Bretagne et la Vendée, quelque ménagement et quelque déférence qu'on garde pour elles, sont encore prêtes à se lever au cri de " Dieu et le Roi » et menacent le gouvernement de leurs armées catholiques et royales dont le premier choc le briserait. Ce n'est pas tout, la fraction des hautes classes qui s'est rattachée au juste milieu l'abandonnera au premier moment. Tout ce qu'elle a promis, c'est de ne point travailler à le renverser ; pour du dévouement, vous savez s'il est possible d'en avoir pour des rogneurs d'espèces. Je dirai plus, la majeure partie des bourgeois qui se pressent, qui se groupent autour du gouvernement, par haine du peuple qu'ils redoutent, par effroi de la guerre qui les épouvante, puisqu'ils s'imaginent qu'elle leur prendra leurs écus, ces bourgeois n'aimant que médiocrement l'ordre actuel, ils le sentent impuissant à les protéger : vienne le drapeau blanc qui leur garantira l'oppression du peuple et la sécurité matérielle, et ils sont prêts à sacrifier leurs anciennes prétentions politiques, car ils se repentent durement d'avoir, par amour-propre, miné le pouvoir des Bourbons et préparé leur chute. Ils abdiqueront leur part du pouvoir entre les mains de l'aristocratie, troquant volontiers la tranquillité contre la servitude.

Car le gouvernement de Louis-Philippe ne les rassure guère. Il a beau copier la Restauration, persécuter les patriotes, s'appliquer à effacer la tache d'insurrection dont il est souillé aux yeux des adorateurs de l'ordre public : le souvenir de ces terribles trois jours le poursuit, le domine, dix-huit mois d'une guerre faite contre le peuple avec succès n'ont pu contre-balancer une seule victoire du peuple; le champ de bataille est encore à lui et cette victoire déjà vieille est suspendue sur la tête du pouvoir comme l'épée de Damoclès ; chacun regarde si le fil ne va pas bientôt se briser.

Citoyens, deux principes se partagent la France, le principe de la légitimité et celui de la souveraineté du peuple. Le premier, c'est la vieille organisation du passé, ce sont les cadres dans lesquels la société a vécu quatre cents ans et que les uns veulent conserver par l'instinct de leur propre salut, les autres parce qu'ils craignent que les cadres ne puissent être promptement remplacés et que l'anarchie ne suive leur dissolution. Le principe de la souveraineté du peuple rallie tous les hommes d'avenir, les masses qui, fatiguées d'être exploitées, cherchent à briser ces cadres dans lesquels elles se sentent étouffer. Il n'y a pas de troisième drapeau, de terme moyen. Le juste milieu est une niaiserie, un gouvernement bâtard qui veut se donner des airs de légitimité dont on ne fait que rire. Ainsi, les royalistes, qui comprennent parfaitement cette situation, profitent les ménagements et des complaisances du pouvoir qui cherche à les amener à lui, pour travailler plus activement à sa perte. Leurs nombreux journaux démontrent chaque jour qu'il n'y a d'ordre possible qu'avec la légitimité, que le juste milieu est impuissant à constituer le pays, que, hors de la légitimité, il n'y a que la révolution et qu'une fois sorti du premier principe il faut nécessairement tomber dans le second. Qu'arrivera-t-il de là ? Les hautes classes n'attendent que le moment de relever le drapeau blanc. Dans la classe moyenne, la grande majorité composée de ces 
hommes qui n'ont de patrie que leur comptoir ou leur caisse, qui se feraient de grand cœur Russes, Prussiens, Anglais pour gagner deux liards sur une pièce de toile ou un quart pour cent de bénéfice de plus sur un escompte, se rangera infailliblement sous le drapeau blanc; le seul nom de guerre et de souveraineté du peuple les fait frémir. La minorité de cette classe, formée des professions intellectuelles et du petit nombre de bourgeois qui aiment le drapeau tricolore, le symbole de l'indépendance et de la liberté de la France, prendra parti pour la souveraineté du peuple.

Au reste, le moment de la catastrophe approche rapidement. Vous voyez que la Chambre des pairs, la magistrature et la plupart des fonctionnaires publics conspirent ouvertement le retour d'Henri V, en se moquant du juste milieu. Les gazettes légitimistes ne cachent plus ni les espérances, ni les projets de la contrerévolution. Les royalistes, à Paris et dans les provinces, rassemblent leurs forces, organisent la Vendée, leur Bretagne, le Midi, et plantent fièrement leur bannière. Ils disent tout haut que la bourgeoisie est pour eux, et ils ne se trompent pas. Ils n'attendent qu'un signal de l'étranger pour relever le drapeau blanc. Car, sans l'étranger, ils seraient écrasés par le peuple, ils le savent, et nous comptons bien, nous, qu'ils seront écrasés, même avec l'appui de l'étranger.

Cet appui, soyez-en persuadés, citoyens, ne leur manquera pas. C'est ici le lieu de jeter un coup d'œil sur nos relations avec les puissances de l'Europe. Remarquez en effet que la situation extérieure s'est développée parallèlement à la marche politique du gouvernement à l'intérieur. La honte du dehors a grandi dans la même proportion exactement que le despotisme bourgeois et la misère des masses au dedans.

Au premier bruit de notre révolution, les rois perdirent la tête, et, l'étincelle électrique de l'insurrection ayant embrasé rapidement la Belgique, la Pologne, l'Italie, ils se crurent sincèrement à leur dernier jour. Comment imaginer aussi que la révolution ne serait pas une révolution, que l'expulsion des Bourbons ne serait pas l'expulsion des Bourbons, que le renversement de la Restauration serait une nouvelle édition de la Restauration ? Cela ne pouvait entrer dans la tête la plus folle. Les Cabinets virent dans les trois journées le réveil du peuple français, et le commencement de sa vengeance contre les oppresseurs des nations. Les nations jugèrent comme les Cabinets. Mais, pour nos amis comme pour nos ennemis, il fut bientôt évident que la France était tombée entre les mains de lâches marchands qui ne demandaient qu'à trafiquer de son indépendance et à vendre sa gloire et sa liberté au meilleur prix possible. Tandis que les rois attendaient notre déclaration de guerre, ils reçurent des lettres suppliantes dans lesquelles le gouvernement français implorait le pardon de sa faute. Le nouveau maître s'excusait d'avoir participé malgré lui à la révolte, protestait de son innocence et de sa haine contre la révolution, qu'il promettait de dompter, de châtier, d'écraser, si ses bons amis les 
rois voulaient lui promettre leur protection, une petite place dans la SainteAlliance dont il serait le très dévoué serviteur.

Les Cabinets étrangers comprirent que le peuple n'était pas complice de cette trahison et qu'il ne tarderait pas à en faire justice. Leur parti fut pris. Exterminer les insurrections qui avaient éclaté en Europe, et, quand tout serait rentré dans l'ordre, réunir leurs forces contre la France et venir étrangler dans Paris même la révolution et le génie révolutionnaire. Ce plan a été suivi avec une constance et une habileté admirables. Il ne fallait pas aller trop vite, parce que le peuple de Juillet, tout plein encore de son récent triomphe, aurait pris l'alarme à une menace trop directe et forcé les mains à son gouvernement. D'ailleurs, il était nécessaire d'accorder un temps au juste milieu pour amortir l'enthousiasme, décourager les patriotes et jeter la défiance et la discorde dans la nation. Il ne fallait pas non plus aller trop lentement, car les masses pouvaient se lasser de la servitude et de la misère qui pesaient sur elles au dedans et briser une seconde fois le joug, avant que l'étranger fût en mesure.

Tous ces écueils ont été évités. Les Autrichiens ont envahi l'Italie; les bourgeois qui nous gouvernent ont crié : «Bien!» et se sont inclinés devant l'Autriche. Les Russes ont exterminé la Pologne. Notre gouvernement a crié : « Très bien ! » et s'est prosterné devant la Russie. Pendant ce temps, la conférence de Londres amusait le tapis avec ses protocoles destinés à assurer l'indépendance de la Belgique. Car une restauration en Belgique aurait fait ouvrir les yeux à la France et elle eût été en mesure de défendre son ouvrage. Maintenant, les rois font un pas en avant. Ils ne veulent plus de la Belgique indépendante; c'est la restauration hollandaise qu'ils prétendent lui imposer. Les trois cours du Nord, levant le masque, refusent de ratifier le fameux traité qui a coûté seize mois de travail à la conférence.

Eh bien ! le juste milieu va-t-il répondre par une déclaration de guerre à cette insolente agression? La guerre Bon Dieu! Ce mot fait pâlir les bourgeois. Entendez-les ! La guerre, c'est la banqueroute, la guerre, c'est la République ! On ne peut soutenir la guerre qu'avec le sang du peuple ; la bourgeoisie ne s'en mêle pas. Il faudrait donc faire appel à ses intérêts, à ses passions, au nom de la liberté et de l'indépendance de la patrie ! Il faudrait remettre dans ses mains le pays que lui seul pourrait sauver. Plutôt cent fois voir les Russes à Paris, que de déchaîner les passions de la multitude. Les Russes sont amis de l'ordre au moins; ils ont rétabli l'ordre dans Varsovie... Voilà le calcul et le langage du juste milieu...

Les royalistes se tiendront prêts et, au printemps prochain, les Russes en franchissant la frontière trouveront leurs logements réparés jusqu'à Paris. Car soyez persuadés que, dans le moment même, la classe bourgeoise ne se résoudra pas à la guerre. Sa terreur sera augmentée de toute la crainte que lui inspirera la colère du peuple trahi et vendu, et vous verrez les marchands arborer la cocarde 
blanche et recevoir l'ennemi en libérateur parce que les cosaques l'effraient moins que la canaille en veste...

Voilà le sort qui nous attend, si le peuple ne retrouve pas son énergie pour punir les traîtres. Mais, citoyens, un peuple ne fait pas une révolution sans un grand motif. Il faut un puissant levier pour le mettre debout; il n'a recours à l'insurrection qu'au dernier moment, quand le danger est aux portes. Je le dis avec douleur, la Belgique sera restaurée sans que les masses se mettent en mouvement. Mais j'en ai la ferme confiance, si l'étranger franchit nos frontières, le peuple ne tendra pas les mains aux fers et malheur à nos ennemis !...

La France a encore quatorze armées à lancer sur l'Europe des rois, et de plus, l'Europe des peuples est de notre côté.

\section{3. - QUI FAIT LA SOUPE DOIT LA MANGER * (1834) ${ }^{1}$}

$\underline{\text { Retour à la table des matières }}$

La richesse naît de l'intelligence et du travail, l'âme et la vie de l'humanité. Mais ces deux forces ne peuvent agir qu'à l'aide d'un élément passif, le sol, qu'elles mettent en œuvre par leurs efforts combinés. Il semble donc que cet instrument indispensable devrait appartenir à tous les hommes. Il n'en est rien.

Des individus se sont emparés par ruse ou par violence de la terre commune, et, s'en déclarant les possesseurs, ils ont établi par des lois qu'elle serait à jamais leur propriété, et que ce droit de propriété deviendrait la base de la constitution sociale, c'est-à-dire qu'il primerait et au besoin pourrait absorber tous les droits humains, même celui de vivre, s'il avait le malheur de se trouver en conflit avec le privilège du petit nombre.

Ce droit de propriété s'est étendu, par déduction logique, du sol à d'autres instruments, produits accumulés du travail, désignés par le nom générique de capitaux. Or, comme les capitaux, stériles d'eux-mêmes, ne fructifient que par la main-d'œuvre, et que, d'un autre côté, ils sont nécessairement la matière première ouvrée par les forces sociales, la majorité, exclue de leur possession, se trouve condamnée aux travaux forcés, au profit de la minorité possédante. Les instruments ni les fruits du travail n'appartiennent pas aux travailleurs, mais aux

Article destiné au numéro du Libérateur de mars 1834, qui n'a pas paru. L'article est retouché. (Note de Blanqui.)

Voir Critique sociale, t. II, 118-128. 
oisifs. Les branches gourmandes absorbent la sève de l'arbre, au détriment des rameaux fertiles. Les frelons dévorent le miel créé par les abeilles.

Tel est notre ordre social, fondé par la conquête, qui a divisé les populations en vainqueurs et en vaincus. La conséquence logique d'une telle organisation, c'est l'esclavage. Il ne s'est pas fait attendre. En effet, le sol ne tirant sa valeur que de la culture, les privilégiés ont conclu, du droit de posséder le sol, celui de posséder aussi le bétail humain qui le féconde. Ils l'ont considéré d'abord comme le complément de leur domaine, puis, en dernière analyse, comme une propriété personnelle, indépendante du sol.

Cependant le principe d'égalité, gravé au fond du cœur, et qui conspire, avec les siècles, à détruire, sous toutes ses formes, l'exploitation de l'homme par l'homme, porta le premier coup au droit sacrilège de propriété, en brisant l'esclavage domestique. Le privilège dut se réduire à posséder les hommes, non plus à titre de meuble, mais d'immeuble annexe et inséparable de l'immeuble territorial.

$\mathrm{Au} \mathrm{XVI}^{\mathrm{e}}$ siècle, une recrudescence meurtrière de l'oppression amène l'esclavage des noirs, et aujourd'hui encore les habitants d'une terre réputée française possèdent des hommes au même titre que des habits et des chevaux. Il y a du reste moins de différence qu'il ne paraît d'abord entre l'état social des colonies et le nôtre. Ce n'est pas après dix-huit siècles de guerre entre le privilège et l'égalité que le pays, théâtre et champion principal de cette lutte, pourrait supporter l'esclavage dans sa nudité brutale. Mais le fait existe sans le nom, et le droit de propriété, pour être plus hypocrite à Paris qu'à la Martinique, n'y est ni moins intraitable, ni moins oppresseur.

La servitude, en effet, ne consiste pas seulement à être la chose de l'homme ou le serf de la glèbe. Celui-là n'est pas libre qui, privé des instruments de travail, demeure à la merci des privilégiés qui en sont détenteurs. C'est cet accaparement et non telle ou telle constitution politique qui fait les masses serves. La transmission héréditaire du sol et des capitaux place les citoyens sous le joug des propriétaires. Ils n'ont d'autre liberté que celle de choisir leur maître.

De là sans doute cette locution railleuse : "Les riches font travailler les pauvres. " À peu près, en effet, comme les planteurs font travailler leurs nègres, mais avec un peu plus d'indifférence pour la vie humaine. Car l'ouvrier n'est pas un capital à ménager comme l'esclave ; sa mort n'est pas une perte ; il y a toujours concurrence pour le remplacer. Le salaire, quoique suffisant à peine pour empêcher de mourir, a la vertu de faire pulluler la chair exploitée ; il perpétue la lignée des pauvres pour le service des riches, continuant ainsi, de génération en génération, ce double héritage parallèle d'opulence et de misère, de jouissances et de douleurs, qui constitue les éléments de notre société. Quand le prolétaire a suffisamment souffert et laissé des successeurs pour souffrir après lui, il va, dans 
un hôpital, fournir son cadavre à la science, comme moyen d'études, pour guérir ses maîtres.

Voilà les fruits de l'appropriation des instruments de travail ! Pour les masses, des labeurs incessants, à peine l'obole de la journée, jamais de lendemain sûr, et la famine, si un caprice de colère ou de peur retire ces instruments ! Pour les privilégiés, l'autocratie absolue, le droit de vie et de mort ! car ils ont les mains pleines, ils peuvent attendre. Avant que l'épuisement de leur réserve les contraigne à capituler, le dernier plébéien serait mort.

Qui ne se rappelle les misères de 1831, quand le capital s'est caché par crainte ou par vengeance ? Du fond de leur fromage de Hollande les barons du coffre-fort contemplaient froidement les angoisses de ce peuple décimé par la faim, en récompense de son sang versé au service de leurs vanités bourgeoises. Les représailles de la grève sont impossibles.

Les ouvriers de Lyon viennent de les tenter ${ }^{1}$. Mais à quel prix ! Soixante mille hommes ont dû fléchir devant quelques douzaines de fabricants et demander grâce. La faim a dompté la révolte. Et n'est-ce pas un miracle même que cette velléité de résistance ? Que de souffrances n'a-t-il pas fallu pour lasser la patience de ce peuple et le raidir enfin contre l'oppression !

Le pauvre ne connaît pas la source de ses maux. L'ignorance, fille de l'asservissement, fait de lui un instrument docile des privilégiés. Écrasé de labeur, étranger à la vie intellectuelle, que peut-il savoir de ces phénomènes sociaux où il joue le rôle de bête de somme ? Il accepte comme un bienfait ce qu'on daigne lui laisser du fruit de ses sueurs, et ne voit dans la main qui l'exploite que la main qui le nourrit, toujours prêt, sur un signe du maître, à déchirer le téméraire qui essaie de lui montrer une destinée meilleure.

Hélas! l'humanité marche avec un bandeau sur les yeux, et ne le soulève qu'à de longs intervalles pour entrevoir sa route. Chacun de ses pas dans la voie du progrès écrase le guide qui le lui fait faire. Toujours ses héros ont commencé par être ses victimes. Les Gracques sont mis en pièces par une tourbe ameutée à la voix des patriciens. Le Christ expire sur la croix, aux hurlements de joie de la populace juive excitée par les Pharisiens et les prêtres et, naguère, les défenseurs de l'égalité sont morts sur l'échafaud de la Révolution par l'ingratitude et la stupidité du peuple, qui a laissé la calomnie vouer leur mémoire à l'exécration. Aujourd'hui encore, les stipendiés du privilège enseignent chaque matin aux Français à cracher sur la tombe de ces martyrs.

Qu'il est difficile au prolétariat d'ouvrir les yeux sur ses oppresseurs ! Si à Lyon il s'est levé comme un seul homme, c'est que l'antagonisme flagrant des intérêts ne

Il s'agit de la révolte des canuts du mois d'avril 1834. 
permettait plus l'illusion à l'aveuglement même le plus obstiné. Alors se sont révélés les trésors de haine et de férocité que recèlent les âmes de ces marchands ! $\mathrm{Au}$ milieu des menaces de, carnage, de toutes parts accouraient pour l'extermination canons, caissons, chevaux, soldats. Rentrer dans le devoir ou périr sous la mitraille, telle est l'alternative posée aux rebelles. Le devoir du travailleur lyonnais, l'homme-machine, c'est de pleurer la faim, en créant jour et nuit, pour les plaisirs du riche, des tissus d'or, de soie et de larmes.

Mais une si dure tyrannie a ses dangers: le ressentiment, la révolte. Pour conjurer le péril, on essaie de réconcilier Caïn avec Abel. De la nécessité du capital comme instrument de travail, on s'évertue à conclure la communauté d'intérêts, et par la suite la solidarité entre le capitaliste et le travailleur. Que de phrases artistement brodées sur ce canevas fraternel ! La brebis n'est tondue que pour le bien de sa santé. Elle redoit des remerciements. Nos Esculapes savent dorer la pilule.

Ces homélies trouvent encore des dupes, mais peu. Chaque jour fait plus vive la lumière sur cette prétendue association du parasite et de sa victime. Les faits ont leur éloquence ; ils prouvent le duel, le duel à mort entre le revenu et le salaire. Qui succombera? Question de justice et de bon sens. Examinons.

Point de société sans travail ! partant point d'oisifs qui n'aient besoin des travailleurs. Mais quel besoin les travailleurs ont-ils des oisifs ? Le capital n'est-il productif entre leurs mains, qu'à la condition de ne pas leur appartenir ? Je suppose que le prolétariat, désertant en masse, aille porter ses pénates et ses labeurs dans quelque lointain parage. Mourrait-il par hasard de l'absence de ses maîtres ? La société nouvelle ne pourrait-elle se constituer qu'en créant des seigneurs du sol et du capital, en livrant à une caste d'oisifs la possession de tous les instruments de travail ? N'y a-t-il de mécanisme social possible que cette division de propriétaires et de salariés?

En revanche, combien serait curieuse à voir la mine de nos fiers suzerains, abandonnés par leurs esclaves ! Que faire de leurs palais, de leurs ateliers, de leurs champs déserts? Mourir de faim au milieu de ces richesses, ou mettre habit bas, prendre la pioche et suer humblement à leur tour sur quelque lopin de terre. Combien en cultiveraient-ils à eux tous ? J'imagine que ces messieurs seraient au large dans une sous-préfecture.

Mais un peuple de trente-deux millions d'âmes ne se retire plus sur le Mont Aventin. Prenons donc l'hypothèse inverse, plus réalisable. Un beau matin, les oisifs, nouveaux Bias, évacuent le sol de France, qui reste aux mains laborieuses. Jour de bonheur et de triomphe ! Quel immense soulagement pour tant de millions de poitrines, débarrassées du poids qui les écrase ! Comme cette multitude respire à plein poumon! Citoyens, entonnez en chœur le cantique de la délivrance ! 
Axiome : la nation s'appauvrit de la perte d'un travailleur; elle s'enrichit de celle d'un oisif ${ }^{1}$. La mort d'un riche est un bienfait.

Oui ! le droit de propriété décline. Les esprits généreux prophétisent et appellent sa chute. Le principe essénien de l'égalité le mine lentement depuis dixhuit siècles par l'abolition successive des servitudes qui formaient les assises de sa puissance. Il disparaîtra un jour avec les derniers privilèges qui lui servent de refuge et de réduit. Le présent et le passé nous garantissent ce dénouement. Car l'humanité n'est jamais stationnaire. Elle avance ou recule. Sa marche progressive la conduit à l'égalité. Sa marche rétrograde remonte, par tous les degrés du privilège. Jusqu'à l'esclavage personnel, dernier mot du droit de la propriété. Avant d'en retourner là, certes, la civilisation européenne aurait péri. Mais par quel cataclysme ? Une invasion russe ? C'est le Nord, au contraire, qui sera lui-même envahi par le principe d'égalité que les Français mènent à la conquête des nations. L'avenir n'est pas douteux.

Disons tout de suite que l'égalité n'est pas le partage agraire. Le morcellement infini du sol ne changerait rien, dans le fond, au droit de propriété. La richesse provenant de la possession des instruments de travail plutôt que du travail luimême, le génie de l'exploitation, resté debout, saurait bientôt, par la reconstruction des grandes fortunes, restaurer l'inégalité sociale.

L'association, substituée à la propriété individuelle, fondera seule le règne de la justice par l'égalité. De là cette ardeur croissante des hommes d'avenir à dégager et mettre en lumière les éléments de l'association. Peut-être apporterons-nous aussi notre contingent à l'œuvre commune.

1 Réminiscence de la Parabole de Saint-Simon. Cf. SAINT-SIMON : Textes choisis (Classiques du Peuple). 


\section{APPENDICE}

\section{1. - APPEL DE BLANQUI AUX ÉTUDIANTS (11 DÉCEMBRE 1830)}

$\underline{\text { Retour à la table des matières }}$

Aux Étudiants en Médecine et en Droit,

Benjamin Constant est mort ${ }^{1}$. La France pleure un des plus fermes soutiens de sa liberté, un grand citoyen et un grand homme. Nous, c'est un ami que nous pleurons. Vous savez quels accents sa voix a trouvés pour repousser les calomnies et les outrages que déversait sur nous un pouvoir oppresseur. Vous savez quelles brûlantes paroles il fit entendre en 1820, 1821, 1822 et 1827, quand, non content de nous dévouer au sabre de ses satellites, le pouvoir nous insultait à la tribune et dans ses journaux. Benjamin Constant se faisait gloire d'être l'ami des jeunes gens. Jusqu'à son dernier moment, il a élevé la voix pour nous défendre, car la jeunesse française de même que la liberté ont eu besoin d'être défendues, même après la bataille de la grande semaine ${ }^{2}$. Cinq jours avant de mourir, il faisait encore retentir la tribune de patriotiques accents ; il est mort sur la brèche en combattant pour les principes et pour les résultats de notre révolution. Un peuple tout entier accompagnera jusqu'au dernier séjour les restes mortels du défenseur de ses droits. Les Écoles doivent à leur ami un deuil particulier, un hommage solennel de reconnaissance. J'invite tous mes camarades à se réunir sur la place du Panthéon, dimanche ${ }^{3}$ à neuf heures précises du matin. Ceux d'entre eux qui possèdent des armes viendront armés, afin de rendre à Benjamin Constant les honneurs funèbres.

\section{Louis-Auguste BLANQUI Étudiant en droit.}

$P$. S. - Le général Lafayette a déclaré approuver cette réunion; un de ses officiers d'état-major se rendra demain ${ }^{4}$ au milieu de nous.

\footnotetext{
Le vendredi 10 décembre 1830.

Allusion aux journées de juillet.

Dimanche 12 décembre 1830.

Ce placard, dont un exemplaire est conservé à la Bibliothèque Nationale, a donc été imprimé et apposé le samedi 11 décembre 1830.
} 


\section{2. - FORMULAIRE DE RÉCEPTION À LA SOCIÉTÉ DES SAISONS ${ }^{1}$ (1830)}

$\underline{\text { Retour à la table des matières }}$

Le récipiendaire est introduit les yeux bandés.

Le président au présentateur. - Quel est le nom du nouveau frère que tu nous amènes ? ...

Au récipiendaire. - Citoyen (...), quel est ton âge ? ta profession ? le lieu de ta naissance ? ton domicile ? Quels sont tes moyens d'existence?

As-tu réfléchi à la démarche que tu fais en ce moment, sur l'engagement que tu viens de contracter ? Sais-tu bien que les traîtres sont frappés de mort ?

Jure donc, citoyen, de ne révéler à personne rien de ce qui se passera dans ce lieu.

Le président pose les questions suivantes. - 1. Que penses-tu de la royauté et des rois ? - Qu'ils sont aussi dangereux pour le genre humain que le tigre pour les autres animaux. - 2. Quels sont maintenant les aristocrates ? - L'aristocratie de naissance a été abolie en juillet 1830. Elle a été remplacée par l'aristocratie d'argent, qui est aussi vorace que la précédente. - 3. Faut-il se contenter de renverser la royauté ? - Il faut renverser tous les aristocrates, abolir tous les privilèges. - 4. Que devons-nous mettre à sa place ? - Le gouvernement du peuple par lui-même, c'est-à-dire la république. - 5. Ceux qui ont des droits sans remplir des devoirs, comme maintenant les aristocrates, font-ils partie du peuple ? - Ils ne devraient point en faire partie ; ils sont pour le corps social ce qu'est un cancer pour le corps humain : la première condition du retour du corps social à l'état juste est l'anéantissement de l'aristocratie. - 6. Immédiatement après la révolution, le peuple pourrait-il se gouverner lui-même ? - L'état social étant gangrené, pour passer à un état sain, il faut des remèdes héroïques ; le peuple aura besoin, pendant quelque temps, d'un pouvoir révolutionnaire. - 7. En résumé, quels sont tes principes ? -Qu'il faut exterminer la royauté et toutes les aristocraties, substituer à

1 Nous donnons ici deux documents relatifs aux sociétés secrètes de la fin des années 1830. Les auteurs en sont inconnus. Toutefois, ces documents reflètent les idées politiques et sociales professées par Blanqui pendant cette période. Les textes sont tirés du Rapport à la Cour. Affaire du 12 et 13 mai, Réquisitoire de M. Franck Carré, procureur général du roi, p. 40-42.

La structure de la Société des Saisons était la suivante: la cellule de base, appelée la "semaine" comprenait 6 hommes et un chef qui, seul, connaissait les chefs de 3 autres « semaines »; 4 semaines formaient un mois et groupaient ainsi 28 hommes; seul le chef de ce groupe, une 29e personne, connaissait les chefs de 2 autres mois; 3 mois constituaient une "saison » à la tête de laquelle il y avait un homme qui, seul, connaissait les chefs des autres saisons. Quatre saisons formaient une année, dont le chef s'appelait « agent de la révolution ». Il y avait à Paris 3 « années » présidées par Blanqui, Barbès et Martin-Bernard (triumvirat secret). 
leur place la république, c'est-à-dire le gouvernement de l'égalité ; mais, pour passer à ce gouvernement, employer un pouvoir révolutionnaire, qui mette le peuple à même d'exercer ses droits.

Citoyen, les principes que tu viens d'énoncer sont les seuls justes, les seuls qui puissent faire marcher l'humanité vers le but qui lui est fixé ; mais leur réalisation n'est pas facile. Nos ennemis sont nombreux et puissants ; ils ont à leur disposition toutes les forces sociales : nous, républicains, notre nom même est proscrit; nous n'avons que notre courage et notre bon droit. Réfléchis, il est temps encore, sur tous les dangers auxquels tu te voues en entrant dans nos rangs. Le sacrifice de la fortune, la perte de la liberté, la mort peut-être, es-tu décidé à les braver?

Ta réponse nous est la preuve de ton énergie. Lève-toi, citoyen, et prête le serment suivant :

« Au nom de la république, je jure haine éternelle à tous les rois, à tous les aristocrates, tous les oppresseurs de l'humanité. Je jure dévouement absolu au peuple, fraternité à tous les hommes, hors les aristocrates, je jure de punir les traîtres; je promets de donner ma vie, de monter même sur l'échafaud, si ce sacrifice est nécessaire pour amener le règne de la souveraineté du peuple et de l'égalité. »

Le président lui met un poignard à la main.

"Que je sois puni de la mort des traîtres, que je sois percé de ce poignard si je viole ce serment. Je consens être traité comme un traître, si je révèle la moindre chose à quelque individu que ce soit, même à mon plus proche parent, s'il n'est point membre de l'association. »

Le président. - Citoyen, assieds-toi ; la Société reçoit ton serment ; maintenant tu fais partie de l'association, travaille avec nous à l'affranchissement du peuple.

Citoyen, ton nom ne sera point prononcé parmi nous, voici ton numéro d'inscription dans l'atelier. Tu dois te pourvoir d'armes, de munitions. Le Comité qui dirige la Société restera inconnu jusqu'au moment où nous prendrons les armes. Citoyen, un de tes devoirs est de répandre les principes de l'association. Si tu connais des citoyens dévoués et discrets, tu dois nous les présenter.

Le récipiendaire est rendu à la lumière. 


\section{3. - APPEL DU COMITÉ DE LA SOCIÉTÉ DES SAISONS (12 MAI 1839)}

$\underline{\text { Retour à la table des matières }}$

Aux armes, citoyens !

L'heure fatale a sonné pour les oppresseurs.

Le lâche tyran des Tuileries se rit de la faim qui déchire les entrailles du peuple; mais la mesure de ses crimes est comble. Ils vont enfin recevoir leur châtiment.

La France trahie, le sang de nos frères égorgés, crie vers vous, et demande vengeance ; qu'elle soit terrible, car elle a trop tardé. Périsse enfin l'exploitation et que l'égalité s'asseye triomphante sur les débris confondus de la royauté et de l'aristocratie.

Le gouvernement provisoire a choisi des chefs militaires pour diriger le combat ; ces chefs sortent de vos rangs, suivez-les ! ils vous mènent à la victoire.

Sont nommés :

Auguste Blanqui, commandant en chef. Barbès, Martin-Bernard, Quignot, Meillard, Nétré, commandants des divisions de l'armée républicaine.

Peuple, lève-toi ! et tes ennemis disparaîtront comme la poussière devant l'ouragan. Frappe, extermine sans pitié les vils satellites, complices volontaires de la tyrannie ; mais tends la main à ces soldats sortis de ton sein, et qui ne tourneront point contre toi des armes parricides.

En avant! Vive la République!

Les membres du gouvernement provisoire:

BARBÈS, VOYER, D'ARGENSON, AUGUSTE BLANQUI, LAMENNAIS, MARTINBERNARD, DUBOSC, LAPONERAYE

Paris, le 12 mai 1839. 


\section{II \\ BLANQUI \\ SOUS LA SECONDE RÉPUBLIQUE (1848-1852)}

\section{1. - DISCOURS DU 25 FÉVRIER $1848{ }^{1}$}

$\underline{\text { Retour à la table des matières }}$

... La France n'est pas républicaine, la révolution qui vient de s'accomplir est une surprise heureuse, rien de plus. Si nous voulons aujourd'hui porter au pouvoir des noms compromis aux yeux de la bourgeoisie par des condamnations politiques, la province aura peur; elle se souviendra de la Terreur et de la Convention et rappellera peut-être le roi fugitif. La garde nationale elle-même n'a été qu'une complice involontaire ; elle est composée de boutiquiers peureux qui demain pourraient bien défaire ce qu'ils ont laissé faire aux cris de: Vive la République !... Abandonnez les hommes de l'Hôtel de Ville à leur impuissance : leur faiblesse est le signe certain de leur chute. Ils ont entre leurs mains un pouvoir éphémère; nous, nous avons le peuple et les clubs où nous l'organiserons révolutionnairement, comme jadis les jacobins l'organisèrent. Sachons attendre quelques jours encore, et la révolution nous appartiendra! Si nous nous emparons du pouvoir par un audacieux coup de main, comme des voleurs au milieu des ténèbres de la nuit,, qui nous répondra de la durée de notre puissance ? Au-dessous de nous n'y aurait-il pas des hommes énergiques et ambitieux qui brûleront de nous remplacer par de semblables moyens ? Ce qu'il nous faut à nous, c'est le peuple immense, les faubourgs insurgés, un nouveau 10 août. Nous aurons au moins le prestige de la force révolutionnaire.

Mss Blanqui, Bibl. Nat., N.A.F. 9590, liasse II, chemise 13, feuillet 474. Discours prononcé par Blanqui au club du Prado devant 500 citoyens prêts à s'insurger contre le gouvernement provisoire. C'est au cours de cette réunion que le club prit le nom de Société Républicaine Centrale. 


\section{2. - POUR LE DRAPEAU ROUGE (26 FÉVRIER 1848) ${ }^{1}$}

Retour à la table des matières

Nous ne sommes plus en 93 ! Nous sommes en 1848 ! Le drapeau tricolore n'est pas le drapeau de la République; il est celui de Louis-Philippe et de la monarchie.

C'est le drapeau tricolore qui présidait aux massacres de la rue Transnonain ${ }^{2}$, du faubourg de Vaise, de Saint-Étienne. Il s'est baigné vingt fois dans le sang des ouvriers.

Le peuple a arboré les couleurs rouges sur les barricades de 48, comme il les avait arborées sur celles de juin 1832, d'avril 1834, de mai 1839. Elles ont reçu la double consécration de la défaite et de la victoire. Ce sont désormais les siennes.

Hier encore, elles flottaient glorieusement au front de nos édifices.

Aujourd'hui la réaction les renverse ignominieusement dans la boue et ose les flétrir de ses calomnies.

On dit que c'est un drapeau de sang. Il n'est rouge que du sang des martyrs qui l'a fait l'étendard de la République.

Sa chute est un outrage au peuple, une profanation de ses morts. Le drapeau de la garde municipale ombragera leurs tombes.

Déjà la réaction se déchaîne. On la reconnaît à ses violences. Les hommes de la faction royaliste parcourent les rues, l'insulte et la menace à la bouche, arrachant les couleurs rouges de la boutonnière des citoyens.

Ouvriers ! c'est votre drapeau qui tombe. Écoutez bien ! La République ne tardera pas à le suivre.

Voir S. MOLINIER : Blanqui, p. 35.

Le 13 et le 14 avril 1834, les masses populaires s'étaient insurgées contre le gouvernement royal. La répression fut sanglante, surtout dans la rue Transnonain où de nombreux citoyens furent massacrés par les soldats de Bugeaud. 


\section{3. - ADRESSE DE LA SOCIÉTÉ RÉPUBLICAINE CENTRALE AU GOUVERNEMENT (2 MARS 1848) - SALLE DU TIVOLI D'HIVER ${ }^{1}$}

$\underline{\text { Retour à la table des matières }}$

... Nous avons le ferme espoir que le gouvernement sorti des barricades de 1848 ne voudra pas, à l'exemple de son devancier, remettre en place, avec chaque pavé, une loi de compression. Dans cette pensée, nous venons offrir au gouvernement provisoire notre concours pour la [sérieuse] réalisation de la [belle] devise : Liberté ! Égalité ! Fraternité !

Nous demandons [donc] que le gouvernement décrète [immédiatement] comme résultat de la victoire populaire :

$1^{\circ}$ La liberté complète et illimitée de la presse.

$2^{\circ}$ La suppression absolue et irrévocable des cautionnements, des droits de timbre et de poste.

$3^{\circ}$ La liberté entière de circulation des œuvres de la pensée, par toutes les voies possibles, par l'affichage, le colportage, les crieurs publics, sans restrictions ni entraves quelconques, sans nécessité d'autorisation préalable.

$4^{\circ}$ La liberté de l'industrie des imprimeurs et la suppression de tous les privilèges représentés par les brevets, toutefois avec indemnité préalable.

$5^{\circ}$ L'irresponsabilité absolue des imprimeurs pour tout écrit dont l'auteur est connu.

$6^{\circ}$ La suppression de l'article 291 du Code pénal, de la loi du 9 avril 1834, et l'abrogation formelle [des] lois, ordonnances, décrets, arrêtés, édits ou règlements quelconques, antérieurs à la date du 25 février 1848, qui pourraient limiter ou gêner le droit absolu et imprescriptible d'association et de réunion.

$7^{\circ}$ La déchéance de la magistrature debout et assise des trois derniers règnes, et son remplacement provisoire par des avocats, avoués, notaires, etc.

1 Mss Blanqui, N. A. F. 9580, liasse $\mathrm{I}^{\mathrm{a}}$, chemise 2, sous-chemise $\mathrm{B}$, feuillet $\mathrm{U}, \mathrm{n}^{\circ} 107$. Cette adresse comprend une série de résolutions, adoptées au cours des réunions de la Société Républicaine Centrale pendant les premiers jours de la révolution. 
$8^{\circ}$ L'armement et l'organisation [immédiate] en gardes nationales de tous les ouvriers non établis [et] recevant salaire, sans [aucune] exception, avec indemnité de deux francs pour chaque jour de service actif.

$9^{\circ}$ L'abrogation des articles 415 et 416 du Code pénal, ainsi que des lois spéciales contre les coalitions d'ouvriers ${ }^{1}$.

\section{4. - PREMIÈRE PÉTITION POUR L'AJOURNEMENT DES ÉLECTIONS ${ }^{2}$ (6 MARS 1848)}

$\underline{\text { Retour à la table des matières }}$

Citoyens, l'élection immédiate de l'Assemblée nationale serait un danger pour la République.

Depuis soixante ans, la contre-révolution parle seule à la France. La presse, bâillonnée par les lois fiscales, n'a pénétré que l'épiderme de la société ; l'éducation des masses [n']a été faite [que] par [le seul] enseignement oral, qui a toujours appartenu, [et] qui appartient encore aux ennemis de la République.

Les notabilités des partis vaincus [dans les campagnes principalement] attirent seules l'attention du peuple [dans les campagnes surtout]. Les hommes dévoués à la cause démocratique lui sont à peu près inconnus. La liberté du suffrage ne serait qu'apparente, toutes les influences hostiles conjurées fausseraient inévitablement le vœu du peuple.

On peut dire que la nation, considérée comme une vaste assemblée, voterait sous l'empire d'une opinion qui n'a pas de contradicteurs. C'est une injustice et encore plus un danger, car cette opinion, c'est le Royalisme.

Quels sont les hommes qui demandent à grands cris la convocation immédiate des comices? Les ennemis avérés de la République, ceux qui l'ont [toujours]

L'adresse est suivie de la mention :

Le Bureau. Signé : L. A. Blanqui, président Xavier Durrieu, Alex Raisant, Hervé, Napol, Chancel-Sobrier, (etc.).

2 Mss Blanqui, N. A. F. 9580, liasse I-, chemise 2, sous-chemise B, feuillet U, $\mathrm{n}^{\circ} 108$.

Sur l'initiative de Blanqui, la Société Républicaine Centrale avait commencé une campagne pour l'ajournement des élections fixées au 9 avril par le gouvernement provisoire. La première pétition composée par Blanqui fut approuvée par la Société le 6 mars, et transmise au gouvernement le 7. Elle n'eut aucune suite, et, le 14 mars, la Société adopta une nouvelle pétition sur l'ajournement des élections. Cf. Mss Blanqui, liasse Ia, chemise 2, sous-chemise B, feuillets $\mathrm{U}$ et $\mathrm{V}, \mathrm{n}^{\circ} 109$, N. A. F. 9580. 
combattue avec acharnement, qui la subissent comme [un affront], et qui comptent sur l'excès de sa simplicité pour l'étouffer à son berceau.

Une immense comédie se joue devant la France. En serons-nous dupes, citoyens ? Nos ennemis, désarmés de la violence, se réfugient dans l'astuce. Ils veulent recueillir à temps le fruit de trente ans de compression.

Songez-y, citoyens, l'œuvre du 21 février ne saurait périr. Si [une précipitation] aussi imprudente que déloyale devait amener le fléau d'une assemblée réactionnaire, la république ne reculera[it] pas. Que votre sagesse prévienne les désastres d'une telle lutte.

N'oubliez pas qu'entre les élections faites demain ou dans six mois il y a un abîme. C'est à la discussion de le combler. Le vote aujourd'hui serait une surprise et un mensonge.

Il ne deviendra vérité que par une libre polémique. Mais cette polémique ne saurait être l'œuvre d'un jour.

En conséquence, nous demandons l'ajournement indéfini des élections et l'envoi dans les départements de citoyens chargés d'y porter la lumière démocratique.

\section{5. - DEUXIÈME PÉTITION POUR L'AJOURNEMENT DES ÉLECTIONS (14 MARS 1848)}

$\underline{\text { Retour à la table des matières }}$

Citoyens, nous demandons l'ajournement des élections de l'Assemblée constituante et de la garde nationale. Ces élections seraient dérisoires.

À Paris, un très petit nombre d'ouvriers sont inscrits sur les listes électorales. L'urne ne recevrait que les suffrages de la bourgeoisie.

Dans les villes, la classe des travailleurs, façonnée au joug par de longues années de compression et de misère, ne prendrait aucune part au scrutin, ou bien elle y serait conduite par ses maîtres, comme un bétail aveugle.

Dans les campagnes, toutes les influences sont aux mains du clergé et des aristocraties. Une tyrannie savante a étouffé par son système d'isolement individuel toute spontanéité au cœur des masses. Les malheureux paysans, réduits à la condition de serfs, deviendraient le marche-pied des ennemis qui les oppriment et les exploitent. 
Notre âme s'indigne à la pensée que les oppresseurs puissent ainsi recueillir le bénéfice de leur crime ; c'est un sacrilège de faire mentir à leur propre salut dix millions d'hommes, d'arracher à leur inexpérience la sanction de leur esclavage. Ce serait un défi par trop insolent aux barricades de Février.

Le peuple ne sait pas : il faut qu'il sache. Ce n'est pas l'œuvre d'un jour, ni d'un mois. Lorsque la contre-révolution a seule la parole depuis cinquante ans, est-ce donc trop de l'accorder une année peut-être à la liberté, qui ne réclame que la moitié de la tribune et ne mettra pas, elle, la main sur la bouche de son adversaire?

Il faut que la lumière se fasse jusque dans les moindres hameaux, il faut que les travailleurs redressent leurs fronts courbés par la servitude et se relèvent de cet état de prostration et de stupeur où les castes dominantes les tiennent, le pied sur la tête.

Et ne dites pas que nos craintes sont chimériques ! Les élections, si elles s'accomplissent, seront réactionnaires. C'est le cri universel. Le parti royaliste, le seul organisé grâce à sa longue domination, va les maîtriser par l'intrigue, la corruption, les influences sociales ; il sortira triomphant de l'urne.

Ce triomphe, ce serait la guerre civile ! Car Paris, le cœur et le cerveau de la France, Paris ne reculera pas devant le retour offensif du passé. Réfléchissez aux sinistres conséquences d'un conflit entre la population parisienne et une Assemblée qui croirait représenter la nation, qui ne la représenterait pas; car le vote de demain sera une surprise et un mensonge.

Que votre prudence épargne à la France de tels périls. Laissez le peuple naître à la République. Il est encore emprisonné dans les langes étouffants de la Monarchie.

Ajournement des élections, c'est le cri des Parisiens ! 


\section{6. - ADRESSE AU GOUVERNEMENT (17 MARS 1848) ${ }^{1}$}

Retour à la table des matières

Citoyens, le peuple se plaint des tendances réactionnaires d'une partie du gouvernement provisoire.

Son désir est que le pouvoir inaugure sur les barricades tienne d'une main ferme les rênes de l'État et coupe court aux hésitations, aux tiraillements qui compromettraient l'avenir de la République.

Il réclame comme mesures d'urgence : $1^{\circ}$ l'éloignement de la capitale des troupes soldées; $2^{\circ}$ l'ajournement des élections de la garde nationale et de l'Assemblée Constituante. Paris, tête et cœur de la France, ne doit être gardé que par la population elle-même, par la population tout entière.

Or, par l'effet de certains mauvais vouloirs, la majeure partie des ouvriers n'est pas inscrite encore sur les contrôles des légions et ne prendrait aucune part au choix des officiers. Cela n'est pas juste. Il n'est pas juste non plus que la représentation nationale soit élue sous l'influence à peu près exclusive des aristocraties liguées et des fonctionnaires de Louis-Philippe.

C'est ce qui arrivera cependant, si l'ajournement des élections ne permet pas au parti populaire de détruire les préjugés et les calomnies répandues contre lui par les factions rétrogrades qui se sont violemment arrogé, depuis cinquante ans, le monopole de l'enseignement politique des masses.

Le vote de demain ne serait pas libre. Il serait dicté par des prépondérances hostiles, dont le machiavélisme a de longue main façonné au joug la plus grande partie des populations.

La présence d'une Assemblée réactionnaire, loin de rétablir la sécurité et la confiance, précipiterait la ruine du crédit et des transactions, en déchaînant la guerre civile.

Mss Blanqui, N. A. F. 9580, liasse I $p$, Chemise 2, sous-chemise $b$, feuillet V, $\mathrm{n}^{\circ} 110$. Quinze clubs parisiens avaient élu une commission dont Blanqui faisait partie pour discuter avec le gouvernement du retrait des troupes de Paris et de l'ajournement des élections. Le gouvernement n'ayant pas voulu recevoir la commission, celle-ci lui envoya une adresse le 17 mars. Elle contenait deux projets : un de Cabet et un de Blanqui. Cabet demandait l'ajournement des élections pour la garde nationale jusqu'au 5 avril et pour la Constituante jusqu'au 31 mai. Blanqui renvoyait les élections à une date ultérieure. Ce fut le projet de Cabet que l'Assemblée adopta. 
Le peuple conjure son gouvernement de prévenir ce malheur et de préparer, par une administration ferme et active, l'homogénéité républicaine de la future Assemblée nationale, homogénéité qui peut seule assurer à ses travaux des résultats bienfaisants.

Il est prêt à soutenir le gouvernement dans cette voie contre les tentatives et les machinations des partis royalistes.

\section{7. - AUX CLUBS DÉMOCRATIQUES DE PARIS (22 MARS 1848) ${ }^{1}$}

$\underline{\text { Retour à la table des matières }}$

La République serait un mensonge, si elle ne devait être que la substitution d'une forme de gouvernement à une autre. Il ne suffit pas de changer les mots, il faut changer les choses.

La République, c'est l'émancipation des ouvriers, c'est la fin du règne de l'exploitation, c'est l'avènement d'un ordre nouveau qui affranchira le Travail de la tyrannie du Capital.

Liberté ! Égalité ! Fraternité ! Cette devise qui brille au fronton de nos édifices ne doit pas être une vaine décoration d'opéra.

Point de hochets ! Nous ne sommes plus des enfants. Il n'y a pas liberté quand on manque de pain. Il n'y a pas égalité quand l'opulence fait scandale à côté de la misère. IÎ n'y a pas fraternité quand l'ouvrière, avec ses enfants affamés, se traîne aux portes des palais.

Du travail et du pain ! L'existence du peuple ne peut rester à la merci des frayeurs et des rancunes du capital.

Les sociétés populaires qui partagent nos principes sont invitées à choisir trois délégués qui se réuniront au comité central des élections, dimanche 26 mars, à onze heures du matin, dans la salle des Conférences, rue des Poiriers, près la Sorbonne. Les délégués des clubs seront seuls admis et devront être porteurs de pouvoirs en règle de leurs sociétés respectives ${ }^{2}$.

1 Mss Blanqui, N. A. F. 9580, liasse A, chemise 2, sous-chemise B, feuillet V, ${ }^{\circ} 112$. Manifeste de Blanqui du 22 mars 1848. L'idée d'une organisation centrale des clubs avait été formulée par le club de la Révolution, dirigé par Barbès. La Société Républicaine Centrale s'était associée à cette idée et avait envoyé aux clubs démocratiques de Paris un manifeste signé par Blanqui et par les représentants d'autres clubs.

2 Signé L. A. Blanqui, Feuillâtre, Mouton, Séguin, Dézarny, Villain, ... 


\section{8. - PROFESSION DE FOI (30 MARS 1848) ${ }^{1}$.}

La République, comme la monarchie, peut ombrager la servitude sous son drapeau.

Sparte, Rome, Venise étaient des oligarchies corrompues et oppressives. Aux États-Unis, l'esclavage est une institution.

La formule : «Liberté, Égalité, Fraternité » pourrait devenir un mensonge aussi célèbre que celui de la Charte-vérité : «Tous les Français sont égaux devant la loi !»

La tyrannie du Capital est plus impitoyable que celle du sabre et de l'encensoir. La révolution de Février a pour but de la briser. Ce but est aussi celui de la Société Républicaine Centrale et chacun de ses membres s'engage à le poursuivre jusqu'à ce qu'il soit atteint.

\section{9. - ADRESSE AU GOUVERNEMENT PROVISOIRE (20 AVRIL 1848) ${ }^{2}$}

$\underline{\text { Retour à la table des matières }}$

Des régiments s'avancent sur Paris. Leur approche répand l'alarme dans les rangs des patriotes.

L'armée n'a pas été réorganisée. Ses cadres, préparés par une tyrannie ombrageuse dans des vues meurtrières, sont aujourd'hui ce qu'ils étaient avant les barricades.

Dans Paris même, les royalistes de la veille, grimés en républicains du lendemain, ne dissimulent ni leur haine, ni leurs projets de réaction contre ce qu'ils nomment la populace.

Ce texte fut publié dans Le Courrier français du 30 mars 1848.

Mss Blanqui, N. A. F. 9580, liasse Ia, chemise 2, sous-chemise $b$, feuillet V, no III. Le gouvernement provisoire avait décidé une revue des troupes pour le 20 avril, fête de la Fraternité. C'était un prétexte pour convoquer à Paris des armées qui devaient y rester pour garder le «calme » et l' « ordre ». La Société Républicaine Centrale démasqua la manœuvre et protesta contre la convocation des armées. 
Une coalition de ces sentiments et de ces égoïsmes pourrait coûter cher à la République.

Le peuple n'a que de l'affection pour les soldats sortis de ses rangs, mais sa défiance est profonde envers cette doctrine de l'obéissance passive qui a noyé si souvent Paris dans le sang français.

Pourquoi d'ailleurs des troupes soldées dans nos murs? $\mathrm{Si}$ on le veut sincèrement, dans huit jours, trois cent mille gardes nationaux en armes [veilleront] au service d'ordre et de sûreté de la capitale.

Les républicains de vieille date doivent au gouvernement provisoire l'expression franche de leur pensée. Cette pensée est aujourd'hui bien amère.

Le choix déplorable des commissaires envoyés dans les départements, le maintien de la magistrature et des fonctionnaires de Louis-Philippe, l'écartement systématique des vieux patriotes, partout repoussés par les agents du pouvoir et livrés à la risée des royalistes ralliés ; le désarmement successif des combattants des barricades ; l'appel à Paris des troupes soldées dont la place est aux frontières ; la menace de former une garde urbaine, résurrection, sous un troisième nom, de la gendarmerie et de la garde municipale; la convocation précipitée des comices électoraux qui, sous des influences exclusivement réactionnaires, ne pourront créer qu'une Assemblée rétrograde; tous ces actes réunis semblent annoncer une réédition de 1830.

Déjà, la voix populaire a salué le gouvernement nouveau du nom de la République monarchique. La République monarchique vaudrait-elle donc moins encore que la monarchie républicaine?

Nous faisons une fois encore appel à votre patriotisme, à votre prudence, Citoyens! Arrêtez la réaction! Retenez les troupes loin de la capitale et faites disparaître cette menace de représailles armées contre la victoire du peuple. 


\section{0. - LES MASSACRES DE ROUEN. LA SOCIÉTÉ RÉPUBLICAINE CENTRALE AU GOUVERNEMENT PROVISOIRE (2 MAI 1848) ${ }^{1}$}

$\underline{\text { Retour à la table des matières }}$

Citoyens, la contre-révolution vient de se baigner dans le sang du peuple. Justice, justice immédiate des assassins !

Depuis deux mois la bourgeoisie royaliste de Rouen tramait dans l'ombre une Saint-Barthélemy contre les ouvriers. Elle avait fait de grands approvisionnements de cartouches. L'autorité le savait.

Des paroles de mort éclataient çà et là, symptômes précurseurs de la catastrophe : il faut en finir avec ces canailles ! Canailles, en effet, qui avaient en février, après trois jours de résistance, contraint la garde bourgeoise à subir la République!

Citoyens du gouvernement provisoire, d'où vient que, depuis ces deux mois, les populations ouvrières de Rouen et des vallées environnantes n'avaient pas été organisées en gardes nationales?

D'où vient que l'aristocratie possédait seule l'organisation et les armes ?

D'où vient qu'au moment de l'exécution de son affreux complot elle n'a rencontré devant elle que des poitrines désarmées ? D'où vient la présence à Rouen du $28^{\mathrm{e}}$ régiment de ligne, ce sinistre héros du faubourg de Vaise en 1834 ?

D'où vient que la garnison obéissait aux ordres de généraux, ennemis déclarés de la République, d'un général Gérard, créature et âme damnée de Louis-Philippe ?

Ils avaient soif d'une sanglante revanche, ces sicaires de la dynastie déchue ! Il leur fallait un massacre d'avril pour consolation d'un second juillet ! Leur attente n'a pas été longue.

Mss Blanqui, N. A. F. 9580, liasse $\mathrm{I}^{\mathrm{a}}$, chemise 2, sous-Chemise $b$, feuillet $\mathrm{V}, \mathrm{n}^{\circ} 113$. La lutte de classes entre les ouvriers et la bourgeoisie rouennaise s'était particulièrement envenimée pendant les élections au terme desquelles les ouvriers avaient été dupés par les procédés frauduleux des bourgeois. Les ouvriers sortirent dans la rue et construisirent des barricades. La bourgeoisie répondit par une répression sanglante. Des fusils et des canons furent dirigés contre les ouvriers sans armes. Il y eut beaucoup de victimes parmi les travailleurs. La Société Républicaine Centrale afficha une adresse sur les murs de Paris que les journaux socialistes publièrent. 
Les journées d'avril, deux mois à peine après la Révolution ; c'est aller vite, citoyens du gouvernement provisoire !

Et rien n'y a manqué, à ces nouvelles recrues d'avril ! Ni la mitraille, ni les boulets, ni les maisons démolies, ni l'état de siège, ni la férocité de la soldatesque, ni l'insulte aux morts, l'insulte unanime des journaux, ces lâches adorateurs de la force ! La rue Transnonain est surpassée ! À lire l'infâme récit de ces exploits de brigands, on se retrouve au lendemain des jours néfastes qui naguère ont couvert la France de deuil et de honte.

Ce sont bien les mêmes bourreaux et les mêmes victimes ! D'un côté, des bourgeois forcenés, poussant par derrière au carnage des soldats imbéciles qu'ils ont gorgés de vin et de haine ; de l'autre, de malheureux ouvriers sans défense sous la balle et la baïonnette des assassins !

Pour dernier trait de ressemblance, voici venir la cour royale, les juges de Louis-Philippe, se ruant comme des hyènes sur les débris du massacre, et remplissant les cachots de deux cent cinquante républicains. À la tête de ces inquisiteurs est Franck Carré, l'exécrable procureur général de la Cour des Pairs, ce Laubardemont ${ }^{1}$ qui demandait avec rage la tête des insurgés de mai 1839. Les mandats d'amener poursuivent jusqu'à Paris les patriotes, qui fuient la proscription des royalistes.

Car c'est une terreur royaliste qui règne à Rouen, l'ignorez-vous, citoyens du gouvernement provisoire ? La garde bourgeoise de Rouen a repoussé avec fureur la République au mois de février. C'est la République qu'elle blasphème et qu'elle veut renverser.

Tout ce qu'il y avait de républicains de la veille a été jeté dans les fers. Vos propres agents sont menacés de mort, destitués, gardés à vue. Les magistrats municipaux, Lemasson, Durand, ont été traînés par les rues, les baïonnettes sur la poitrine, leurs vêtements en lambeaux. Ils sont au secret de par l'autorité des rebelles ! C'est une insurrection royaliste qui a triomphé dans la vieille capitale de la Normandie, et c'est vous, gouvernement républicain, qui soutenez ces assassins révoltés ! Est-ce trahison ou lâcheté ? Êtes-vous des pleutres ou des complices ?

On ne s'est pas battu, vous le savez bien ! On a égorgé ! Et vous laissez raconter glorieusement les prouesses des égorgeurs. Serait-ce qu'à vos yeux, comme à ceux des rois, le sang du peuple n'est que de l'eau bonne à laver de temps en temps des rues trop encombrées ? Effacez donc alors, effacez de vos édifices ce

LAUBARDEMONT : magistrat français mort en 1653. Un des soutiens les plus actifs et les plus cruels de Richelieu. On lui attribue ce mot : « Montrez-moi une ligne écrite de la main d'un homme, je saurai le faire pendre. » 
détestable mensonge en trois mots que vous venez d'y inscrire : Liberté, Égalité, Fraternité !

Si vos femmes, si vos filles, ces brillantes et frêles créatures, qui promènent dans de somptueux équipages leur oisiveté tissée d'or et de soie, étaient jetées tout à coup à vos pieds, la poitrine ouverte par le fer des ennemis sans pitié, quels rugissements de douleur et de vengeance vous feriez retentir jusqu'aux extrémités du monde !

Eh bien, allez! allez voir, étendus sur les dalles de vos hôpitaux, sur la paillasse des mansardes, ces cadavres de femmes égorgées, le sein troué de balles bourgeoises, ce sein, entendez-vous, qui a porté et nourri les ouvriers dont la sueur engraisse les bourgeois !

Les femmes du peuple valent les vôtres et leur sang ne doit pas, ne peut pas rester sans vengeance!

Justice donc, justice des assassins !

Nous demandons :

$1^{\circ}$ La dissolution et le désarmement de la garde bourgeoise de Rouen.

$2^{\circ}$ L'arrestation et la mise en jugement des soi-disant membres de la cour d'appel, séides nommés par Louis-Philippe, qui, agissant au nom et pour le compte de la faction royaliste victorieuse, ont emprisonné les magistrats légitimes de la cité, et rempli les cachots des républicains.

$3^{\circ}$ L'éloignement immédiat de Paris des troupes de ligne, qu'en ce moment même les réacteurs chassent, dans des banquets fratricides, à une Saint-Barthélemy des ouvriers parisiens. 


\section{1. - AVIS AU PEUPLE (TOAST DU 25 FÉVRIER 1851) ${ }^{1}$}

Retour à la table des matières

Quel écueil menace la révolution de demain ? L'écueil où s'est brisée celle d'hier, la déplorable popularité de bourgeois déguisés en tribuns.

Ledru-Rollin, Louis Blanc, Crémieux, Marie, Lamartine, Garnier-Pagès, Dupont (de l'Eure), Flocon, Albert, Arago, Marrast ${ }^{2}$ !

Liste funèbre ! noms sinistres écrits en caractères sanglants sur tous les pavés de l'Europe démocratique.

C'est le gouvernement provisoire qui a tué la révolution! C'est sur sa tête que doit retomber la responsabilité de tous les désastres, le sang de tant de milliers de victimes.

La réaction n'a fait que son métier en égorgeant la démocratie. Le crime est aux traîtres que le peuple confiant avait acceptés pour guides et qui ont livré le peuple à la réaction.

Misérable gouvernement! Malgré les cris, les prières, il lance l'impôt de quarante-cinq centimes qui soulève les campagnes désespérées ${ }^{3}$.

Il maintient les états-majors royalistes, la magistrature royaliste, les lois royalistes. Trahison!

1 Toast envoyé par Blanqui de Belle-Île à Londres, en réponse à une demande de toast pour le banquet du 25 février 1851, anniversaire de la révolution de 1848. "Voici l'histoire de ce toast contée par Engels : « Barthélemy, se disant blanquiste, persuada Blanqui d'envoyer un toast au banquet. Mais il ne reçut qu'une attaque magnifique contre le gouvernement provisoire, Louis Blanc et Cie entre autres. Barthélemy, stupéfié, remit le document et il fut décidé de ne pas le publier... Nous traduisîmes le toast en allemand et le diffusâmes en Allemagne et en Angleterre. » Ce toast, publié d'abord en tract par les « Amis de l'Égalité », fut, ensuite, repris par La Patrie le 27 février 1851. Blanqui s'explique longuement sur l'origine et l'utilisation de ce texte dans une lettre (B. N., N. A. F., 9580, liasse $\mathrm{I}^{\mathrm{a}}$, chemise 2 , sous-chemise $a$, feuillet 41 et sq. du 19 mars 1851, [voir appendice p. 122 et sq.).

2 LEDRU-ROLLIN, Louis BLANC, CRÉMIEUX, etc. -Membres du gouvernement provisoire au début de la révolution de 1848.

3 Impôt des 45 centimes. Par un décret du 16 mars 1848, le gouvernement provisoire augmenta de 45 centimes par franc les 4 impôts directs qui pesaient surtout sur les paysans. Cette augmentation suscita un vif mécontentement dans les campagnes. 
Il court sus aux ouvriers de Paris le 16 avril, il emprisonne ceux de Limoges, il mitraille ceux de Rouen le 27 ; il déchaîne tous leurs bourreaux, il berne et traque tous les sincères républicains. Trahison! trahison!

À lui, à lui seul le fardeau terrible de toutes les calamités qui ont presque anéanti la révolution!

Oh ! ce sont là de grands coupables, et entre tous, les plus coupables ceux en qui le peuple, trompé par des phrases de tribun, voyait son épée et son bouclier, ceux qu'il proclamait avec enthousiasme arbitres de son avenir.

Malheur à nous si, au jour du prochain triomphe populaire, l'indulgence oublieuse des masses laissait remonter au pouvoir un de ces hommes qui ont forfait à leur mandat ! une seconde fois c'en serait fait de la révolution !

Que les travailleurs aient sans cesse devant les yeux cette liste de noms mandats, et si un seul, oui, un seul, apparaissait jamais dans un gouvernement sorti de l'insurrection, qu'ils crient tout d'une voix : Trahison !

Discours, sermons, programmes ne seraient encore que piperies et mensonges ; les mêmes jongleurs ne reviendraient que pour exécuter le même tour avec la même gibecière; ils formeraient le premier anneau d'une chaîne nouvelle de réactions plus furieuses. Sur eux, anathème et vengeance, s'ils osaient reparaître ! Honte et pitié sur la foule imbécile qui retomberait dans leurs filets !

Ce n'est pas assez que les escamoteurs de Février soient à jamais repoussés de l'Hôtel-de-Ville, il faut se prémunir contre de nouveaux traîtres.

Traîtres seraient les gouvernants qui, élevés sur le pavois prolétaire, ne feraient pas opérer à l'instant même : $1^{\circ}$ le désarmement général des gardes bourgeoises ; $2^{\circ}$ l'armement et l'organisation en milice nationale de tous les ouvriers.

Sans doute il est bien d'autres mesures indispensables; mais elles sortiront naturellement de ce premier acte, qui est la garantie préalable, l'unique gage de sécurité pour le peuple.

Il ne doit pas rester un fusil aux mains de la bourgeoisie. Hors de là, point de salut !

Les doctrines diverses qui se disputent aujourd'hui les sympathies des masses pourront un jour réaliser leurs promesses d'amélioration et de bien-être, mais à la condition de ne pas abandonner la proie pour l'ombre.

Elles n'aboutiraient qu'à un lamentable avortement si le peuple, dans un engouement exclusif pour les théories, négligeait le seul élément pratique assuré, la force ! 
Les armes et l'organisation, voilà l'élément décisif du progrès, le moyen sérieux d'en finir avec la misère ! Qui a du fer, a du pain. On se prosterne devant les baïonnettes, on balaie les cohues désarmées. La France hérissée de travailleurs en armes, c'est l'avènement du socialisme.

En présence des prolétaires armés, obstacles, résistances, impossibilités, tout disparaîtra.

Mais pour les prolétaires qui se laissent amuser par des promenades ridicules dans les rues, par des plantations d'arbres de liberté, par des phrases sonores d'avocat, il y aura de l'eau bénite d'abord, des injures ensuite, enfin, de la mitraille, de la misère toujours !

QUE LE PEUPLE CHOISISSE.

Prison de Belle-Île-en-Mer, 10 février 1851.

\section{2. - À PROPOS DES CLAMEURS CONTRE

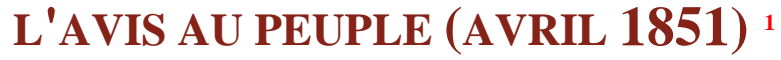

$\underline{\text { Retour à la table des matières }}$

Oui, les journaux ont raison ; c'est le langage d'avant le 15 mai ; ce sont les redites du club Blanqui, les bribes de ses discours; et le hourra unanime que soulève cette simple réapparition des idées d'alors montre tout l'espace dont la révolution a reculé. Ce sont ces idées qui avaient ameuté toutes les nuances de la réaction depuis Henri V jusqu'à Louis Blanc ; ce sont ces idées qu'on poursuivait par la calomnie, par la violence, par les cris de mort, qui provoquaient les colères du gouvernement provisoire, ses intrigues de police, ses mandats d'arrêt. Elles ont succombé sous le nombre et, avec elles, la démocratie ; leur défaite a ouvert la brèche au flot de la réaction qui monte encore. Combien de fois, dans les rangs populaires, on s'est écrié : «Blanqui avait raison! » Que d'hommes convertis par les enseignements de l'expérience ont rapporté leur souvenir sur cette justesse de

1 Le toast de Blanqui, publié dans La Patrie du 27 février 1851, déchaîna les protestations des « socialistes » et des «républicains » bourgeois; par contre, les milieux révolutionnaires l'accueillirent avec enthousiasme. Au mois d'avril 1851, Blanqui écrivit un article qui peut servir de commentaire à son texte, Des copies de cet article circulaient parmi les socialistes français. Blanqui y confirme avec encore plus de véhémence la nécessité de mettre le peuple en garde contre la trop grande confiance dans les « socialistes »bourgeois ; il exige la rupture entre les milieux révolutionnaires et les républicains bourgeois.

En 1878, à l'occasion de la candidature de Blanqui aux élections parlementaires, le journal socialiste L'Égalité publia dans le numéro du 16 juin presque intégralement le texte du commentaire, sous le titre de « La comédie des programmes ». 
prévision, sur ce don de seconde vie qui l'avait, en quelque sorte, illuminé au milieu de l'aveuglement universel ! On a répété souvent : " Il l'avait bien dit ! » et ce détrompement tardif, cette expression de regret et de repentir était une réhabilitation, une amende honorable.

Mais voici que le prophète reprend la parole. Est-ce pour montrer un horizon inconnu, pour révéler un monde nouveau? Non, c'est pour remâcher les prédications de son club. Tous les journaux les publient. À la veille peut-être des mêmes déceptions, il vient répéter ses avertissements. Aux périls qui menacent de renaître identiques, il oppose son cri d'alarme : «Prolétaires, garde à vous ! » Et aussitôt, du sein des mêmes factions, s'élève le vieux concert d'anathèmes qui dévouent sa tête aux furies.

On veut donc recommencer 48 ! Il n'y a donc rien de changé, ni dans les intentions, ni dans les actes !

Il n'y a que des programmes, c'est-à-dire des mensonges de plus, une nouvelle mystification, prélude d'une nouvelle apostasie. Ceux qui rééditent contre la sentinelle populaire leurs imprécations de 48 , ceux-là préparent une réédition des premières tromperies, et à l'instant ils retrouvent leurs vieux complices dans les intéressés de toutes couleurs, et leur dupe ordinaire dans ce peuple, toujours bafoué, mais toujours crédule parce qu'il est toujours ignorant et malheureux. La coalition se reforme et se lève comme un seul homme.

«Allons-nous revoir les scènes de Février ? - Non, non », répondent en chœur les fripons et les dupes. La leçon a porté ses fruits : le peuple voit clair; il a maintenant des formules, des programmes, phares des prochaines tempêtes, feux sauveurs qui le conduisent au port.

Dites plutôt feux follets de perdition qui vont le rejeter sur les brisants.

Parlons-en un peu, de ces recettes, de ces panacées qui s'étalent dans les colonnes de la presse, grande et petite ! Parlons un peu du gouvernement du peuple par le peuple et de toutes ces balivernes, fantaisies de la parade que le pauvre travailleur prend au sérieux et dont les acteurs pouffent de rire dans la coulisse.

À l'indifférence et au dédain qui accueillent ces beaux chefs-d'œuvre chez nos seigneurs et maîtres, si jaloux de leurs privilèges, si ombrageux pour leur domination, comment le prolétaire ne voit-il pas que ces prétendus évangiles ne sont que des prospectus de charlatans ? Des programmes ? A-t-on perdu si vite la mémoire des harangues de MM. Ledru-Rollin et Louis Blanc avant Février ? Estce que dans les banquets de Lille, Dijon, Châlons, les journaux n'avaient pas formulé, par la bouche de ces tribuns, le Code magnifique de l'Égalité que devait inaugurer le lendemain de la Révolution?

Que sont devenus ces solennels engagements? 
On ignore la comédie des programmes; voici comment elle se joue : En montant à l'Hôtel de Ville, on les jette au coin de la borne ; et le jour où l'on redescend les escaliers sous les coups de pied du royalisme, la botte du royalisme dans les reins, on ramasse dans le ruisseau ces lambeaux souillés ; on les essuie, on les défripe, on les retape, on les rajuste, on les promène à grand orchestre devant la foule ébahie. Qu'importe à la réaction ? Elle connaît trop la valeur de ces chiffons de papier pour en prendre souci. Elle sait d'où ils viennent et où ils retournent à un moment donné. Elle laisse tranquillement les saltimbanques en faire étalage sur les champs de foire pour la mystification des badauds.

Mais qu'un homme sincère, laissant là ce mirage fantastique des programmes, ces brouillards du royaume d'Utopie, sorte du roman pour rentrer dans la réalité, qu'il prononce une parole sérieuse et pratique :

« Désarmer la bourgeoisie, armer le peuple, c'est la première nécessité, le seul gage de salut de la révolution. »

Oh ! alors l'indifférence s'évanouit ; un long hurlement de fureur retentit d'un bout de la France à l'autre. On crie au sacrilège, au parricide, à l'hydrophobe. On ameute, on déchaîne les colères sur cet homme, on le voue aux dieux infernaux pour avoir épelé modestement les premiers mots du sens commun.

Eh quoi ! A-t-on oublié le drame de Juin ? A-t-on oublié [Paris fouillé tout entier de la cave au grenier], Paris désarmé, garrotté, bâillonné, frémissant, se tordant sous l'outrage que lui avaient épargné les hordes étrangères, maîtresses de ses murs ! Quoi ! une once de poudre, la poignée d'un sabre, la crosse d'un pistolet trouvées dans la pauvre mansarde d'un ouvrier, envoient ce malheureux pourrir au fond des cachots !

Et, victorieux, vous hésitez ! Vous reculez devant le désarmement d'une caste implacable qui ne procède avec le peuple que par extermination !

Le prestige de sa longue puissance vous en impose, et le souvenir de ses violences assure son inviolabilité. Allez, race d'esclaves, qui n'osez lever les yeux ni la main sur vos tyrans! Rebelles d'un jour, repentants et prosternés le lendemain, restez accroupis dans votre misère et votre servitude ! Ne tentez pas de briser vos chaînes ! Il vous faudrait les ressouder de vos propres mains. Ne faites plus de révolutions pour vous sauver du moins la honte d'en demander pardon à genoux. 


\section{3. - LETTRE À MAILLARD ${ }^{1}$}

Retour à la table des matières

Belle-Île, 6 juin 1852.

Je ne me suis pas pressé de vous répondre, mon cher citoyen, dans la crainte de blesser vos opinions qui ne sont pas toujours les miennes, du moins en apparence, mais vous insistez, vous semblez même attribuer mon silence à des motifs de mécontentement personnel. Je ne veux pas laisser votre imagination courir les champs et je vous dirai mon avis, puisque vous y tenez. Nous sommes d'accord sur le point capital, je veux dire les moyens pratiques qui, en définitive, sont toute la Révolution. Mais les moyens pratiques se déduisent des principes et dépendent aussi de l'appréciation des hommes et des choses. Ici, nous différons. Vous accusez de l'avortement de Février les chefs d'école: les peureux, les philosophes, les avocats, les divisions du parti.

De toutes ces causes, je n'en admets qu'une seule, les avocats, non point en qualité d'avocats, mais comme fraction assez notable de cette tourbe d'intrigants qui ont dévoré la République et, ne pouvant la digérer, n'ont pas tardé à la rendre par haut et par bas. Les renégats, soyez-en convaincu, ne prétendaient rien changer, rien détruire; bien au contraire, ils n'avaient qu'un but, qu'un désir, conserver, conserver les places. Vous les croyez plus bêtes qu'ils ne sont. C'est l'erreur générale. On accuse leur intelligence plutôt que leurs intentions, et c'est ainsi qu'on leur aplanit tout doucement la voie pour un nouveau tour de passepasse. Comment croire que des gens rompus à toutes les roueries de la politique vont se tromper si grossièrement sur l'a. $b$. $c$. du métier ? S'ils n'ont pas fait de la révolution, c'est qu'ils n'en voulaient pas faire. Leur trahison s'est trouvée une ineptie, voilà tout. Ils tenaient enfin la queue de la poêle ; ils ont voulu frire à leur tour. Leur sottise a été d'imaginer qu'ils friraient longtemps. Mais c'est l'incurable infirmité des pouvoirs. Ils se croient tous immortels.

Rayez du catalogue des coupables les peureux - personne n'a eu peur en Février, si ce n'est de perdre sa part dans la curée ! - Les philosophes - ils sont

Cette longue lettre politique a été adressée à un des disciples de Barbès, ancien fondateur et président du club républicain du $\mathrm{V}^{\mathrm{e}}$, filiale du club de la Révolution. Sa participation aux combats de juin lui avait valu d'être déporté en Afrique, d'où il réussit à s'évader pour se réfugier à Barcelone, où la lettre de Blanqui lui est adressée.

Maillard était un républicain sincère, mais sans idées claires et précises.

La lettre de Blanqui fut publiée, pour la première fois, dans Le Cri du peuple (numéros du $1^{\mathrm{er}}, 2$ et 3 octobre 1885). Mss Blanqui, N. A. F. 9590-2, liasse VII, chemise 3, sous-chemise 5, feuillet 379 et sq. 
bien innocents de nos désastres; et d'ailleurs, c'est aujourd'hui plus que jamais qu'il faut être philosophe. Les chefs d'école, les accusations dirigées contre eux sont une des perfidies de la faction des intrigants. Qu'est-ce donc que les chefs d'école? Les auteurs, ou du moins les tenants principaux des diverses théories sociales qui se proposent de reconstituer le monde sur la base de la justice et de l'égalité. Le socialisme, c'est la croyance à l'ordre nouveau qui doit sortir du creuset de ces doctrines. Elles se combattent sans doute sur bien des points, mais elles poursuivent le même but, elles ont les mêmes aspirations ; elles s'accordent sur les questions essentielles et déjà, de leurs efforts, il est sorti une résultante qui, sans être encore bien déterminée, a cependant saisi l'esprit des masses, est devenue leur foi, leur espérance, leur étendard. Le socialisme est l'étincelle électrique qui parcourt et secoue les populations. Elles ne s'agitent, ne s'enflamment qu'au souffle brûlant de ces doctrines, aujourd'hui l'effroi des intrigants et bientôt, je l'espère, le tombeau de l'égoïsme. Les chefs d'école tant maudits sont en définitive les premiers révolutionnaires, comme propagateurs de ces idées puissantes qui ont le privilège de passionner le peuple et de le jeter dans les tempêtes. Ne vous y trompez pas, le socialisme, c'est la révolution. Elle n'est que là. Supprimez le socialisme, la flamme populaire s'éteint, le silence et les ténèbres se font sur toute l'Europe.

Vous déplorez la division de la démocratie. Si par là vous entendez les haines personnelles, les jalousies, les rivalités d'ambition, je me joins à vous pour les flétrir, elles sont un des fléaux de notre cause ; mais remarquez que ce n'est pas une plaie spéciale au parti, nos adversaires de toutes couleurs en souffrent comme nous. Elles n'éclatent plus bruyamment dans nos rangs que par suite du caractère plus expansif, des mœurs plus ouvertes du monde démocratique. Ces luttes individuelles, d'ailleurs, tiennent à l'infirmité humaine; il faut s'y résigner et prendre les hommes tels qu'ils sont. S'emporter contre un défaut de nature, c'est de la puérilité, sinon de la sottise. Les esprits fermes savent naviguer au travers de ces obstacles qu'il n'est donné à personne de supprimer, et qu'il est possible à tous d'éviter ou de franchir. Sachons donc nous plier à la nécessité et, tout en déplorant le mal, n'en laisser ralentir notre marche. Je le répète, l'homme vraiment politique ne tient pas compte de ces entraves et va droit devant lui, sans s'inquiéter autrement des cailloux qui sèment la route. Aussi les récriminations dont vous me parlez entre les diverses écoles, si toutefois vous n'y attachez pas trop d'importance, me paraissent aussi misérables que burlesques. Proudhoniens et communistes sont également ridicules dans leurs diatribes réciproques, et ils ne comprennent pas l'utilité immense de la diversité dans les doctrines. Chaque nuance, chaque école a sa mission à remplir, sa partie à jouer dans le grand drame révolutionnaire, et, si cette multiplicité des systèmes vous semblait funeste, vous méconnaîtriez la plus irrécusable des vérités : " La lumière ne jaillit que de la discussion. » Ces débats théoriques, cet antagonisme des écoles sont la plus grande force du parti républicain ; c'est ce qui constitue sa supériorité sur les autres partis, frappés d'immobilisme et pétrifiés dans leur vieille forme immuable. Nous sommes un parti vivant, nous ; nous avons le mouvement, l'âge, la vie. Les autres ne sont 
que des cadavres. Plaignez-vous donc de vivre en chair et en os, au lieu d'être une statue de pierre, couchée sur un vieux tombeau !

Venons aux professions de foi : vous vous dites Républicain révolutionnaire. Prenez garde de vous payer de mots et d'être dupe. C'est précisément ce titre de Républicain révolutionnaire qu'affectent de prendre les hommes qui ne sont ni révolutionnaires, ni peut-être même républicains, les hommes qui ont trahi, perdu, et la Révolution et la République. Ils le prennent en opposition à celui de socialiste, qu'ils excommunient, et dont ils n'hésitaient pas à s'affubler cependant, lorsque le vent populaire soufflait de ce côté et que le socialisme paraissait à la veille de son triomphe. Ils l'ont renié depuis, renié et conspué, lorsque nos défaites ont abattu son drapeau. Je me rappelle le temps où Ledru-Rollin ${ }^{1}$ se prétendait plus socialiste que Proudhon ou Cabet, et se posait en Don Quichotte du socialisme. Ce temps est loin. Nous avons perdu une série de batailles qui ont chassé des premiers plans de la scène les doctrines avancées. Aujourd'hui, LedruRollin et ses amis lancent l'anathème au socialisme et lui imputent tous nos malheurs. C'est un mensonge et une lâcheté.

Vous me dites : je ne suis ni bourgeois, ni prolétaire, je suis un Démocrate. Gare les mots sans définition, c'est l'instrument favori des intrigants. Je sais bien ce que vous êtes, je le vois clairement par quelques passages de votre lettre. Mais vous mettez sur votre opinion une étiquette fausse, une étiquette empruntée à la phraséologie des escamoteurs, ce qui ne m'empêche pas de démêler parfaitement que vous et moi avons les mêmes idées, les mêmes vues, fort peu conformes à celles des intrigants. Ce sont eux qui ont inventé ce bel aphorisme : ni prolétaire, ni bourgeois! mais démocrate. Qu'est-ce donc qu'un démocrate, je vous prie ? C'est là un mot vague, banal, sans acception précise, un mot en caoutchouc. Quelle opinion ne parviendrait pas à se loger sous cette enseigne ? Tout le monde se prétend démocrate, surtout les aristocrates. Ne savez-vous pas que M. Guizot est démocrate ${ }^{2}$ ? Les roués se complaisent dans ce vague qui fait leur compte ; ils ont horreur des points sur les $i$. Voilà pourquoi ils proscrivent les termes : prolétaires et bourgeois. Ceux-là ont un sens clair et net ; ils disent catégoriquement les choses. C'est ce qui déplaît. On les repousse comme provocateurs de la guerre civile. Cette raison ne suffit-elle pas pour vous ouvrir les yeux ? qu'est-ce donc que nous sommes contraints de faire depuis si longtemps, sinon la guerre civile ? Et contre qui ? Ah ! voilà précisément la question qu'on s'efforce d'embrouiller par l'obscurité des mots ; car il s'agit d'empêcher que les deux drapeaux ennemis ne se

LEDRU-ROLLIN : Démocrate petit bourgeois, s'était attaqué maintes fois au communisme ; mais il était capable de cacher, sous une phraséologie socialiste, le caractère bourgeois de sa politique.

2 François-Pierre-Guillaume GUIZOT (1787-1874) : Homme politique et historien. Libéral modéré pendant la Restauration. En 1816-1820, l'un des chefs du parti royaliste constitutionnel. Nommé en 1830 ministre de l'Intérieur, Guizot se montra conservateur à outrance. Sa politique des années 40, alors qu'il était ministre des Affaires étrangères, fut particulièrement réactionnaire. Guizot occupe une place importante dans l'historiographie française. 
posent carrément en face l'un de l'autre, afin d'escroquer, après le combat, au drapeau victorieux les bénéfices de la victoire et de permettre aux vaincus de se retrouver tout doucement les vainqueurs. On ne veut pas que les deux camps adverses s'appellent de leurs vrais noms : Prolétariat, Bourgeoisie. Cependant ils n'en ont pas d'autres.

N'est-il pas vrai qu'il existe dans la nation une certaine classe, moins bien définie, si l'on veut, que la noblesse et le clergé, mais pourtant très distincte, et parfaitement connue de tout le monde par ce nom: classe bourgeoise ? Elle comprend la plupart des individus possédant une certaine somme d'aisance et d'instruction : financiers, négociants, propriétaires, avocats, médecins, gens de loi, fonctionnaires, rentiers, tous gens vivant de leurs revenus ou de l'exploitation des travailleurs. Joignez-y un assez bon nombre de campagnards qui ont de la fortune, mais point d'éducation, et vous atteindrez un chiffre maximum de quatre millions d'individus peut-être. Restent trente-deux millions de prolétaires, sans propriété, ou du moins sans propriétés sérieuses, et ne vivant que du maigre produit de leurs bras. C'est entre ces deux classes que se livre la guerre acharnée, dont les chances vous ont jeté en Espagne et moi à Belle-Île. Sous quel drapeau combattions-nous, je vous prie, si ce n'est sous le drapeau du prolétariat? Cependant par ma famille, par mon éducation, je suis un bourgeois et vous aussi peut-être. C'est que, grâce au ciel, il y a beaucoup de bourgeois dans le camp prolétaire. Ce sont eux qui en font même la principale force, ou du moins la plus persistante. Ils lui apportent un contingent de lumières que le peuple malheureusement ne peut encore fournir. Ce sont des bourgeois qui ont levé les premiers le drapeau du Prolétariat, qui ont formulé les doctrines égalitaires, qui les propagent, qui les maintiennent, les relèvent après leur chute. Partout ce sont les bourgeois qui conduisent le peuple dans ses batailles contre la bourgeoisie. Voilà justement ce qui a permis aux roués d'accréditer leur astucieux axiome : ni Bourgeois ! ni Prolétaire ! mais démocrate ! Quoi ! parce que nombre d'habits figurent dans le camp des blouses, et que bien plus de blouses encore combattent à la solde des habits, s'ensuit-il que la lutte ne soit pas entre la masse bourgeoise d'une part et la masse prolétaire de l'autre, c'està-dire entre le Revenu et le Salaire, entre le Capital et le Travail ? Mais beaucoup de nobles et de prêtres avaient pris fait et cause pour la première révolution ; faut-il en conclure que la révolution n'était pas dirigée contre le clergé et la noblesse ? Qui oserait soutenir une telle absurdité ? Le malheur de notre parti, c'est que l'alliance de la plupart des bourgeois avec les travailleurs n'est pas sincère. L'ambition, la cupidité les poussent dans le camp des prolétaires soulevés contre l'oppression. Ils se placent à leur tête, les mènent à l'assaut du gouvernement, s'en emparent, s'y installent, s'y retranchent, et, dès ce moment transformés en conservateurs, se retournent contre ce pauvre peuple qui perd la Tramontane, en voyant ses généraux de la veille, devenus ses fustigateurs du lendemain.

Cette mystification, toujours renouvelée avec le même succès, date de 1889. La classe moyenne lance le peuple contre la noblesse et le clergé, les met par terre et prend leur place. Tout lui a paru légitime pour emporter l'héritage des castes 
déchues ; tout lui parut légitime ensuite pour le conserver et maintenir son nouveau joug sur les épaules du prolétariat qui se rebiffe. À peine l'ancien régime abattu par l'effort commun, la lutte commence entre les deux alliés vainqueurs, la Bourgeoisie et le Prolétariat. Elle en est revenue aujourd'hui juste au point de 89. Lire l'histoire de la première révolution, c'est lire l'histoire du jour. Similitude complète ; mêmes mots, même terrain, mêmes épithètes, mêmes péripéties, c'est un calque exact. Seulement, l'expérience a mieux profité à la bourgeoisie qu'au prolétariat. Vous retrouverez aujourd'hui les hommes d'alors, ces prétendus amis du peuple, qui entendent simplement prendre la place des exploiteurs chassés. Nos soi-disant montagnards, Ledru-Rollin en tête, sont des Girondins, copies fidèles de leurs devanciers. Ils ont adopté, il est vrai, la devise et la bannière de l'ancienne Montagne ; ils ne jurent que par Robespierre et les Jacobins. Mais il le faut bien. Comment tromper sans cela? C'est la ruse habituelle des intrigants d'arborer le drapeau populaire. Les masses sont confiantes et crédules, elles se laissent prendre aux grosses paroles et aux grands gestes. On cherche aujourd'hui à leur en imposer et à les fourvoyer en même temps par des banalités ronflantes telles que: Républicains! Révolutionnaires! Démocrates! Mais on repousse avec emportement les termes précis qui tranchent et expliquent la situation : Bourgeois ! Prolétaires ! Ne vous y laissez pas prendre. Soyez de votre camp et mettez votre cocarde. Vous êtes prolétaire, parce que vous voulez l'égalité réelle entre les citoyens, le renversement de toutes les castes et de toutes les tyrannies. Que doit être la Révolution? L'anéantissement de l'ordre actuel, fondé sur l'inégalité et l'exploitation, la ruine des oppresseurs, la délivrance du peuple du joug des riches. Eh bien ! les soi-disant républicains révolutionnaires ou démocrates ne veulent rien de cela. Ils l'ont prouvé en février. Ne croyez pas qu'alors ils n'aient pas su renverser; ils ne l'ont pas voulu, ils ne le veulent pas davantage à présent, ils se moquent de nous, ce sont des égoïstes prêts à se jeter sur une nouvelle curée et à crier encore : ôte-toi de là que je m'y mette ! - Les imbéciles ! ils perdraient une dernière fois et pour toujours la révolution. Car, vous le voyez, chaque avortement entraîne une réaction plus terrible, Au surplus, vous avez vu tout ce monde à l'œuvre depuis quatre ans, jugez de l'avenir par le passé. Le sage ne doit pas faire autrement.

Je ne suis, dites-vous, ni Français, ni Espagnol, je suis cosmopolite. Ah ! très bien, moi aussi, mais gare encore la mystification! Dans votre enthousiasme cosmopolite, vous venez précisément d'envoyer votre adhésion à l'homme le moins cosmopolite et le plus égoïstement national de toute l'Europe, à Mazzini ${ }^{1}$.

\footnotetext{
Giuseppe MAZZINI (1805-1872) : Un des principaux militants du Risorgimento. Leader de la bourgeoisie italienne pendant la lutte pour l'unification de l'Italie, il combattit ardemment pour sa liberté et son indépendance. En 1831, il fonda une société secrète, « La jeune Italie », et, en 1834, une organisation européenne «La Jeune Europe». Mazzini ne proposait pas de transformations sociales, estimant que le peuple devait lutter pour son indépendance non pas pour améliorer sa condition matérielle, mais au nom d'idées de caractère moral et religieux. Sa devise était : Dieu et le Peuple. Son attitude à l'égard du socialisme était négative.
} 
Connaissez-vous Mazzini ? Non, certes ! C'est un charlatan, un arrogant, un ambitieux et même pis que tout cela, vous le voyez s'ériger en dictateur de la démocratie européenne, en champion de la révolution universelle. Eh bien ! c'est un révolutionnaire de la force de Thiers, à peu près. Savez-vous ce qu'il veut ? Une seule chose : reconstituer la nationalité italienne, faire de l'Italie une puissance de premier ordre, dont il serait le chef, bien entendu ; établir la suprématie de cette puissance, lui créer une armée permanente, une marine, un budget, en un mot tous les éléments de force ou d'oppression des gouvernements actuels, puis parler haut dans les conseils de la diplomatie et surtout abaisser la France, la poursuivre, la traquer, la mettre au ban de l'Europe, la précipiter de sa splendeur matérielle et morale. Cet homme a deux passions : la soif de l'unité italienne, la haine de la France ...

Après la catastrophe de décembre, certes, le moment était venu de l'union, de l'oubli, de la concorde; le moment était venu de se serrer en faisceau contre l'ennemi commun, en faisant trêve aux vieilles dissensions. Mais non ! Mazzini hait la France, il abhorre le socialisme, il ne peut pas perdre une si belle occasion d'insulter l'une, d'écraser l'autre, et d'assouvir ainsi sa double haine... Déblayer le terrain des idées qui le gênent, ameuter contre la France le mépris des peuples : il n'a point failli à cette mission, il a détaché à notre patrie le coup de pied de l'âne.

Comment lire sans un mélange d'indignation et de pitié ce torrent d'invectives odieuses et ridicules contre les idées sociales ? Croira-t-on qu'un homme ait pu, sans soulever des huées universelles, accuser le socialisme de la défaite de Décembre ${ }^{1}$ ! Quelle impudence chez le charlatan! Quelle imbécillité chez le public ! Comment ! C'est Pierre Leroux ${ }^{2}$, Louis Blanc et Cabet ${ }^{3}$ qui ont perdu ou fait perdre la bataille de 1851 ! Si, dans la Nièvre, l'Allier, la Saône-et-Loire, le Jura, la Drôme, l'Ardèche, le Var, l'Hérault, le Gard, le Gers, le Lot-et-Garonne, etc., des milliers d'hommes armés ont fui devant le tricorne d'un gendarme ou le pompon d'un Jeanjean, c'est la faute du socialisme ! Quelle moquerie ! Et cela se débite impunément au nez de l'Europe ! Le crime ici est aux accusateurs, l'honneur à l'accusé ! C'est le socialisme qui avait levé ces populations; ce sont les chefs politiques qui n'ont pas su les mettre en œuvre. -Que faisaient à Londres, en Suisse

Il s'agit du coup d'État du 2 décembre 1851. L'« homme », c'est Mazzini.

Pierre LEROUX (1797-1871) : Socialiste utopique. Au début des années 30, il faisait partie des saint-simoniens, puis créa sa propre théorie dans laquelle il voulait concilier le socialisme avec la religion de «l'Humanité » qu'il avait inventée. En 1848, élu à l'Assemblée constituante, puis à l'Assemblée législative. Il critiqua violemment le régime social existant, mais n'eut pas beaucoup d'influence politique pendant la révolution.

3 Étienne CABET (1788-1856) : Un des principaux représentants du communisme utopique. A exposé ses idées sur l'organisation communiste de la société dans le Voyage en Icarie (1840). Cabet jouissait d'une certaine popularité parmi les ouvriers et les artisans. Il organisa un village communiste au Texas, qu'il appela Icarie. Cette entreprise fut un échec. Cabet était opposé aux méthodes de luttes révolutionnaires. 
et ailleurs, MM. Ledru-Rollin et Compagnie, pendant les douze mortels jours de la lutte ? Pourquoi ne sont-ils pas accourus sur le champ de bataille jeter dans la balance le poids de leur nom et de leur immense popularité ? Leur présence aurait rallié ces masses abandonnées, sans direction, raffermi les courages, démoralisé l'armée et conquis la victoire. Mais non ! ces Messieurs, en vrais prétendants, attendaient majestueusement à Londres que le peuple, vainqueur sans eux, vînt humblement déposer à leurs augustes pieds son triomphe et sa puissance. Le socialisme a rempli sa mission et accompli son rôle. Les hommes ont manqué au leur. Si, par hasard, il s'était rencontré une tête vigoureuse pour maintenir ces niasses, les organiser, les conduire à l'ennemi, lui aurait-on demandé par hasard la nuance de son opinion?

Quelles inepties, que les tirades de ce Mazzini ! Le mouvement de Décembre a échoué par des raisons purement militaires. Il ne s'est trouvé ni généraux, ni soldats, lorsqu'il a fallu combattre, mais des troupeaux effarés. Comme vous le dites, on n'a vu partout que faiblesse, hésitations, terreurs, incapacité, bêtise. Les chefs d'école n'ont rien à revendiquer dans cette déroute. Mazzini soutiendra peutêtre que la piteuse figure des insurgés dans cette campagne tient à l'essence même des prédications socialistes, et qu'on ne peut pas puiser le dévouement, le courage dans la religion de l'estomac, dans les doctrines du bien-être matériel, des appétits égoïstes, etc. Mais d'abord, sans le socialisme, personne ne se serait levé du tout, ce qui simplifiait beaucoup les choses. Mazzini oublie que nulle influence au monde ne peut aujourd'hui remuer un bras au prolétaire, si ce n'est l'influence des idées sociales, que le temps du fanatisme religieux est passé, qu'on ne fait plus mouvoir les populations avec des formules creuses, des miracles et des dogmes inintelligibles. On dirait vraiment qu'il regrette ces âges de superstition et d'idiotisme, où des masses abruties se levaient à la voix d'un prêtre pour égorger leurs semblables en l'honneur de Jésus et de la Sainte-Vierge...

Je ne puis assez m'étonner que vous ayez aperçu la moindre analogie entre mes idées et celles de Mazzini. D'abord, Mazzini n'a aucune espèce d'idées révolutionnaires ou autres, si ce n'est l'indépendance et la prépondérance de l'Italie. Hors de là, rien. Je vous le demande, que nous importe à nous l'indépendance italienne, si elle ne doit pas fonder, en même temps, le régime d'égalité et de fraternité qui est notre seule religion?

... Cet homme veut se servir de nous contre nous-mêmes ; il n'est pas seulement l'ennemi de notre patrie ; il l'est aussi de nos convictions, de notre foi sociale. Il compte implanter dans son pays une exploitation bourgeoise semblable à celle qui soulève notre colère et nos armes depuis vingt-deux ans. Vous croyez peut-être que je le calomnie. Mais lisez donc ses monitoires tâchez d'y trouver autre chose que des déclamations vagues et vides, une phraséologie creuse, un parlage sans idées, des espèces de lieux communs démocratiques qui ne disent rien, n'engagent 
à rien, de grands mots, la foi, le dévouement, la révolution, sans la moindre pensée positive. Thiers ${ }^{1}$, dans l'opposition, pourrait signer ces tartines. Est-ce avec un pareil bourdonnement qu'on soulèverait les masses en France ? Elles n'en sont plus là, dieu merci. Elles comprennent la révolution comme il faut la comprendre, et comme Maître Mazzini ne la veut pas. On ne s'insurgera plus chez nous pour des phrases creuses, quand même le mot révolution y mugirait d'un bout à l'autre. Les campagnes n'ont commencé à s'ébranler qu'après avoir attaché un sens très positif et très catégorique à ce mot de Révolution. Guerre aux châteaux ! À bas les riches ! Mort aux exploiteurs ! Voilà le cri de ralliement des campagnes et leur traduction du mot: Socialisme. Ces cris sont l'épouvante de Mazzini et de ses pareils : N'oubliez pas non plus les anathèmes de Kossuth contre le Socialisme, en Angleterre, lorsqu'il a eu pris langue, et connu le dernier mot des divers partis. Lui ne demande que l'indépendance de la Hongrie, avec le maintien du régime aristocratique et féodal qui la gouverne. Jugez de son goût pour nos doctrines en nous pendrait, là-bas. La France est bien loin en avant du reste de l'Europe ; elle a franchi les phases qui restent à parcourir pour nos voisins. Le mot de révolution et de révolutionnaire n'a donc pas le même sens dans notre bouche et dans celle de la plupart des étrangers. Presque tous en sont à la guerre des bourgeois contre les rois, les nobles et les prêtres. Quelques-uns, les Hongrois, les Polonais, ne sont que des aristocrates, en lutte pour leur nationalité, contre des conquérants étrangers. Chez nous, le clergé, la noblesse sont à peu près morts et ont dû se confondre avec la Bourgeoisie pour soutenir la guerre en commun contre le Prolétariat. Rois, nobles, prêtres, bourgeois sont coalisés contre le peuple des travailleurs. Dans la dernière insurrection, partout Bonaparte a eu les bourgeois pour auxiliaires de ses troupes. Sans eux, il aurait échoué ${ }^{2}$. Sans doute nombre de bourgeois étaient dans les rangs du peuple, mais ce sont là des exceptions. Elles confirment la règle. La finance, le négoce, la propriété, le barreau ont été partout en masse contre le mouvement. On dit qu'aujourd'hui la bourgeoisie fait la guerre au pouvoir ; mais ce n'est pas pour nos beaux yeux, c'est au profit des Bourbons, aînés ou cadets.

Mazzini déblatère avec fureur contre le matérialisme des doctrines socialistes, contre la préconisation des appétits, l'appel aux intérêts égoïstes ; il foudroie la théorie avilissante et démoralisatrice du bien-être matériel. Or ne voyez-vous pas que ce sont tout simplement des déclamations contre-révolutionnaires ? Qu'est-ce que la révolution, si ce n'est l'amélioration du sort des masses ? Et quelle sottise

1 Louis-Adolphe THIERS (1797-1877) : Homme politique français. Dans sa jeunesse, il fut le chef du parti bourgeois-libéral. Au cours de la révolution de 1830, il aida Louis-Philippe à prendre le pouvoir. Ministre sous la monarchie de juillet. Pendant l'insurrection de Juin, partisan de la dictature de Cavaignac. Après les journées de Juin, chef du parti de l'« ordre ».

Le 17 février 1871, Thiers fut élu chef du pouvoir exécutif. Sa politique fut extrêmement réactionnaire. Après la proclamation de la Commune, il s'enfuit à Versailles et déclencha, avec le soutien de Bismarck, la guerre civile contre Paris révolutionnaire. A mérité le surnom de Bourreau de la Commune.

2 Blanqui évoque ici des insurrections qui eurent lieu dans certaines régions de la France après le 2 décembre 1851. 
que ces invectives contre la doctrine des intérêts ! Les intérêts d'un individu ne sont rien, mais les intérêts de tout un peuple s'élèvent à la hauteur d'un principe ; ceux de l'humanité entière deviennent une religion.

Est-ce que les peuples agissent jamais pour autre chose que des intérêts ? L'appel à la liberté est aussi un appel à l'égoïsme, car la liberté est un bien matériel et la servitude une souffrance. Combattre pour le pain, c'est-à-dire pour la vie de ses enfants, est une chose plus sainte encore que de combattre pour la liberté. D'ailleurs, les deux intérêts se confondent et n'en font vraiment qu'un seul. La faim, c'est l'esclavage. Sont-ils libres, cet ouvrier, ce paysan que la misère livre en bêtes de somme à l'exploitation du fabricant et du propriétaire ? Allez donc parler à ces malheureux de liberté. Ils vous répondront : «La liberté, c'est du pain sur la planche. Nous leur disons : «La liberté, c'est le bien-être ! " Avons-nous tort ? Nous ne parlons ni à des nègres, ni à des compagnons de Spartacus, nous autres, mais à des serfs qui ont les apparences de la liberté au milieu des douleurs de la servitude. Il faut leur faire toucher la plaie du doigt, leur montrer le nœud de l'énigme pour qu'ils le tranchent avec l'épée. Mazzini pourra nous gourmander à l'aise sur l'insurrection des appétits. Il n'y en a jamais d'autre. Mais le fanatisme religieux, dira-t-on, n'est-ce pas un mobile noble et désintéressé ? Les Croisés combattaient pour la vie éternelle, c'est le plus vorace des appétits.

... Adieu, mon cher citoyen, vous vouliez mon avis, je vous l'ai donné net et franc quoiqu'un peu long. J'ai d'autant moins dissimulé que j'éprouvais plus de regrets de cette adhésion envoyée à Mazzini. Je vous le dis, en vérité, vous n'êtes pas de son bord, tant s'en faut. Vous l'avez cru ce qu'il n'est pas et vous vous donnez à vous-même des qualifications qui ne sont pas les vôtres. Vous êtes socialiste-révolutionnaire ; on ne peut pas être révolutionnaire sans être socialiste, et réciproquement. Il y a cependant des socialistes pacifiques, gens de cabinet, d'un caractère paisible, dépaysés au milieu des armes et du tumulte et révolutionnaires seulement par les idées. En général, les chefs d'école sont de cette trempe et n'en servent pas moins pour cela la révolution. Mais on ne leur prend que leurs idées et on leur laisse leur tempérament. Quant au socialisme pratique, il n'est d'aucune secte spéciale, d'aucune église. Il prend ce qui lui convient dans chaque système, n'a point d'engouement d'école et veut renverser ce qui existe non point au hasard ni au profit des intrigues, mais en vertu de principes bien arrêtés avec la ferme résolution de construire l'avenir sur les nouvelles bases que fournira le socialisme éclairé, développé et fixé par les événements.

Nous sommes de cette catégorie, vous et moi, avec les 999 millièmes des socialistes, avec les ouvriers et les paysans, mais pas avec les Montagnards qui se chauffent d'un tout autre bois et s'intitulent, comme Ledru-Rollin, RépublicainsRévolutionnaires. 
Ils vous ont donné leur mesure depuis quatre ans. Je sais ce qu'ils veulent: recommencer Février, pas davantage ; amateurs de législature à vingt-cinc francs par jour, de préfecture à quarante, ou bien de l'hermine, de la grosse épaulette, mais surtout de l'émargement. Si les intrigants parvenaient à rééditer leur mystification de Février, cette fois nous serions bien perdus. Ce nouvel avortement amènerait Nicolas à Paris. Il ne resterait aux survivants qu'à partir pour l'Amérique. Mais à la prochaine révolution, je compte sur les paysans pour escamoter les escamoteurs. Ceux-ci s'en doutent bien, ils ont peur. La peur, voilà la clé de leur conduite dans ces dernières années. Montagne et Presse ont une sainte terreur de la canaille. La perspective d'une révolution par la Rue leur a toujours donné la chair de poule. Au 31 mai, leur conduite se définit par deux mots : Lâcheté et perfidie! Ils se sentaient entre l'enclume et le marteau noyés dans la victoire, noyés dans la défaite. Ils ont su très bien manœuvrer pour esquiver la bourrasque et garder leurs vingt-cinq francs.

Alors faut en finir. Adieu, encore une fois, et salut fraternel. 


\section{III \\ LA CRITIQUE SOCIALE}

\section{1. - L'USURE}

$\underline{\text { Retour à la table des matières }}$

Le sacrifice de l'indépendance individuelle, conséquence forcée de la division du travail, a-t-il été brusque ? Non ! Personne ne l'aurait consenti. Il y a dans le sentiment de la liberté personnelle une si âpre saveur de jouissance, que pas un homme ne l'eût échangée contre le collier doré de la civilisation.

Cela se voit bien par les sauvages que le monde européen tente d'apprivoiser. Les pauvres gens s'enveloppent dans leur linceul, en pleurant la liberté perdue, et préfèrent la mort à la servitude. Les merveilles du luxe, qui nous paraissent si éblouissantes, ne les séduisent pas. Elles dépassent la portée de leur esprit et de leurs besoins. Elles bouleversent leur existence. Ils les sentent seulement comme des étrangetés ennemies qui enfoncent une pointe acérée dans leur chair et dans leur âme. Les peuplades infortunées que notre irruption a surprises ans les solitudes américaines ou dans les archipels perdus du Pacifique vont disparaître à ce contact mortel.

Depuis bientôt quatre siècles, notre détestable race détruit sans pitié tout ce qu'elle rencontre, hommes, animaux, végétaux, minéraux. La baleine va s'éteindre, anéantie par une poursuite aveugle. Les forêts de quinquina tombent l'une après l'autre. La hache abat, personne ne replante. On se soucie peu que l'avenir ait la fièvre. Les gisements de houille sont gaspillés avec une incurie sauvage.

Des hommes étaient apparus soudain, nous racontant par leur seul aspect les premiers temps de notre séjour sur la terre. Il fallait conserver avec un soin filial, ne fût-ce qu'au nom de la science, ces échantillons survivants de nos ancêtres, ces précieux spécimens des âges primitifs. Nous les avons assassinés. Parmi les puissances chrétiennes, c'est à qui les achèvera.

1 La Critique sociale, recueil en 2 volumes des travaux de Blanqui édité en 1885 chez Alcan, comprend des articles sur des questions politiques et sociales, ainsi que plusieurs notes sur des sujets divers. 
Nous répondrons du meurtre devant l'histoire. Bientôt, elle nous reprochera ce crime avec toute la véhémence d'une moralité bien supérieure à la nôtre. Il n'y aura pas assez de haines ni de malédictions contre le christianisme qui a tué, sous prétexte de les convertir, ces créatures sans armes, contre le mercantilisme qui les massacre et les empoisonne, contre les nations qui assistent d'un œil sec à ces agonies.

Les malheureux n'ont pu s'assimiler à nous. Est-ce leur faute ? L'humanité n'a franchi que par des transitions insensibles les étapes sans nombre qui séparent son berceau de son âge viril. Des milliers de siècles dorment entre ces deux moments. Rien ne s'est improvisé chez les hommes, pas plus que dans la nature, si ce n'est les catastrophes qui détruisent et ne fondent jamais.

Les révolutions elles-mêmes, avec leurs apparences si brusques, ne sont que la délivrance d'une chrysalide. Elles avaient grandi lentement sous l'enveloppe rompue. On ne les voit jamais qu'autonomes, bien différentes de la conquête, invasion brutale d'une force extérieure qui brise et bouleverse sans améliorer. L'évolution spontanée d'une race, d'une peuplade, n'offre rien de pareil. Elle s'accomplit par degrés, sans trouble sensible, comme le développement d'une plante.

Le régime de la division du travail n'a dû remplacer l'isolement individuel que par une série de transformations, réparties sur une période immense. Chaque pas dans cette voie était applaudi comme une victoire attendue, désirée, et le changement s'est ainsi opéré peu à peu, à travers une longue suite de générations, sans froissement de mœurs, d'habitudes, ni même de préjugés.

C'était un progrès décisif sans doute... mais le prix ? abandon complet de l'indépendance personnelle ; esclavage réciproque sous l'apparence de solidarité ; les liens de l'association serrés jusqu'au garottement. Nul ne peut désormais pourvoir seul à ses besoins. Son existence tombe à la merci de ses semblables. Il doit en attendre son pain quotidien, presque toutes les choses de la vie. Car il ne peut se livrer qu'à une industrie unique. La qualité du produit est à cette condition qui asservit, et, à mesure que la division du travail s'accentue par les perfectionnements de l'outillage, l'homme se trouve plus étroitement rivé à son métier.

On sait où en sont venues les choses aujourd'hui. Des êtres humains passent leur existence à faire des pointes d'aiguille et des têtes d'épingle.

Certes, une telle situation crée des devoirs impérieux entre les citoyens. Chacun étant voué à une occupation simple, la presque totalité de son produit lui est parfaitement inutile. Ce produit servira par quantités infinitésimales à une foule d'autres individus. L'ensemble de ces consommateurs est donc tenu de fournir aux besoins de celui qui a travaillé pour eux. 
La société, dès lors, repose sur l'échange. La loi, qui en règle les conditions, doit être une loi d'assistance mutuelle, strictement conforme à la justice. Car cette aide réciproque est maintenant une question de vie ou de mort pour tous et pour chacun. Or, si le troc en nature suffisait aux temps primitifs, alors que la consommation portait sur un très petit nombre d'objets, tous de nécessité absolue, il devenait radicalement impossible entre les milliers de produits d'une industrie perfectionnée.

Un intermédiaire était donc indispensable. Les qualités spéciales des métaux précieux ont dû les désigner de bonne heure à l'attention publique. Car l'origine de la monnaie remonte à des époques inconnues. On la suppose née à peu près avec l'âge de bronze. Du reste, ceci n'a aucune importance économique et n'intéresse que l'archéologie. Ce qui nous touche, c'est l'expérience, acquise depuis trop longtemps, que les services rendus par le numéraire ont été payés bien cher. Il a créé l'usure, l'exploitation capitaliste et ses filles sinistres, l'inégalité, la misère. L'idée de Dieu seule lui dispute la palme du mal.

En pouvait-il être autrement ? Quand naquit la monnaie, deux procédés s'offraient aux hommes pour l'emploi de ce moyen d'échange, la fraternité, l'égoïsme. La droiture eût conduit rapidement à l'association intégrale. L'esprit de rapine a créé l'interminable série de calamités qui sillonne l'histoire du genre humain. Entre ces deux routes, pas même un sentier. Car, avec le maintien du régime individualiste, l'échange honnête au pair, sans le dîmage des écus, aurait castorisé notre espèce, en la figeant dans l'immobilisme. Maintenant encore, il amènerait le même résultat.

Il est permis de supposer que les hommes auraient senti la nécessité de combiner leurs efforts pour la production compliquée, qui exige une quantité considérable de matériaux de provisions et d'instruments. Tant que la simplicité de l'outillage eût permis au producteur d'obtenir par l'échange ce qui suffit pour travailler et pour vivre, on s'en serait tenu là. Mais l'homme est perfectionneur par nature. Bientôt, les exigences d'une industrie plus avancée auraient déterminé la coopération des activités particulières et, les travailleurs recueillant le fruit intégral de leur labeur, la prospérité générale aurait pris un rapide essor. Par suite, accroissement progressif de la population, du bien-être, des lumières, réseau de plus en plus développé des divers groupes, et enfin aboutissement assez prompt à l'association complète, sans despotisme, ni contrainte, ni oppression quelconque.

Le vampirisme a fait évanouir un si beau rêve. L'accumulation $d u$ capital s'est opérée non par l'association, mais par l'accaparement individuel, aux dépens de la masse, au profit du petit nombre.

En conscience, ce rêve de fraternité, au temps jadis, n'eut-il pas été une illusion, une utopie ? Entre la loyauté et la trahison, les âges de ténèbres et de sauvagerie pouvaient-ils hésiter ? Ils ne connaissaient d'autre droit que la force, 
d'autre morale que le succès. Le vampire s'est lancé à pleine carrière dans l'exploitation sans merci. L'usure est devenue la plaie universelle.

Son origine se perd dans la nuit du passé. Cette forme de la rapine n'a pu se montrer avant l'usage de la monnaie. Le troc en nature ne la comporte pas, même avec la division du travail. L'écriture n'existait certainement point alors. Elle eût conservé un souvenir précis de cette grande innovation. Or la tradition est muette.

L'usure fut un mal, non pas nécessaire, ce serait du fatalisme par trop dévergondé, mais inévitable. Ah ! si l'instrument d'échange avait porté, dès le principe, ses fruits légitimes, s'il n'avait pas été faussé, détourné de sa destination !... Oui, mais si... est toujours une niaiserie. Faire du présent une catilinaire contre le passé, n'est pas moins absurde que de faire du passé la règle, ou plutôt la routine de l'avenir.

Chaque siècle a son organisme et son existence propres, faisant partie de la vie générale de l'Humanité. Ceci n'est point du fatalisme. Car la sagesse ou la débauche du siècle ont leur retentissement sur la santé de l'espèce. Seulement, l'Humanité, être multiple, peut toujours guérir d'une maladie. Elle en est quitte pour quelques milliers d'années d'hôpital. L'individu risque la mort.

Il serait donc oiseux et ridicule de perdre ses regrets sur l'abus lamentable qu'on a fait du moyen d'échange. Hélas ! Faut-il l'avouer ? C'était l'inconvénient d'un avantage, l'expiation, disaient les chrétiens, doctrinaires de la souffrance. C'était la substitution de l'escroquerie à l'assassinat... un progrès. La dynastie de sa majesté l'Empereur-Écu venait d'éclore. Elle devait pour longtemps filouter et pressurer le monde. Elle a traversé la vie presque entière de l'humanité, debout, immuable, indestructible, survivant aux monarchies, aux républiques, aux nations et même aux races.

Aujourd'hui, pour la première fois, elle se heurte à la révolte de ses victimes. Mais un si antique et puissant souverain compte plus de serviteurs que d'ennemis. Les thuriféraires accourent en masse à la rescousse, avec l'encensoir et la musique, criant et chantant : «Hosannah ! Gloire au veau d'or, père de l'abondance ! " Une sévère analyse fera justice de ces cantiques et, dépouillant le sire de ses oripeaux, le montrera nu, ce qu'il est un pick-pocket.

1869-1870. 


\section{2. - LE COMMUMISME, AVENIR DE LA SOCIÉTÉ}

Retour à la table des matières

L'étude attentive de la géologie et de l'histoire révèle que l'humanité a commencé par l'isolement, par l'individualisme absolu, et qu'à travers une longue série de perfectionnements elle doit aboutir à la communauté.

La preuve de cette vérité se fera par la méthode expérimentale, la seule valable aujourd'hui, parce qu'elle a fondé la science.

L'observation des faits et leurs déductions irréfutables établiront pied à pied cette marche constante du genre humain. On verra nettement que tout progrès est une conquête, tout recul une défaite du communisme, que son développement se confond avec celui de la civilisation, que les deux idées sont identiques; que tous les problèmes successivement posés dans l'histoire par les besoins de notre espèce ont eu une solution communiste, que les questions aujourd'hui pendantes, si ardues, si pleines de trouble et de guerre, n'en peuvent pas davantage recevoir d'autre, à peine d'aggravation du mal et de chute dans l'absurde.

Tous les perfectionnements de l'impôt, la régie substituée à la ferme, les postes, le tabac, le sel, innovations communistes. Les compagnies industrielles, les sociétés commerciales, les assurances mutuelles de toute nature, même estampille. L'armée, les collèges, les prisons, les casernes, communisme dans les limbes, grossier, brutal, mais inévitable. Rien ne se fait hors de cette voie. L'impôt, le gouvernement lui-même sont du communisme, de la pire espèce à coup sûr, et cependant, d'une nécessité absolue. L'idée a dit à peine son premier mot. Avant d'en être à son dernier, elle aura tout changé de face. Nous ne sommes encore que des barbares.

Voyez les effets du régime actuel ! Le bas prix et par conséquent l'abondance des denrées sont tenus pour une calamité, qui ruine les producteurs, met aux abois l'industrie et le commerce. L'économie politique consacre ouvertement ce blasphème par ses définitions. Elle dénomme utilité la richesse naturelle, et valeur la richesse sociale. Or, l'utilité, c'est l'abondance, et la valeur c'est la rareté. Plus il $\mathrm{y}$ a de valeur utile, moins il y a de valeur vénale. Ô démence ! comment ce qui est un bienfait par soi-même peut devenir un fléau ? Par l'avidité du capital, qui exige la part du lion et se retire dès que les prix la lui refusent. Sa retraite renchérit les produits, et il revient pêcher en eau trouble.

Les Hollandais, dans leurs possessions asiatiques, interdisaient la culture du poivre, de la muscade, etc., et détruisaient par masses les épices, afin d'en maintenir le haut prix sur le marché. Dans les pays civilisés, chaque producteur désire la cherté de son produit et l'avilissement de tous les autres. La baisse des 
farines désole l'agriculteur, et la hausse désespère l'industriel. Cette guerre sociale en permanence n'est-elle pas une accusation terrible contre l'organisation présente?

Sous le régime communautaire, le bien profite à tout le monde et le mal ne profite à personne. Les bonnes récoltes sont une bénédiction, les mauvaises une calamité. Nul ne bénéficie de ce qui nuit aux autres et ne souffre de ce qui leur est utile. Toutes choses se règlent selon la justice et la raison. Le stock peut regorger, sans qu'il s'ensuive des crises industrielles et commerciales. Bien au contraire, l'accumulation des produits, impossible aujourd'hui sans désastres, n'aura de limite alors que leur détérioration naturelle.

Les pires plantes s'emparent souvent du terrain au détriment des meilleures. Le capitalisme, âpre au gain, l'œil aux aguets, a saisi la partie de l'association, et ce magnifique instrument de progrès est devenu entre ses mains un véritable chassepot. Il en use pour exterminer la petite et moyenne industrie, le moyen et le petit commerce.

Ces pauvres gens meurent, étouffés dans l'ombre, à la muette. Ni éclat, ni scandale. On ne voit, on n'entend rien. Ils disparaissent incognito. Ceci est bien autre chose que les émeutes de 1848, cause de tant de fureurs aveugles et de vengeances sans pitié. Les commerçants peuvent méditer à loisir la fable de La Fontaine, le torrent au fracas inoffensif, la rivière qui engloutit sans bruit dans ses eaux tranquilles. On passe le torrent, les pieds un peu mouillés ; on reste au fond de la rivière.

Sur les ruines du bourgeois modeste s'élève, plus savante et plus terrible que le vieux patriciat, cette triple féodalité financière, industrielle et commerciale qui tient sous ses pieds la société entière ; l'astuce au lieu de la violence, le détrousseur de grande route supplanté par le pickpocket.

Il était écrit que le passé, avant de mourir, frapperait son dernier coup avec l'arme même qui doit le tuer. En frappant, il s'est porté de sa propre main une blessure mortelle. L'association, au service du Capital, devient un fléau tel qu'il ne sera pas longtemps supporté. C'est le privilège de ce glorieux principe de ne pouvoir faire que le bien. Il est pour le mal l'insecticide Vicat. Les punaises qui s'y frottent périssent empoisonnées.

Quand l'heure a sonné d'une évolution sociale, tout se précipite à sa rescousse, pour aider l'enfantement. Les énergies épuisées qui vont s'éteindre lui apportent elles-mêmes, sans en avoir conscience, le concours de leur dernier effort. Nous assistons à un curieux spectacle. Sous nos yeux se déroulent les préliminaires de la communauté. 
Qu'est-ce que l'assistance mutuelle, dont le principe reçoit à chaque instant une application nouvelle, et travaille à solidariser peu à peu tous les intérêts ? Une des faces de la transformation qui s'approche. Et l'association, cette favorite du jour, panacée universelle dont les louanges retentissent en chœur, sans une seule voix discordante, qu'est-ce également sinon la grande avenue et le dernier mot du communisme?

Point d'illusions cependant. Ce dernier mot ne se dira pas, tant que la grande majorité reste accroupie, dans l'ignorance. La lune descendrait sur notre globe, plutôt que la communauté, privée de son élément indispensable, les lumières. Il nous serait aussi facile à nous de respirer sans air qu'à elle d'exister sans l'instruction, son atmosphère et son véhicule. Entre ces deux choses, instruction et communisme, le lien est si étroit que l'une ne saurait faire sans l'autre, ni un pas en avant, ni un pas en arrière. Elles ont constamment marché de conserve et de front dans l'humanité et ne se distanceront jamais d'une ligne jusqu'à la fin de leur commun voyage.

Ignorance et communauté sont incompatibles. Généralité de l'instruction sans communisme, et communisme sans généralité de l'instruction, constituent deux impossibilités égales. L'homme de la communauté, c'est celui qu'on ne trompe, ni ne mène. Or tout ignorant est une dupe et un instrument de duperie, un serf et un instrument de servitude...

Un insensé, sinon un jésuite, a osé dire dans une réunion publique : « Si la société était composée de producteurs, de bons ouvriers, mais ignorants, elle marcherait tombant de l'exploitation au despotisme, mais elle vivrait. Si la société était composée de savants, nullement producteurs, elle ne saurait vivre. »

Le même homme a dit aussi : " Je redoute cette anomalie de déclassés qu'on voit chaque jour, qui sont très instruits, très intelligents, et qui sont hors d'état de gagner leur vie. »

C'est encore ce précieux orateur qui «repousse l'enseignement gratuit, obligatoire et laïque, comme attentatoire à la liberté et aggravant la réglementation centralisatrice. »

Ce sont là tous les vœux et toutes les haines des prêtres, vœux de ténèbres, haines des lumières. La guerre aux déclassés était, après le coup d'État, le cri de ralliement de la chasse impitoyable faite aux instituteurs et aux collèges laïques. Il faut lire les circulaires des préfets de cette époque néfaste pour comprendre les projets de la réaction clérico-monarchique.

L'enseignement libre livrerait toute l'éducation aux jésuites. Nulle concurrence possible devant la coalition du clergé et du Capital. La trahison seule osera soutenir le contraire. Enfin, l'anathème lancé à une société toute composée de 
savants révèle suffisamment l'intention de perpétuer le régime des castes, ici les parias du travail manuel, là les privilégiés de l'intelligence, une masse d'abrutis et une poignée d'abrutisseurs.

Il faut beaucoup d'audace, si ce n'est encore plus d'ineptie, pour prétendre qu'une nation de savants ne saurait vivre et sans doute se lasserait de mourir de faim. Aucun peuple des temps actuels ne pourrait lutter de puissance productive avec une nation de savants, soit en agriculture, soit en industrie. La distance entre les deux serait plus grande qu'entre les Gaulois de César et les Français de 1870.

Que les réunions publiques, si elles durent, prennent garde aux émissaires de la Compagnie de Jésus. C'est sa tactique d'en entretenir dans tous les clubs, et, pour enlever les questions qui tiennent à cœur aux révérends pères, ces limiers ont l'ordre de prendre tous les masques. Or l'intérêt clérical, c'est l'enseignement libre, la mise en suspicion de la science et des savants, et la guerre aux déclassés, autrement dit, aux hommes instruits et pauvres.

Quiconque, sous prétexte de liberté et d'économie, rejette l'enseignement gratuit et obligatoire, pour demander l'enseignement libre, est un agent du jésuitisme. Qu'il se dise d'ailleurs républicain, révolutionnaire, athée, matérialiste, socialiste, communiste, proudhoniste, tout ce qu'il voudra, peu importe la couleur de son masque, on peut, sans crainte d'erreur, l'appeler suppôt des jésuites. En effet, le bon sens montre que l'enseignement libre, sans intervention de l'État, ni gratuité, c'est, par la toute-puissance de l'écu, le monopole de l'éducation aux mains des prêtres.

Or enseignement du prêtre signifie ténèbres et oppression. L'armée noire, forte de cent mille soldais mâles et femelles, s'en va pleine de furie, colportant la nuit et posant partout l'éteignoir. Appuyée sur l'État, elle domine, gouverne, menace, comprime. Le bras séculier est à ses ordres, le Capital lui prodigue toutes ses ressources, la sachant son meilleur auxiliaire, ou plutôt sa dernière planche de salut.

Qui ne connaît aujourd'hui ce péril ? La démocratie entière, sans distinction de nuances, le proclame, en invoquant l'unique remède, l'instruction. Divisée pour tout le reste, elle est unanime sur ce point. Le même cri s'échappe de toutes les poitrines : « De la lumière ! De la lumière ! Plus d'abrutissement clérical ! »

Vaines clameurs ! le gouvernement fait la sourde oreille et ne répond que par l'accélération fiévreuse de l'influence jésuitique. Chaque année se ferment par centaines les écoles laïques et s'ouvrent plus nombreuses encore les écoles congréganistes. Si l'on compare 1848 à 1870, on verra que les filles, il y a vingtcinq ans, appartenaient par moitié aux deux enseignements, et qu'il en reste à peine un sixième aujourd'hui aux laïques; que de dix-sept pour cent, le chiffre des garçons empoisonnés par l'éducation sacerdotale s'est élevé à cinquante pour cent, 
et que cette effrayante progression continue avec redoublement pour les deux sexes. Le plan de crétinisation universelle se poursuit sans relâche. S'accomplira-til ?

Non! Mais quel retard dans l'avènement des jours heureux ! Quelle halte désolante dans l'antagonisme et la misère! Les années fuient, inutiles et monotones, les générations passent, dévorées l'une après l'autre par le monstre de la superstition et de l'ignorance. Il est là debout, barrant à l'humanité le chemin de la terre promise qu'elle entrevoit dans le lointain, sans pouvoir l'atteindre.

Combien de temps encore faudra-t-il lutter contre cet ennemi qui ne fait jamais quartier, lui, et qu'on pardonne toujours, après l'avoir terrassé ? Ah ! si la révolution avait fait son devoir en 1830, en 1848, ce demi-siècle, si tristement perdu, aurait suffi pour toucher le but. La guerre serait finie, et les nations, laissant derrière elles le passé s'enfoncer rapidement dans la nuit, s'avanceraient à grands pas vers un avenir toujours plus radieux.

La révolution sera-t-elle sage enfin à son prochain triomphe, ou fera-t-elle grâce encore une fois au génie du mal, qu'elle a laissé jusqu'ici se relever plus terrible de chacune de ses chutes ? Il y a dans nos rangs des traîtres qui le protègent aux heures de revers, avec des phrases cabalistiques dont le peuple est dupe. Le mot d'ordre de la prochaine trahison sera : "Suppression du budget des cultes ; séparation de l'Église et de l'État. » Traduisez : victoire du catholicisme, écrasement de la révolution. Que notre devise à nous soit: «Suppression des cultes, expulsion des prêtres ! » et qu'elle ne fléchisse ni devant la prière, ni devant la menace, ni devant l'astuce.

Céder serait la mort. La république victorieuse n'aura pas de temps à gaspiller en luttes inutiles. Trop d'obstacles exigeront des années de tranchée ouverte, pour s'amuser à l'attaque en règle d'une haie qui peut se franchir à la course. L'armée, la magistrature, le christianisme, l'organisation politique, simples haies. L'ignorance, bastion formidable. Un jour pour la haie ; pour le bastion, vingt ans.

La haie gênerait le siège ; - rasée. Il ne sera encore que trop long, et, comme la communauté ne peut s'établir que sur l'emplacement du bastion détruit, il n'y faut pas compter pour le lendemain. Un voyage à la lune serait une chimère moins dangereuse. C'est pourtant le rêve de bien des impatiences, hélas ! trop légitimes, rêve irréalisable avant la transformation des esprits. La volonté même de la France entière resterait impuissante à devancer l'heure, et la tentative n'aboutirait qu'à un échec, signal de furieuses réactions.

Il y a des conditions d'existence pour tous les organismes. En dehors de ces conditions, ils ne sont pas viables. La communauté ne peut s'improviser, parce qu'elle sera une conséquence de l'instruction qui ne s'improvise pas davantage. N'oublions pas la race des vampires, qui est aussi celle des caméléons. Elle ne 
disparaîtrait pas plus, le lendemain de la révolution, que la race des naïfs et des simples, sa pâture ordinaire.

Les habits seraient tôt retournés. On verrait surgir de terre, en foule, comme les champignons après l'orage, des charlatans de communisme pour embrigader les hommes, des tartufes de communauté pour embobeliner les femmes. À eux, prix infaillible de l'intrigue, la gérance, c'est-à-dire la disposition discrétionnaire des biens communs. La masse des ignorants deviendrait leur proie et leur armée... absolument comme aujourd'hui, avec des conséquences bien autrement terribles : une telle mêlée de tyrannie et d'anarchie que la contre-révolution arriverait foudroyante, non pour un jour, mais pour de longues années, sous les terreurs vivaces du souvenir. Un bond effroyable en arrière !

N'est-ce point d'ailleurs folie de s'imaginer que, par une simple culbute, la société va retomber sur ses pieds, reconstruite à neuf? Non ! les choses ne se passent pas ainsi, ni chez les hommes, ni dans la nature.

La communauté s'avancera pas à pas, parallèlement à l'instruction sa compagne et son guide, jamais en avant, jamais en arrière, toujours de front. Elle sera complète le jour où, grâce à l'universalité des lumières, pas un seul homme ne pourra être la dupe d'un autre. Ce jour-là, nul ne voudra souffrir l'inégalité de fortune. Or le communisme seul satisfait à cette condition...

On objectera peut-être que l'égalité de l'éducation n'entraîne point du tout celle des intelligences, et qu'il restera toujours l'inégalité des cerveaux pour constituer une hiérarchie intellectuelle, depuis le génie jusqu'à la nullité.

D'accord. Mais, chez le plus pauvre cerveau, l'instruction intégrale sera une armure suffisante, à l'épreuve de la tromperie, quel qu'en soit le masque. L'expérience le prouve. L'exploiteur rencontrerait sur chaque visage ce sourire écrasant qui veut dire : «Banquiste, va! » La conviction de son impuissance lui épargnera ce déboire. D'ailleurs, l'ordre établi n'étant point une improvisation, la race des vampires aura eu le temps de s'acclimater et de se résigner au nouveau milieu. Qu'on ne s'y trompe pas, la fraternité, c'est l'impossibilité de tuer son frère.

La plus utile des facultés humaines, la faculté protectrice par excellence, qui nous défend à la fois contre le dedans et le dehors, contre les autres et contre nousmêmes, le jugement, trop rare aujourd'hui, prendra, par l'instruction intégrale, un essor prodigieux qui en fera l'arme de la société nouvelle. Fruit de l'expérience et de la comparaison, il y puisera une force inconnue. C'en sera fait alors de la ruse. Une clairvoyance implacable ira la dépister sous ses derniers déguisements. Fripons et dupes cesseront de former les deux grandes divisions de l'humanité.

Déjà la crédulité est partout battue en brèche. L'armée noire garde encore sous séquestre les enfants et les femmes. Les hommes l'abandonnent. Tenir l'enfant et 
perdre l'adulte ! Avoir toujours à soi, par privilège, la page blanche où se gravent si aisément les impressions ineffaçables, et les voir ensuite effacer, remplacer... travail si rude ! Quelle sentence irrévocable ! Puisse-t-elle s'exécuter à bref délai !

Le génie demeurera une exception. Le jugement deviendra l'apanage commun. Il suffit pour détrôner à jamais l'hypocrisie, reine actuelle du monde. Tartufes de sentiment, tartufes de franchise, tartufes de mansuétude, tartufes de dévouement, tartufes de cordialité, tartufes de candeur, tartufes de chevalerie, tartufes de vertu, tartufes de bonhomie, tartufes de bienveillance, tartufes, mes amis, abominables pestes, vous serez démasqués à la minute, sifflés, bafoués, et la tartuferie religieuse, la plus infernale de toutes, ne sera plus qu'un souvenir historique, souvenir d'étonnement et d'horreur.

Les gens auront des regards si perçants que, chez tout individu, défauts et qualités se compteront un à un, comme dans un bocal de verre. Ah! il faudra marcher droit, sous peine des rires et des huées. Et cependant l'indulgence sera le fond général des esprits, car le libre arbitre, par arrêt définitif de la science, aura cessé d'exister. Quant au crime, disparu avec le Capital et la religion, ses père et mère.

Telles seront, d'après nous, les conséquences de l'universalité des lumières. Notez que, dans cet horoscope, le communisme figure comme simple effet, non comme cause. Il naîtra fatalement de l'instruction généralisée et ne peut naître que de là.

Or on lui reproche d'être le sacrifice de l'individu et la négation de la liberté. Certes, s'il venait, par forceps, avant terme, ce triste avorton ferait fuir à toutes jambes vers les oignons d'Égypte. Mais, s'il doit être fils de la science, qui osera se porter accusateur contre l'enfant d'une telle mère ? Où sont d'ailleurs les preuves à l'appui de l'imputation qu'on lui lance ? Elle n'est qu'une insulte gratuite, puisque l'accusé n'a jamais vécu.

Et au nom de qui cette arrogante supposition ? Au nom de l'individualisme qui, depuis des milliers d'années, assassine en permanence la liberté et l'individu. Combien sont-ils, dans notre espèce, les individus dont il n'ait pas fait des ilotes et des victimes ? Un sur dix mille peut-être. Dix mille martyrs pour un bourreau ! Dix mille esclaves pour un tyran ! et l'on plaide de par la liberté ! Je comprends ! Quelque sinistre escobarderie, embusquée derrière une définition. L'oligarchie ne s'intitule-t-elle pas démocratie, le parjure honnêteté, l'égorgement modération ?

La liberté qui plaide contre le communisme, nous la connaissons, c'est la liberté d'asservir, la liberté d'exploiter à merci, la liberté des grandes existences, comme dit Renan, avec les multitudes pour marchepied. Cette liberté-là, le peuple l'appelle oppression et crime. Il ne veut plus la nourrir de sa chair et de son sang. 
Moralistes et législateurs posent tous en principe que l'homme est tenu de faire à la société le sacrifice d'une portion de sa liberté, en d'autres termes que la liberté de chacun a pour limite la liberté d'autrui. Cette définition est-elle obéie par l'ordre actuel, avec ses deux catégories de privilégiés et de parias ? Combien faut-il de servitudes pour faire une liberté ? 10, 20, 60, 100, 2 000, 30000,100000 ? innombrables les tarifs, innombrables leurs applications. La chaîne seule ne varie pas.

Tout empiétement sur la liberté d'autrui viole la définition des moralistes, la seule légitime, quoique toujours restée un vain mot. Elle implique donc parité sociale entre les individus, d'où il suit que la liberté a pour limite l'égalité.

Seule, l'association intégrale peut satisfaire cette loi souveraine. Le vieil ordre la trépigne sans pudeur et sans pitié. Le communisme est la sauvegarde de l'individu, l'individualisme en est l'extermination. Pour l'un, tout individu est sacré. L'autre n'en tient pas plus compte que d'un ver de terre, et l'immole par hécatombe à la sanglante trinité Loyola César et Shylock ; après quoi, il dit avec flegme : « La communauté serait le sacrifice de l'individu. »

Elle troublerait le festin des anthropophages, cela est clair. Mais ceux qui en font les frais ne trouveront pas mauvais ce dérangement. C'est l'essentiel. Sous quel prétexte d'ailleurs nous chercher querelle ? S'agit-il d'imposer le communisme a priori ? Nullement. On se borne à prédire qu'il sera le résultat infaillible de l'instruction universalisée. Qui pourrait condamner le développement rapide des lumières ? S'il doit s'ensuivre l'avènement régulier de la communauté, personne n'a mot à dire.

Chacun proclame l'instruction la seule réponse possible aux énigmes du sphinx social. Il n'est pas bien sur que cette invocation soit sincère dans toutes les bouches. Il en est encore de ce mot comme de tous ceux qui posent un problème. Autant de partis, autant de définitions. Pour les prêtres, c'est le catéchisme et point de science ; pour les socialistes, c'est la science et plus de catéchisme.

Rien d'étonnant dès lors dans cette unanimité des voix. Elle n'en cache pas moins une guerre à mort. Le peuple n'a pas à s'en inquiéter. Il est sans arrièrepensée, lui, et ne prend point de fausses enseignes. Il a toujours écrit sur la sienne : Liberté, Instruction, avec un sens clair et précis. Le cléricalisme, au contraire, après avoir longtemps chargé ces deux mots de ses anathèmes, s'est ravisé, voyant son impuissance, et les colle aujourd'hui à sa bannière, pour bénéficier de leur prestige. Double et impudent mensonge. Que lui importe, pourvu qu'il fasse des dupes !

Que le conservatisme pressente où conduit la diffusion des lumières, son alliance avec l'éteignoir le dit assez haut. Plus d'ignorance, plus d'oppression ! Il est sapé par la base et lutte pour prolonger les ténèbres, son milieu vital. Au 
socialisme la tâche opposée : faire émerger de la nuit présente le ciel lumineux qui éclairera sa victoire, victoire de la justice et du sens commun sur la malfaisance et l'absurdité. Sa mission alors sera remplie.

On prétend toutefois exiger de lui davantage. La doctrine capitaliste, qui a comblé et comble encore le genre humain de tant de bienfaits, se tourmente fort de voir son pupille s'acheminer vers d'autres drapeaux. Dans sa sollicitude, elle somme le communisme, son jeune rival, d'exposer par le menu les détails de l'organisation future, de résoudre toutes les difficultés qu'il lui plaît de prévoir, de servir enfin à sa curiosité un édifice, complet de la cave au grenier, sans omission d'un clou ni d'une cheville.

« Comment le citoyen de la nouvelle Salente disposera-t-il de sa personne, de son temps, de ses fantaisies de voyage ou de repos ? Qui lavera la vaisselle ? Qui balaiera ? Qui videra les pots de chambre et remplira les tinettes ? Qui tirera la houille des mines, etc. "

À ces interrogations impertinentes, une seule réponse «Cela ne vous regarde pas, ni moi non plus. »

Eh ! quoi ! Voici quarante à cinquante millions d'hommes, tous ferrés à glace, mieux que pas un académicien, tous armés de pied en cap contre la violence et la ruse, tous susceptibles comme des sensitives, ombrageux comme des chevaux sauvages. Rien de ce quelque chose d'exécrable et d'exécré qui s'appelle un gouvernement ne pourrait montrer son nez au milieu d'eux; pas une ombre d'autorité, pas un atome de contrainte, pas un souffle d'influence ! Et ces quarante millions de capacités, à qui nul de nous n'irait à la cheville, auraient besoin, pour s'organiser, de nos conseils, de nos règlements, de notre férule ! Ils ne sauraient, sans nous, où trouver des chemises et des culottes, et ils seraient gens à mettre dans leur oreille, si nous ne les avions prévenus qu'on mange par la bouche ! C'est fort. Quant à moi, s'ils venaient me relancer dans ma tombe sur la question des pots de chambre, je leur dirais tout net : «Quand on ne sait pas se boucher le nez, on se bouche le derrière. "

Nos quarante immortels eux-mêmes, si une multiplication soudaine par six zéros improvisait un million de Thiers, un million d'Ollivier ${ }^{1}$, un million de

Émile OLLIVIER (1825-1913) : Homme d'État, membre de l'Académie française. Pendant les Premières années du second empire, il avait appartenu à l'opposition bourgeoise républicaine modérée. Au fur et à mesure que la lutte des classes s'accentua, il se rapprocha des bonapartistes et, le 2 janvier 1870, fut mis à la tête du nouveau cabinet. Dans l'été 1870, il déclara la guerre à la Prusse, « le cœur léger », selon sa propre expression. Le 9 août, après une série de défaites, le ministère Ollivier, qui s'était révélé complètement incapable de faire face aux difficultés de la guerre, fut renversé. Après la chute de l'Empire, Ollivier s'enfuit en Italie. Le reste de sa vie, il l'employa à justifier ses reniements et sa politique. 
Dupanloup $^{1}$, etc. ; avec la France déserte à leur disposition, croyez-vous bonnement que, montés au chiffre de quarante millions, ils passeraient tout leur temps à s'adresser des harangues en vers et en prose ? Pas si fous ! Item, il faut déjeuner, et ils n'attendraient pas une heure pour mettre la main à la pâte.

Naturellement, le premier vote aurait pour objet la division du travail. Le système des castes, presque installé d'avance par le fait des quarante types, serait-il acclamé d'enthousiasme ? Oh ! que nenni ! Plus si écrevisses les quarante, après la multiplication ! Je me persuade que les Mérimée, par exemple, ne tiendraient pas obstinément au privilège de rincer les vases de nuit, fût-ce des vases étrusques. Tant de fortes têtes sauraient bien entourer cette besogne indispensable d'une auréole de poésie, qui permît de dire de tous et de chacun

Ce réac édenté devint, à son honneur, D'assez triste écrivain, merveilleux vidangeur.

C'est une chose réjouissante, quand on discute communisme, comme les terreurs de l'adversaire le portent d'instinct sur ce meuble fatal ! «Qui videra le pot de chambre? » C'est toujours le premier cri. "Qui videra mon pot de chambre ? » veut-il dire, au fond. Mais il est trop avisé pour user du pronom possessif, et, généreusement, il consacre ses alarmes à la postérité.

Sale chose que l'égoïsme de l'heure vivante ! Un mélange de cynisme et d'hypocrisie! Est-il question du passé ? Feuilles mortes ! on en fait litière. L'Histoire s'esquisse à grands traits, du plus beau sang-froid ; avec des monceaux de cadavres et de ruines. Nulle boucherie ne fait sourciller ces fronts impassibles. Le massacre d'un peuple, évolution de l'humanité. L'invasion des barbares ? infusion de sang jeune et neuf dans les vieilles veines de l'Empire romain. La trombe des Germains et des Huns n'a passé sur le monde latin que pour en purifier l'atmosphère corrompue. Ouragan providentiel! Quant aux populations et aux villes que le fléau a couchées sur son passage... nécessité... marche fatale du progrès. Tout est bien qui a enfanté le présent, c'est-à-dire nous. Pas d'avances trop dispendieuses pour un si beau produit.

Mais s'agit-il des générations à venir ? Quel changement ! À l'insensibilité succède une passion délirante. On est pris d'une telle furie de tendresse devant ces poupards en perspective, qu'on se hâte de les mettre sous clé, afin de les préserver des accidents. Leurs pas, leurs gestes sont comptés, équilibrés, crainte de chute. Tout est réglé d'avance, comme un papier de musique, pour les pauvres petits automates, et à perpétuité, s'il vous plaît. Religion perpétuelle, dynastie

Félix-Antoine DUPANLOUP (1802-1878) : Évêque d'Orléans, réactionnaire à outrance. Il participa à l'élaboration de la loi Falloux (1850) qui donna au clergé la haute main sur l'enseignement. En 1871, il fut élu à l'Assemblée nationale. 
perpétuelle, lois perpétuelles, et surtout dette perpétuelle, en payement légitime de tant de sollicitude et d'amour.

Hé ! bonnes gens, quand vous aurez rejoint vos ancêtres, on fera de vous le cas, et un peu moins que vous avez fait d'eux. Après s'être mises à l'abri de l'infection de vos carcasses matérielles, les poupées à ressort de votre usine casseront tous leurs ressorts et feront, à peu près en ces termes, l'oraison funèbre de vos carcasses morales :

«Dans l'histoire de l'Humanité, vous êtes la page du choléra et de la peste. Les barbaries et les sottises de vos aïeux étaient la faute de l'ignorance, le résultat de convictions aveugles. Vous avez fait le mal, vous, sciemment, avec préméditation, par noir égoïsme. Car vous n'avez jamais cru à rien qu'à votre intérêt, ignobles sceptiques, et à cet intérêt vous avez voulu sacrifier jusqu'à vos plus lointains neveux. »

«Qui vous avait donné mandat de stipuler en notre nom, de penser et d'agir pour nous ? Avons-nous consenti la traite tirée sur notre travail ? Tartufes ! sous prétexte d'assurer notre bien-être, vous avez dévoré d'avance le fruit de nos sueurs, nous crevant de votre mieux les yeux et les oreilles, pour nous empêcher de voir et d'entendre. Que ne vous borniez-vous à vos affaires, en nous laissant le soin des nôtres ? Vous aviez l'impôt annuel, pour recette et pour dépense. Il fallait rester dans cette limite et vous conduire en loyaux usufruitiers, frais et profits compensés. Nous n'acceptons l'héritage que sous bénéfice d'inventaire. Qui fait les dettes les paye.

«On dit que vos emprunts avaient pour but des travaux profitables à la postérité, et qu'elle doit prendre sa part des charges comme des bénéfices. On travaille pour elle, à elle de payer. - Pour elle ? Hypocrites! Quelle entreprise a jamais été conçue dans un intérêt futur ? Non ! le présent ne songe qu'à lui. Il se moque de l'avenir aussi bien que du passé. Il exploite les débris de l'un et veut exploiter l'autre par anticipation. Il dit : «Après moi le déluge ! » ou, s'il ne le dit pas, il le pense et agit en conséquence. Ménage-t-on les trésors amassés par la nature, trésors qui ne sont point inépuisables et ne se reproduiront pas ? On fait de la houille un odieux gaspillage, sous prétexte de gisements inconnus, réserve de l'avenir. On extermine la baleine, ressource puissante, qui va disparaître, perdue pour nos descendants. Le présent saccage et détruit au hasard, pour ses besoins ou ses caprices. »

Donc, occupons-nous d'aujourd'hui. Demain ne nous appartient pas, ne nous regarde pas. Notre seul devoir est de lui préparer de bons matériaux pour son travail d'organisation. Le reste n'est plus de notre compétence. Un bas Breton n'a point à faire la leçon à l'Institut Simons Veuillot soutient le contraire, comme c'est probable, disons à son intention personnelle : «Gros-Jean n'en doit pas remontrer à son curé ! » Ce rôle de bas Breton ou de Gros-Jean n'est-il pas grotesque ? et ne 
faut-il pas admirer la fatuité de ces Lycurgue qui se croient tenus en conscience de minuter article par article le code de lavenir ! ? Ils semblent craindre que ces pauvres générations futures ne sachent pas mettre un pied devant l'autre et s'empressent de leur fabriquer, qui un bourrelet, qui des brassières, qui une petite prison roulante pour leur apprendre à marcher libres.

Il est vrai que ces générations ne seront pas en reste de charité et s'attendriront à leur tour sur la folie de ces bons ancêtres, maçonnant à l'envi des édifices sociaux pour y claquemurer la postérité. La vieille prison est encore debout ; menaçante et noire, avec deux ou trois lézardes à peine qui ont permis l'évasion de quelques captifs, et déjà comme les mères-poules, à la vue de leurs petits canards descendus à l'eau, les néo-révélateurs sont dans les transes pour les malheureux évadés qui s'ébattent joyeusement au soleil :

«Eh! mes enfants! Quelle imprudence ! Vous allez vous enrhumer au grand air. Vite, rentrez dans le beau palais que j'ai construit en votre faveur. On n'a jamais vu, on ne verra jamais son pareil ! »

Ils sont déjà trois ou quatre Moïses qui assurent avoir bâti à chaux et à ciment pour l'éternité, et les portes de l'enfer ne prévaudront certes pas contre ces paradis neufs à l'enchère. Libre à un croyant de chercher, à travers la brume, quelque fugitive échappée sur le monument de l'avenir. C'est un but honnête de promenade et un excellent exercice pour les yeux. Mais nous rapporter de cette excursion un dessin complet et minutieux de l'édifice, plan, coupe, hauteur et détails, avec état de lieux authentique... non, mon ami, non, rempochez votre épure.

La manie serait innocente, si ces fanatiques amants de claustration ne prêtaient main-forte contre les démolisseurs de la vieille geôle, qui refissent de travailler à la confection de la nouvelle et prétendent laisser le public en promenade, chose horrible suivant tous les messies.

Que la civilisation ait pour couronnement inévitable la communauté, il serait difficile de nier cette évidence. L'étude du passé et du présent atteste que tout progrès est un pas fait dans cette voie, et l'examen des problèmes aujourdhui en litige ne permet pas d'y trouver une autre solution raisonnable. Tout est en pleine marche vers ce dénouement. Il ne relève que de l'instruction publique, par conséquent de notre bonne volonté. Le communisme n'est donc pas une utopie. Il est un développement normal et n'a aucune parenté avec les trois ou quatre systèmes sortis tout équipés de cervelles fantaisistes.

Cabet, par son Icarie et sa tentative de Nauvoo ${ }^{1}$, a eu précisément le tort d'assimiler l'idéal régulier de l'avenir aux hypothèses en l'air des révélateurs de pacotille. Il a dû échouer plus rudement encore que ses émules, le communisme étant

Colonie communiste fondée aux États-Unis par Cabet en 1848. 
une résultante générale, et non point un œuf pondu et couvé dans un coin de l'espèce humaine, par un oiseau à deux pieds, sans plume ni ailes.

Saint-simoniens, fouriéristes, positivistes ont tous déclaré la guerre à la révolution, accusée par eux de négativisme incorrigible. Pendant une trentaine d'années, leurs prêches ont annoncé à l'univers la fin de l'ère de destruction et l'avènement de la période organique, dans la personne de leurs messies respectifs. Rivales de boutique, les trois sectes ne s'accordaient que dans leurs diatribes contre les révolutionnaires, pécheurs endurcis, refusant d'ouvrir les yeux à la lumière nouvelle et les oreilles à la parole de vie.

Chose remarquable qui suffit pour établir la distinction, les communistes n'ont cessé de former l'avant-garde la plus audacieuse de la démocratie, tandis que les poursuivants d'hypothèses ont rivalisé de platitude devant tous les gouvernements rétrogrades et mendié leurs bonnes grâces par l'insulte à la république. C'est que le communisme est l'essence, la moelle de la révolution, tandis que les nouvelles religions n'en furent jamais que les ennemis, tout comme l'ancienne.

Personne n'ignore ce que sont aujourd'hui les saint-simoniens: des piliers de l'Empire. On ne peut pas certes les accuser d'apostasie. Leurs doctrines ont triomphé : la souveraineté du Capital, l'omnipotence de la banque et de la haute industrie. Ils trônent avec elles, rien de mieux. Mais dire que ces braves gens ont été pris pour de dangereux novateurs !

Les fouriéristes, après avoir fait, dix-huit ans, leur cour à Louis-Philippe sur le dos des républicains, ont passé à la république avec la victoire, fort étonnés bientôt et encore plus déconfits de rencontrer la proscription où ils avaient cru trouver la puissance. Disparus dans la tempête avec leur burlesque utopie. Les débris restent mêlés aux rangs démocratiques. Ils n'ont plus d'espoir ailleurs.

Le positivisme, troisième chimère du siècle, a débuté par la négation de tous les cultes, et fini par le système des castes, enté sur une caricature de catholicisme. Du reste, il s'est divisé. Les orthodoxes disent gravement la messe comtiste dans la chambre mortuaire du prophète. Les protestants passent leur vie à nier la doctrine qu'ils prêchent, ou prêcher la doctrine qu'ils nient, comme on voudra. Tous également remarquables par leur crainte des coups, leur respect de la force et leur soin de fuir le contact des vaincus.

Comte ${ }^{1}$ a consacré ses dernières années au panégyrique dé l'empereur Nicolas et au trépignement des révolutionnaires. Il avait imaginé ses castes pour gagner le cœur de la réaction. La réaction et le tsar n'ont pas daigné tourner la tête.

1 Auguste COMTE (1798-1857) : Philosophe et sociologue, fondateur de la philosophie et de la sociologie positivistes. La philosophie de l'histoire de Comte est idéaliste. Sa thèse fondamentale est que les idées régissent et transforment le monde. Dans sa classification des 
Les schismatiques font un certain bruit et possèdent un simulacre d'influence, grâce aux trembleurs de l'athéisme qui sont venus s'abriter sous une équivoque. Passé le péril, cette ombre d'existence s'évanouira, et les positivistes prendront la queue du socialisme ou émigreront dans le camp conservateur.

Le communisme, qui est la révolution même, doit se garder des allures de l'utopie et ne se séparer jamais de la politique. Il en était dehors naguère. Il s'y trouve en plein cœur aujourd'hui. Elle n'est plus que sa servante. Il ne doit pas la surmener, afin de conserver ses services. Il lui est impossible de s'imposer brusquement, pas plus le lendemain que la veille d'une victoire. Autant vaudrait partir pour le soleil. Avant d'être bien haut, on se retrouverait par terre, avec membres brisés et une bonne halte à l'hôpital.

N'oublions pas notre axiome : instruction et communauté cheminent de front et ne peuvent se devancer d'un pas. C'est beaucoup déjà d'avoir une sœur siamoise que tout le monde appelle à grands cris. L'une ne viendra pas sans l'autre.

Il est vrai que ces appels unanimes ont un sous-entendu : la définition. Or, nous l'avons vu, la définition est double, noire et blanche. Ne soyons pas dupes. Les pièces sont là. Le gouvernement et le conservatisme ne veulent que l'instruction donnée par les prêtres, ce qui signifie : ténèbres. Ils poussent avec frénésie à ce résultat. César, Shylock et Loyola marchent, les coudes serrés, à la conquête de la nuit. Ils n'arriveront pas, mais ils nous empêchent aussi d'arriver.

Les deux forces aux prises se tiennent mutuellement en échec. Personne n'avance, personne ne recule. Immobilité sur place. Pour nous, dans la situation, c'est un succès. La nuit tient à ses ordres 50000 prêtres, 50000 congréganistes et à peu près 40000 instituteurs. Car presque tous aujourd'hui obéissent à la sacristie. L'Université est en pleine trahison.

On ne peut même pas compter sur la presse. Celle de l'opposition ne dépasse guère les murs des villes. La campagne appartient aux feuilles rétrogrades qui viennent appuyer de leur propagande écrite la propagande orale du curé, des ignorantins et des grands propriétaires. Tout est contre nous, rien pour nous.

Que nous reste-t-il donc ? Le souffle du progrès qui circule dans l'air, les communications d'homme à homme par les routes ferrées, la conscience publique, le spectacle de nos ennemis surtout, notre meilleur plaidoyer. Ce qui grandit peutêtre, c'est la colère, force précaire. La colère d'aujourd'hui devient souvent la peur

sciences, la sociologie, étant la science la plus complexe, occupe la première place. Dans le domaine de la politique, le système de Comte est réactionnaire, car il professe la nécessité de « modérer » l'antagonisme des classes et d'établir l'équilibre dans la société capitaliste. Blanqui avait étudié attentivement les ouvrages de Comte avant 1848. 
de demain. Point de base solide que l'instruction, et les efforts adverses la paralysent. Nous marquons le pas.

Mais le lendemain d'une révolution, coup de théâtre. Non pas qu'il s'opère une transformation subite. Hommes et choses sont les mêmes que la veille. Seulement l'espoir et la crainte ont changé de camp. Les chaînes sont tombées, la nation est libre, et un horizon immense s'ouvre devant elle.

Que faire alors ? Atteler un nouveau relais au même chariot, comme en 1848, et reprendre tranquillement les mêmes ornières ? On sait où elles mènent. $\mathrm{Si}$, au contraire, le sens commun a pris enfin le dessus, voici, tracées côte à côte, deux routes parallèles, L'une, d'étape en étape, aboutit à l'instruction intégrale universelle ; l'autre, par des étapes correspondantes, à la communauté.

Sur les deux routes, au début, même mesure : destruction des obstacles. Ils sont bien connus. Ici, l'armée noire ; à côté, la conspiration du Capital. L'armée noire, on l'évacue au delà des frontières, besogne simple. Le Capital est moins accommodant. On sait son procédé invariable : il fuit ou se cache. Après quoi, le capitalisme se met à la fenêtre et regarde tranquillement le peuple barboter dans le ruisseau. C'est l'histoire de 1848 . Le peuple a gémi, pleuré, maugréé, puis, se fâchant trop tard, a été bien battu et a repris ses fers. Ne recommençons pas.

Empêcher la disparition du numéraire, impossible! Il n'y faut pas songer seulement. Mais les meubles, voire les immeubles, ne peuvent ni se cacher, ni fuir. Cela suffit. On court au plus pressé.

\section{DISPOSITIONS IMMÉDIATES}

\section{Dans l'ordre économique.}

$1^{\circ}$ Commandement à tous les chefs d'industrie et de commerce, sous peine d'expulsion du territoire, de maintenir provisoirement dans le statu quo leur situation présente, personnel et salaire. L'État prendrait des arrangements avec eux. Substitution d'une régie à tout patron expulsé pour cause de refus.

$2^{\circ}$ Convocation d'assemblées compétentes, pour régler la question des douanes, celle des mines et des grandes compagnies industrielles, celle du crédit et de l'instrument d'échange.

$3^{\circ}$ Assemblée chargée de jeter les bases des associations ouvrières.

Par le commandement aux patrons, le coup de Jarnac du Capital serait paré. À la première heure, c'est l'essentiel. Les travailleurs pourront attendre ailleurs que dans le ruisseau les nouvelles mesures sociales. 


\section{Dans l'ordre politique.}

Suppression de l'armée et de la magistrature. - Révocation immédiate des fonctionnaires moyens et supérieurs. Maintien provisoire des employés. Expulsion de toute l'armée noire, mâle et femelle. - Réunion au domaine de l'État de tous les biens meubles et immeubles, des églises, communautés et congrégations des deux sexes, ainsi que de leurs prête-noms. -Répétitions à exercer contre les ennemis sérieux de la République, pour actes postérieurs au 24 février 1848. -Annulation de toute vente de ces biens ou de toute hypothèque prise sur eux, depuis cette même date.

Réorganisation du personnel fonctionnaire. - Plus de Code pénal, ni de magistrature. - Arbitres au civil, jurés au criminel. Peine proportionnelle à la faute, et toujours édictée par le jury, selon sa conscience, sans tarif obligatoire. - Nature des diverses peines, seule formulée d'avance.

Formation d'une armée nationale sédentaire. - Armement général des ouvriers et des populations républicaines.

Aucune liberté pour l'ennemi.

\section{Ordre financier.}

Suppression du grand livre de la dette publique.

- Commission, pour le règlement de la Caisse d'épargne.

Remplacement de toutes les contributions directes ou indirectes par un impôt direct, progressif, sur les successions et sur le revenu.

\section{Instruction publique.}

Constitution d'un corps enseignant des trois degrés : primaire, secondaire et supérieur.

\section{Gouvernement.}

Dictature parisienne.

L'appel précipité au suffrage universel en 1848 fut une trahison réfléchie. On savait que, par le bâillonnement de la presse depuis le 18 Brumaire, la province était devenue la proie du clergé, du fonctionnarisme et des aristocraties. Demander un vote à ces populations asservies, c'était le demander à leurs maîtres. Les républicains de bonne foi réclamaient l'ajournement des comices jusqu'à pleine libération des consciences par une polémique sans entraves. Grand effroi pour la 
réaction, aussi certaine de sa victoire immédiate, que de sa défaite au bout d'un an. Le gouvernement provisoire lui a livré avec préméditation la République qu'il avait subie avec colère.

Le recours au scrutin le lendemain de la révolution ne pourrait avoir que deux buts également coupables: enlever le vote par contrainte, ou ramener la monarchie. On dira que c'est là un aveu de minorité et de violence. Non! la majorité acquise par la terreur et le bâillon n'est pas une majorité de citoyens, mais un troupeau d'esclaves. C'est un tribunal aveugle qui a écouté soixante-dix ans une seule des deux parties. Il se doit à lui-même d'écouter soixante-dix ans la partie adverse. Puisqu'elles n'ont pu plaider ensemble, elles plaideront l'une après l'autre.

En prévision des événements, déjà les mielleux de la réaction brodent des homélies sentimentales sur cette antienne : «Il est bien malheureux que les partis ne cherchent dans la victoire que les représailles, au lieu d'y chercher la liberté. » L'antienne est fausse.

En 1848, les républicains, oubliant cinquante années de persécutions, ont accordé liberté pleine et entière à leurs ennemis. L'heure était solennelle et décisive. Elle ne reviendra plus. Les vainqueurs, malgré de longs et cruels griefs, prenaient l'initiative, donnaient l'exemple.

Quelle fut la réponse ? L'extermination. Affaire réglée. Le jour où le bâillon sortira de la bouche du Travail, ce sera pour entrer dans celle du Capital.

Un an de dictature parisienne en 48 aurait épargné à la France et à l'histoire le quart de siècle qui touche à son terme. S'il en faut dix ans cette fois, qu'on n'hésite pas. Après tout, le gouvernement de Paris est le gouvernement du pays par le pays, donc le seul légitime. Paris n'est point une cité municipale cantonnée dans ses intérêts personnels, c'est une véritable représentation nationale.

Il importe au salut de la révolution qu'elle sache unir la prudence à l'énergie. L'attaque au principe de la propriété serait inutile autant que dangereuse. Loin de s'imposer par décret, le communisme doit attendre son avènement des libres résolutions du pays, et ces résolutions ne peuvent sortir que de la diffusion générale des lumières.

Les ténèbres ne se dissipent pas en vingt-quatre heures. De tous nos ennemis, c'est le plus tenace. Vingt années ne suffiront peut-être pas à faire le jour complet. Les ouvriers éclairés savent déjà par expérience que le principal, on peut même dire, le seul obstacle au développement des associations, est l'ignorance. Les masses ne comprennent pas et se défient. Défiance trop légitime, hélas ! La race des vampires est toujours là, prête à recommencer l'exploitation sous de nouveaux masques. Les ignorants, par un instinct vague de ce danger, préfèrent encore la simplicité du salariat. Ils en savent par cœur les inconvénients et les avantages. La 
complication les effraie. Rien d'aussi décourageant que de ne pas voir clair dans son jeu, quand la vie en dépend.

Néanmoins, les bienfaits manifestes de l'association ne tarderont pas à éclater aux yeux de tout le prolétariat de l'industrie, dès que le pouvoir travaillera pour la lumière, et le ralliement peut s'accomplir avec une extrême rapidité.

Autrement grave est la difficulté dans les campagnes. D'abord l'ignorance et le soupçon hantent beaucoup plus encore la chaumière que l'atelier. Puis il n'existe pas d'aussi puissants motifs de nécessité et d'intérêt qui entraînent le paysan vers l'association. Son instrument de travail est solide et fixe. L'industrie, création artificielle du Capital, est un navire battu par les flots et menacé à chaque instant du naufrage. L'agriculture a sous ses pieds le plancher des vaches qui ne sombre jamais.

Le paysan connaît son terrain, s'y cantonne, s'y retranche et ne redoute que l'empiètement. Le naufrage, pour lui, serait l'engloutissement dé sa parcelle dans cet océan de terres dont il ignore les limites. Aussi partage et communauté sont-ils des mots qui sonnent le tocsin à ses oreilles. Ils ont contribué pour une bonne part aux malheurs de la République en 1848, et servent derechef contre elle, depuis la nouvelle coalition des trois monarchies.

Ce n'est pas une raison pour rayer le mot communisme du dictionnaire politique. Loin de là, il faut habituer les campagnards à l'entendre non comme une menace, mais comme une espérance. Il suffit de bien établir que la communauté est simplement l'association intégrale de tout le pays, formée peu à peu d'associations partielles, grossies par des fédérations successives. L'association politique du territoire français existe déjà. Pourquoi l'association économique n'en deviendrait-elle pas le complément naturel, par le progrès des idées?

Mais il faut déclarer nettement que nul ne pourra jamais être forcé de s'adjoindre avec son champ à une association quelconque, et que, s'il y entre, ce sera toujours de sa pleine et libre volonté. Les répétitions sur les biens des ennemis de la république seront exercées, à titre d'amende, par arrêt de commissions judiciaires, ce qui n'implique en rien le principe de propriété.

Il sera indispensable également d'annoncer que ces arrêts respecteront les petits et moyens propriétaires, attendu que leur hostilité, sans importance quand elle existe, ne mérite pas une représaille. Ce qu'il faut balayer du sol, sans hésitation, sans scrupule, ce sont les aristocraties et le clergé. À la frontière, marche !

Dans quels délais le communisme pourra-t-il s'installer en France ? Question difficile. À juger par la disposition présente des esprits, il ne frapperait pas précisément aux portes. Mais rien de si trompeur qu'une situation, parce que rien n'est si mobile. La grande barrière, on ne le redira jamais trop, est l'ignorance. Là- 
dessus, Paris se fait illusion. C'est tout simple. D'un milieu lumineux, on n'aperçoit pas la région de l'ombre. Les journaux, les voyageurs racontent la province, ils ne sauraient la peindre. Il faut plonger dans les ténèbres pour les comprendre. Elles couvrent la France par couches si épaisses qu'il semble impossible de les soulever. Sur un point unique le soleil, sur quelques autres à peine des aubes naissantes, de faibles crépuscules, partout ailleurs la nuit.

De là, pour nous, l'impossibilité de voir clairement la solution du problème social. Entre ce qui est et ce qui veut être, il existe une distance si prodigieuse que la pensée n'arrive pas à la franchir. Une hypothèse cependant donne la clé de l'énigme. Si chaque citoyen avait l'instruction du lycée, par quel procédé s'établirait l'égalité absolue, moyen unique de concilier les impérieuses prétentions de tous ? Par le communisme, sans une ombre de doute. Le communisme est la seule organisation possible d'une société, savante à l'extrême, et dès lors violemment égalitaire.

Que la soif de l'égalité soit le premier, le plus irrésistible effet de l'instruction, il suffit, pour s'en convaincre, de jeter les yeux autour de soi et sur soi. Qui, parmi les gens éclairés, voudrait souffrir une prédominance quelconque, s'il n'y était contraint par la force? L'habitude de cette contrainte donne l'habitude de la résignation. On n'y songe même pas, ou si l'on y songe, c'est avec ce haussement d'épaules, geste éloquent de l'impuissance.

Or qu'est-ce que la force brutale ? C'est l'ignorance, Par la grâce du hasard, aux ordres du premier venu, l'ignorance embrigadée, tremblante et soumise, instrument à la fois et victime de la violence. Plus d'ignorants, plus de soldats ! Toute prépotence est anéantie. Qui pourra régenter son voisin ou vivre à ses dépens ? L'éga1ité sera la première loi. La fraternité et la fierté deviendront ses compagnes naturelles, toujours par nécessité. Le communisme sera certainement la forme obligée d'un tel ordre social, car, seul, il résout, d'après le sens commun, tous les problèmes économiques.

Voilà justement aussi pourquoi il ne saurait être la forme de la société présente. Il n'est compatible qu'avec l'universalité des lumières, et nous n'en sommes pas là. Les tentatives prématurées pour l'implanter dans un milieu réfractaire n'enfanteraient que désastres. En 1848 la majorité des ouvriers a mal accueilli l'égalité des salaires, peu conciliable en effet avec une instruction bornée.

L'association, cette mère future du communisme, n'en est encore qu'à la première période de gestation. Elle maintient ses adhérents sous le régime de l'échange, par conséquent de l'individualisme. Nul ne la consentirait plus étroite. Rien n'est mûr pour de si profondes transformations. Jusqu'ici, la communauté n'a donné d'elle au monde qu'une manifestation hideuse, le cloître. Celle de l'avenîr sera la liberté. Un chemin est sec et ferme par le froid comme par le chaud. Entre les deux, il y a le dégel. 
On a osé, à Paris, en pleine réunion publique, reprendre contre les déclassés les diatribes du coup d'État. On a osé dire qu'une société de savants ne serait pas viable, et qu'on doit lui préférer une société d'abrutis. Se plaindre qu'il y ait trop d'hommes instruits, alors que la nation est esclave par ignorance, n'est-ce point le langage des ennemis du peuple? Ils le sentent si bien que leur tactique s'enveloppe de gros compliments. Ils dorent la pilule avec une flagornerie, en prêchant aux prolétaires que les habiletés de la main valent les puissances du cerveau. Les travailleurs dévoués àl'émancipation des masses connaissent bien tout le poison de cet encens. Ils savent trop que ni la force, ni l'adresse ne sont l'intelligence, et que l'auteur de tel chef-d'œuvre industriel peut être en même temps une dupe aveugle.

Combien d'animaux même se montrent les émules, sinon les supérieurs de l'homme dans la manipulation de la matière! Certains nids d'oiseaux sont d'inimitables chefs-d'œuvre. Quels plus merveilleux ouvriers que l'abeille et l'araignée? L'abeille juxtapose ses tubes hexagones avec une précision géométrique que nous ne pourrons jamais surpasser. L'araignée défie la science du mathématicien et tout l'art du tisseur, dans les mille calculs qui savent nouer ses fils et adapter ses toiles aux emplacements les plus divers. Deux simples insectes pourtant!

Non ! ce n'est pas la dextérité manuelle, c'est l'idée seule qui fait l'homme. L'instrument de la délivrance n'est point le bras, mais le cerveau, et le cerveau ne vit que par l'instruction. L'attaque à cette mère nourrice de la pensée est un attentat contre l'être pensant lui-même, un crime social.

L'estomac ne peut supporter l'abstinence. Le cerveau s'y habitue aisément, au contraire. Plus il pâlit, moins il ressent le besoin. L'excès de privation ne lui donne pas l'avidité, mais le dégoût et la fatigue de la nourriture. Il ne sent pas son mal, il s'y complaît même, et s'abandonne volontiers aux langueurs de cette léthargie. Si le jeûne de l'estomac cause la mort physique, celui du cerveau amène la mort intellectuelle. Il ne reste que des brutes satisfaites de croupir dans une vie purement bestiale. C'est ainsi que, par une atrophie savante des facultés de l'âme, la tyrannie sait arriver à l'extinction morale d'un peuple, et le raie en quelque sorte de l'humanité. Une nation peut pardonner à ses oppresseurs la servitude, les prisons, les supplices, la misère, la faim, toutes les violences, toutes les calamités, toutes les douleurs, mais l'attentat sur son cerveau, mais l'étouffement de son intelligence, jamais, jamais, jamais ! Pour un tel forfait, point de pardon possible !

Laissons donc là les billevesées, les programmes fantaisistes, les querelles de mots et de formes. Le salut du peuple est dans l'instruction. C'est le cri universel : De la lumière ! De la lumière ! L'ennemi n'en veut pas, lui. Il s'épuise en efforts désespérés pour nous refouler dans le moyen âge. Qui ne se rappelle ces paroles 
mémorables de Montalembert ${ }^{1}$ à la tribune législative de 1850 : «Deux armées sont en présence, l'armée du bien et l'armée du mal. L'armée du bien, 40000 curés ; l'armée du mal, 40000 instituteurs. »

Eh bien! ces deux armées aujourd'hui n'en font plus qu'une. L'appel de Montalembert a été entendu. Qu'on ouvre Le Moniteur ${ }^{2}$ après le coup d'État, on y trouvera l'exécution littérale de son programme : les collèges partout remplacés par des jésuitières; les instituteurs traqués comme des bêtes fauves; les anathèmes contre le déclassement, ce qui veut dire contre l'instruction du pauvre; l'enseignement primaire réduit au catéchisme ; dans les lycées, la suppression de la philosophie, et la bifurcation ou plutôt l'étranglement des études; les jeunes générations livrées au clergé ; partout une guerre à mort aux lumières, partout la race du Capital appelant à grands cris le prêtre et les ténèbres au secours de son omnipotence en péril.

En ces jours néfastes, qui aurait pu retenir ses larmes devant le déchaînement de toutes les perversités contre la pensée humaine ! Quelle conscience de leur crime dans un tel acharnement ! Oh ! s'il leur eût été donné d'emporter la France loin, bien loin, au sein des plus reculés océans, avec quelle volupté de rage ils auraient anéanti tous les monuments de l'esprit humain, la lettre moulée elle-même et jusqu'au nom de l'imprimerie !

Malheureusement pour eux, si on transporte les citoyens, le sol reste en place, et comme, au milieu du monde civilisé, l'intelligence seule fait la véritable force, nos triomphateurs allaient périr bientôt par leur propre victoire. Il a fallu s'arrêter sous peine de mort, et ne pas détruire complètement les fonctions du cerveau. Mais quelles ruines déjà! Et nous ne sommes pas au bout. La triade Sabre-ÉcuGoupillon, toujours souveraine, ne peut se maintenir que par la violence et l'abrutissement. Le suffrage universel, son misérable esclave, marche au scrutin, tenu au collet par le gendarme et le prêtre, avec le Capital qui l'escorte, le pied au derrière.

Comment s'en étonner? L'ignorant est à peine un homme, et on peut le mener comme un cheval, avec la bride et l'éperon. Le dresser au travail et à l'obéissance, c'est l'unique préoccupation du maître. Si l'on veut connaître à fond les rêves du conservatisme, qu'on étudie son langage et ses œuvres, après le coup d'État, alors que, tenant le peuple sous ses pieds, il avait levé le masque et se croyait dispensé de ménagements. Suppression immédiate des écoles normales où se formaient de vrais instituteurs. Il faut lire les déblatérations furieuses de l'époque contre ces «pépinières de boute-feux et d'empoisonneurs de jeunesse ». Discours officiels, journaux, sermons proclament à l'envi qu'on ne doit apprendre aux enfants du

1 MONTALEMBERT (1810-1870): Publiciste et homme politique, défenseur acharné du catholicisme et de la conservation sociale.

2 Le Moniteur : Journal officiel du Second empire. 
peuple que le catéchisme et un métier, que tout autre enseignement est une source perpétuelle de révolte, une calamité publique. C'est partout un déchaînement de blasphèmes contre l'instruction qui allume l'envie des masses et les précipite sur la société ; une tempête d'imprécations à l'adresse des déclassés, ces ennemis de tout ordre social, ces fauteurs de bouleversements.

Quand on voit reparaître aujourd'hui, jusqu'au sein des assemblées populaires, les attaques au déclassement, la guerre à l'instruction gratuite et obligatoire, il n'est pas difficile de deviner, sous son faux nez socialiste, l'intrigue clérico-féodale. En creusant le projet des écoles professionnelles, on retrouverait aisément le venin de 1852, cette idée fixe d'incarcérer le travailleur dans un métier, et d'en revenir par ce chemin au système des castes.

Tel ouvrier de la pensée est souvent plus besogneux que le moindre ouvrier de la matière. Qu'est-ce que les déclassés, sinon les parias de l'intelligence ? On ne les insulte que parce qu'ils sont pauvres. Dès qu'ils ont des écus, ils cessent d'être des déclassés et montent au premier rang. Quelle meilleure preuve que la fortune seule, et non le mérite, classe les individus dans notre ordre social ?

Une foule de savants vivent et meurent pauvres, après avoir rendu des services ignorés. Ils avaient le savoir. Ils manquaient du savoir-faire, qui seul enrichit. Le savoir-faire, ce suçoir du vampire, est le souverain maître de notre cruelle société. Malheur à ceux que la nature a oublié d'en pourvoir ! Ils serviront de pâture à la science-reine, la science de l'exploitation.

Des milliers de gens d'élite languissent dans les bas-fonds de la misère. Ils sont l'horreur et l'effroi du Capital. Le Capital ne se trompe pas dans sa haine. Ces déclassés, arme invisible du progrès, sont aujourd'hui le ferment secret qui gonfle sourdement la masse et l'empêche de s'affaisser dans le marasme. Demain, ils seront la réserve de la révolution.

1869-1870. 


\section{3. - SAINT-ÉTIENNE. LUTTE ENTRE LES FABRICANTS ET LES OUVRIERS ${ }^{1}$}

$\underline{\text { Retour à la table des matières }}$

L'association des ouvriers rubanniers, organisée en 1848, sous le nom de Société populaire, a un peu allégé le joug qui pèse sur le prolétariat de cette ville. Les fabricants, contenus par cette puissance nouvelle, fulminent et prophétisent la ruine de Saint-Étienne. Ils prétendent que les commandes étrangères se retirent devant l'élévation des prix et refluent sur Bâle et l'Angleterre. Ils sont furieux de recevoir la loi des ouvriers. Ils étaient habitués à la faire. C'est la condition de l'ordre social actuel. Le Capital commande et n'obéit pas. Dès qu'il ne peut plus dominer, il crie à l'oppression. La liberté, pour lui, c'est le pouvoir absolu. Il n'admet d'autres rapports avec le Travail que ceux de maître à esclave.

Il est fort probable que la prétendue servitude, qui lui fait pousser les hauts cris en ce moment à Saint-Étienne, n'est qu'un amoindrissement de son autocratie, une limitation de son despotisme jusqu'aujourd'hui sans frein. L'ouvrier, par la force de l'union, cesse de subir la volonté de ses anciens dominateurs. Il lutte à armes plus égales contre leur avidité, et ne se trouve plus dans la condition du ver de terre. Il peut arrêter la dépréciation du salaire, tenir en échec l'exploitation, débattre, au lieu de subir, les conditions du travail. Il entre alors en partage des bénéfices et diminue l'iniquité de la répartition.

C'est une révolte intolérable aux yeux du fabricant qui n'est plus l'arbitre suprême du taux de la main d'œuvre, et qui se voit enlever, par cette rébellion, son principal élément de gain, la diminution discrétionnaire du salaire, par conséquent la vente à prix réduit, appât de la commande, garantie du débouché.

Toutes ces luttes sont grosses de guerre civile. Jamais le Capital ne consentira à l'abandon de la moindre parcelle de sa puissance. Moins traitable et moins résigné que les rois absolus, il ne veut pas, il ne peut pas faire de concessions. Il entend ne connaître de loi que son bon plaisir.

L'assemblée contre-révolutionnaire, qui essaie aujourd'hui de rebâillonner la France, a mis toutes ses frénésies au service de ce maître inexorable, le Capital. Elle a reforgé à neuf l'une des chaînes qui garrottent le Travail, par le maintien des pénalités contre les coalitions. L'ascedant pris à Saint-Étienne par les ouvriers anime d'une fureur secrète et mal contenue la faction royaliste. L'accord et la fermeté de la vaste association rubanière lui imposent encore certains

Le second volume de La Critique sociale est composé essentiellement de notes. Nous donnons, ci-après, les plus caractéristiques. 
ménagements qui se laissent voir dans le style diplomatique du Joumal des Débats, ce respectueux serviteur de la force.

Mais il doit coûter à ces souverains seigneurs de transiger avec des esclaves. Cette nécessité des ménagements, cette contrainte imposée par la prudence, amasse au fond de leurs âmes des trésors de colère. Il y a du sang dans la pensée, parfois aussi dans la parole de ces tyrans dissimulés. La pauvre ville de SaintÉtienne n'a pas vu ses dernières boucheries, n'a pas porté son dernier deuil. Elle est en état de siège, malgré le calme qui n'a pas été troublé un seul instant. On a supprimé ses journaux républicains, mis sa population sous le joug du sabre, installé dans ses murs les Radetsky ${ }^{1}$ et les Haynau ${ }^{2}$.

On ne s'en tiendra pas aux menaces. Le Capital n'est pas satisfait pour si peu. Il veut avoir raison de l'audace de ses sujets, et en finir avec ces associations qui ont osé mettre une borne à sa puissance. Voici qu'on demande le transfert de la préfecture, de Montbrison ${ }^{3}$ à Saint-Étienne, pour établir une surveillance plus efficace sur ce foyer du socialisme. "Le socialisme a fait des progrès effrayants!» s'écrie le général de Grammont, le pacha de la localité. Ces hommes roulent des projets sinistres.

Décembre 1849.

\section{4. - L'ORIGINE DES FORTUNES}

$\underline{\text { Retour à la table des matières }}$

Les fortunes se sont faites aux premiers temps de notre histoire, par la conquête ; plus tard, par les confiscations, le pillage, les grâces royales ; chez la classe moyenne, par l'usure, les abus de confiance ; pendant la Révolution, par les achats de biens nationaux, par l'agiotage, par les fournitures d'armées; sous l'Empire, par la guerre, les donations impériales; depuis 1814, par les spéculations, les jeux de bourse, les faillites habiles. Chez les modernes enrichis la première génération se compose d'usuriers, la deuxième de débauchés et de joueurs.

1850.

1 Joseph RADETSKY (1766-1838) : Général autrichien. Pendant la révolution de 1848, il avait dirigé des opérations militaires contre le Piémont, la Lombardie et la Vénétie. Ses armées se distinguèrent par leur extrême cruauté.

2 Julius-Jacob HAYNAU (1784-1855) : Maréchal autrichien, connu pour sa férocité pendant la répression de la révolution de 1848 en Italie. En mai 1849, il étouffa la révolution hongroise et persécuta ses instigateurs avec férocité. Il fut surnommé l' «hyène de Brescia ». Quand, en 1850, il fit un voyage à travers l'Europe, les ouvriers organisèrent des manifestations contre lui.

3 Effectivement, la préfecture du département de la Loire sera transférée, un peu plus tard, à Saint-Étienne. 


\section{5. - LES PARTAGEUX}

$\underline{\text { Retour à la table des matières }}$

Curieux article de L'Ordre, journal réactionnaire de Dijon :

Les socialistes promettent aux malheureux le bonheur le plus décevant en leur parlant du partage des terres. Nous en avons l'application sous nos yeux. Les anciens biens communaux ont été partagés dans un grand nombre de localités. Les pauvres habitants qui avaient droit de pâture, de parcours, ont reçu un lot de propriété exclusive. Qu'est-il arrivé ? C'est que, par misère ou par imprévoyance, la plupart ont vendu leur portion et en ont dissipé le prix, de sorte qu'ils sont plus pauvres qu'autrefois, parce qu'ils n'ont plus les droits de pâture. Voilà ce qu'ils ont gagné à la théorie du partage des biens. C'est un fait notoire que nous livrons aux méditations des égalitaires.

Ce pauvre journal prend les socialistes pour des partageux. Ils sont précisément tout le contraire. Ils prêchent l'association universelle comme l'unique remède aux maux actuels, la seule solution possible de tous les problèmes sociaux qui engendrent la misère, le désordre, la guerre civile. Le partage des terres, à leurs yeux, n'est pas même un palliatif et ne ferait que généraliser la pauvreté et la souffrance. Le partage des communaux leur a toujours paru un expédient désastreux qui devait entraîner l'aggravation du sort des pauvres par leur dépossession inévitable, et la perte de l'ancienne ressource commune. Ils ont prophétisé le fait malheureux que l'ignorant journal met à leur charge. Le plaisant de l'aventure, c'est que ce journal, en plaidant à son insu le thème de ses adversaires, devient ainsi un adepte de leur doctrine, s'enrôle sous le drapeau socialiste et déserte la cause de la famille et de la propriété. Quelle bévue ! parler contre la propriété individuelle! Comment sa plume n'a-t-elle pas rebondi d'horreur en écrivant cette parole :

Les pauvres sont devenus plus pauvres par la transformation d'une propriété commune en propriétés particulières.

C'est tout bonnement du communisme pur. Car la logique est inexorable. L'argument emprunté aux communaux est applicable à la généralité des terres. L'approriation est donc un fléau ; elle ne peut pas être tantôt un bienfait et tantôt une calamité. Si elle était un bienfait, elle le serait en toute circonstance, aussi bien pour les partages des communaux que pour toute autre division des terrains communs. Cette cessation de l'indivis, à propos des biens de commune, devient en quelque sorte une pierre de touche pour le système actuel de propriété. Ses résultats en sont la condamnation ou l'apologie. Heureux, ils le légitiment; funestes, ils le condamnent. Les défenseurs de l'ordre prononcent eux-mêmes. Le partage des communaux a eu des conséquences déplorables. Il n'a fait qu'aggraver la misère. Donc l'appropriation du sol en général a pour résultat nécessaire la 
création simultanée de la pauvreté et de l'opulence. Indigence et richesse, telle est sa double formule.

\section{6. - LA PRESSE CAPITALISTE}

$\underline{\text { Retour à la table des matières }}$

La presse du Capital, impuissante et discréditée, n'a rien pu sur les élections. Il ne faut jamais croire un mot de ce qu'elle dit. Derrière chaque journal quotidien, il y a la faction capitaliste, ennemie ouverte ou cachée, procédant par violence ou par jésuitisme.

Rothschild, avec ses 1,800 millions, peut fournir chaque jour à la geôle et au parquet des gérants, des imprimeurs et des écrivains par douzaines. Cette même misère, créée par son opulence, lui offre au choix des milliers d'affamés, trop heureux peut-être, hélas ! de trouver un morceau de pain sous les verrous.

1869.

Comme les riches ont maintenant la faculté de faire des journaux sans permission, Le Phare de la Loire assure que le gouvernement a rétabli la liberté de la presse.

Mais les pauvres sont bâillonnés par le cautionnement. L'abolition du timbre ne ferait que renforcer le monopole du Capital, en lui permettant d'écraser le pauvre par le bas prix du produit. Car le pauvre ne peut imprimer qu'en province, et chaque feuille arrive grevée de quatre centimes de port.

Mars 1869.

Le Figaro déblatère contre l'Internationale et refuse d'insérer la réponse à ses mensonges. Voilà le monopole de la presse par le Capital. Le cautionnement, le timbre, les droits de poste exorbitants assurent aux écus l'impunité de l'outrage et de la calomnie. Le pauvre est bâillonné et doit subir muet la bastonnade.

Juin 1870. 


\section{7. - SAINT-SIMONIENS. - CRÉDIT INTELLECTUEL}

\section{Retour à la table des matières}

Société du Crédit intellectuel proposée aux saint-simoniens par Enfantin ${ }^{1}$ pour embrigader tous les ouvriers de la pensée sous les ordres et au service de la féodalité financière. Coupons d'actions délivrés aux savants, écrivains, artistes, etc. Avances et prêts faits aux mêmes sur évaluation de leur mérite pris pour hypothèque. Par ce moyen, on fera disparaître le chômage intellectuel, on enrôlera la pensée sous les drapeaux de la Bourse et on convertira des démons en anges. L'intelligence deviendra une auxiliaire, une servante du monde financier, au lieu d'en être l'ennemie la plus redoutable.

Les saint-simoniens ne trouvent pas l'idée pratique et refusent de tenter l'expérience. Ils se doutent bien qu'il y aurait quelques réfractaires, ce qui suffirait pour que le but fût manqué. Ceux-là deviendraient tout et les embrigadés rien.

Mars 1863.

\section{8. - LA GUERRE DU CAPITAL À LA RÉVOLUTION}

Revue des Deux Mondes du $1^{\mathrm{er}}$ avril 1866. - Chronique politique par E. Forcade :

... Après 1851, on put substituer à l'ancienne activité politique de la France l'activité industrielle et financière. On avait les anciennes compagnies de chemins de fer à restaurer, le réseau à continuer et à terminer, une immense partie du domaine public à mettre en valeur, tout cela au grand profit des capitaux, d'ailleurs extraordinairement grossis par les épargnes prudemment accumulées durant les alarmes de la période républicaine.

Voilà donc un aveu définitif et clair! Pendant la période républicaine, le Capital s'est retiré sur le mont Aventin et a livré la France au chômage, à la misère, à la famine. Le Capital ne souffrait pas. Il a accumulé les épargnes. Il levait sa dîme comme à l'ordinaire sur le Travail, il accaparait le fruit des sueurs populaires et le retirait de la circulation. Cet excédent, ce revenu qu'il prélève et qu'il ne restitue au courant qu'en échange de nouvelles primes, il préférait le garder improductif, diminuant ses propres gains pour affamer les masses et les contraindre àcapituler. Faites donc des révolutions qui laissent le Capital aux mains de l'ennemi. Le cri du Capital, c'est l'esclavage ou la mort !

Avril 1866.

1 Barthélemy Prosper ENFANTIN (1796-1864) : Utopiste, disciple de Saint-Simon. Chef de l'école saint-simonienne. Sous sa direction, le saint-simonisme dégénéra en secte religieuse. 


\section{9. - L'INFANTICIDE. SES CAUSES : DIEU ET LE CAPITAL}

$\underline{\text { Retour à la table des matières }}$

L'infanticide a deux causes : le Capital qui fait des pauvres et empêche les filles de trouver des maris, le christianisme qui flétrit sans pitié la maternité hors mariage.

Les filles riches n'ont que le choix entre les prétendants. Les filles pauvres restent au rebut. Toutes ont un cœur. Mais, aux unes la maternité est une gloire, aux autres un opprobre. Ainsi le veut l'ordre actuel.

Dieu et le Capital s'associent pour exterminer la fille mère. Le Capital lui ôte le pain. Dieu lui ôte l'honneur. C'est de leur main que l'enfant périt ; la mère est folle de désespoir. Que de millions de ces victimes!

Que deviennent les deux meurtriers ? Où sont-ils ? L'un sur le trône, l'autre sur l'autel. Et les âmes honnêtes ne voueraient pas une haine implacable à ces monstres !

1867.

\section{0. - PROJET DE DISCOURS}

Citoyens, je prends la parole, l'esprit obsédé de doutes pénibles que je ne puis taire. Quand il s'agit de la cause des masses, la franchise est le plus impérieux des devoirs, et la duplicité, ce vice toujours odieux, devient alors un véritable crime. Car le peuple, simple et loyal, n'a pas de défense contre l'astuce, et sa bonne foi en fait une dupe facile. Je dirai donc ici toute ma pensée, nettement, sans ambages, et j'espère qu'on ne cherchera pas à l'étouffer. Cette violence, d'ailleurs, ne profiterait pas à l'intrigue et ne ferait que démasquer ses projets.

... [La] coopération est une étrange créature, un être hybride, moitié Proudhon ${ }^{1}$, moitié Malthus ${ }^{1}$, ou plutôt Malthus en chair et en os, coiffé de

1 Pierre-Joseph PROUDHON (1809-1865) : Socialiste petit-bourgeois, un des fondateurs de l'anarchisme. Connu surtout par son livre Qu'est-ce que la propriété ? dans lequel il déclare que « la propriété, c'est le vol ». Dans son principal ouvrage économique, Philosophie de la misère, Proudhon fait apparaître le caractère antiscientifique et utopique de son idéal social. Pour répondre à ce livre, Marx écrivit Misère de la philosophie, où il critiqua l'idéologie réactionnaire de Proudhon.

Proudhon luttait pour la « liquidation sociale » sans révolution et sans dictature du prolétariat. Pendant la révolution de 1848, il eut une attitude hésitante. D'une façon générale, l'instabilité et l'hésitation caractérisent son activité littéraire et politique. 
quelques semblants de loques proudhoniennes. On colporte partout l'idole en triomphe, la larme à l'œil, avec de grands cris de joie : « Voici la bonne nouvelle ! Voici le vrai, le bon socialisme ! Le mauvais est mort. Ses forfaits l'ont tué. Le peuple lui dit : Raca ! et abjure ses vieilles erreurs. Il renie ses extravagances de 48 et pousse même le repentir jusqu'à jeter aux ordures le mot: association, en châtiment de ses crimes. Il remplace ce mot coupable par l'humble terme de coopération, qui exclut toute intrusion de la pensée et ne comporte que la notion d'attelage, plus conforme à la modestie de ses aspirations. Dignes et excellentes basses classes! »

Erreur, messieurs ! Le peuple n'a rien renié, rien abjuré, rien jeté à l'égout. Le socialisme de 48 a été proscrit, voilà tout, et ce n'est point par le peuple. La proscription n'est pas un argument, et le libéralisme, en trépignant avec tant de mépris le corps d'un supplicié politique, montre seulement toute sa joie d'avoir été débarrassé d'un ennemi par la main d'un adversaire. Hum ! il lui a bien donné un petit coup d'épaule à cet ex-allié.

Patience ! ces morts-là ressuscitent quelquefois. Mais, pour le quart d'heure, c'est vrai, le socialisme de 48 est toujours dans son sépulcre. On ne lui a jamais permis d'en soulever la pierre. Ses gardes ne s'endorment point. Depuis seize ans, il est muet comme la tombe, et il n'a pas mis un seul de ses cheveux dans la toilette du coopératif. Toute la place demeure au socialisme proudhonien qui fait beaucoup moins peur, surtout depuis qu'on voit comment l'entendent et l'appliquent ses prétendus adeptes. Pauvre Proudhon! Eût-il jamais soupçonné qu'un enfant, son fils putatif, emmailloté de ses doctrines, serait tenu au baptême, choyé, baisé, éduqué et prôné par l'économie politique de Malthus et Cie ?

Il faut s'entendre pourtant. Oui, en 1848, il y avait en présence et aux prises deux socialismes : l'un, celui de Proudhon ${ }^{2}$, fondé sur l'individualisme tempéré de mutualité gratuite ; l'autre, anonyme, basé sur l'association générale progressive. Ni l'un ni l'autre ne pouvaient triompher alors. Ces victoires-là ne sont pas l'affaire d'un jour. Ils ont succombé également. C'étaient des frères ennemis. Mais ces frères, au milieu de leurs hostilités acharnées, n'en conservaient pas moins une ressemblance essentielle qui attestait la communauté d'origine, et qui leur a toujours permis de porter le même nom. Tous deux faisaient une guerre sans

1 MALTHUS (1766-1834): Économiste bourgeois, pasteur anglican, adversaire déclaré des travailleurs. Prétendait que la misère des classes laborieuses dans les conditions du capitalisme était une conséquence de l'accroissement de la population. Selon la doctrine antiscientifique et réactionnaire de Malthus, la population tendrait à s'accroître suivant les termes d'une progression géométrique, alors que les moyens d'existence ne s'accroîtraient que suivant les termes d'une progression arithmétique.

Blanqui, en parlant de Malthus, envisage l'économie politique bourgeoise en général.

2 Il est significatif que Blanqui ne comprenne pas l'étendue de l'abîme qui sépare la doctrine de Proudhon du communisme révolutionnaire. 
quartier à la tyrannie capitaliste et proclamaient l'illégitimité de l'intérêt sous toutes ses formes, rente, loyer, fermage, primes, etc.

Ils ne reconnaissaient de droit qu'au travail. Ils n'en accordaient aucun au capital. Cette doctrine n'est pas seulement la vérité scientifique, mais encore la plus haute morale. En effet, le travail, c'est l'homme ; le capital, c'est la matière. L'homme seul agit, le capital n'agit pas. Il n'est qu'un instrument inerte entre les mains du travailleur. Il n'y a donc aucune part à lui faire dans le produit.

Ce n'est point ici le lieu de réfuter les sophismes de l'économie politique en faveur de la rémunération du capital. Ce serait un hors-d'œuvre qui déborderait mon cadre. Il suffit de rappeler que les deux socialismes en lutte, le mutuellisme et l'association, malgré leur divergence radicale, s'accordaient néanmoins sur le point décisif, l'illégitimité de l'intérêt. Ce n'est pas tout sans doute. Mais qu'on demande si c'est peu aux propriétaires, aux hommes de finance, d'industrie et de négoce. Sans méconnaître les difficultés de l'organisation du travail dans les deux systèmes socialistes, et c'est précisément à propos de cette organisation qu'éclate leur antagonisme, on peut avancer hardiment que l'essence même du socialisme gît dans la formule : Illégitimité de l'intérêt du capital.

Si donc, comme s'en vantent ses fondateurs, comme le répètent avec complaisance ses journaux, la coopération est une fille bien élevée du socialisme proudhonien, c'est bien le moins qu'elle eût dû choisir pour assise le seul point de doctrine qui fasse Proudhon socialiste. Loin de là, le tant pour cent est son dieu et le capital son souverain seigneur. Elle repose sur la même base que toutes les sociétés commerciales possibles -anonyme - en participation - en commandite. Qu'on lise ses statuts, ses comptes rendus, tous ses manifestes, c'est l'argot de la finance, sans un point de plus, sans une virgule de moins. Amende honorable aux pieds du laisser faire et du laisser passer ; triomphe complet de cette économie politique sans entrailles qui jette les victimes par millions dans l'engrenage dévorant de la concurrence..., et l'on peut bien ajouter, de l'offre et de la demande ; car il y a des auxiliaires dans la coopération. Auxiliaires! mot pudique pour déguiser salariés. Et qui sait si les patrons à plusieurs têtes ne seraient pas plus durs que les patrons monocrânes? Qu'on s'étonne, après cela, des tendresses malthusiennes pour le poupon coopératif !

Ses parrains disent aux prolétaires : « Ne vous inquiétez pas du gouvernement. Vous n'avez nul besoin de son aide. Ne lui demandez pas l'aumône de ses millions. Vous n'en avez pas le droit, et, d'ailleurs, ils vous seraient plus nuisibles qu'utiles. Tirez, sou par sou, de votre pauvre bourse, pour vous créer un capital, un instrument de travail, et, de ce jour, vous cesserez d'être des salariés, des exploités, pour devenir des capitalistes, cumulant le double profit de l'intérêt d'abord, puis de la main-d'œuvre, sans prélibation. Voilà le vrai chemin de l'affranchissement et du bien-être ! Laissez donc là le gouvernement, et, loin de solliciter son intervention, faites plutôt des vœux pour qu'il ne se mêle pas de vos affaires ! » 
Et comment pourrait-il ne point s'en mêler, puisqu'il est l'État ? Certes, le conseil serait admirable, s'il n'était une raillerie. On engage les ouvriers à bâtir avec leurs centimes de petites associations de dix, vingt, trente, cinquante, cent personnes, et à s'acoquiner dans ces recoins, pour tenir à l'œil le gérant et soigner la fructification du magot. Par cela même, en réalité, on les dissuade de fourrer le nez dans la grande association où vont s'engloutir les gros sous jusqu'à concurrence de deux milliards et demi de francs.

S'imagine-t-on, par hasard, que ce prélèvement de deux milliards sur la production nationale soit chose indifférente au bien-être des travailleurs, et qu'ils n'aient pas plus à s'en soucier que des montagnes de la lune ? Et l'emploi de ces milliards, est-il aussi pour eux sans intérêt ? 500 millions de dette publique, dont le capital a passé qui sait à quoi ? 500 millions servant àempêcher six cent mille hommes de travailler, 60 millions alloués à l'Église, c'est-à-dire à la production des ténèbres, 25 millions à la soi-disant instruction publique, souvent simple succursale des sacristies, tout au plus manufacture de pénombre ; tout cela n'a-t-il aucune influence sur le sort des masses ? Comment ose-t-on leur dire de détourner leurs regards de l'État et de ne compter que sur elles-mêmes?

Je sais bien qu'on va répondre : « Personne ne cherche àdistraire les ouvriers de la chose publique, tout au contraire. On les presse vivement d'y prendre une part active. Qu'ils s'occupent de politique, c'est leur droit et leur devoir. Mais la politique est une chose, et le travail social en est une autre. Réclamer de l'État une bonne gestion des intérêts communs, c'est bien. Lui demander de l'argent pour leurs intérêts privés, comme ils l'ont fait en 48, c'est insensé. Il ne faut pas confondre deux questions distinctes et essentiellement différentes. »

«Différentes ! Distinctes ! » Mille et mille fois non ! La question est une et indivisible. J'accorde que le budget ne commandite pas les associations de travailleurs... Et encore ! En supposant quelques avances, faites à fonds perdus, à des sociétés ouvrières, contrairement aux axiomes sacramentels de l'économie politique officielle, qu'est-ce que ce chiffre de centaines et de mille, auprès des milliers de millions semés à pleines mains sur tous les grands chemins de l'Europe, de l'Asie, de l'Afrique et de lAmérique ? Une rivière et un verre d'eau ! On jette de hauts cris pour le verre d'eau répandu, on regarde en silence couler la rivière. Et pourtant le verre d'eau a produit quelque chose là où il est tombé, et le fleuve est allé se perdre stérile dans la mer.

Mais point de chicanes ! Supprimée la commandite du budget ! Les ouvriers ne demandent point d'argent à l'État. C'est l'État, au contraire, qui leur en demande, et beaucoup, sous prétexte des intérêts généraux. Leurs intérêts particuliers ne souffrent-ils pas de cette saignée ? Si la grande association prend leurs sous, avec quoi pourraient-ils constituer le capital des petites ? Et si elle use mal des sommes prélevées, plus désastreux encore sera pour eux le mauvais usage que l'excès de 
l'impôt. Car l'excès n'attente qu'à leur bourse. Le mauvais usage peut tuer leur intelligence, source première de toute activité.

Évidemment, la cause principale qui paralyse la coopération, qui la rend dérisoire, en la circonscrivant d'avance dans un cercle imperceptible, c'est l'ignorance. La plupart des prolétaires n'ont pas les connaissances suffisantes pour juger par eux-mêmes la gestion d'une société, à plus forte raison pour y intervenir, et ils s'abstiennent par défiance. Ils craignent, àbon droit, d'être dupes et préfèrent la sécurité du salaire. Fût-il seul, et il n'en manque pas d'autres, cet obstacle suffit pour faire du coopératif une mystification.

Or, d'où vient l'ignorance ? « Du défaut d'instruction », dirait M. de la Palisse. Je me permets d'ajouter : elle vient surtout de l'enseignement clérical qui a pour but et pour résultat l'extinction des lumières et l'abrutissement par la superstition. $\mathrm{Si}$, au lieu de gaspiller 500 millions par an à tenir, dans une oisiveté qui les désespère, les six cent mille jeunes gens les plus robustes du pays, l'État consacrait cette somme àl'instruction publique et voulait organiser un enseignement sérieux, rationnel, basé sur la science, en moins de dix ans la transformation de la France serait complète. Tous les travailleurs, devenus, d'instruments passifs, des citoyens éclairés, associeraient spontanément leurs intelligences et leurs bras, et le problème de l'organisation du travail selon la justice se trouverait résolu.

Par malheur, nous n'en sommes point là ; et on se consume en lutte sans issues, en efforts impuissants. Considérons, par exemple, le mouvement coopératif, et voyons quelle est sa portée dans la situation actuelle. Il se présente sous trois formes : sociétés de consommation, sociétés de crédit, sociétés de production.

Les sociétés de consommation sont les plus faciles et les plus simples. On y risque peu. Mais elles ne peuvent conduire qu'à des résultats insignifiants, parfois même à des déceptions. Elles ne sont praticables d'ailleurs que dans les fortes localités. En somme, ce n'est qu'une amusette, pas même un palliatif.

Les sociétés de crédit sont déjà un péril pour les ouvriers, un mirage fascinateur les entraîne et les embrouille dans les questions ardues de comptes courants, d'échéances d'intérêts accumulés, dans tout le dédale des combinaisons financières, où leur inexpérience risque fort de se perdre. Elles exigent une instruction qui en rétrécit singulièrement le cercle.

Quant aux sociétés de production, je les tiens pour le piège le plus funeste où puisse tomber le prolétariat. Il est manifeste qu'un très petit nombre de travailleurs seulement possède la capacité nécessaire pour de pareilles entreprises. C'est donc l'élite intellectuelle qui s'engagerait dans cette voie. Eh bien! dans cette voie, échec et succès seraient également un malheur. L'échec, c'est la ruine et le découragement. Le succès, pis encore ; c'est la division des ouvriers en deux classes : d'un côté, la grande masse ignorante, abandonnée, sans appui, sans espoir, 
dans les bas-fonds du salariat; de l'autre, une petite minorité intelligente, préoccupée désormais de ses seuls intérêts privés, et séparée à jamais de ses frères malheureux.

Voudrait-on, par impossible, écrémer le peuple, lui enlever ses protecteurs naturels, pour en faire une caste nouvelle, une espèce de demi-bourgeoisie, plus égoïste encore, parce qu'elle serait plus près de ses pièces, par conséquent plus ombrageuse et plus brutalement conservatrice ? Voilà donc le dernier mot de l'expédient bâtard qu'on a baptisé à son berceau de ce grand nom : résurrection du socialisme, et qui en est la négation, le tombeau! C'est une amorce pour attirer le peuple hors de sa route naturelle dans une impasse aboutissant à des fondrières, pour le fourvoyer dans je ne sais quel enfantillage de spéculations, sans autre résultat possible que de souffler aux malheureux ouvriers la fièvre continue du profit et de la perte qui dévorera sa vie et ne lui laissera plus une pensée pour la chose publique.

Il ne faut pas s'étonner, si le congrès international vient siéger sur les bords de la Seine. À Lausanne ${ }^{1}$, il eût été difficile peut-être de fermer encore une fois la bouche aux contradicteurs. À Paris, on n'aura pas cette peine, puisqu'il ne leur sera pas permis de l'ouvrir. Cette rubrique coopérative est, sans contredit, le coup le plus puissant et le plus habile, frappé pour la sécurité quand même de l'ordre actuel ; la preuve en est dans le désarroi et dans le tohu-bohu croissant de l'opinion depuis cette dérivation du courant populaire. Une telle victoire du conservatisme pourrait devenir la fin de la France. Car rien n'est fatal à une nation comme la sécurité absolue de son gouvernement. Il s'emporte alors vers les régions de la mort et rien ne l'arrête, tout le précipite.

Ah! l'on prétend émanciper le peuple à l'encontre même de l'action gouvernementale, avec de petites sociétés coopératives ! Chimère ! Trahison, peutêtre ! Le peuple ne peut sortir de servage que par l'impulsion de la grande société, de l'État et bien osé qui soutiendrait le contraire. Car l'État n'a pas d'autre mission légitime.

Quelle est donc cette thèse nouvelle, soulevée, en dépit de l'expérience et du sens commun, par une prétendue science qui s'intitule économie politique ; thèse étrange, qui place toute l'activité d'un peuple en dehors de son gouvernement et l'en déclare radicalement indépendante ? Une pareille doctrine est le plus audacieux démenti à l'évidence et à l'histoire, par conséquent une sottise. Pis que cela, elle est une immoralité et un crime.

L'histoire le proclame bien haut à la face des siècles, ce sont les gouvernements qui perdent ou qui sauvent les nations. Elles vivent et meurent par eux. Tout sort

\footnotetext{
Allusion aux Congrès de l'Association Internationale des Travailleurs. Congrès de Lausanne (1867), second congrès de l'Internationale. Les blanquistes avaient été en violent désaccord avec les proudhoniens français au premier congrès, Genève (1866).
} 
d'eux, le bien et le mal. Ils savent à merveille se faire honneur de l'un, comment n'auraient-ils pas la responsabilité de l'autre ? Ils sont responsables de tout, de l'ignorance, de la misère, de la perversion des idées et des mœurs, de la décadence et de la ruine matérielle, intellectuelle et morale. Le pain du peuple dépend d'eux aussi bien que son honneur. C'est donc en toute justice qu'il leur impute ses souffrances. On ne mange pas une bouchée sans leur permission, pas plus en Angleterre qu'ailleurs, n'en déplaise à messieurs les économistes. Ils nous tiennent par toutes les coutures. Quand une nation, affligée d'un mauvais gouvernement, n'a plus la volonté ou la force de le changer, elle tombe en agonie et glisse peu à peu dans le sépulcre. La question de gouvernement est une question de vie ou de mort.

Rien ne serait plus funeste que de détruire cette vérité dans l'esprit des masses et de leur persuader que leur bien-être matériel n'est pas de la compétence de l'État. C'est ce qu'a tenté la coopération, soufflée par l'économie politique du laissezpasser et du laissez-faire, qui veut, paraît-il, qu'on passe et qu'on fasse, alors même qu'il n'est permis ni de faire, ni de passer. Elle a essayé de convaincre les prolétaires qu'il serait facile de marcher, pieds et mains liés. L'illusion ne sera pas longue. Ils s'apercevront qu'on ne peut pas faire route, les membres garrottés et un bandeau sur les yeux.

Dans les conditions politiques actuelles, il ne saurait y avoir d'utile aux ouvriers qu'une société d'assurance mutuelle pour la sauvegarde des droits du Travail et de la résistance au Capital. Toute tentative organique de production serait un faux pas et un anachronisme. Une telle entreprise n'a chance de succès qu'avec la liberté et la lumière ;

Les travailleurs n'ont donc en ce moment qu'une marche àsuivre : réunir leurs efforts pour se garantir contre l'autocratie du Capital, puis pour obtenir :

$1^{\circ}$ La liberté complète de la presse, sans entraves fiscales, sans répression draconienne ; la liberté de réunion et d'association ; la liberté du colportage.

$2^{\circ}$ L'affectation annuelle d'une somme de cinq cents millions àl'instruction publique.

C'est ici la question capitale qui décidera du sort de la nation. L'enseignement ne peut rester ce qu'il est aujourd'hui, une dérision, un éteignoir. Il doit être non pas seulement gratuit et obligatoire, mais complet. Savoir lire et écrire ou ne rien savoir, c'est presque tout un. À quoi bon un instrument dont il est impossible de se servir ? Il faut apprendre à tous les Français sans exception : la langue française, l'arithmétique, la cosmographie et la géométrie élémentaires, la géographie, l'histoire, le dessin, des notions suffisantes de géologie, de physique et de chimie. L'enseignement professionnel doit être organisé partout, sur une vaste échelle, pour l'agriculture, l'industrie et le commerce. 
Défense absolue à tout clergé de mettre le pied dans les écoles.

De cinq à quinze ans, l'enfant acquerrait sans peine toutes ces connaissances, et, si on voulait les étendre aux adultes dans la mesure du possible, la dépense, au bout de trois années se couvrirait déjà par l'accroissement énorme de la production. Qu'on joigne à ce système d'études la liberté d'association et la liberté de la presse, avant dix ans l'exploitation aura disparu et le peuple sera son propre maître. On pourra commencer alors àparler de self-government. Pour l'instant, le selfgovernment est une pasquinade. Il n'existe nulle part, pas même aux États-Unis, où l'instruction des masses est beaucoup trop rudimentaire pour comporter un tel degré de civilisation.

Que si les prolétaires s'obstinent à barboter dans de vains essais de coopération sans avenir, ils riveront leurs chaînes au lieu de les briser. Tout ce qui tend à les distraire des améliorations gouvernementales leur est mortel, et la première, la plus importante de ces améliorations, est la diffusion des lumières. Ils ne savent pas que l'instruction, c'est le pain aussi bien que la liberté, et que l'ignorance est à la fois l'esclavage et la misère. Si, à ceux qui ont vingt ans aujourd'hui, on avait commencé en 1857 à donner un enseignement complet, au lieu de vivre à la glèbe en humbles salariés, ils marcheraient les égaux de n'importe qui. L'instruction vaut mieux pour les hommes que cinquante Californies.

Hélas! elle est gravement menacée dans notre pauvre pays, grâce à l'insouciance du peuple qui ne songe pas à la demander de sa grande voix, parce qu'il n'en sent pas le prix. Fatal aveuglement ! Oui, l'instruction perd constamment du terrain, tout le terrain que le cléricalisme gagne pied à pied, jour par jour, dans son infatigable marche de taupe. Ses écoles s'élèvent peu à peu sur les ruines des écoles laïques. Naguère, il n'avait pas le quart de la totalité. Bientôt il en a eu le tiers, puis la moitié. La progression continue, rapide, et il poursuit fiévreusement ses conquêtes, que chaque année vient constater au milieu de l'indifférence générale. Tout ce qui est riche le sert et le pousse avec fureur. Quand il aura terminé son œuvre d'envahissement, quand l'éducation aura passé tout entière entre ses mains, alors la nuit sera faite sur la France, et le travailleur verra ce que la nuit lui apporte, ou plutôt il ne le verra pas, car on cesse de voir dans les ténèbres.

La coopération est venue en aide à l'ennemi et s'est mise àdémolir la révolution en remplaçant son drapeau par le doit et l'avoir. Depuis 89, l'idée seule est la force et le salut des prolétaires. Ils lui ont dû toutes leurs victoires. La formule : Liberté ! Égalité ! Fraternité ! renferme la vie matérielle autant que le progrès moral. Elle donnera au peuple le bien-être en même temps que la dignité. Qu'il ne sorte donc pas de l'idée pour se jeter dans la spéculation. La spéculation, c'est la voix de l'iniquité et des exploiteurs, ce n'est pas la sienne. Il y périrait. 


\section{1. - GRÈVE ET COOPÉRATION.}

$\underline{\text { Retour à la table des matières }}$

La grève est intelligible à tous ; c'est l'idée simple, la résistance à l'oppression. Tous s'y rallient.

La coopération, dans ses diverses formes, société de crédit, société de production, est une complication qui peut séduire les intelligences déjà enveloppées, mais qui effraie les ignorants et les simples. Elle trouvera dix adhérents à peine et la grève dix mille.

À l'une la généralité, à l'autre de rares exceptions. Le drapeau qui rallie la masse n'est-il pas préférable à celui qui groupe quelques individus ?

La grève, malgré ses inconvénients, est le moyen naturel, à la portée de tous, auquel tous participent. La coopération n'est qu'un moyen accessible seulement aux plus instruits, suspect ou indifférent, ou même inconnu à tout le reste. La grève est la seule arme vraiment populaire dans la lutte contre le Capital.

Appuyées provisoirement sur la grève comme moyen défensif contre l'oppression du Capital, les masses populaires doivent concentrer tous leurs efforts vers les changements politiques, reconnus seuls capables d'opérer une transformation sociale et la répartition des produits selon la justice.

Octobre 1867.

\section{2. - LE COMMUNISME PRIMITIF}

... L'homme est très ancien sur la terre, beaucoup plus ancien qu'on ne l'avait longtemps imaginé et probablement même qu'on ne le suppose encore.

Sa première existence, sans nul doute, était toute bestiale. Vivait-il seul ou en société ? Ses débuts dans l'assistance mutuelle ont-ils eu lieu sous la forme de la communauté ou de l'échange ? Mystère. Toute hypothèse sur l'état social de cette humanité primitive ne saurait être qu'un roman.

Les Australiens, par analogie, pourraient fournir quelques indices sur les mœurs et les agissements de ces périodes reculées. Ils semblent récents dans la famille humaine, à juger d'après leur extrême sauvagerie.

Cependant, on a exagéré jusqu'à l'absurde en les plaçant au niveau et même audessous des singes. Les singes n'ont pas de parole ; encore moins des armes aussi 
remarquables que le boomerang, sujet perpétuel d'étonnement pour les Européens. Ils ne manœuvrent pas des flottilles nombreuses de pirogues.

Les Australiens possèdent tout cela et probablement encore d'autres signes de progrès qui échappent à l'observation dédaigneuse et superficielle des blancs. Ces observateurs sont des touristes trop dégoûtés que révoltent la saleté et la puanteur des pauvres diables, et ils s'inquiètent beaucoup plus de tracer des tableaux pittoresques pour l'amusement des oisifs, que de faire des études d'anthropologie profitables à la science.

Il est assez difficile de démêler le système social des noirs de la baie de Carpentarie. Est-il communiste ou individualiste ? Ils paraissent associés, sans communisme, même sans échange, et seulement pour la défense commune, non pour les besoins de la vie usuelle.

En effet, ils ne cultivent pas, marchent nus, n'ont pour abri que des branchages placés le soir, abandonnés le matin. Donc, point de propriété immobilière. Ils sont nomades; point de meubles. Restent, pour unique richesse, quelques armes et instruments fort simples, de fabrique tout personnelle.

Cannibales, pêcheurs, chasseurs, en lutte permanente contre la faim, ils travaillent probablement chacun pour son compte. Cependant des pirogues ne s'improvisent pas. Dans quelles conditions sont-elles construites ? Isolément ou en commun ? Il serait intéressant de le savoir. On n'en dit rien. Ce qui est certain, c'est qu'ils vivent en troupe et par tribus, avec une organisation et des chefs, société fort rudimentaire peut-être, mais positive.

Nos ancêtres de l'âge de pierre étaient-ils plus avancés, et même autant ? C'est douteux. Ils ont cependant une postérité présentable. Quant aux Australiens, leur compte est réglé. Ils ont rencontré une race qui n'épargne pas les autres. On a essayé de les amener à la culture du sol, à la civilisation blanche, tentative ridicule et stupide qui exigeait de ces infortunés ce que ne peut donner leur organisme. Les transformations du cerveau ne s'improvisent pas. Elles sont l'œuvre des siècles. Au contact des Anglais, les peaux noires d'Australie vont périr comme les peaux rouges d'Amérique, comme la race zélandaise elle-même, si intelligente et si belle. C'est triste.

Par une cruelle fatalité, toutes les jeunes familles humaines, dont l'enfance avait besoin de protection et de tendresse pour arriver à la virilité, ont eu le malheur de rencontrer la variété la plus égoïste, la plus grossière, la plus impitoyable, la plus hypocrite de la race blanche, les Anglo-Saxons, qui détruisent froidement, sans remords comme sans bruit, tout ce qui se trouve devant eux et fait obstacle à leurs envahissements.

Des renseignements judicieux et précis sur les coutumes australiennes pourraient éclairer la condition première de nos propres aïeux. 
Avril 1869.

\section{3. - COOPÉRATION ET RÉACTION}

Retour à la table des matières

Le coopératif, dans la pensée du gouvernement, avait le même but que la caisse d'épargne, désarmer et endormir le prolétariat par un mirage de bien-être. Combinaison plus savante, quoiqu'elle ait échoué et même abouti à un résultat tout révolutionnaire.

Il ne s'agissait plus, en effet, d'une entorse brutale àl'économie politique, mais, au contraire, d'une application rigoureuse de ses doctrines. Il n'en coûtait plus à l'État ni un sou, ni un geste. L'épargne pour moyen, la capitalisation pour but, consécration du vieil ordre et reniement du socialisme, tel était le programme. Le peuple se déclare lui-même très humble serviteur et vassal de la science officielle. Il signe la déchéance du Travail et proclame la productivité, autrement dit, la souveraineté du Capital.

Ainsi l'avait rêvé la réaction, et son rêve a paru d'abord se réaliser. Le congrès de Genève inaugurait hautement le système pur de l'économisme. Tout sans l'État, rien par l'État. Indifférentisme politique et religieux. La coopération fondée sur l'intérêt légitime du capital. Anathème aux idées de 48. Proudhon lui-même condamné dans sa guerre à l'usure.

Ainsi parlaient à Genève, au nom des sociétés coopératives, les ouvriers délégués par l'Association internationale. Et la presse entière d'applaudir à cette abjuration, par le peuple lui-même, de ses anciennes folies révolutionnaires. Devant ces rétractations solennelles, les hommes de l'égalité baissaient la tête. Ils l'ont relevée depuis. Car tout ce qui avait triomphé à Genève, en 1866, chancelait à Lausanne en 1867, s'écroulait à Bruxelles en 1868, et a disparu à Bâle en $1869{ }^{1}$.

Blanqui évoque ici les congrès de la $1^{\text {re }}$ Internationale.

$\mathrm{Au}$ Congrès de Genève, les proudhoniens demandèrent que l'Internationale devînt une association coopérative internationale et qu'elle limitât sa tâche à l'étude des conditions qui pourraient permettre au régime coopératif de remplacer le régime capitaliste. Après des discussions passionnées, le congrès, approuvant Marx, admit que le mouvement coopératif n'était qu'un des moyens de transformer la société et que, laissé à lui seul, il était incapable de combattre le capitalisme. Au Congrès de Lausanne (2-8 septembre 1867), on adopta une résolution déclarant que l'émancipation sociale des travailleurs ne pouvait être séparée de leur libération politique.

Le problème qui préoccupa le Congrès de Bruxelles (6-19 septembre 1868) était celui de la propriété, et en particulier celui de la propriété foncière. La résolution adoptée à ce congrès montra que le développement de l'économie exigeait le passage à la grande industrie et que, par conséquent, non seulement la terre, mais les mines, les forêts, les chemins de fer, etc., devaient être transformés en propriété collective. 
L'idée communiste a ressaisi la victoire, écrasé l'individualisme, et, dans le camp bourgeois, l'allégresse a fait place à la consternation.

1870.

\section{4. - L'ÉCONOMIE POLITIQUE SANS MORALE}

Retour à la table des matières

Son indifférence morale lui ôte toute puissance de critique. La justice est le seul critérium vrai dans l'application des choses humaines. Elles ne sont que ténèbres pour le sceptique. Il y chemine à tâtons, constate isolément les objets par le toucher, mais ne distingue rien, n'aperçoit ni détails, ni ensemble. C'est un aveugle volontaire. Son scepticisme le frappe d'impuissance. On ne peut pas étudier une vitalité changeante et perfectible comme une matière inerte et immuable.

La justice est le ferment du corps social. N'en tenir compte équivaut à se fermer la perspective, à s'ôter la faculté de comprendre. On voit peut-être le présent, jamais l'avenir, pas même ses éléments.

Mars 1870.

\section{5. - LES CONQUÊTES DE L'INDUSTRIE}

Rabâchage de l'économie politique sur les progrès de la civilisation, ses conquêtes industrielles, le développement progressif du bien-être matériel, etc.

Tout cela est en dehors de la question. Les conquêtes de l'industrie ne sont point l'œuvre du Capital, mais de l'intelligence. Bastiat ${ }^{1}$ fait honneur au Capital de la marche de l'esprit humain, du progrès des lumières. C'est le sophisme cum hoc, ergo propter hoc.

La pensée a successivement créé les idées appliquées par l'industrie. Les inventeurs seuls ont l'honneur de ses conquêtes. Le Capital est le frelon qui s'en approprie les avantages. Il ne laisse au travail de la pensée et des bras que ce qu'il lui est impossible de leur enlever.

Exploiteur, parasite, étouffeur, tel est son rôle à travers les siècles, et, parce qu'il s'empare de tout, on le proclame créateur de tout !

Le Congrès de Bâle (6-11 septembre 1869) confirma la résolution de Bruxelles sur l'abolition de la propriété foncière. C'est à ce congrès que fut condamnée la propagande de Bakounine qui recommandait que les ouvriers s'abstiennent de toute action politique.

Frédéric BASTIAT (1801-1850): Économiste, vulgarisateur de l'économie politique bourgeoise. Ses principaux écrits sont: Cobden et la Ligue, Sophismes économiques et Les Harmonies économiques. Bastiat défendait chaleureusement les idées du libéralisme économique contre les protectionnistes et les socialistes. 
Quand le moyen âge mettait au pilori l'audacieux qui avait porté une chemise, c'est l'idée chrétienne qui mettait au pilori l'idée païenne de la satisfaction matérielle.

Ce n'était point la pensée d'égalité qui condamnait la jouissance acquise aux dépens de la privation d'autrui.

Toutes ces conquêtes du bien-être sont l'œuvre de l'intelligence, non du Capital qui les a exploitées, qui en a privé la masse au profit du petit nombre.

Juin 1870. 


\section{IV}

\section{LA PATRIE EN DANGER .}

\section{1 - L'AFFAIRE DE LA VILLETTE}

$\underline{\text { Retour à la table des matières }}$

16 septembre 1870 .

Il y a aujourd'hui un mois, une centaine d'hommes se réunissaient lentement sur le boulevard de La Villette, près du pont du canal.

C'était un dimanche, par un beau soleil. De nombreux promeneurs, répandus sur les contre-allées, dissimulaient la formation du rassemblement.

Un bateleur, à quelques pas de la caserne des pompiers, était le centre de quelques curieux attirés par ses tours.

Le chef du mouvement projeté, qui avait précédé sûr les lieux les citoyens engagés dans cette entreprise, les fit avertir de se joindre à l'auditoire réuni autour du jongleur. Le groupe put ainsi se concentrer sans éveiller les soupçons des sergents de ville.

Vers trois heures et demie, Blanqui donna le signal, et le rassemblement se dirigea au petit pas, sans tumulte, vers la caserne des pompiers. On suivait une contre-allée, et il fallut descendre sur la chaussée pour arriver au corps de garde.

Ce brusque détour à angle droit donna l'alarme à la sentinelle et aux soldats du poste, qui coururent à leurs fusils.

Ce fut un cruel mécompte.

1 La Patrie en danger, journal fondé par Blanqui après la proclamation de la République, le 4 septembre 1870. Son existence fut brève : du 7 septembre au 8 décembre, 89 numéros. Blanqui écrivait dans chaque numéro. Ses articles ont été réunis en volume dès 1871. 
On avait espéré se saisir des armes par surprise, sans collision. Il était convenu de ne faire aucun mal aux pompiers, corps aimé et estimé des Parisiens, étranger aux lunes civiles, et réputé même pour ses idées démocratiques. Le factionnaire fut blessé d'un coup de revolver en se débattant, et le corps de garde fut le théâtre d'une lutte assez vive pour l'enlèvement des armes.

Les insurgés répugnaient profondément à l'emploi de la violence. Ils ne voulurent pas abuser de leur nombre pour s'emparer des fusils de vive force. On parlementa pour les obtenir de bon gré. Ces pourparlers firent perdre du temps.

Un poste de sergents de ville, situé dans le voisinage, accourut au bruit et se précipita, l'épée à la main, sur les insurgés. Au cri : "Les sergents de ville ! » Blanqui, Eudes et Granger sortirent de la cour intérieure, et une courte et rude mêlée s'engagea aussitôt.

Les hommes de police s'enfuirent, laissant sur la place un mort et deux blessés.

Restés maîtres du terrain, les insurgés firent de nouveaux efforts pour avoir les armes des pompiers.

Ces moyens de douceur ne pouvaient qu'échouer. Mais les citoyens ne voulaient à aucun prix user de la force brutale contre ce corps d'élite. La surprise était manquée.

Après ces inutiles pourparlers, les insurgés abandonnèrent la caserne et se mirent en marche vers Belleville par le boulevard extérieur. Il fut alors évident pour eux que leur projet n'avait aucune chance de réussite. La population paraissait frappée de stupeur.

Attirée tout à la fois par la curiosité et retenue par la crainte, elle se tenait, immobile et muette, adossée des deux côtés aux maisons. Le boulevard parcouru par les insurgés restait complètement désert. En vain ils faisaient appel aux spectateurs par les cris: «Vive la République! Mort aux Prussiens! Aux armes!»

Pas un mot, pas un geste ne répondaient à ces excitations.

Les chefs de l'entreprise avaient supposé que la gravité de la situation et les tumultes des jours précédents seraient des motifs suffisants pour rallier les masses.

Mais un certain découragement avait succédé aux émotions impuissantes des premiers jours. Les idées prenaient un autre courant. Elles tournaient au soupçon, à la crainte exagérée de l'espionnage prussien. 
La police poussait avec autant de succès que de perfidie à ces terreurs puériles qui détournaient le peuple de la question sérieuse, le renversement de l'empire. Le fait est que, dans ce quartier si révolutionnaire de Belleville, l'émeute n'entraîna pas une seule recrue.

La colonne insurgée avait parcouru ainsi plus de deux mille mètres sur le boulevard de Belleville, au milieu de l'isolement et du silence.

Blanqui, Eudes, Granger, jugeant l'entreprise avortée, arrêtèrent la colonne et dirent à leurs compagnons :

«C'est une affaire manquée. Nous n'avons pas les fusils, et puis, vous voyez que personne ne se joint à nous. Nous ne pouvons rien sans le peuple. Avant dix minutes, notre petit noyau va rencontrer des chassepots contre lesquels nos revolvers ne signifient rien. Il faut nous séparer. Le terrain est libre, nul n'inquiétera notre retraite. Cachez vos armes et dispersez-vous à travers les rues voisines. »

Tous se rangèrent à cette opinion. Les trois fusils enlevés furent abandonnés ; les revolvers rentrèrent sous les vêtements, et la dispersion s'accomplit sans obstacle.

Nous ne laissions ni morts, ni prisonniers, ni blessures sérieuses.

Personne, d'ailleurs, n'eût songé à nous barrer le chemin. La stupeur était complète autour de nous.

Il faut bien le dire, cette troupe d'hommes déterminés répandait au loin l'effroi. De l'entrée des rues qui aboutissent au boulevard, on apercevait la foule amassée à plusieurs centaines de mètres, et n'osant approcher. On voyait aussi les sergents de ville, qui se tenaient au loin, à distance respectueuse.

... Voici l'histoire des arrestations. Après le départ du rassemblement armé, des curieux se sont attroupés aux portes de la caserne, questionnant, s'informant, suivant la mode parisienne. La police - sergents de ville et mouchards, - survenant tout à coup, s'est abattue sur les badauds, a frappé, assommé, arrêté à tort et à travers.

... Les seuls, deux ou trois peut-être, que la police ait pu saisir avaient été dénoncés, par suite d'indiscrétions.

Eudes et Brideau ne sont tombés aux mains de l'autorité bonapartiste que par effet du hasard. Un mouchard amateur, du nom de Leleu, ayant entrevu le revolver d'Eudes sous son paletot, suivit les deux amis et les fit arrêter par les sergents de ville. 
La police avait jeté dans les prisons quatre-vingts malheureux qui attendaient les sentences iniques des conseils de guerre. Les témoins reconnaissaient invariablement tous les accusés qu'on amenait devant eux. On ne peut savoir jusqu'où seraient allées ces fureurs sanguinaires contre des innocents, si la Révolution du 4 septembre n'y avait coupé court.

... Tous les hommes, sans exception, qui, dans la presse ou à la tribune, ont lancé aux révoltés de La Villette le nom d'agents prussiens, mentaient sciemment, car ils étaient certains du contraire, et tel d'entre eux, renseigné de bonne source, connaissait fort bien les chefs du mouvement. ... Non, Basile, ce n'est pas la Prusse, c'est le citoyen Granger qui a donné pour ces achats [d'armes] 18000 francs, toute sa fortune, sans se réserver un centime.

C'est un idiot sans doute, puisqu'il a sacrifié son modeste patrimoine et s'est mis sur la paille, pour courir cette agréable chance : " Être fusillé comme traître. » Souhaitons cependant à la patrie beaucoup de ces idiots désintéressés, et aussi peu que possible de leurs calomniateurs rapaces.

Le temps et les événements ont fait justice de ces turpitudes. Eudes a été élu chef de bataillon de la garde nationale au faubourg Antoine, et l'affaire de La Villette était son seul titre au choix de ses concitoyens. À Montmartre, Blanqui aussi a été appelé par acclamation au même grade.

Paris comprend que ces hommes ont voulu faire le 14 août ce qui s'est accompli le 4 septembre. Ils se sont trompés sans doute, l'heure n'était pas venue ; il faut savoir la deviner, et, dans des questions si redoutables, la méprise, l'erreur de calcul, devient une lourde responsabilité. «J'ai cru » n'est jamais une justification.

Jouer à faux, de son chef, la partie de la liberté peut-être d'une nation tout entière est une faute, souvent irréparable, dont rien ne saurait absoudre. Heureusement, cette faute n'était ici qu'un simple incident, bientôt disparu dans la tourmente.

... On peut justement reprocher aux insurgés de La Villette un retard de huit jours. C'est le dimanche, 7 août, au lendemain du désastre de Reischoffen qui avait soulevé Paris, qu'il fallait se précipiter sur l'empire.

Le 14, il était trop tard ou trop tôt. La seule réponse possible, c'est que le chef de l'entreprise, surpris à Bruxelles par les nouvelles foudroyantes de l'Alsace et dépourvu de passeport, a dû franchir à pied la frontière dans la nuit du 11 au 12 août. Cette excuse n'est pas valable. Quand on se mêle de politique sérieuse, on ne doit pas se laisser surprendre. 
Mais enfin, on n'est pas vendu à la Prusse parce qu'on s'est attardé malgré soi et qu'on a mal pris son temps. Cette rigueur impitoyable, ces honteuses calomnies contre les hommes qui préfèrent les actes aux paroles, est une des misères de notre époque et un des plus tristes symptômes de la décadence.

... Les principaux auteurs de l'attaque de La Villette sont Blanqui, Eudes, Granger, Caria, Pilhes, ex-représentant du peuple, Flotte, qui arrivait de Californie. Tridon était malade et n'a pu se trouver sur le terrain.

Voilà une singulière collection de Prussiens !

\section{2. - LA RÉACTION}

$\underline{\text { Retour à la table des matières }}$

19 septembre 1870 .

Le 4 septembre, devant la grandeur du péril, les républicains, d'un mouvement unanime, ont abjuré toute dissidence et offert leur concours au gouvernement provisoire.

Il y avait une condition à ce concours, la défense en commun et à outrance contre l'envahisseur étranger.

Personne n'abdiquait l'usage de sa raison et de ses yeux. Une question restait palpitante devant toutes les pensées: «La patrie est-elle énergiquement défendue ?»

Chacun des jours écoulés a répondu avec tristesse : « Non ! »

C'est en vain qu'on a prétendu séparer la cause de l'indépendance de celle de liberté. En France, les deux n'en font qu'une.

L'empire a trahi et il est tombé, parce que d'une main il essayait de combattre le dehors, et que de l'autre il comprimait le dedans. Sa main gauche a paralysé sa main droite. Il a perdu nos armées et laissé le pays roulant dans l'abîme.

Hélas ! cette leçon n'a pas servi.

Après un moment d'enthousiasme et quelques simulacres de concorde, le funèbre antagonisme a reparu. Il grandit toujours plus menaçant. La situation du 
mois d'août ${ }^{1}$ s'est refaite. Le gouvernement provisoire n'est qu'une pâle contrefaçon de l'empire.

À son tour, il craint plus la révolution que la Prusse, et prend ses précautions contre Paris avant de les prendre contre Guillaume. Il se hérisse de soupçons et d'hostilité envers le peuple.

Quel est le coupable de cette rupture ? Qui a failli le premier aux conditions de l'alliance ? Elle s'était conclue sur le terrain de la défense nationale. Le pouvoir nouveau n'est-il pas sorti le premier de ce programme ? - Il n'y est pas même entre une seule minute.

Certes, après le 4 septembre, la cause de l'empire et celle de la Prusse se sont aussitôt confondues. Guillaume et Bonaparte sont deux alliés. Disons mieux. La monarchie, quelle qu'elle soit, est aujourd'hui coalisée avec l'invasion contre la République, et la République, c'est la France.

Si une paix ignominieuse démembre le territoire ou rançonne la nation, quel en sera le bénéficiaire en commun après l'ennemi ? Un monarque. C'est au profit d'une monarchie que la France sera disloquée ou mise à sac.

Si donc il y aurait injustice à voir dans tous les monarchistes des auxiliaires actifs de l'invasion, certes on n'est pas tenu à la même indulgence envers les fonctionnaires de l'empire, mendiants de places sous tous les pouvoirs corrompus.

Dès le premier jour, leurs fureurs ont éclaté contre la République. Ils ont ouvertement passé à l'ennemi, ils sont ses pionniers et ses recruteurs. Inutile de raconter leurs exploits. La presse est gorgée des récits de ces trahisons.

Demander la révocation de ces traîtres, était-ce violer le pacte de concorde ?

Maintenir leur autorité, n'était-ce pas se rendre solidaire de l'usage criminel qu'ils en font !

Depuis le 4 septembre, les républicains supplient le gouvernement de destituer les maires et les juges de paix, ces instruments serviles de la tyrannie, aujourd'hui artisans de complots et de désorganisation.

Le gouvernement reste sourd et muet.

Il s'agit de la manifestation blanquiste du 14 août 1870, boulevard de La Villette, qui avait pour but de rétablir la république en France. La manifestation échoua à cause de sa mauvaise organisation et de son caractère prématuré. Blanqui pense qu'après la chute de l'empire la situation exige de nouveau la lutte contre le gouvernement de la « défense nationale ». 
Paris ne cesse de réclamer le licenciement et la dispersion des anciennes forces de police qui ont laissé de si sanglants souvenirs. Le gouvernement reste sourd et muet.

Seulement, le préfet de police transforme ironiquement les gardes municipaux en gardes républicains, et les sergents casse-tête en gardiens de paix. Dès aujourd'hui, le pouvoir s'appuie complètement sur ces milices abhorrées.

Plaintes, reproches, prières, supplications viennent expirer devant l'implacable inertie du parti pris. On ne répond que par des appels moqueurs au calme et à l'obéissance. On exploite avec cynisme le dévouement et la douleur des patriotes.

Le mot «Union » est devenu l'arme de guerre de tous les ennemis de la liberté. Qu'on le sache bien, concorde, pour les républicains, ne signifie pas asservissement aux contre-révolutionnaires. Ils veulent l'union pour le salut et non pour la ruine de la République.

$$
\text { 3. }-1792-1870
$$

$\underline{\text { Retour à la table des matières }}$

30 octobre 1870.

Quatre-vingts ans d'intervalle seulement entre ces deux dates ! La vie d'un vieillard. Mais, de ce berceau à cette tombe, dix siècles ordinaires ont trouvé place. Plus rien ne se ressemble. La filiation morale a disparu. On est de race par le sang ; on ne l'est ni par la conscience, ni par le caractère. La tradition n'a pas laissé vestige. Aux deux extrémités de la période, deux drapeaux : - 1792, l'enthousiasme ; - 1870, la spéculation.

De toutes parts, une lamentation s'élève : nos pères de 1792 n'avaient ni le nombre, ni la richesse, ni la science qu'on possède aujourd'hui. Ils ont étéhéroïques. Ils ont sauvé la patrie, écrasé les monarchies coalisées. Allons-nous, avec tant de ressources qu'ils n'avaient pas, périr sous le talon de la Prusse, devant le sourire méprisant de l'Europe ?

Et ce cri retentit plus désespéré : «92 ! Soyons les hommes de 92 ! ou la France sombre. » Puis cet étrange refrain : «Serrons-nous autour du gouvernement de la défense nationale. »

Nos pères de 92 se serraient autour d'un gouvernement révolutionnaire qui foulait aux pieds l'ennemi intérieur, le monarchisme, et portait la pointe de l'épée au visage, de son complice, l'envahisseur étranger.

Et vous vous ralliez, vous, à un pouvoir contre-révolutionnaire, proscripteur des républicains, courtisan des royalistes et très humble serviteur de l'invasion. 
Les plus énergiques se hasardent à dire : « Il faut le pousser en avant, suppléer sa faiblesse, sa lenteur, et néanmoins le maintenir. »

Ah ! vous prenez le gouvernement pour un colis qu'on traîne avec soi par les chemins, parce qu'il faut des malles en voyage ?

Eh bien ! c'est le bagage qui règle la marche et qui domine le voyageur.

Les peuples sont ce que les fait leur gouvernement. Ils ne vivent et ne meurent que par lui. Toute leur destinée est dans ses mains. Il est singulier qu'on l'oublie si vite, après vingt ans de Bonaparte.

La République de 92 proscrivait sans pitié les suppôts de la monarchie, ses états-majors civils et militaires, ses lois, ses mœurs, sa religion, ses idées et jusqu'à ses costumes. Debout sur ses débris dispersés, elle entraînait la France furieuse aux batailles, et, si le Prussien du dehors faisait un pas de trop sur le sol de la patrie, elle ne reculait pas devant un 2 novembre contre le Prussien du dedans ${ }^{1}$.

La République de I870 ne connaît d'autre ennemi que les républicains, elle est aux genoux des aristocrates et du clergé. Elle paye des pensions de 20000 francs aux veuves millionnaires des scélérats qui ont pillé, saccagé, égorgé le pays. Elle livre l'enfance aux jésuites, les citoyens au militarisme. Elle immole l'avenir au passé, les démocrates aux réactionnaires ; elle paralyse nos bras, n'oppose aux envahisseurs qu'un simulacre de résistance, mendie leur pardon et leurs bonnes grâces, s'appuie sur les royalistes alliés de l'étranger et tient suspendue sur la tête des révolutionnaires la menace d'une Saint-Barthélemy.

Que vient-on nous parler de 92 en criant : « Hosannah au gouvernement de la défense nationale ! » Ce sont les deux antipodes. 92 a sauvé la Révolution et fondé la République ; l'Hôtel de Ville ${ }^{2}$ est en train de les anéantir.

Il a pour auxiliaires tous ces monarchiens qui hurlent : «Vive la République !» après l'avoir égorgée et proscrite durant vingt années, et en se préparant à l'égorger, à la proscrire avec plus de rage encore.

Il est le drapeau des traîtres et des caméléons, des amphibies qui ont un pied dans chaque antichambre, un article pour chaque couleur, une pierre d'attente dans chaque édifice. Toutes les armes gangrenées se réfugient à son ombre, font escorte et chorus à ses tromperies.

Selon toute vraisemblance, c'est une erreur de date : il s'agit des événements de septembre 1792 alors que, sous l'influence des nouvelles de la chute de Verdun et des troubles en Vendée, de nombreux ennemis du peuple furent mis à mort par la justice sommaire du peuple.

2 Il s'agit du gouvernement de la défense nationale qui siégeait à l'Hôtel de Ville de Paris. 
Il est la contre-révolution et creuse le tombeau de la France.

\section{4. - ARMISTICE ET CAPITULATION}

Retour à la table des matières

5 novembre 1870.

On lit dans Le Temps du 2 novembre :

... Paris devenu soldat, la France marchant, la province courant aux armes,... on a ouvert les yeux, et aujourd'hui la France a reconquis l'estime de l'Europe et du monde... Les puissances ont compris. La première, la Russie a décidé qu'une plus longue inaction serait coupable... Une entente s'est établie. Cette entente est arrivée à ce résultat, qu'une condition préalable de toute tentative de pacification c'était la constitution en France d'un gouvernement régulier, que cette constitution était soumise à la conclusion d'un armistice ; qu'il y avait lieu, dès lors, de proposer un armistice...

On ne saurait mieux démasquer ses projets. La défaite rapide des armées impériales, la marche victorieuse des Prussiens avaient convaincu l'Europe de notre décrépitude et de notre impuissance.

Les rois ont salué notre chute d'un cri de joie.

Lorsque le gouvernement de la défense nationale a imploré leur pitié, ils ont répondu froidement : «Cela ne nous regarde pas. Nous ne pouvons rien. » Et ils se sont croisé les bras, attendant notre dernière heure.

Mais, tandis que l'Hôtel de Ville mendiait partout compassion et assistance, Paris se levait plein de colère et d'enthousiasme. En vain, nos prétendus gouvernants laissaient à Brest les canons de marine, en Angleterre ou ailleurs les fusils offerts ; en vain, ils s'abstenaient de tous préparatifs, se faisaient petits, humbles, soumis, Paris devenait chaque jour plus menaçant. Il fallait lui fournir des armes, simuler ses sentiments et son langage, s'appliquer un masque de fermeté et de résistance, sous peine de désaveu et d'abandon.

L'ennemi, qui avait cru entrer d'emblée dans une ville tremblante, se heurtait à des remparts hérissés de baïonnettes. Le temps s'écoulait en vaines tentatives et sanglants combats. Ni l'incapacité, ni le mauvais vouloir des chefs ne prévalaient sur l'énergie de la population.

Depuis deux mois, les Prussiens se morfondent sous nos murs. Et l'Europe de s'étonner, les monarchies de frémir au bruit du soulèvement parisien. Elles s'étaient 
enfermées dans un silence dédaigneux, pour attendre l'agonie de la grande Révolutionnaire.

Mais la garde Révolutionnaire n'agonise point. Elle se hérisse de cinq cent mille baïonnettes ; elle brave et raille Bismarck, la famine, le bombardement. Elle repousse l'ennemi aujourd'hui ; demain elle se prépare à l'attaquer. Elle s'indigne contre la mollesse, l'inaction de son gouvernement, elle demande à grands cris des fusils, des canons.

Les rois tremblent, et leur effroi prend le masque de la sympathie. Ils laissaient aller, quand le courant portait la France au naufrage. Ils se ravisent lorsque le courant menace de la ramener au salut et à la victoire.

Les voilà pleins d'humanité, de bienveillance. Le sang versé les afflige. Il faut mettre un terme à ces horreurs. Si Paris allait écraser Guillaume sous ses murs, rallier la province, enterrer dans nos sillons les hordes allemandes, et ruer sur l'Europe monarchique la France républicaine !

Quel désastre, pour le monde des oppresseurs! Royautés, aristocraties, superstitions précipitées ensemble au tombeau, et les peuples, émergeant des ténèbres et de la misère, debout au grand soleil - la lumière - de la Science et de l'Égalité ! Ô malheur ! malheur ! Vite au secours de la nuit et du sabre !

Vite un armistice, afin que la Prusse masse ses armées autour du rebelle endurci et lui dicte la loi au nom de la force ! Vite, la paix, quand Bismarck peut la dicter de par la victoire et le fait accompli.

La nuit du $31^{1}$ octobre va rendre aux despotes l'espoir et l'insolence. Ces Parisiens, qui les remplissaient de terreur, sont vaincus, non par l'ennemi, mais par la trahison. Ils ont voulu rompre la trame ourdie dans l'ombre par les auxiliaires et les complices de l'étranger. Ils ont succombé par horreur de la guerre civile. Ils périssent par le scrupule que n'ont jamais connu leurs odieux adversaires, celui de verser le sang des concitoyens.

Le Prussien, vainqueur par les baïonnettes de la réaction, va relever la tête et retrouver son langage de Ferrières ${ }^{2}$. La révolution avait rabattu son insolence,

L'insurrection du 31 octobre 1870, à laquelle les blanquistes prirent une grande part, avait pour but de renverser le gouvernement de la défense nationale. Cette insurrection échoua. Le gouvernement s'engagea à ne pas poursuivre les insurgés. Ce qui ne l'empêcha pas d'arrêter Blanqui et de le condamner, en 1872, pour sa participation à l'insurrection.

2 Allusion à l'entretien du ministre des Affaires étrangères Jules Favre avec Bismarck, au château de Ferrières-en-Brie (Seine-et-Marne), le 19 septembre 1870. Favre demandait que l'intégrité de la France soit sauvegardée, Bismarck exigeait l'annexion de l'Alsace-Lorraine à l'Allemagne. Les pourparlers furent sans résultat. 
mais la révolution s'est laissé arracher ses armes. Bismarck ${ }^{1}$ respire. Cette populace - sa terreur, - cette populace, dont il montrait la victoire prochaine à ses alliés royalistes comme leur ruine commune, elle disparaît de la scène.

Le dévouement est écrasé. L'égoïsme triomphe. Paris historique a disparu. Reste celui du lucre et de la luxure, de la goinfrerie et du lupanar.

Il n'est plus, le Paris qui faisait trembler l'ennemi présent et lointain. Aujourd'hui, Paris a peur, Paris est lâche. Il veut de la bonne chère et des spectacles, des filles et de la musique.

Loin de la patrie et de l'indépendance! Buvons et mangeons ! Au diable l'Alsace et la Lorraine ! Vive l'armistice et la paix à tout prix !

Guillaume a cessé de craindre. Il va hausser le ton. Derechef, il est en présence des couards qui ne veulent pas de la lutte surtout quand elle doit fonder la République, qu'ils abhorrent. Livrer l'Alsace afin de ravoir la monarchie, pour eux c'est une affaire d'or, charmés de jouer à qui perd gagne.

Il leur coûtera peu de donner plus ou moins. Le marché sera tôt conclu. À quel prix l'armistice ? À quel prix la levée du siège ? À quel prix la honte et la ruine de la France?

La démagogie est désarmée. La Bourse et la sacristie sont maîtresses. On va les voir à l'œuvre. Pays fini, à moins d'un retour qui le délivre de ces deux pestes.

\section{5. - ALLIANCE OUVERTE DE LA RÉACTION AVEC BISMARCK}

$\underline{\text { Retour à la table des matières }}$

25 novembre 1870 .

L'alliance est conclue entre les orléanistes et les bonapartistes.

«Ils font cause commune, écrit Gambetta au gouvernement, en date du 18 novembre. Les deux partis réclament une Assemblée et y poussent avec rage. »

Otto-Édouard-Léopold BISMARCK (1815-1898) : Homme politique de Prusse et d'Allemagne, convaincu de la supériorité des monarchies. Principal inspirateur de la guerre franco-prussienne qu'il avait préparée dès 1867. À partir de 1871, Bismarck fut le chancelier de l'Empire allemand. 
M. Gambetta ${ }^{1}$, l'irréconciliable, commence son expiation. Les républicains lui ont fait la courte échelle. Une fois hissé au pouvoir, il les a repoussés du pied et livrés à l'ennemi, comptant gagner ses bonnes grâces.

Illusion ! on achète et on paye les transfuges, on n'en prend pas livraison. C'est toujours leur folie de se croire acceptés. La réaction entame sa seconde fournée de proscrits. Les gendarmes de la première seront en tête de liste. M. Gambetta a servi de cravache contre les républicains. Son tour vient de passer par la cravache.

Il était déjà suspect. Il prêche la résistance. Il a fait une proclamation pour Bazaine, Bazaine ${ }^{2}$, l'espoir et le benjamin du conservatisme, le sauveur de la société ! Bazaine, qui voulait marcher avec son armée et les Prussiens, pour mettre l'anarchie à la raison.

Gambetta comble la mesure de ses crimes par cette phrase : « Les deux partis réclament une Assemblée et y poussent avec rage. » Il ne faut pas s'y tromper, le chef du parti conservateur en France, c'est Bismarck. Le gouvernement légitime n'est point à Paris, mais à Versailles. Bismarck demande une Assemblée, il sait qu'il a pour lui les classes riches, et que ces classes, maîtresses du scrutin, nommeront, par leur influence et par la terreur étrangère, une Assemblée prussienne et monarchique.

Il suffit de parcourir ici les feuilles réactionnaires. N'a-t-on pas lu hier dans ces journaux éhontés l'infâme libelle publié au Moniteur prussien par l'agent qui les représente auprès du roi Guillaume? Ils appellent cette pièce un document important.

Très important, en effet, car il est la reproduction des calomnies éditées par eux-mêmes, à Paris, contre les victimes du 31 octobre, et révèle ainsi leurs relations intimes avec Bismarck. Ils font réimprimer par lui, à Versailles, leurs turpitudes, et ils en sont venus à ce degré d'impudence d'étaler leur complicité ouverte avec l'ennemi, en le citant comme une autorité morale.

On voit que les choses vont vite. Bismarck et ses associés de Paris accusent l'Hôtel de Ville de faiblesse et de ménagements envers les brigands du 31 octobre.

\footnotetext{
Léon-Michel GAMBETTA (1838-1882): Homme d'État. Excellent orateur. Se prétendit démocrate au début de son activité. C'est à lui que fut confiée la défense nationale après la chute de l'empire. Gambetta refusa d'accepter les conditions de paix de Bismarck (1871) et se réfugia en Espagne.

Après la Commune de Paris, Gambetta fut le chef du parti républicain, promoteur d'une politique de modération et d'opportunisme. Lors d'une réunion électorale en 1881, il appela les ouvriers à abandonner la lutte et à établir l'harmonie des classes.

2 Achille-François BAZAINE (1811-1888) : Militaire réactionnaire et démagogue, maréchal de France. Le 27 octobre 1870, il abandonna traîtreusement Metz aux Prussiens et leur ouvrit le chemin de Paris ; il engagea des pourparlers avec le commandement prussien pour étouffer la république et rétablir la monarchie.
} 
Nos dictateurs n'ont qu'à bien se tenir. Ils ont déjà à un pied en prison, car la réaction a d'ores et déjà pour gendarmes les soldats prussiens, et le grand ministre du Nord ne refusera rien à ses bons amis. Pourvu qu'ils lui cèdent toutes les provinces à sa convenance, ils pourront, avec ses sbires, pendre, fusiller, déporter à discrétion les brigands qui s'opposent aux volontés du roi de Prusse et des monarchiens.

Qui le croirait ? M. Jules Favre lui-même ${ }^{1}$, le grand élégiaque de la situation, sera prochainement un anarchiste, un brigand peut-être. Il n'accepte pas l'injonction, que lui signifient $M$. de Bismarck et ses journaux de Paris et de Versailles, de convoquer une Assemblée nationale. Il ose dire « que le besoin de diviser et d'affaiblir la résistance du pays explique suffisamment une pareille injonction, ainsi que le reproche de ne pas s'y soumettre ».

Voici donc le cygne de l'Hôtel de Ville en pleine révolte contre les hommes d'ordre, personnifiés aujourd'hui par le grand chancelier de Guillaume ! Il va être mis au ban de la presse prussienne de Paris. Il y est déjà non pas sur le même ton qu'un vieux révolutionnaire, mais dans un amphigouri gros de menace à clairevoie.

Et qu'on ne l'oublie pas, la presse prussienne de Paris, c'est la réaction. La réaction, c'est la société. Oui, la société française a aujourd'hui pour représentant le roi de Prusse, et pour organe son premier ministre.

Cela ne veut pas dire, au moins, que la France soit folle de Guillaume. Tant s'en faut! La société française n'est pas la nation française. Ne confondons pas deux êtres distincts et ennemis. La Société, c'est le Capital, - la Nation, c'est le Travail, le Maître et l'Esclave.

On répète souvent : "Pourquoi cette division antagonique de deux choses inséparables ? " Inséparables, en effet. Point de maîtres sans esclaves; point d'esclaves sans maîtres. La question à résoudre serait : ni maître, ni esclave. Mais, halte à cette digression ! Elle nous écarte. J'ai traité ailleurs ce sujet qui a toujours un attrait invincible. Il ne faut point se laisser aller. Ce serait bien peu le moment. Revenons à la politique.

Il est certain que la société gouverne la nation et fort mal. Il s'ensuit des culbutes pour cet être biforme, qui finit toujours par se retrouver sur ses pieds comme devant. C'est alors à recommencer. Cette fois, la culbute, au lieu d'être simple, se trouve compliquée d'un tiers intervenant qui assomme le malade pour le dépouiller.

Jules FAVRE (1809-1880) : Homme politique, républicain modéré. Membre de l'Assemblée constituante en 1848. Après la chute de l'empire, ministre des Affaires étrangères. Participa activement à la répression de la Commune de Paris et à l'organisation de la terreur blanche. 
Comme le malade est double par essence, le larron étranger, suivant l'usage, s'adresse à l'un des membres en lutte et lui offre, contre l'autre, moyennant récompense, son appui qui est accepté. Mais le combattant lésé repousse cette médiation onéreuse et prétend continuer la querelle.

Le roi de Prusse, ce brigand du dehors, est le bienvenu de la société française qu'il veut replanter sur ses jambes. La nation, mécontente, le repousse avec colère. Elle est lasse de son mauvais gouvernement et s'obstine à ne pas terminer la bataille avant d'avoir rossé les envahisseurs et mis au pas leurs complices.

Son succès est fort douteux. Elle avait d'abord l'avantage. Elle l'a perdu par inexpérience et faiblesse d'esprit. La société, son adversaire, est toute-puissante. Le nombre, entravé par l'ignorance et la misère, ne saurait prévaloir contre la richesse et l'instruction, privilèges de la minorité.

Nous assistons à une nouvelle défaite du peuple. Mais la victoire sera plus criminelle cent fois que les précédentes, car le vainqueur va triompher par la grâce des brigands germaniques.

C'est ce que les masses aveugles n'aperçoivent pas encore et verront trop tard.

Toutefois, la victoire aura bientôt conscience de la trahison, et les traîtres n'en profiteront pas longtemps.

\section{6. - LES ENVAHISSEURS}

Retour à la table des matières

5 décembre 1870.

Ce n'est pas nous qui avons appelé les hordes allemandes. Guillaume a beau répéter chaque jour que l'Allemagne a été provoquée. Il ment. Qui donc l'ignore ?

Le provocateur dé la guerre, c'est l'homme qui, depuis quatre ans, préparait dans l'ombre et le silence l'invasion et la destruction de notre pays.

Le coupable de la guerre, c'est le peuple qui se proclame une race supérieure, dont l'humanité entière est le marchepied naturel.

Les Français en voulaient-ils à la race germanique? Ils ne s'occupaient seulement pas de ses fureurs et de ses imprécations. Ils les ignoraient même, affront de plus, qui s'ajoute aux griefs imaginaires de ces monomanes. 
Oui, le guet-apens se dressait par toute une nation. Elle avait décidé que la France était un pays maudit, condamné de Dieu, et elle est entrée chez nous, avec la modeste prétention d'Attila d'être un fléau céleste. Cette justicière du Très-Haut n'a pas failli à l'habitude de ses pareils, habitude spéciale du métier, le raffinement de la scélératesse. Tous les vengeurs de Dieu sont des monstres.

L'hypocrisie est leur première qualité, racine de toutes les autres. Est-il rien d'abominable comme ce traquenard Hohenzollern ? Pouvait-on mieux choisir pour attirer la victime ? L'Europe l'a compris à l'instant, et, malgré ses jalousies contre nous, elle a donné tort à Bismarck.

Mais Bismarck connaissait son Bonaparte. Il le savait désireux d'un prétexte quelconque de se défaire de la révolution. Il lui a tendu cette perche pour le noyer.

Il comptait bien noyer la France du même coup, et les Teutons y comptaient aussi. Les misérables ! ils fulminaient contre Napoléon III. Est-ce que tous nos ennemis ne nous souhaitaient pas Napoléon III ? N'ont-ils pas tous salué avec bonheur son crime de Décembre ? Ils voyaient en lui notre perdition, et, quand ils frappaient sur sa tête, c'était pour l'enfoncer dans notre sol et qu'il y prît racine.

Ce Guillaume, l'homme de Dieu, il ne venait en guerre que contre Bonaparte, point contre le peuple français ! Et, quand le peuple français a jeté bas le drôle, Guillaume prétend le lui replanter sur les épaules! Comme punition d'en haut, sans doute?

La France a failli sombrer, pour avoir laissé au gouvernail des collaborateurs de Bonaparte, des hommes souillés du contact de son commandement, à un titre quelconque. Si elle échappe au naufrage, c'est presque un miracle, et pourtant il ne s'agissait que d'un coup de vent en surprise. Il a fallu l'ineptie de pareils pilotes pour la laisser si longtemps en perdition.

Qu'elle se relève enfin et qu'à son tour elle fasse justice de ses prétendus justiciers.

Il y a dans la victoire, même d'un jour, une insolence qui ne se corrige pas aisément. Bismarck, accueilli par un peuple en armes, ne reviendra pas volontiers de son rêve de Louis XIV trônant à Versailles et disant : "La France, c'est moi ! » Peut-être aussi, triste effet de la peur, ceux qui étaient sous les pieds se croiront-ils quittes à bon compte, en se trouvant debout, et laisseront-ils s'échapper le bandit.

Faute impardonnable et qui pourrait se payer cher! Des bandits tels que Bismarck et ses Allemands sont des récidivistes de la pire espèce. Si Paris leur échappe, on leur aura volé Paris. Et, si la population qu'ils ont saccagée les laisse impunis, pourquoi ne recommenceraient-ils pas? 
Ces hordes ont prétendu nous châtier de crimes imaginaires que leur convoitise et leur jalousie fabriquent à notre charge. Leur crime, à elles, retentit par toute la terre. Leurs docteurs n'ont-ils pas osé dire, au bruit des applaudissements, que la race latine ou la race germanique devait périr, parce que leur existence était inconciliable?

Nous admettons, nous, la coexistence, bien mieux, la fraternité de toutes les races. Celles qui paraissent inférieures, ont toujours quelque don particulier qui tiendra sa place dans l'humanité fusionnée. Mais, quand une horde se rue traîtreusement sur un peuple sans haine, criant qu'elle arrive avec mission divine de le détruire, ce peuple n'est-il pas en droit de lui répondre : "C'est toi, race de brigands, qui vas périr !»

Si on ne l'extermine pas, on peut du moins lui présenter la note de sa tournée divine, avec invitation de payer les frais.

J'aime à croire qu'à la fin, et malgré tout, on ne manquera pas à cette précaution nécessaire et que nos malheureuses provinces seront indemnisées largement de la promenade d'Attila. 


\section{V \\ INSTRUCTION POUR UNE PRISE D'ARMES '}

$\underline{\text { Retour à la table des matières }}$

Une insurrection parisienne, d'après les vieux errements, n'a plus aujourd'hui aucune chance de succès.

En 1830, le seul élan populaire a pu suffire à jeter bas un pouvoir surpris et terrifié par une prise d'armes, événement inouï qui était à mille lieues de ses prévisions.

Cela était bon une fois. La leçon a profité au gouvernement, resté monarchique et contre-révolutionnaire, bien que sorti d'une révolution. Il s'est mis à étudier la guerre des rues, et il y a repris bientôt la supériorité naturelle de l'art et de la discipline sur l'inexpérience et la confusion.

Cependant, dira-t-on, le peuple en 48 a vaincu par la méthode de 1830. Soit, mais point d'illusions : la victoire de Février n'est qu'un raccroc. Si Louis-Philippe s'était sérieusement défendu, force serait restée aux uniformes.

À preuve, les journées de juin. C'est là qu'on a pu voir combien est funeste la tactique, ou plutôt l'absence de tactique, de l'insurrection. Jamais elle n'avait eu la partie aussi belle : dix chances contre une.

D'un côté, le gouvernement en pleine anarchie, les troupes démoralisées ; de l'autre, tous les travailleurs debout et presque certains du succès. Comment ont-ils succombé ? Par défaut d'organisation. Pour se rendre compte de leur défaite, il suffit d'analyser leur stratégie.

1 Première partie d'une étude rédigée en 1868, dont le manuscrit est conservé à la Bibliothèque Nationale, dans le carton V, livre IX, liasse IX, des papiers de Blanqui. Cf. La Pensée, $\mathrm{n}^{\circ}$ 19, juillet-août 1948. 
Le soulèvement éclate. Aussitôt, dans les quartiers du travail, des barricades s'élèvent çà et là, à l'aventure, sur une multitude de points.

Cinq, dix, vingt, trente, cinquante hommes recrutés par hasard, la plupart sans armes, commencent à renverser des voitures, lèvent et entassent des pavés pour barrer la vole publique, tantôt au milieu des rues, plus souvent à leur intersection. Quantité de ces barrages seraient à peine un obstacle pour la cavalerie. Parfois, après une grossière ébauche de retranchement, les constructeurs la plantent là pour se mettre en quête de fusils et de munitions.

En juin, on a compté plus de six cents barricades. Une trentaine au plus ont fait à elles seules tous les frais de la bataille. Les autres, dix-neuf ou vingt, n'ont pas brûlé une amorce. De là, ces glorieux bulletins qui racontaient avec fracas l'enlèvement de cinquante barricades, où il ne se trouvait pas une âme.

Tandis qu'on dépave ainsi les rues, d'autres petites bandes courent çà et là, désarment les corps de garde en prenant de la poudre et des armes chez les arquebusiers. Tout cela se fait sans concert ni direction, au gré de la fantaisie individuelle.

Peu à peu, cependant, un certain nombre de barricades, plus hautes, plus fortes, mieux construites, attirent de préférence les défenseurs qui s'y concentrent. Ce n'est point le calcul, mais le hasard qui détermine l'emplacement de ces fortifications principales; quelques-unes seulement, par une sorte d'usurpation militaire assez concevable, occupent les grands débouchés.

Durant cette première période de l'insurrection, les troupes, de leur côté, se sont réunies. Les généraux reçoivent et étudient les rapports de police. Ils se gardent bien d'aventurer leurs détachements sans données certaines, au risque d'un échec qui démoraliserait le soldat. Dès qu'ils connaissent bien les positions des insurgés, ils massent les régiments sur divers points, qui constitueront désormais la base des opérations.

Les armées sont en présence. Ici va se montrer à nu le vice de la tactique populaire ; cause certaine des désastres.

Point de commandement général, partant point de direction; pas même de concert entre les combattants. Chaque barricade a son groupe particulier, plus ou moins nombreux, mais toujours isolé. Qu'il compte dix ou cent hommes, il n'entretient aucune communication avec les autres postes. Souvent, il n'y a même pas un chef pour diriger la défense, et, s'il y en a un, son influence est à peu près nulle. Les soldats n'en font qu'à leur tête : l'un s'en va, l'autre arrive ; ils restent, ils partent, ils reviennent, suivant leur bon plaisir. Le soir, ils vont se coucher. 
Par suite de ces allées et venues perpétuelles, on voit le nombre des citoyens présents varier rapidement du tiers, de la moitié, quelquefois de trois quarts. Personne ne peut compter sur personne. De là, bientôt, défiance du succès et découragement.

De ce qui se passe ailleurs, on ne sait rien et on ne s'embarrasse pas davantage. Les canards circulent, tantôt noirs, tantôt roses. On écoute paisiblement le canon et la fusillade, en buvant sur le comptoir des marchands de vins. Quant à porter secours aux positions assaillies, on n'en a même pas l'idée. «Que chacun défende son poste et tout ira bien », disent les plus solides. Ce singulier raisonnement tient à ce que la plupart des insurgés se battent dans leurs propres quartiers; faute capitale, qui a des conséquences désastreuses, entre autres la dénonciation des voisins après la défaite.

Car, avec un pareil système, la défaite ne peut manquer. Elle arrive à la fin sous la forme de deux ou trois régiments qui tombent sur la barricade, et en écrasent quelques défenseurs. Toute la bataille n'est que la répétition monotone de cette manœuvre invariable. Tandis que les insurgés fument leur pipe derrière leur tas de pavés, l'ennemi porte successivement toutes ses forces sur un point, puis sur un second, un troisième, un quatrième, etc., et il extermine ainsi en détail l'insurrection.

La population n'a garde de contrarier cette agréable besogne. Chaque groupe attend philosophiquement son tour et ne s'aviserait pas de courir à l'aide du voisin. Non ! « Il défend son poste, il ne faut pas abandonner son poste. »

Et voilà comme on périt par l'absurde.

Lorsque, grâce à une si lourde faute, la grande révolte parisienne de 48 a été brisée comme verre par le plus pitoyable des gouvernements, quelle catastrophe n'aurait-on pas à redouter, si on recommence la même sottise devant un militarisme farouche qui a maintenant à son service les formidables conquêtes de la science et de l'art, les chemins de fer, le télégraphe électrique, les canons rayés, le fusil Chassepot?

Par exemple, ce qu'il faut rayer du nombre des nouveaux avantages de l'ennemi, ce sont les voies stratégiques qui sillonnent maintenant la ville dans tous les sens. On les craint, on a tort. Il n'y a pas à s'en inquiéter. Loin d'avoir créé un danger de plus à l'insurrection, comme on se l'imagine, elles offrent au contraire un mélange d'inconvénients et d'avantages pour les deux parties. Si la troupe y circule avec plus d'aisance, par contre, elle y est exposée fort à découvert.

De telles rues sont impraticables sous la fusillade. En outre, les balcons, bastions en miniature, fournissent des feux de flanc que ne comportent point les fenêtres ordinaires. Enfin, ces longues avenues en ligne droite méritent 
parfaitement le nom de boulevards dont on les a baptisées. Ce sont en effet de véritables boulevards qui constituent des fronts naturels de défense d'une très grande force.

L'arme par excellence, dans la guerre des rues, c'est le fusil. Le canon fait plus de bruit que de besogne. L'artillerie ne pourrait agir sérieusement que par l'incendie. Mais une telle atrocité, employée en grand et comme système, tournerait bientôt contre ses auteurs et ferait leur perte.

La grenade, qu'on a pris la mauvaise habitude d'appeler bombe, est un moyen secondaire, sujet d'ailleurs à une foule d'inconvénients. Elle consomme beaucoup de poudre pour peu d'effet, est d'un maniement très dangereux, n'a aucune portée et ne peut agir que des fenêtres. Les pavés font presque autant de mal et ne coûtent pas si cher. Les ouvriers n'ont pas d'argent à perdre.

Pour l'intérieur des maisons, c'est le revolver, puis l'arme blanche, baïonnette, épée, sabre et poignard. Dans un abordage, la pique ou la pertuisane de huit pieds triompherait de la baïonnette.

L'armée n'a sur le peuple que deux grands avantages, le fusil Chassepot et l'organisation. Ce dernier surtout est immense, irrésistible. Heureusement, on peut le lui ôter et, dans ce cas, l'ascendant passe du côté de l'insurrection.

Dans les luttes civiles, les soldats, sauf de rares exceptions, ne marchent qu'avec répugnance, par contrainte et par eau-de-vie. Ils voudraient bien être ailleurs et regardent plus volontiers derrière que devant eux. Mais une main de fer les retient. Esclaves et victimes d'une discipline impitoyable, sans affection pour le pouvoir, ils n'obéissent qu'à la crainte et sont incapables de la moindre initiative. Un détachement coupé est un détachement perdu. Les chefs, qui ne l'ignorent pas, s'inquiètent avant tout de maintenir les communications entre tous leurs corps. Cette nécessité annule une partie de leur effectif.

Dans les rangs populaires, rien de semblable. Là, on se bat pour une idée. Supérieurs à l'adversaire par le dévouement, ils le sont bien plus encore par l'intelligence. Ils l'emportent sur lui, dans l'ordre moral et même physique, par la conviction, la vigueur, la fertilité des ressources, la vitalité du corps et de l'esprit. Ils ont la tête et le cœur. Nulle troupe au monde n'égale ces hommes d'élite.

Que leur manque-t-il donc pour vaincre ? Il leur manque l'unité et l'ensemble qui fécondent, en les faisant concourir au même but, toutes ces qualités que l'isolement frappe d'impuissance. Il leur manque l'organisation. Sans elle, aucune chance. L'organisation, c'est la victoire ; l'éparpillement, c'est la mort.

Juin 48 a mis cette vérité hors de conteste. Que serait-ce donc aujourd'hui ? Avec les vieux procédés, le peuple tout entier succomberait si la troupe voulait 
tenir, et elle tiendra tant qu'elle ne verra devant elle que des forces irrégulières, sans direction. Au contraire, l'aspect d'une armée parisienne en bon ordre, manœuvrant selon les règles de la tactique, frappera les soldats de stupeur et fera tomber leur résistance.

Une organisation militaire, surtout quand il faut l'improviser sur le champ de bataille, n'est pas une petite affaire pour notre parti. Elle suppose un commandement en chef et, jusqu'à un certain point, la série habituelle des officiers de tout grade. Où prendre ce personnel ? Les bourgeois révolutionnaires et socialistes sont rares, et le peu qu'il y en a ne fait que la guerre de plume. Ces messieurs bouleversent le monde avec leurs livres et leurs journaux, et depuis seize ans ils barbouillent du papier à perte de vue, sans se fatiguer de leurs déboires. Ils souffrent avec une patience chevaline le mors, la selle, la cravache et ne lâcheraient pas une ruade. Fi donc ! Rendre les coups ? C'est bon pour les goujats.

Ces héros de l'écritoire professent pour l'épée le même dédain que l'épauletier pour leurs tartines. Ils ne semblent pas se douter que la force est la seule garantie de la liberté, qu'un pays est esclave où les citoyens ignorent le métier des armes et en abandonnent le privilège à une caste ou à une corporation.

Dans les républiques de l'antiquité, chez les Grecs et les Romains, tout le monde savait et pratiquait l'art de la guerre. Le militaire de profession était une espèce inconnue. Cicéron était général, César avocat. En quittant la toge pour l'uniforme, le premier venu se trouvait colonel ou capitaine et ferré à glace -sur l'article. Tant qu'il n'en sera pas de même en France nous resterons les Pékins taillés à merci par les traîneurs de sabre.

Des milliers de jeunes gens instruits, ouvriers et bourgeois, frémissent sous un joug abhorré. Pour le briser, songent-ils à prendre l'épée ? Non ! la plume, toujours la plume, rien que la plume. Pourquoi donc pas l'une et l'autre, comme c'est le devoir d'un républicain ? En temps de tyrannie, écrire est bien, mais combattre est mieux quand la plume esclave demeure impuissante. Eh bien, point ! On fait un journal, on va en prison, et nul ne songe à ouvrir un livre de manœuvres, pour y apprendre en vingt-quatre heures le métier qui fait toute la force de nos oppresseurs et qui nous mettrait dans la main notre revanche et leur châtiment.

Mais à quoi bon ces plaintes ! C'est la sotte habitude de notre temps de se lamenter au lieu de réagir. La mode est aux jérémiades. Jérémie pose dans toutes les attitudes. Il pleure, il flagelle, il dogmatise, il régente, il tonne, fléau lui-même entre tous les fléaux. Laissons ces bobèches de l'élégie, fossoyeurs de la liberté. Le devoir d'un révolutionnaire, c'est la lutte toujours, la lutte quand même, la lutte jusqu'à extinction.

Les cadres manquent pour former une armée ? Eh bien ! il faut en improviser sur le terrain même pendant l'action. Le peuple de Paris fournira les éléments, 
anciens soldats, ex-gardes nationaux. Leur rareté obligera de réduire au minimum le chiffre des officiers et sous-officiers ; il n'importe, le zèle, l'ardeur, l'intelligence des volontaires compenseront ce déficit.

L'essentiel, c'est de s'organiser à quelque prix que ce soit. Plus de ces soulèvements tumultueux à dix mille têtes isolées, agissant au hasard, en désordre, sans nulle pensée d'ensemble, chacun dans son coin, et selon sa fantaisie ! Plus de ces barricades à tort et à travers, qui gaspillent le temps, encombrent les rues et entravent la circulation nécessaire à un parti comme à l'autre, Le républicain doit avoir la liberté de ses mouvements aussi bien que les troupes. Point de courses inutiles, de tohu-bohu, de clameurs! Les minutes et les pas sont également précieux. Surtout ne pas se claquemurer dans son quartier ainsi que les insurgés n'ont jamais manqué de le faire, à leur grand dommage. Cette manie, après avoir causé la défaite, a facilité les proscriptions. Il faut s'en guérir, sous peine de catastrophes. 